\title{
unesp
}

UNIVERSIDADE ESTADUAL PAULISTA "JÚLIO DE MESQUITA FILHO"

Faculdade de Filosofia e Ciências - Marília

Ciência da Informação

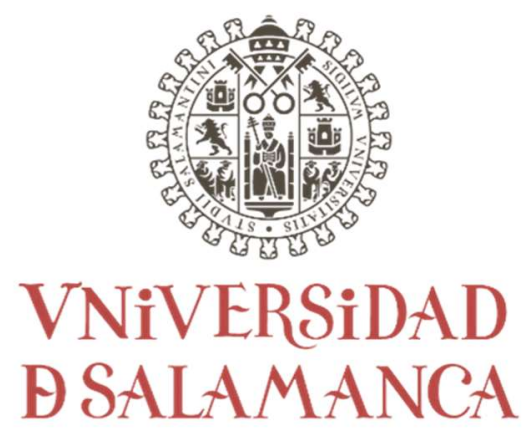

Facultad de Traducción y Documentación

Biblioteconomía y Documentación

HELOÁ CRISTINA CAMARGO DE OLIVEIRA

A NATUREZA FENOMENOLÓGICA DA MEDIAÇÃO:

CONTRIBUIÇÕES PARA A MEDIAÇÃO DA INFORMAÇÃO 


\section{A NATUREZA FENOMENOLÓGICA DA MEDIAÇÃO: CONTRIBUIÇÕES PARA A MEDIAÇÃO DA INFORMAÇÃO}

Tese apresentada aos Programas de PósGraduação em: "Ciência da Informação", da Universidade Estadual Paulista "Júlio de Mesquita Filho", Unesp-Marília-Brasil, e "Formación en la Sociedad del Conocimiento", da Universidad de Salamanca, USALSalamanca-Espanha, como requisito parcial obrigatório para obtenção do título de Doutorado, em modalidade cotutela.

Orientadores: Oswaldo Francisco de Almeida Júnior (Unesp) e José Antônio Frías Montoya (USAL). 


\title{
A NATUREZA FENOMENOLÓGICA DA MEDIAÇÃO: CONTRIBUIÇÕES PARA A MEDIAÇÃO DA INFORMAÇÃO
}

\begin{abstract}
Tese apresentada aos Programas de Pós-Graduação em: "Ciência da Informação", da Universidade Estadual Paulista "Júlio de Mesquita Filho", Unesp-Marília-Brasil, e "Formación en la Sociedad del Conocimiento", da Universidad de Salamanca, USAL-Salamanca-Espanha, como requisito parcial obrigatório para obtenção do título de Doutorado, em modalidade cotutela.
\end{abstract}

\section{BANCA EXAMINADORA}

Orientador: Prof. Dr. Oswaldo Francisco de Almeida Júnior

Universidade Estadual Paulista "Júlio de Mesquita Filho"

Prof. Dr. Carlos Cândido de Almeida Universidade Estadual Paulista "Júlio de Mesquita Filho"

Profa. Dra. Tamara de Souza Brandão Guaraldo

Universidade Estadual Paulista "Júlio de Mesquita Filho"

Prof. Dr. Críspulo Travieso Rodríguez Universidad de Salamanca
Orientador: Prof. Dr. José Antônio Frías Montoya Universidad de Salamanca

Prof. Dr. Jefferson Veras Nunes Universidade Federal do Ceará

Prof. Dr. Pedro Garrido Rodríguez Universidade Portucalense 
OLIVEIRA, Heloá Cristina Camargo de. A natureza fenomenológica da mediação: contribuições para a mediação da informação. 2020. Tese (Doutorado em Ciência da Informação e em Educação na Sociedade do Conhecimento) - Faculdade de Filosofia e Ciências, Universidade Estadual Paulista "Júlio de Mesquita Filho", Marília, Marília, 2020; Facultad de Traducción y Documentación, Universidad de Salamanca, Salamanca, 2020.

\section{Resumo}

Buscou-se nessa tese o entendimento de um "ponto de vista" gnosiológico da mediação, para que se possa entender sua abrangência e limitações, tendo como principais focos investigativos expressões da mediação, mediação da informação e mediação de leitura de mundo, buscando relacionar esses aspectos junto a atuação da Ciência da Informação frente a comunidades culturalmente marginalizadas. Esses aspectos se mostram dependentes de diferentes especificidades sociais, culturais, históricas e geográficas e, por isso, para discuti-los é interessante manter uma perspectiva que leve em consideração tais fenômenos. A fenomenologia traz a possibilidade de encontrar na subjetividade exposta em realidades complexas a objetividade que não pode ser separada do fenômeno, mas que, separada dele, não deixa de ser axioma da relação estabelecida; ela caracteriza, portanto, um norte que visa explorar fenômenos sem desconsiderar uma cadeia fenomenológica que os impacta. O objetivo principal deste trabalho é analisar aspectos da natureza da mediação sob uma visão fenomenológica, buscando identificar e entender o momento em que o processo da mediação inicia e como se perpetua em diferentes realidades complexas. A pesquisa foi delineada em consonância ao código Ethical Guidelines For Educational Research, a fim de manter-se em um desenvolvimento eticamente responsável e livre de preconceitos. Foram realizadas duas etapas de pesquisa e análise, sendo a primeira bibliográfica e com apoio e orientações do método Análise Textual Discursiva, e a segunda de cunho etnográfico (Interacionismo Simbólico), com uso dos instrumentos: levantamento bibliográfico, entrevista semiestruturada e observação. No âmbito brasileiro a pesquisa foi aplicada em uma aldeia indígena ( $A^{\prime}$ uwe - Xavante), e, no Espanhol, com um grupo de imigrantes advindos da África Subsaariana. Como resultados, destacam-se: a partir das concepções estudadas (Hegel - perspectiva filosófica; Marx - social; e Vygotsky - psicológica educacional), identificou-se que a atividade de mediar se ancora na busca do impacto no desenvolvimento humano, no âmbito imaterial da consciência e do processo cognitivo humano - carrega características de transformação, evolução e/ou superação, ressaltando a importância de espaços sociais, apropriação, e impactos recíprocos ou reflexivos materiais da mediação. Foi identificado que a leitura de mundo, ainda que seja individual, reconhece a coletividade de um ser que se desenvolve continuamente, com um universo informacional mutável e reflexivo. Foi possível entender que sociedades marginalizadas, ainda que individualmente complexas e em constante evolução, possuem similaridades contextuais e que o entendimento sobre isso e seu 
impacto em comportamentos e necessidades pode auxiliar o trabalho mediador. Foram identificadas grandes dificuldades de trabalho e desenvolvimento nos centros educacionais visitados e, devido à complexidade do contexto estudado e limitações formativas existentes, tais dificuldades podem ser consideradas previsíveis de reprodução em contextos similares. Conclusivamente, considera-se que o reconhecimento do potencial facilitador do mediador da informação na composição de uma perspectiva que favoreça a interdisciplinaridade pode resultar numa aproximação entre sociedades marginalizadas e ambientes culturalmente hegemônicos e/ou colonizadores, ressignificando serviços informacionais e assim contribuindo para o desenvolvimento de uma sociedade intercultural. Como sugestão de trabalhos futuros, apresenta-se delineações iniciais para a criação de um aplicativo que concentre diretrizes e modelos de práticas, voltados para profissionais da informação, para o apoio e ampliação do trabalho desses profissionais junto a comunidades marginalizadas.

Palavras-chave: Mediação. Mediação da Informação. Fenomenologia. Leitura de mundo. 
OLIVEIRA, Heloá Cristina Camargo de. La naturaleza fenomenológica de la mediación: contribuciones a la mediación de la información. 2020. Tesis (Doctorado en Ciencias de la Información y Formación en Sociedad del Conocimiento) Facultad de Filosofía y Ciencias, Universidade Estadual Paulista "Júlio de Mesquita Filho”, Marília, Marília, 2020; Facultad de Traducción y Documentación, Universidad de Salamanca, Salamanca, 2020.

\section{Resumen}

En esta tesis se busca entender un "punto de vista" gnoseológico de la mediación, de manera que se puedan comprender sus alcances y limitaciones, teniendo como principales focos de investigación las expresiones de mediación, la mediación de la información y la mediación de lectura del mundo, buscando relacionar estos aspectos con la actuación de la ciencia de la información frente a las comunidades culturalmente marginadas. Estos aspectos dependen de diferentes especificidades sociales, culturales, históricas y geográficas $y$, por lo tanto, para discutirlos es fundamental partir de una perspectiva que tenga en cuenta dichos fenómenos. La fenomenología hace posible encontrar en la objetividad expuesta en realidades complejas la objetividad que no se puede separar del fenómeno, pero que, separada de él, sigue siendo un axioma de la relación establecida; caracteriza, por tanto, un norte que pretende explorar fenómenos sin dejar de lado una cadena fenomenológica que los impacta. El objetivo principal de este trabajo es analizar aspectos de la naturaleza de la mediación bajo una mirada fenomenológica, buscando identificar y comprender el momento en que empieza el proceso de mediación y cómo se perpetúa en diferentes realidades complejas. La investigación fue diseñada en línea con el código Ethical Guidelines For Educational Research, con el fin de ajustarse a un desarrollo éticamente responsable y libre de prejuicios. Se realizaron dos etapas de investigación y análisis, la primera de carácter bibliográfico y con el apoyo y orientación del método de Análisis Textual Discursivo, y la segunda de carácter Etnográfico (Interaccionismo Simbólico), utilizando los instrumentos: revisión bibliográfica, entrevista semiestructurada y observación. En Brasil, la investigación se llevó a cabo en una aldea indígena ( $A^{\prime}$ uwe - Xavante) y, en España, con un grupo de inmigrantes del África subsahariana. Como resultados destacan: de las concepciones estudiadas (Hegel - perspectiva filosófica; Marx - social; y Vygotsky - psicológica educacional), se identificó que la actividad de mediar está anclada en la búsqueda del impacto sobre el desarrollo humano, en el ámbito inmaterial de la conciencia y del proceso cognitivo humano - conlleva características de transformación, evolución y/o superación, enfatizando la importancia de los espacios sociales, la apropiación y los impactos materiales recíprocos o reflexivos de la mediación. Se identificó que la lectura del mundo, aunque sea individual, reconoce la colectividad de un ser que se desarrolla continuamente, con un universo informacional cambiante y reflexivo. Fue posible comprender que las sociedades marginadas, aunque individualmente complejas y en constante evolución, 
tienen similitudes contextuales y que la comprensión de ello y de su impacto en los comportamientos y necesidades puede ayudar en el trabajo de mediación. Se identificaron grandes dificultades de trabajo y desarrollo en los centros educativos visitados y, debido a la complejidad del contexto estudiado y a las limitaciones formativas existentes, dichas dificultades pueden considerarse como predecibles en lo que respecta a su reproducción en contextos similares. En conclusión, se establece que el reconocimiento del potencial facilitador del mediador de la información en la composición de una perspectiva que favorezca la interdisciplinariedad puede resultar en una aproximación entre sociedades marginadas y entornos culturalmente hegemónicos y/o colonizadores, resignificando los servicios de información y contribuyendo así al desarrollo de una sociedad intercultural. Como sugerencia para trabajos futuros, se presentan puntos iniciales para la creación de una aplicación que concentre guías y modelos de práctica, dirigidos a los profesionales de la información, para el apoyo y expansión del trabajo de estos profesionales junto a comunidades marginadas.

Palabras clave: Mediación. Mediación de la información. Fenomenología. Lectura de mundo. 


\title{
OLIVEIRA, Heloá Cristina Camargo de. The phenomenological nature of
} mediation: contributions to mediation of information. 2020. Thesis (PhD in Information Sciences and Education in the Knowledge Society) - Faculty of Philosophy and Sciences, Universidade Estadual Paulista "Júlio de Mesquita Filho", Marília, Marília, 2020; Faculty of Translation and Documentation, Universidad de Salamanca, Salamanca, 2020.

\begin{abstract}
This thesis sought to understand a gnoseological "point of view" of mediation, so that its scope and limitations can be understood, having as main investigative focuses expressions of mediation, information mediation and world reading mediation, seeking to relate these aspects of Information Science activities in the face of culturally marginalized communities. These aspects are dependent on different social, cultural, historical, and geographical specificities and, therefore, to discuss them, it is interesting to maintain a perspective that takes such phenomena into account. Phenomenology brings the possibility of finding in objectivity exposed in complex realities the objectivity that cannot be separated from the phenomenon, but that, separated from it, is still an axiom of the established relationship; it characterizes, therefore, a north that aims to explore phenomena without disregarding a phenomenological chain that impacts them. The main objective of this work is to analyze aspects of the nature of mediation under a phenomenological view, seeking to identify and understand the moment when the mediation process begins and how it is perpetuated in different complex realities. The research was designed in line with the Ethical Guidelines for Educational Research code, to remain in an ethically responsible and free from prejudice development. Two stages of research and analysis were carried out, the first being bibliographic and with support and guidance from the Discursive Textual Analysis method, and the second of an ethnographic nature (Symbolic Interactionism), using the instruments: bibliographic survey, semi-structured interview and observation. In Brazil, the research was carried out in an indigenous village (A'uwe - Xavante), and, in Spanish, with a group of immigrants from Sub-Saharan Africa. As results, stand out: from the studied conceptions (Hegel - philosophical perspective; Marx - social; and Vygotsky educational psychology), it was identified that the activity of mediating is anchored in the search for the impact on human development, in the immaterial scope consciousness and the human cognitive process - carries characteristics of transformation, evolution and/or overcoming, emphasizing the importance of social spaces, appropriation, and reciprocal or reflective material impacts of mediation. It was identified that the reading of the world, even if it is individual, recognizes the collectivity of a being that develops continuously, with a changing and reflective informational universe. It was possible to understand that marginalized societies, although individually complex and constantly evolving, have contextual similarities and that the understanding of this and its impact on behaviors and needs can help mediating work. Serious difficulties for work and development were identified in the educational centers visited and, due to the complexity of the studied context and existing formative
\end{abstract}


limitations, such difficulties can be considered predictable for reproduction in similar contexts. Conclusively, it is considered that the recognition of the potential facilitator of the information mediator in the composition of a perspective that favors interdisciplinarity can result in an approximation between marginalized societies and culturally hegemonic and/or colonizing environments, resignifying information services and thus contributing to the development of an intercultural society. As a suggestion for future work, initial designs are presented for the creation of an application that concentrates guidelines and practice models, aimed at information professionals, for the support and expansion of the work of these professionals beside marginalized communities.

Keywords: Mediation. Mediation of Information. Phenomenology. Reading of the world. 


\section{RESUMEN EXTENDIDO EN ESPAÑOL}

\section{INTRODUCCIÓN}

La Ciencia de la Información se ha preocupado en su actuación como mediadora de la información. Así, nuevos estudios en el ámbito científico se han desarrollado en el área en la búsqueda de caracterizar y diagnosticar aspectos de acción y desarrollo de la mediación en la actuación de sus profesionales.

Las discusiones que abarcan el uso del término "mediación" y su aplicabilidad crecen y se deslumbran conquistas con relación a esclarecer estas discusiones.

Este trabajo tiene la intención de entender y explorar la posibilidad de la mediación de la lectura de mundo. La lectura de mundo puede ser definida como la lectura de los signos que el mundo nos presenta. Se asume que la lectura de mundo impacta en la apropiación de la información y que, por tanto, puede ser usada tanto de apoyo para un trabajo mediador de calidad, como para prácticas de manipulación.

Como los aspectos de mediación, mediación de la información y mediación de lectura de mundo son dependientes de diferentes aspectos sociales, culturales, históricos y geográficos, para discutirlos es interesante mantener una perspectiva que tenga en consideración estos fenómenos. La fenomenología trae la posibilidad de encontrar en la subjetividad expuesta en realidades complejas, la objetividad que no puede ser separada del fenómeno, pero que, separada de él, no deja de ser axioma de la relación establecida. La fenomenología se caracteriza, por tanto, en un norte que tiene como objetivo explorar fenómenos sin desconsiderar una cadena fenomenológica que lo impacta.

Así, en un escenario donde la mediación dentro de la Ciencia de la Información aun no posee profundidad teórica consistente en relación con su naturaleza y amplitud, se cuestiona: ¿Cuál es la real naturaleza de la mediación? ¿Existe apenas una sola naturaleza? ¿Es posible mediar una lectura de mundo? ¿Es posible entender el impacto de la lectura de mundo en la construcción del conocimiento?

Se observó la imposibilidad de seguir cuestionamientos como los previamente mencionados, por no tener clara una base en la cual se construye la 
mediación y así, sus posibles limitaciones. Lo que se busca, por tanto, es un "punto de vista" gnoseológico de la mediación para que sea posible entender su dimensión.

En este sentido, se destaca en este proyecto la principal problemática: ¿Cuándo, cómo y en qué grado se inicia la mediación en la vida de las personas bajo una perspectiva fenomenológica?

Esta aclaración es vital ya que, a partir de ella, es posible resaltar los puntos desarrollados en la actuación del profesional del acto "intuitivo" de mediar. En este trabajo el término "intuitivo" fue utilizado con la intención de mencionar la mediación utilizada superficialmente, es decir, sin un desarrollo más elaborado. Al entender ese posible impacto profesional, se puede buscar en la mediación la respuesta para su desarrollo en cuanto impulsor social, constituyendo una herramienta fuertemente influenciadora. Sería ella entonces, la forma, el camino, de establecer actividades que tengan el objetivo de impactar en lo que se asume es el núcleo potenciador del desarrollo humano - su desarrollo de lectura de mundo.

La motivación para realizar esta investigación surgió durante el proceso de la maestría en Ciencia de la Información, con la exploración del tema "La mediación en proyectos de incentivo a la lectura: la apropiación de la información para la construcción del conocimiento y del pensamiento crítico" (2013-2015), por medio del cual, fue posible observar la real importancia de la mediación de la lectura de mundo junto a la lectura escrita, en un proceso complejo que, cuando ejercido ampliamente, se muestra fundamental para la apropiación de la información y posibilita, finalmente, ocasionar un impacto en la construcción de conocimiento. Se notó, sin embargo, la insuficiencia de estudios con la atención en perspectiva de la lectura de mundo, como puede observarse abajo en el resultado de un levantamiento realizado en bases de Tesis y Disertaciones de Brasil, Portugal y España: 
Cuadro 1 - Levantamiento realizado el 12 de enero de 2015.

\begin{tabular}{|c|c|c|c|}
\hline BASE & TERMOS & REGISTROS & OBS \\
\hline \multirow{4}{*}{ Biblioteca Digital Brasileira de Teses e Dissertações (BDTD) } & mediação da informação & 11 & 2 teses e 9 dissertações \\
\hline & mediação da(e) leitura & 5 & 0 teses e 5 dissertações \\
\hline & leitura de mundo & 32 & 14 teses e 18 dissertações \\
\hline & mediação da leitura de mundo & 0 & \\
\hline \multirow{4}{*}{ Banco de Teses e Dissertações da Capes } & mediação da informação & 45 & 40 em Ciência da Informação \\
\hline & mediação da(e) leitura & 4 & 1 em Ciência da Informação \\
\hline & leitura de mundo & 20 & 0 em Ciência da Informação \\
\hline & mediação da leitura de mundo & 0 & \\
\hline \multirow{4}{*}{$\begin{array}{l}\text { Estudo Geral - Repositório Digital da Universidade de } \\
\text { Coimbra }\end{array}$} & mediação da informação & 1 & \\
\hline & mediação da(e) leitura & 0 & \\
\hline & leitura de mundo & 1 & \\
\hline & mediação da leitura de mundo & 0 & \\
\hline \multirow{4}{*}{ DIALNET - Tesis doctorales } & mediação da informação & 23 & \\
\hline & mediação da(e) leitura & 8 & \\
\hline & leitura de mundo & 5 & \\
\hline & mediação da leitura de mundo & 0 & \\
\hline
\end{tabular}

Fuente: Elaborado por la autora.

La intención de explorar la lectura de mundo surge del objetivo de utilizar la visión compleja expuesta por Morin, donde se destaca el esfuerzo de "[...] não sacrificar o todo à parte, a parte ao todo, mas por conceber a difícil problemática da organização [...]. (MORIN, 1990, p. 29, traducción nuestra)1. Esta propuesta es difícil porque somos históricamente motivados a formas "mutilantes" de pensar. (MORIN, 1990, p. 157).

En esa perspectiva, para desarrollar habilidades de lectura de códigos (como la escrita, por ejemplo), hay que vincular esa enseñanza en un contexto complejo, que en esta propuesta envuelve la lectura inicial, la cual es realizada por todos - la lectura de mundo (FREIRE, 2011), que surge cargada de influencias culturales, históricas y sociales.

La propuesta de este trabajo es entender como aspectos subjetivos como la lectura de mundo pueden (o no) ser mediadas entre diferentes grupos, en realidades y necesidades diferentes, con el fin de encontrar la naturaleza, el núcleo, del acto de mediar. Con la posibilidad de esclarecer el aspecto intrínseco a la mediación, se buscará delinear un norte a la mediación en el ámbito profesional (para la $\mathrm{Cl}$ propiamente).

Se defiende, por ejemplo, la posibilidad de mediar una lectura de mundo, de impactar en la forma en el que el otro ve la propia existencia y su relación con el medio, impactando así en el desarrollo intelectual y espacial de determinada sociedad. Tal peculiaridad sería utilizada también para manipular individuos: cuando

\footnotetext{
${ }^{1}$ Texto original: "Il s'efforce non pas de sacrifier le tout à la partier, la partier ao tout, mais de concevoir la difficile problámatique de l'organisation [...]".
} 
el individuo crece inmerso en un sistema de enseñanza que ignora su conocimiento cultural tácito y lo condiciona a observar enseñanzas prefabricados por una sociedad que no ve beneficio en el espíritu indagador rebelde de la naturaleza humana y que, por eso, hace de todo para reprimirla - se tiene así la formación de meros codificadores de la escrita, receptores de datos que aceptaron su condición y pararon de reflexionar en cuanto a su impacto en el mundo y en la sociedad. (FREIRE, 1979; 2005; 2013).

Al comprender la posibilidad de la mediación ser utilizada con ese impacto y al explorar la posibilidad de una mejor relación entre el mediador y grupos mediados (siempre con el objetivo de apropiación), se vislumbra la posibilidad de encontrar insuficiencias en procesos educativos actuales (específicamente la mediación de la lectura), abriendo así, nuevos cuestionamientos sobre su uso (de la mediación) para el beneficio de la sociedad, por posibilitar el entendimiento de la necesidad de grupos específicos de la comunidad (como personas con deficiencia), adaptándose a la forma de enseñanza en diferentes realidades.

No obstante, conforme se ha discutido previamente, no es posible establecer tales cuestionamientos y estudios en cuanto no exista claridad de aplicabilidad de la mediación en este ámbito. Así, los resultados obtenidos podrán traer luz en relación a la importancia de la mediación y cuáles son sus posibilidades de uso para la $\mathrm{Cl}$. En caso de que haya comprobación de que es posible mediar la lectura de mundo, por ejemplo, eso puede promover la valorización de la lectura de mundo en el desarrollo del conocimiento y la posibilidad de usarla con el objetivo de ayudar a la sociedad, contribuyendo para proyectos sociales, resaltando también, la necesidad de exploración de nuevos proyectos e investigaciones en el área, que demuestren interés para profundizar en este tema. En contrapartida, en caso de que no sea posible encontrar evidencias amplias del uso de la mediación en el área, las restricciones pueden consolidar las vertientes y aplicabilidades del concepto.

La perspectiva de esta investigación demuestra el carácter multidisciplinar (por explorar aspectos de base filosófica y de la educación) y objetiva destacar las dimensiones sociales y humanas que la Cl abarca. (SARACEVIC,1995).

El Objetivo General de este trabajo es analizar aspectos de la naturaleza de la mediación sobre una visión fenomenológica, buscando identificar y entender el momento en el que el proceso de la mediación inicia y cómo esta se perpetua en diferentes realidades complejas. 
Sus Objetivos Específicos son:

$\checkmark$ Conocer las concepciones y formas de entender la mediación sobre una perspectiva fenomenológica.

$\checkmark \quad$ Identificar aspectos de la lectura de mundo.

$\checkmark$ Explorar posibilidades de utilizar la mediación como aspecto de unión entre el contexto socio-cultural-ambiental de individuos y su construcción de conocimiento (entendiendo matices de la profesionalización de la mediación, o la aplicación propiamente de la mediación de la información y de lectura), con la intención de adecuar materiales y actividades que objetiven el desarrollo cognitivo.

$\checkmark$ Entender las comunidades brasileñas y extranjeras que posean singularidades de relacionamiento y mediación de lectura de mundo.

\title{
1.1 Aspectos METOdológicos
}

Esta investigación posee una naturaleza cualitativa, teniendo en cuenta que tal abordaje puede ser utilizado para traer significación a fenómenos y posiciones relativos, contemplando la propuesta que se objetiva delinear. Silva, Gobbi y Simão destacan que:

\begin{abstract}
A pesquisa social vem acompanhando a evolução da humanidade e à medida que se distancia da visão positivista das leis universais incorpora e aprimora pressupostos próprios da pesquisa qualitativa dentro do paradigma interpretativo. Isso ocorre pelo entendimento do homem como um agente social que influencia e é influenciado pela estrutura social, dotado de percepções peculiares da realidade que permitem uma interpretação própria da sua realidade. Esta poderá ser distinta de acordo com o observador e a posição do mesmo frente ao fenômeno estudado. (2005, p. 70).
\end{abstract}

Así, se busca ceñirse a la comprensión de significación basada en la figura social del hombre y la influencia de su medio y estructura social, en relación al fenómeno de objeto de estudio. (MAY, 2004).

La investigación fue delineada en consonancia al código Ethical Guidelines for Educational Research en cuanto a su responsabilidad ética con sus participantes, patrocinadores, y en relación a la comunidad de investigadores educacionales y profesionales de la educación, formuladores de políticas y público en 
general, con el fin de mantenerse en un desarrollo éticamente responsable y libre de prejuicios. (BRITISH EDUCATIONAL RESEARCH ASSOCIATION, 2011).

Fueron realizadas dos etapas de investigación y análisis, siendo la primera bibliográfica y realizada con el apoyo y orientaciones del método Análisis Textual Discursivo, y la segunda de índole etnográfico, realizado con los instrumentos para la recolección de datos: levantamiento bibliográfico, entrevista semiestructurada y observación.

El objetivo de la parte teórica de la investigación fue explorar, sobre una perspectiva fenomenológica, cómo la mediación puede ser entendida, y también cómo entender aspectos de la lectura de mundo y la posibilidad de una mediación de esta última; su ejecución envolvió etapas realizadas en Brasil, en la Universidade Estadual Paulista “Júlio de Mesquita Filho" y en España, en la Universidad de Salamanca.

Posteriormente, se realizó estudios de campo con el fin de conclusivamente analizar, en determinados contextos, la validación de aspectos de la investigación teórica, principalmente en el ámbito de la lectura de mundo. El universo de la investigación a ser utilizado en esta etapa es compuesto de expresiones de personas que demuestran especificidades culturales de lectura de mundo en Brasil y España.

En el ámbito brasileño, la investigación fue aplicada en una aldea de pueblos indígenas y en el ámbito español con un grupo de inmigrantes. Para esa etapa, el uso de la etnografía se fundamenta en su perspectiva de descripción de un pueblo, en el sentido colectivo, objetivando el estudio de "personas en grupos organizados". (ANGROSINO, 2009, p. 16) en consonancia a los objetivos de la investigación.

La orientación etnográfica a ser delineada es el Interaccionismo Simbólico, en el cual la "sociedade não é um conjunto de instituições entrelaçadas, como os funcionalistas pensavam, mas um caleidoscópio em constante mutação de indivíduos interagindo uns com os outros", caracterizando un abordaje dinámico con supuestos que envuelven aspectos de significación, simbología, y de la importancia de las interacciones sociales inclusive en la construcción del self, y que objetiva "desvelar os significados que os atores sociais atribuem às suas ações". (ANGROSINO, 2009, p. 20). 
Los principios del Interaccionismo Simbólico son definidos por Blumer (autor más celebre de esta formulación), y compartida por diferentes autores que trabajan con el tema (como Mead, Dewey, Thomas, Znaniecki, Baldwin, Redfeld e Wirth):

[...] os seres humanos agem com as coisas com base nos sentidos que as coisas apresentam para elas; essas 'coisas' incluem tudo que os seres humanos podem perceber no mundo, como objetos físicos, categorias de objetos, instituições, ideais, atividades e situações; o sentido dessas coisas é derivado ou emerge da interação social que temos com nossos semelhantes; esses sentidos são manipulados e modificados por um processo interpretativo, usado pela pessoa ao lidar com as coisas que ela encontra. (NUNES, 2013).

Los interesantes discursos propuestos en esa orientación ampliamente desarrollada a partir de la Escuela de Chicago y que permea diferentes discusiones, especialmente en contextos filosóficos y sociales, trae aspectos de acción social y identidad en una perspectiva más amplia, quebrando una perspectiva inicial cartesiana que pretendemos evitar.

Las etapas serán descritas y justificadas en secuencia.

\subsubsection{Etapa 1}

En la investigación bibliográfica, los temas mediación, fenomenología y lectura de mundo fueron analizados en la literatura disponible en las lenguas portuguesa, española, inglesa y francesa, en la perspectiva de utilizar el conocimiento disponible de teorías públicas para delinear discusiones de los temas propuestos.

Las pesquisas se centraron en las bases de datos: Portal Capes, Scientific Electronic Library Online (SciELO), Base de Dados Referenciais de Artigos de Periódicos em Ciência da Informação (Brapci) y E-prints in library and information science (e-LiS).

Para estudiar los principales abordajes a componer la investigación en el ámbito de la naturaleza de la mediación, fue seleccionado, en literatura directa o indirecta, los conceptos de Hegel, Weber, Vygotsky y Marx. Las áreas de filtro utilizadas fueron Ciência de la Información, Filosofía y Educación. Para el análisis de los datos obtenidos fue utilizada la técnica del Análisis Textual Discursivo (ATD) método cualitativo que posibilita la fragmentación y organización de materiales 
pertinentes con el fin de establecer un proceso que posibilite nuevas y amplias comprensiones de un tema propuesto.

La escogencia del ATD fue anclada en su propuesta de proporcionar "dos reconstrucciones concomitantes: 1. Del entendimiento de la ciencia y de sus caminos de producción; 2 . Del objeto de la investigación y de su comprensión" y en la argumentación de que ella "cria espaços de reconstrução, envolvendo-se nisto diversificados elementos, especialmente a compreensão dos modos de produção da ciência e reconstruções de significados de fenômenos investigados". (MORAES; GLIAZZI, 2006, p. 118).

De forma práctica, el empleo del ATD envuelve dos etapas de 1 Desmontaje de los textos, 2 - Establecimiento de relaciones y 3 - Captación del nuevo emergente. La primera etapa envolvió una fragmentación de los textos, el segundo, la categorización y, el tercero y último, la extracción de comprensiones emergentes de los procesos anteriores. (MORAES, 2003, p. 191).

El objetivo de esta fase fue extraer un cuadro descriptivo moderno de la mediación de la información con posibles niveles, significaciones y aplicaciones, desarrollados a partir de concepciones de los autores listados. Los resultados obtenidos en esta primera etapa serán la base de análisis de los datos obtenidos en la etapa 2.

\subsubsection{Etapa 2}

La segunda parte de la investigación tiene como base el método etnográfico y fue dividida en tres fases de recolección de datos: la primera envuelve un levantamiento bibliográfico, la segunda, entrevistas, y la tercera, observaciones.

Conforme define Angrosino, "a etnografia é a arte e a ciência de descrever um grupo humano - suas instituições, seus comportamentos interpessoais, suas produções materiais e suas crenças" (2009, p. 30).

La elección específica de los grupos se pauta en el objetivo de trabajar con personas que puedan demostrar necesidades de investigaciones profundas en el tema (lectura de mundo) para que se pueda entender el contexto en el que viven y cómo ese contexto influencia su relación con el aprendizaje y su desarrollo sociocultural. 
Como criterio de inclusión y exclusión, en el ámbito brasileño, se delimitó la aplicación de la investigación a los habitantes de la aldea Xavante Nova Esperança, localizada en Mato Grosso. La elección de esa aldea se basó en su desarrollo en negociaciones educacionales en nombre de los pueblos indígenas, comprendiendo representantes que actúan directamente con la Fundación Nacional del indio (Fundação Nacional do Índio- Funai) y que participan del foro Tsihorirã A'uwẽ Uptabi, evento que surgió como resultado de una reunión ordinaria del Conselho Estadual de Educação Escolar Indígena - CEEl, en septiembre de 2015, a partir de la necesidad de la elaboración de la Política de Educación Escolar Indígena para el Mato Grosso. Las entrevistas fueron realizadas solo con los coordinadores y profesores durante una visita a la aldea, en la cual fue posible también conocer la escuela y la biblioteca de la aldea.

Como criterio de inclusión y exclusión en el ámbito español, se delimitó la aplicación de la investigación a los habitantes de la región de Almería, debido al hecho de que en esa región se demuestra expresiva concentración de inmigrantes a nivel nacional, principalmente en los nichos de invernaderos, ya que esa concentración ha impactado en el índice de natalidad de la región y, consecuentemente, ha ampliado cuestiones socioculturales. La aplicación de entrevistas fue realizada apenas con personas de edad adulta civil. Las observaciones buscaron una inmersión en el quehacer cotidiano de los participantes y así fueron realizadas dentro de barrios donde hay una mayor concentración de esas personas, con atención en espacios de mayor interacción entre ellos (bares y plazas).

Los resultados obtenidos en los estudios de campo fueron analizados con el apoyo de los resultados de la investigación teórica.

Se tiene la intención de contribuir para la concientización de enseñanza en cuánto a la necesidad de una visión compleja de mundo antes de la preparación de materiales y actividades que objetiven el desarrollo cognitivo. Destacando que, conforme lo expuesto por Borko, la "Information Science as a discipline has as its goal to provide a body of information that will lead to improvements in the various institutions and procedures dedicated to the accumulation and transmission of knowledge" (BORKO, 1968, p. 4).

Para la realización de las entrevistas fueron construidas guías (instrumento de recolección de datos), de forma semiestructurada, con atención en los objetivos general y específicos de este trabajo y anclados en los resultados 
obtenidos del análisis bibliográfico (los documentos relacionados, así como las propias guías, se encuentran en el Apêndice $A$ - Instrumentos de apoio para Coleta de Dados das Pesquisas de Campo.

La elección de entrevistas como técnica de recolección de datos se basa en las premisas de que ellas permiten que el entrevistador pueda "registrar informação qualitativa sobre o tópico em questão", ya que existirá la posibilidad de "sondar além das respostas e, assim, estabelecer um diálogo com o entrevistado." (MAY, 2004, p. 148).

Respecto a la técnica semiestructurada, May destaca:

Considera-se que esses tipos de entrevistas permitem que as pessoas respondam mais nos seus próprios termos do que as entrevistas padronizadas, mas ainda forneçam uma estrutura maior de comparabilidade do que nas entrevistas focalizadas. (2004, p. 148).

La oportunidad de mantener la naturalidad de las personas, pero sin desviarse extensivamente de los objetivos de la investigación, son los principales puntos que llevaron la elección de este abordaje.

Durante las entrevistas, las siguientes orientaciones fueron importantes a destacar:

Algumas exigências devem ser consideradas no momento da entrevista: marcar com uma certa antecedência a hora e o local apropriados; garantir ao entrevistado o sigilo e o anonimato, caso seja necessário; utilizar vocabulário adequado ao informante; não apresentar questões que extrapolem o universo cultural do entrevistado; ouvir atentamente a resposta do informante; estimulá-lo a discorrer sobre o assunto e não forçar o rumo das respostas.

No decorrer da entrevista, o pesquisador tem que evitar a ocorrência de saltos bruscos em relação ao tópico abordado, colocar questões mais simples antes das complexas e, principalmente, manter flutuante a atenção para observar gestos, entonações da voz, hesitações e outros comportamentos que podem conter significados específicos. (LUDWIG, 2003, p. 66).

Las exigencias mencionadas son de extrema importancia, pues garantizan la buena ejecución del método, lo que facilita el posterior tratamiento de los datos y aumenta su confiabilidad.

Para la aplicación de las entrevistas en Brasil, los sujetos seleccionados fueron: representantes de las comunidades investigadas que están involucrados en proyectos centrados en la educación para esos pueblos, conforme 
autorizaciones y con el uso de grabaciones en audio para un análisis posterior. En el caso de las entrevistas en España, los sujetos fueron inmigrantes nativos del África Subsahariana que aceptaron participar, y fueron registrados en audio para posteriores análisis.

La observación en ese contexto de fenómenos sociales no es un proceso narrativo puro, sino la búsqueda no en la descripción y sí en la constitución de hechos. No podemos "fotografiar", por así decirlo, "hechos en bruto", pero implica la observación científica de fenómenos metódicamente escogidos y aislados de otros, respetando y asumiendo sus complejidades que imposibilitan su estudio en la totalidad, en los aspectos de detalles y relaciones, constituyendo así, una gran dificultad para el investigador. Para superar tales dificultades, es necesario el uso de métodos y rigores de observación, con el direccionamiento esencial de la criticidad del método adoptado. (MAUSS; FAUCONNET, 1901).

Las fases de recolección de datos (análisis bibliográfica y entrevistas) proporcionaron la familiaridad con el universo de la investigación y facilitó la inmersión en el ambiente de observación.

Durante la parte práctica, como ya fue mencionado, fue adoptado el Interaccionismo Simbólico, el cual describe los diferentes papeles que pueden ser adoptados por el investigador: participante completo (exigen completa inmersión y sin agenda); participante-como-observador (exige inmersión, pero con el conocimiento y autorización de su investigación); observador-como-participante (permite un mayor distanciamiento de la comunidad, con la integración en momentos específicos); e completo observador (radica en la recolección de los datos objetivos sin participación o anuncio de su presencia).

Debido a que la investigación no posee una completa orientación etnográfica, fueron adoptadas las posturas de participante-como-observador y observador-como-participante, dependiendo de la abertura encontrada por los grupos investigados.

La investigación realizada en Brasil fue evaluada y aprobada por los consejos de ética del país (Anexo A: Autorizações CEP-Unesp / CONEP), por el órgano brasileño Fundação Nacional do Índio - FUNAI (Anexo B - autorização FUNAI Regional Xavante $M T$ ), responsable de tratar con las aldeas Xavantes de la región de Barra do Garças - Mato Grosso - Brasil, y por los indígenas de la aldea visitada (Anexo C - Autorização Aldeia Nova Esperança). 
En España no existe un órgano que acompañe ese tipo de investigación. La composición de los instrumentos, su evaluación y aplicación fueron amparadas en el apoyo recibido por el Sindicato Andaluz de Trabajadores/as (SAT). Los instrumentos están disponibles en el Apêndice $A$ - Instrumentos de apoio para Coleta de Dados das Pesquisas de Campo. No fueron utilizados términos de consentimiento debido a la imposibilidad de presentar documentos formales a los participantes, ya que la mayoría se encuentran ilegalmente en el país y tienen dificultades con el idioma.

En ambos casos serán expuestos los diarios de campo. Las entrevistas no serán publicadas completamente para proteger a los participantes por cuestiones éticas y de seguridad, especialmente por tratarse de comunidades ya inmersas en contextos frágiles y/o violentos.

\subsection{DESARROLLO DE LA TESIS}

Los próximos párrafos presentarán, resumidamente, los temas abordados en los capítulos de esta tesis, delineados con los objetivos general y específicos previamente presentados como dirección.

En el capítulo 3 son expuestas las discusiones y exploraciones acerca de las bases fenomenológicas utilizadas Si asumimos la importancia de la implicación social y cultural en el desarrollo de la mediación, debemos traer la percepción para orientar nuevas preguntas, debemos apoyar el estudio de los fenómenos.

La palabra "fenómeno", del griego phainómenon, significa "aquello que aparece", y se deriva del verbo griego phainomenai: "yo aparezco". A pesar de esa relación con "lo que aparece", con el "brillo", para la fenomenología su concepto tiene como núcleo el aparecer, el propio fenómeno de la conciencia, el fenómeno subjetivo y comprende, de manera simultánea, "[...] tanto o aparecer quanto aquilo que aparece: a relação indissociável entre o sujeito e o mundo, a consciência e seus objetos." Resumidamente, lo que en la mayoría de las veces no se muestra sería entonces el único "fenómeno" que interesaría, y para identificarlo es necesario el "retorno a la conciencia", no establecida por Husserl de manera abstracta e ingenua, 
pero usada para explicitar la investigación del propio acontecimiento de la conciencia. (GALEFFI, 2000, p. 25).

Muchos autores han trabajado con diferentes abordajes para el concepto de fenomenología, pero, conforme Zlatev destaca que así como Husserl "pediu para 'voltar para as coisas em si', é necessário 'voltar para Husserl' para entender verdadeiramente o que a fenomenologia é sobre”. (ZLATEV, sin paginación, 2009). Por eso, los supuestos de Husserl fueron escogidos como rector en la discusión inicial de este capítulo.

Husserl aborda la fenomenología dentro de un contexto polémico entre los estudios del conocimiento, en una contraposición de significados y posibilidades de estudio dentro de la perspectiva del propio conocimiento - esto es, la problemática sobre la posibilidad del conocimiento tener contacto con su objeto, colocando en escena, las deficiencias del pensamiento positivista, las ineficiencias de los abordajes metafísicos y las incertezas de la duda cartesiana. Son las complejidades implicadas en los estudios de la percepción, donde el objeto percibido deber ser dato inmediatamente - allí está la cosa antes de que nuestros ojos las puedan percibir. Yo veo eso; yo entiendo. Aunque si la percepción no es nada más que una experiencia que me pertenece, del sujeto que percibe - ¿cuál es la objetividad contenida en el análisis del objeto? (HUSSERL, 1999).

En una propuesta de retorno a las "mismas cosas", habría una superación del discurso metafísico considerado especulativo, así como del raciocinio de las ciencias positivistas, colocando las investigaciones en el "mismo plano de la realidad". Sería el encuentro de una "vía media" en cómo pensar la naturaleza y sus matices, en una nueva rigurosidad filosófica que se libera de las antiguas tradiciones y solo presta atención a la realidad en una perspectiva gnoseológica. (DARTIGUES, 2003).

Así, la idea de la fenomenología de Husserl nace de la problemática de las ciencias empíricas, que se refieren al mundo como dato, al mismo tiempo en que son ellas propias, elementos del mundo evaluado. Ella entonces, no se adecua a ninguna clasificación filosófica ya que las antecede, no necesariamente en el concepto temporal habitual, sino de cuestionamiento y evaluación, "acabando" donde todas las demás comienzan, por su expresa negativa en aceptar acríticamente muchos puntos de partida por mucho tiempo incuestionables en la evaluación filosófica, como por 
ejemplo en las percepciones y hechos biológicos, sociales y ambientales. (SCHUTZ, 1970).

Al trabajarse con la perspectiva fenomenológica, se buscó el entendimiento de la esencia de lo que es el objeto que se busca comprender y sus diferentes expresiones en realidades contextuales de ese objeto con el medio social estudiado, y así será posible prever manifestaciones y limitaciones de ese objeto. En el caso de esta investigación, específicamente, se posibilitará el entendimiento de los factores involucrados en el proceso de mediación, sus posibles variaciones y así, los alcances y limitaciones a partir de una perspectiva fenomenológica.

En el capítulo 4 se presenta los supuestos teóricos de la mediación y mediación de la información que abarcan este trabajo.

Cuando se propone diferentes abordajes de mediaciones, como la mediación de la lectura de mundo, se encuentra la brecha anteriormente mencionada sobre la base y, por extensión, de los límites de la mediación en la actuación profesional. En este momento surge la perspectiva de volverse para una visión de la naturaleza de la mediación. Se objetivó en este trabajo explorar los conceptos de Hegel, tomado de la dialéctica (BRAGA, 2004), Marx, centrado en el materialismo histórico (SILVA; SILVA; MARTINS, 2005) y Vygotsky, con enfoques semióticos y psicológicos (MARTINS; MOSER, 2012), que traen perspectivas filosóficas en las cuáles el Ser presenta relaciones más complejas al acto de mediar, en el sentido de que eses autores llevarán la mediación a un nivel más amplio, partiendo de la existencia y relacionamiento establecido con el mundo y la cultura. Lo que se busca es entender en qué local existencial y en cuál esencia, la mediación es colocada en las diferentes vertientes trabajadas por los autores.

Hegel, en discusiones que culminaron en desarrollos teóricos que desembocan en lo que son considerados estudios del imaginario y posmodernismo crítico, presenta en su obra La Fenomenología del Espíritu, discusiones y exposiciones que buscan problematizar y esclarecer aspectos de la ciencia del Ser, pasando por aspectos de la existencia de la verdad, del conocimiento, de la composición de lo absoluto, de la negatividad, y, entre otros, de cómo la mediación es vista y usada en ese contexto.

Ahora Marx, analiza la mediación en la esfera del trabajo y producción, donde, en los procesos explorados por el autor, se ve en la posibilidad de rompimiento 
del carácter natural primitivo de sobrevivencia, por la mediación que acompaña los objetivos de la economía.

Finalmente, en Vygotsky se encuentra una perspectiva de mediación dentro del contexto educacional y presenta la inclusión de estímulos en procesos de solución de problemas lógicos en edad infantil, buscando entender cómo esos estímulos pueden ser útiles para la solución de problemas y planeación de acciones futuras. (VYGOTSKY, 1991, p. 50).

Sus ideas influenciaron muchas investigaciones que buscan entender y aplicar aspectos del "papel de los sistemas semióticos en el desarrollo mental, sobre el desarrollo del lenguaje" dentro de estudios de la mediación semiótica. (IVIC, 2010, p. 27).

Se asume en este proyecto la hipótesis de que la mediación existe en el mundo sine qua non. Al asumir esta hipótesis, es importante resaltar la diferencia entre mediación y relacionamiento. Es posible aclarar en ese momento la importancia de la búsqueda de un impacto al concepto de mediación. En la mediación se observa la existencia de un $1^{\circ}$ elemento: sujeto principal (y no necesariamente individual, que será el foco del acto de mediar); un $2^{\circ}$ elemento: problema/exigencia/necesidad/conflicto/deseo (dependiendo del contexto involucrado), aliados a un $3^{\circ}$ elemento (en el cual figuraría el mediador), estando entonces, esos tres elementos involucrados en un proceso mediador específico (de información, de lectura, etc.) que busca el impacto sobre el $2^{\circ}$ elemento, y un $4^{\circ}$ elemento compuesto, por así decirlo, que es el producto (no necesariamente físico) mediado propiamente (una información, un libro, etc. con la composición del impacto implícito de su productor - el autor del libro, por ejemplo). Ya en un proceso de relación, tendríamos una vía de rutina, sin deseo de interferencias, identificadas por la semiótica como el campo de la primeridad.

En la vida cotidiana, la mediación estaría presente como habilidad y siendo, por tanto, pasible de desarrollo. ¿Cuál sería entonces el principal diferencial impulsador del desarrollo de la mediación? Se entiende la praxis, en cuanto envolvimiento social, como impulsador para tal desarrollo, siendo el uso del término "impulsar" con el propósito de destacar que no habrá una anulación de la mediación sin ella, pero sí restricciones en su potencial.

Con lo expuesto anteriormente, lo que se busca no es retrabajar las vertientes de la mediación ya utilizadas en el área, sino encontrar un "punto de vista" 
gnoseológico de la mediación, para que se pueda entender su alcance en la $\mathrm{Cl}$, consolidando sus limitaciones y posibilidades. Se vislumbra principalmente encontrar respuestas relacionadas con la posibilidad de explorar la mediación de la lectura de mundo.

En el capítulo 5 se exponen los aspectos identificados en el análisis de la naturaleza de la mediación a partir de la base fenomenológica. Fue posible identificar a partir de la aplicación del Análisis Textual Discursivo (expuesto detalladamente en el capítulo 4), que los trabajos anclados en las teorías de los tres autores investigados (Hegel, Marx y Vygotsky) traen el núcleo del concepto de la mediación al desarrollo, en el ámbito inmaterial de la consciencia y del proceso cognitivo humano, atribuyendo a la mediación, una potencialidad para alcanzar transformación, evolución y/o superación, resaltando la importancia de espacios sociales (incluso en diferentes perspectivas), de la apropiación y de los impactos recíprocos o reflexivos materiales de la mediación (también con diferentes abordajes).

Por lo tanto, se mantienen y se basan en la tríada teórica orientadora básica enumerada, el destacar que la mediación se ancla en la búsqueda del impacto en el desarrollo humano y que ese desarrollo es dependiente de interacciones espacio sociales y que también es reflexivo.

Así, suspendiendo aspectos que independiente del contexto, surgirían (como por ejemplo influencias anteriores y/o externas al proceso e interferencias por su inherencia), y sin analizar aspectos subjetivos (como bien/mal y positivo/negativo), se identificó esencialmente un proceso que exige una interacción entre al menos dos seres, y un factor de impacto sobre al menos uno de ellos, con reflexión material. Se observa que es un fenómeno esencialmente humano, anclado en aspectos sociales.

Dentro de los patrones situados, y reconectando los factores esenciales con las posibles subjetividades, en la construcción inversa que no desconsidera la esencia y aliada a los aspectos materiales de apoyo a la mediación (tecnologías), se puede trazar posibilidades de interacción dentro de la concepción general de mediación, diferenciándola del proceso de comunicación habitual, especialmente por su complejidad que involucra el impacto en la búsqueda por ejercer en el desarrollo humano, en la "espera" de un resultado específico y no en una "transmisión" estándar comunicacional de un mensaje entre fuente/transmisor/receptor/destino, con una preocupación anclada en el recibimiento 
del mensaje propiamente, aunque pasible de análisis de factores externos, ruidos, etc. Este salto de complejidad se materializa, bien sea en la expresión social o en la construcción de conocimiento que modifica los involucrados.

El proceso sería dependiente del contexto humano, un fenómeno esencialmente humano y, por tanto, imposible de existir a partir de una concreción antropomórfica, pero sin necesidad de contacto inmediato con el iniciador del proceso, es decir - es posible que el mediador no esté presente durante el proceso, pero no es posible que el proceso ocurra sin el mediador.

Cuando el núcleo del estudio es direccionado para el campo de la Ciencia de la Información, y ateniéndose a la mediación de la información como proceso complejo, dentro de la perspectiva de la relación Información y Sociedad, se presenta una posible exploración del concepto englobando 4 aspectos principales: mediador, protoinformación, forma, y lector, didácticamente aquí representados en este orden, en la práctica, pero no dependiente de él en un proceso linear propiamente, o sea, en la práctica el orden de los factores puede variar y repetirse. Esos 4 aspectos pueden ser explicados/justificados como:

1. El término mediador, para la Ciencia de la Información, carga en sí la intencionalidad de exprimir que la mediación constituye una acción intencional, que tiene un orientador y que no puede ser considerado imparcial ya que todo agente no puede disociarse de su existencia en cuanto ejerce sus actividades profesionales, ni una institución puede disociarse de sus bases culturales, metas y objetivos. Ese profesional puede actuar en diferentes unidades informacionales y en diferentes sectores. La mediación de la información no se sujeta a sectores de atendimiento, aunque está presente en todas las fases y sectores de la organización. (OLIVEIRA, 2015; ALMEIDA JÚNIOR; BORTOLIN, 2008).

2. El término protoinformación objetiva señalizar la importancia de apropiación ya que se considera en ese proceso, que la información solo es información en el momento de la apropiación, o sea, ella se muestra dependiente del sujeto y solo es así categorizada (consciente o inconscientemente) por él y, por tanto, solo es posible el trabajo con protoinformaciones, aquellos que sean datos considerables pasibles de apropiación, de significación. (ALMEIDA JÚNIOR, 2007);

3. El término forma no se sujeta a las cuestiones materiales y sí, expresa la forma asumida por la mediación, con base en la relación protoinformación-lector que se 
objetiva, pudiendo ser expresa en innúmeras variaciones como, por ejemplo, un libro, una oralidad, un sistema, una interfaz, una presentación teatral, un edificio, un mueble, etc. El mediador analizará cuál es la mejor forma que deberá ser utilizada para promover protoinformaciones a sus lectores.

4. Finalmente, la elección del término lector substituyendo a otros más comúnmente utilizados en el área, como usuario o frecuentador, objetiva destacar que la lectura en su complejidad está intrínsicamente relacionada a la existencia humana, no siendo pasible, por tanto, la idea de "no lectores", y sí lectores de diferentes soportes y aspectos del mundo. Cuando una persona tiene contacto con la forma expresa de la mediación, haría entonces su lectura, el medio por el cual puede o no ocurrir una apropiación; la lectura sería entonces el momento de evaluación y apropiación o refutación. (OLIVEIRA, 2015).

El entendimiento del desarrollo de esos cuatro puntos de base de la mediación de la información en la actuación del profesional del área esclarece el alcance de la necesidad de estudios sobre el tema, para que la práctica de mediar pueda ser consistente y responsable, ya que los puntos sobrepasan todas las esferas de actuación, y cada uno de esos aspectos necesitan ser considerados en la complejidad que cargan.

La falta de dialogo y valorización de todos los aspectos presentados en relación como complementarios, se justifica porque es difícil que la mediación de la información pueda ser colocada en práctica ética y eficientemente. Los que se presentan con mayor frecuencia son las perspectivas que priorizan uno o alguno de esos aspectos, dejando una brecha que puede resultar en problemas como la falta de público en unidades informacionales, baja cobertura o aspectos de colonización. (OLIVEIRA, 2014; OLIVEIRA, 2015).

El $6^{\circ}$ capítulo se adentra en discusiones de aspectos de la educación, cultura e interculturalidad que impactan en los temas abordados en la tesis, trayendo problemáticas dentro de la exposición de contextos de dominaciones territoriales, colonizaciones y globalización, entre otros, que fueron creando sociedades construidas y desarrolladas en diferentes contextos temporales, aunque intentando, al mismo tiempo, igualarse en ese ámbito.

Los tiempos de transposición modernidad-posmodernidad, deja claro ese problemático ser en un amplio que nos fue impuesto con los fenómenos de aproximación desaproximada y jerárquica entre naciones y pueblos. 
En el curso del capítulo son abordados aspectos de la agenda 2030 de la Organización de las Naciones Unidas que, consciente de esa realidad coloca, junto a otros objetivos, el objetivo sustentable 4 Educación de Calidad, que explora la necesidad de "garantizar el acceso a la educación inclusiva, de calidad y equitativa, y promover oportunidades de aprendizaje a lo largo de la vida para todos", cuyo desenvolvimiento expone algunos puntos en destaque considerados importantes, en el contexto de desarrollos de esta tesis: la necesidad de garantía no apenas en determinado nivel, sino en todos los niveles de formación para grupos vulnerables; la relación de la valorización de la diversidad cultural, así como la preocupación con la cultura de paz y no-violencia, como impactantes directos en el desarrollo sustentable; la importancia del espacio físico, reafirmando y traspareciendo las concepciones de seguridad, no-violencia e inclusión; y la necesidad de atención a la formación especializada de profesores. (ONU BRASIL, 2020, sin paginación).

Se presenta la problemática del desequilibrio económico mundial y su impacto no apenas en la relación incomparable entre países, sino también, en la propia ampliación de la diversidad cultural en la medida en que, en busca de una liberación de un contexto sin expectativa, movimientos migratorios son impulsados en busca de mejores condiciones de presente y futuro. También, el frecuente problematizador de la escuela como facilitador de una cultura intolerante, muestra aún más la urgencia de la necesidad de una reformulación en el sistema de educación, cuyo modelo actual ha resultado en una población que demuestra posturas de odio, violencia, intolerancia, entre otros aspectos negativos, generando también un gran desfase de alumnos, víctimas directas de ese sistema intolerante (como gais, transexuales, negros indígenas, quilombolas, inmigrantes y otros grupos olvidados por la educación formal).

Son abordados aspectos de la necesidad de una práctica educadora consciente de las complejidades expresas por Paulo Freire $(2011 ; 1979 ; 2013 ; 2015)$, que busca el desarrollo de una educación libertaria, y es considerada la más coherente con la búsqueda de superación de los procesos educativos frente a su necesidad de inclusión de grupos marginalizados y a la superación de todas las metas presentadas en la agenda ONU 2030; de la manipulación mediática que crece sin precedentes y engloba diferentes medios de comunicación y redes, dificultando un acompañamiento y criticidad a todas las personas, sobre las informaciones; y de los aspectos que engloban una sociedad plural, presentando finalmente, los conceptos de 
multiculturalismo e interculturalidad, aclarando los aspectos que culminaron con la elección de la interculturalidad para el apoyo al desarrollo de esta tesis.

Se concluye que la implementación de las concepciones interculturalidad, y el desarrollo de los principios de interculturalismo, por lo tanto, pueden ser un camino coherente en la búsqueda por la superación a los desafíos contextualizados en este capítulo, así como una propuesta de posible aproximación con las metas de la agenda 2030 para la educación.

En el $7^{\circ}$ capítulo se concentran las observaciones y resultados obtenidos en los estudios de campo realizados en Brasil (2017), presentando algunos aspectos iniciales de contextualización de la colonización de América Latina, impactos territoriales ocasionados por explotaciones capitalistas, y resultados de una investigación sobre la exposición mediática de los pueblos indígenas brasileños, corroborando con la exposición de Castro e Castro (2018) que afirman que, para el discurso de los medios de comunicación, los pueblos indígenas son infantilizados y/o tratados como seres populares y, como resultado del racismo que sufren, son víctimas de crímenes, muchas veces sin un juicio justo y, así, estas personas acaban viviendo fuera del concepto de ciudadanía en su plenitud.

Posteriormente serán aclarados algunos aspectos identitarios del pueblo Xavante ( $A^{\prime}$ uwe), y presentados los resultados obtenidos, divididos en tópicos: Diario de Campo, Observaciones y Entrevista, y Proyecto Político Pedagógico - PPP.

El capítulo 8 presenta la investigación realizada en España (2018), abordando aspectos del incremento de la diversidad cultural como resultado de la complejidad traída por el siglo XXI, resultado de diferentes factores, como migraciones e inmigraciones crecientes, globalización, inmediatismo en las comunicaciones y avances tecnológicos en las distintas esferas.

Serán abordados aspectos legales y de financiamiento, en especial, en aspectos migratorios y de diversidad cultural, resaltando que la falta de políticas públicas sociales de integración para los inmigrantes sería una de las principales brechas no resueltas durante las expansiones migratorias en Europa, y que esa deficiencia no se restringe a España, y sobrepasa a todos los países europeos que, con diferentes contextos e intereses, encuentran dificultades para establecer acuerdos en el nivel de la unión. (GARRIDO, 2014).

Se contextualiza aspectos de inmigración en la región de AlmeríaEspaña, como crecimiento, impacto económico y condiciones de vida, exponiendo los 
resultados obtenidos en observaciones y entrevistas con los inmigrantes que hacían parte del Universo de Investigación de la tesis.

Se finaliza con la presentación de las bibliotecas visitadas y el análisis de las entrevistas realizadas con los profesionales que participaron en la investigación.

El capítulo 9 presenta las consideraciones y la propuesta de actuación sobre el concepto de Lectura de Mundo para el área de Ciencia de la Información.

A partir del análisis de los aspectos de las comunidades estudiadas en Brasil y España es construida y explorada una imagen que tiene como objetivo exponer las influencias de la marginalización y prejuicio sobre las comunidades.

Se presenta también un esquema de cómo los servicios informacionales demostraron ser desarrollados y cómo la mediación fue identificada en esa relación, proponiéndose finalmente, una reorganización de ese esquema teniendo la mediación de la información adaptada a las concepciones interculturales, evaluándose todos los aspectos e implicaciones de la reorganización propuesta. Se buscó de esta manera, transponer de forma práctica cómo un trabajo mediador puede ser desarrollado objetivando dirimir dificultades de actuación frente a grupos marginalizados.

\subsection{CONCLUSIÓN}

El Objetivo General de este trabajo fue analizar aspectos de la naturaleza de la mediación sobre una visión fenomenológica, buscando identificar y entender el momento en el que el proceso de la mediación inicia y cómo se perpetua en diferentes realidades complejas.

En relación a esto, se concluye que, a partir de las concepciones estudiadas: Hegel (en una perspectiva filosófica), Marx (social) y Vygotsky (psicológica educacional), presentadas y discutidas en los capítulos 4 y 5, se identificó que la actividad de mediar se ancla en el impacto del desarrollo humano, "trabajando", por decirlo así, en el ámbito inmaterial de la consciencia y del proceso cognitivo humano - ella carga características de transformación, evolución y/o superación, resaltando la importancia de espacios sociales (aunque sean en diferentes perspectivas) de la apropiación y de los impactos recíprocos o reflexivos materiales de la mediación (también con diferentes abordajes). 
Por lo tanto, se puede considerar que la intencionalidad es un punto de partida para la mediación y así, también una condición para que un fenómeno sea considerado una mediación.

Con relación a los objetivos específicos presentados:

$\checkmark$ Conocer las concepciones y las formas de entender la mediación sobre una perspectiva fenomenológica.

La propuesta de trabajar con autores distantes en el ámbito temporal y de aplicación de investigaciones, fue propuesto con la intención de que la reducción fenomenológica aplicada pudiese ver más claramente, aspectos contextuales que no impactasen el fenómeno y, en ese sentido, se considera que la elección fue provechosa.

La metodología de esta investigación puede ser aplicada en análisis de otros autores y en otros contextos, confrontando sus resultados y así enriqueciéndolos.

\section{$\checkmark \quad$ Identificar aspectos de la lectura de mundo.}

Fue identificado que la lectura de mundo, aunque sea individual, reconoce la colectividad de un ser que se desarrolla continuamente, con un universo informacional mutable y reflexivo.

Como fue explícito en el capítulo 9 (Mediación de Lectura de Mundo), en la medida en que se desarrolla las diferentes lecturas de mundo, se entrelazan y forman redes de comunidades constituidas por individuos que asumen diferentes papeles en las sociedades dominantes y periféricas. Esos papeles impactan en el propio reconocimiento personal y de la sociedad hegemónica, que tiende a dictar reglas específicas para que los consideren como "el otro".

Analizando los diferentes aspectos que se mostraron durante las investigaciones de campo (en Brasil y España), fue posible entender que las sociedades marginalizadas, aunque individualmente complejas y en constante evolución, poseen similitudes contextuales y que el entendimiento sobre eso y su impacto en comportamientos y necesidades, pueden auxiliar en un trabajo mediador. 
$\checkmark$ Explorar posibilidades de utilizar la mediación como aspecto de unión entre el contexto socio-cultural-ambiental de individuos y su construcción de conocimiento (entendiendo matices de la profesionalización de la mediación, o la aplicación propiamente de la mediación de la información y de la lectura), con la intención de adecuar materiales y actividades que tengan como objetivo el desenvolvimiento cognitivo.

La posibilidad más coherente identificada en esta tesis, involucra la adopción de las concepciones de interculturalidad a la mediación, transpuestas en el modelo de la Figura 48 - Mediación de la información adaptada a las concepciones interculturales (presentada, justificada y discutida en el capítulo 9 - Mediación de Lectura de Mundo), en la cual se retira el protagonismo de la sociedad hegemónica e se reubica las comunidades/grupos marginalizados en un primer plano, y también se amplía la actuación del mediador sobre todo el proceso, asumiendo la necesidad de consciencia activa de amplias complejidades, involucradas en todo el esquema de mediación.

$\checkmark$ Entender si las comunidades brasileñas y extranjeras que posean singularidades de relacionamiento y mediación con su medio pueden ser beneficiadas con la mediación de lectura de mundo.

Tanto las comunidades visitadas, como los profesionales entrevistados (hicieran parte o no de las comunidades), externalizaron dificultades de vivencia y desarrollo debido a un contexto opresor que fue capaz de crear, en la mejor de las hipótesis, inserciones de culturas en ambientes educacionales (y aquí se incluye la biblioteca), pero no una inclusión capaz de volverlos parte de una sociedad plural en equidad.

Dentro de las perspectivas esenciales de la mediación aquí presentadas (ancladas exactamente en el desarrollo humano y su reflexibilidad), y de las concepciones de que el trabajo con la lectura de mundo puede iniciar una transposición de algunas barreras, se asume que es posible, dentro de una práctica adecuada y consciente, beneficiar esas comunidades, buscando un camino para la exclusión de su status de marginalizados. 
En la ya mencionada figura 48, como propuesta de mediación, la lectura de mundo pasa a ser el centro del esquema, ya que se busca, antes, el entendimiento de ambos contextos y sus complejidades para, y apenas después de eso, ser posible la construcción o evaluación de servicios informacionales pasibles de desarrollo e incorporación (siendo este el beneficio que, dentro de la Ciencia de la Información, se busca alcanzar).

Fueron identificadas grandes dificultades de trabajo y desarrollo en los centros educacionales visitados (bibliotecas y abrigos) que trabajan con grupos con especificidades culturales de la lectura de mundo (en este caso, con el grupo escogido como representativo en este contexto - inmigrantes de la África Subsahariana). Debido a la complejidad del contexto estudiado y de las limitaciones formativas que se enfrentan, tales dificultades pueden ser consideradas previsibles de reproducción en otros contextos similares,

La reorganización de los aspectos que componen esos contextos, bien como el trabajo consiente en ese sentido, en el ámbito profesional de actuación, es dependiente de un entrenamiento adecuado que ofrezca caminos y escenarios con los cuales esos profesionales deben estar preparados, al menos para lidiar psicológicamente.

El desarrollo de propuestas dentro del multiculturalismo posibilitó el reconocimiento de la necesidad de convivencia entre la pluralidad cultural que constituye el mundo, sin embargo, fue insuficiente en promover la convivencia equitativa entre esas culturas, como observamos en el caso de inmigrantes en España.

Ya en la perspectiva de ampliación para las practicas del interculturalismo, se depara con la complejidad de alcance de la consciencia de la existencia de la interculturalidad en la sociedad, ya que tal concepción rompe con la cultura hegemónica que, históricamente, ha conseguido mantener su soberanía entre territorios y pueblos.

La propuesta de una mediación que busque en las sociedades marginalizadas un entendimiento que objetive proponer que esas comunidades tengan autonomía frente a la determinación de necesidades informacionales.

Los esquemas propuestos y sus discusiones presentadas (Figuras 46- Influencias de la marginalización y prejuicio sobre comunidades y 48 - Mediación de la Información adaptada a las concepciones interculturales) tienen como objetivo, 
proponer un "punto de partida" para profesionales de la información que se deparan con contextos plurales.

Se considera que el reconocimiento del potencial facilitador del mediador de la información en la composición de una perspectiva que favorezca la interdisciplinariedad puede resultar en una aproximación de sociedades marginalizadas a ambientes culturalmente hegemónicos y colonizadores y así contribuir para el desarrollo de una sociedad intercultural.

Como forma de contribución para los desafíos de un trabajo junto a comunidades marginadas, se presenta la propuesta de creación de una aplicación que concentre directrices y modelos de prácticas, centrados para profesionales de la información. Se concluye la tesis con la propuesta inicial para el desarrollo de tal aplicación, exponiendo un briefing con algunos aspectos que pueden componer su estructura.

La ampliación de esta investigación y propuesta, que culmina en el desarrollo práctico de la aplicación, es la sugerencia final de este trabajo para la ejecución de futuras investigaciones. 
A quatro grandes mulheres cujo mundo caminha junto ao meu, ainda que in memorian: minhas avós Thereza, Tilha e Mercedes, e minha amigairmã Carla Fonseca. 


\section{AGRADECIMENTOS}

A Fundação de Amparo à Pesquisa do Estado de São Paulo - FAPESP, pelo financiamento ao desenvolvimento dessa pesquisa (processo 2016/08053-4).

Ao meu orientador Oswaldo Francisco de Almeida Júnior, não apenas pela constante orientação neste trabalho (o que já é muito), mas especialmente pelo respeito e apoio durante toda nossa caminhada em pesquisa juntos, totalizando uma amizade e companherismo em pesquisa de mais de 7 anos.

Ao meu orientador José Antonio Frías Montoya, especialmente por todo apoio e desenvolvimento realizados na Universidad de Salamanca durante o ano de 2018, assim como a grata amizade desenvolvida.

Às todas pessoas que tornaram o desenvolvimento das pesquisas práticas possíveis, incluindo funcionários, interlocutores, associações e amigos que, de diferentes maneiras, estiveram presentes comigo no campo, especialmente Leopoldo Frías, Spitou Mendy, Juan Ramón, Magdalena Garcia, Gabriel Gomes Muria, Gustavo Gomes Sanches Nunes dos Santos, e Xisto Tserenhi'ru Tserenhimi'rami. Um agradecimento especial à todos que não podem ser identificados, por questões éticas, mas que gentimente participaram das entrevistas e observações - imigrantes, indígenas, e funcionários das bibliotecas, associações e FUNAI.

Ao professores membros da banca, Carlos Almeida, Jefferson Nunes, Tamara Guaraldo, Pedro Garrido e Críspulo Travieso, por suas contribuições, avaliações e apoio nessa caminhada - muitos estiveram presentes além do momento da qualificação e defesa, me ajudando em outras orientações, questionamentos e contruções deste trabalho, seja pessoalmente ou com seus textos. Obrigada pelo aprendizado e amizade.

Aos professores e funcionários da Facultad de Traducción y Documentación da USAL, em especial às queridas Manuela Moro, Elvira Miguélez e Marta de la Mano - muito obrigada pelas orientações e acolhimento, sempre lembrarei com muito carinho de todos os nossos cafés.

À Caroline de Novais, Ana Paula Rodrigues e Eder Ludovico de Matos, pelo apoio, ajuda e paciência em todos esses anos, sempre com muita amabilidade.

Aos demais funcionários da Unesp e Usal com quem tive o prazer de conviver nesses últimos anos, em especial aos das secretarias de pós-graduação, NAPEP/Unesp, portaria, limpeza e biblioteca. 
A todos os queridos amigos do grupo de pesquisa Informação, Conhecimento e Inteligência Organizacional - ICIO, por todo aprendizado, vivências e apoio, em especial Marta Valentim, Marcia Pazin, Rosângela Caldas, Carlos Bitencourt, Daniela Reis, leda Damian, Elaine da Silva, João Arlindo, João Guilherme, Luana Maia, Natália Marinho, Ana Clara Pedersoli, Cristiana Yafushi, Maria Aparecida Arruda, Niembo Daniel, e Rafaela Carolina da Silva.

Aos demais queridos amigos que a USAL e UNESP me presentearam, por todas as vivências e aprendizados, em especial Carlos Díaz-Redondo, Laís Landim, Tatiana Costa Rosa, Soraia Magalhães, Gustavo Marttos, e Juan Montoya.

À minha "irmã-cubana", Dunia Llanes Padrón, que levo sempre no coração, assim como à outra família que ela me presenteou, em especial Ariel Llauger Rabaza, Ismary Perez Padron, René Medina Rafols e os demais membros do querido grupo Bahia Rock \& Ron.

Agradeço também minhas "irmãs" queridas, cujo "café" do mestrado virou banquete pra vida: Admeire Sundström, Cassia Dias e Maíra Prado, pela companhia incessante mais uma vez, ainda que não sempre presencialmente, mas durante todo o curso (na saúde e na doença, na alegria e na tristeza, nos prazos finais e nos cafés... e ainda não necessariamente nessa ordem).

Aos amigos que tiveram que lidar com minhas loucas ausências, e mesmo assim continuaram me apoiando e incentivando, em especial meus amados: Márcia Sant'Ana, Nathália Pantaleão, Vânia Carvalho, Ronaldo Andrade e Maria Cláudia Rocha

Pelo apoio, amor e incentivo no trilhar deste trabalho, e pela paciência mesmo quando era difícil entender porque eu "precisava estudar tanto" e "viajar tanto", agradeço especialmente às minhas famílias: a primeira, Camargo Carriel Oliveira principalmente à meus pais, Osvaldo e Vera, e à meu irmão André; e à segunda, Bellaver Del Massa, principalmente Cesar, Benedito, Jussara, Aline e Gabriel. Amo muito todos vocês.

A todos, já mencionados ou não, que me acompanharam nos percalços de 2020 e me ajudaram a concluir essa tese superando as loucuras que foram surgindo - gratidão eterna por toda ajuda, pessoal e profissional.

Finalmente, agradeço a todos que contribuíram de alguma forma na realização dessa grande etapa da minha vida profissional e pessoal, pedindo desculpas por possíveis esquecimentos durante as citações. 
Os olhos tristes da fita

Rodando no gravador Uma moça cosendo roupa

Com a linha do Equador

E a voz da Santa dizendo O que é que eu tô fazendo Cá em cima desse andor

$$
\text { [...] }
$$

O olhar vê tons tão sudestes E o beijo que vós me nordestes Arranha céu da boca paulista [...]

E os sem amor, os sem teto Os sem paixão sem alqueire No peito dos sem peito uma seta E a cigana analfabeta Lendo a mão de Paulo Freire 


\section{LISTA DE QUADROS}

Quadro 1: Levantamento realizado em 12 de janeiro de 2015

Quadro 2: Textos recuperados

Quadro 3: Textos utilizados

Quadro 4: Fragmentação de Texto e Estabelecimento de Unidade de Sentido: Hegel. 72

Quadro 5: Metatexto mediação em Hegel .75

Quadro 6: Fragmentação de Texto e Estabelecimento de Unidade de Sentido: Marx .75

Quadro 7: Metatexto mediação em Marx .76

Quadro 8: Fragmentação de Texto e Estabelecimento de Unidade de Sentido: Vygotsky. .77

Quadro 9: Metatexto mediação em Vygotsky .82

Quadro 10: Coexistência (multiculturalismo) versus convivência (interculturalismo) 114 


\section{LISTA DE FIGURAS}

Figura 1: Mediação natural .95

Figura 2: Modelos sociopolíticos frente a diversidade cultural.

Figura 3: Pluralismo, multiculturalidade e interculturalidade: proposta terminológica e conceitual

Figura 4: Foto aérea de área de território brasileiro

Figura 5: Desmatamento na Amazônia brasileira.

Figura 6: Troca de presentes entre grupos locais Xavante e o Serviço de Proteção ao Índio (SPI)

Figura 7: Xavante vestido para festividade tradicional

Figura 8: Sinalização de início de área indígena protegida

Figura 9: Aldeia Nova Esperança 1 .128

Figura 10: Aldeia Nova Esperança 2 129

Figura 11: Prédio da escola da aldeia 129

Figura 12: Frente de prédio da escola da aldeia 130

Figura 13: Interna de sala de aula 1 .130

Figura 14: Interna de sala de aula 2 .131

Figura 15: Lousa dentro de sala de aula .132

Figura 16: Prédio da biblioteca .133

Figura 17: Espaço interno da biblioteca, com acervo ao fundo 133

Figura 18: Espaço interno da biblioteca .134

Figura 19: Acervo da biblioteca .134 
Figura 20: Evolução de pessoas que chegaram ao território espanhol (terra e mar) pela fronteira Sul do país.

Figura 21: Entradas ao território espanhol (terra e mar) pela fronteira Sul segundo a zona geográfica. 150

Figura 22: Imigrantes chegando à costa de Almería após resgate. 152

Figura 23: Estufas de Roquetas del Mar, Almería 153

Figura 24: Homens trabalhando na troca do plástico de uma estufa. .154

Figura 25: Homem trabalhando em estufa .154

Figura 26: Imigrantes em sua casa improvisada 155

Figura 27: Fachada da biblioteca de Almería 161

Figura 28: Interna da biblioteca de Almería 161

Figura 29: Bebeteca da biblioteca de Almería 162

Figura 30: Escadaria entre andares da biblioteca de Almería 163

Figura 31: Acervo em destaque na biblioteca de Almería 163

Figura 32: Sala de periódicos da biblioteca de Almería 164

Figura 33: Salões de exposições. 164

Figura 34: Teatro da biblioteca de Almería..... 165

Figura 35: Biblioteca de San Isidro 166

Figura 36: Entrada da biblioteca de San Isidro. 167

Figura 37: Imagem interna da biblioteca de San Isidro 167

Figura 38: Livros mais usados por imigrantes na biblioteca de San Isidro 168

Figura 39: Exemplo de conteúdo interior de um dos livros mais usados por imigrantes na biblioteca de San Isidro 168

Figura 40: Fachada da biblioteca de Roquetas del Mar 169 
Figura 41: Hall de entrada da biblioteca de Roquetas del Mar

Figura 42: Quadro de anúncios da biblioteca de Roquetas del Mar 171

Figura 43: Poltronas na entrada da biblioteca de Roquetas del Mar 171

Figura 44: Livros Caritas expostos na entrada da biblioteca de Roquetas del Mar

Figura 45: Acervo da biblioteca de Roquetas del Mar 172

Figura 46: Influências da marginalização e preconceito sobre comunidades 178

Figura 47: Atuação de mediação - cenário 1 180

Figura 48: Mediação da informação adaptada às concepções interculturais 184

Figura 49: Tela principal 193

Figura 50: Tela com legislação 194

Figura 51: Tela para consulta de comunidades cadastradas 195

Figura 52: Tela de exemplo de apresentação de uma comunidade 196 


\section{SUMÁRIO}

1 INTRODUÇÃo

2 METODOLOGIA

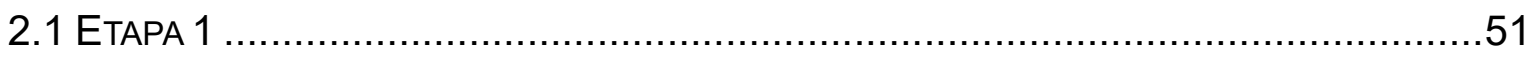

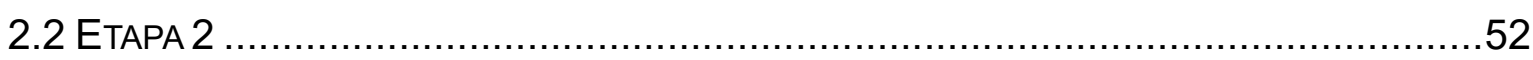

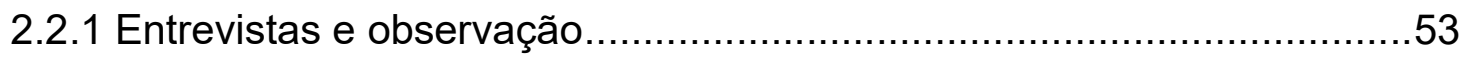

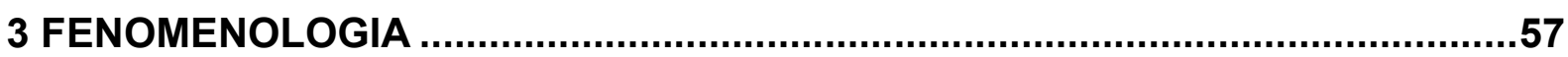

4 MEDIAÇÃO

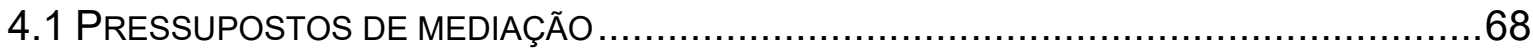

4.1.1 Pressupostos de mediação em Hegel ...............................................72

4.1.2 Pressupostos de mediação em Marx.................................................75

4.1.3 Pressupostos de mediação em Vygotsky .........................................76

4.2 A CompleXIDADE DA MEDIAÇÃo DA INFORMAÇÃo NA CIÊNCIA DA INFORMAÇÃO ....83

5 FENOMENOLOGIA DA MEDIAÇÃO

6 EDUCAÇÃO E INTERCULTURALIDADE . 100

7 PESQUISA DE CAMPO BRASIL: XAVANTES …............................................116

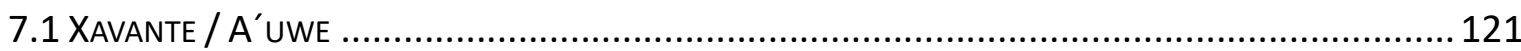

7.2 DIÁRIO DE CAMPO - VISITA À ALDEIA NoVA ESPERANÇA ..................................123

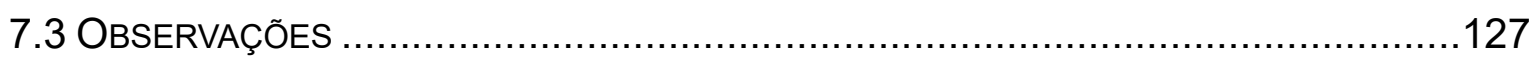

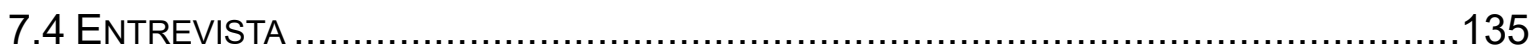

7.5 PRojeto Político PedagógICo - PPP .........................................................140

8 PESQUISA DE CAMPO ESPANHA: IMIGRANTES ADVINDOS DA ÁFRICA

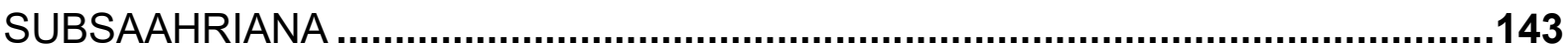

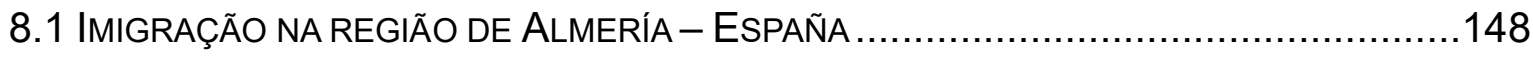

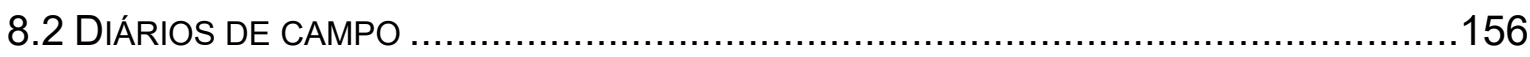




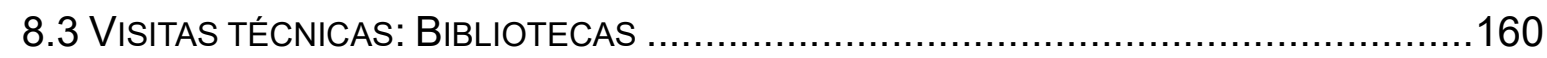

8.3.1 Biblioteca Municipal de Almería …..............................................160

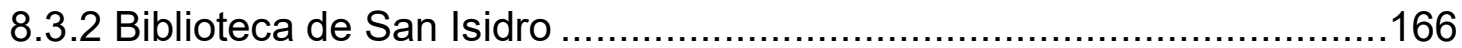

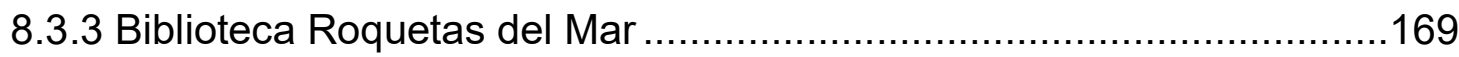

8.4 ENTREVISTAS COM FUNCIONÁRIOS DAS BIBLIOTECAS......................................173

9 MEDIAÇÃO DE LEITURA DE MUNDO

CONCLUSÃO

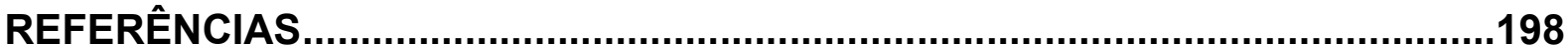

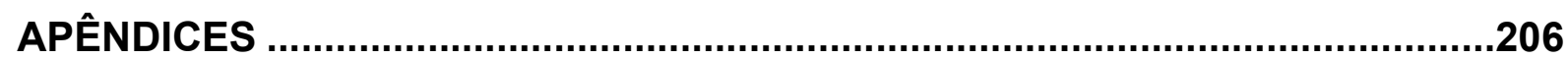

apêndice A - Instrumentos de Apoio para Coleta de Dados das Pesquisas de CAMPO .207

ANEXOS

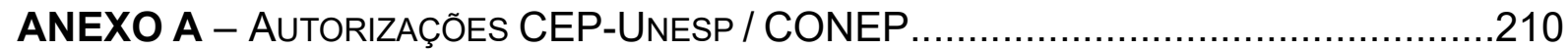

ANEXO B - AUTORIZAÇÃo FUNAI REgIONAL XAVANTE - MT ................................214

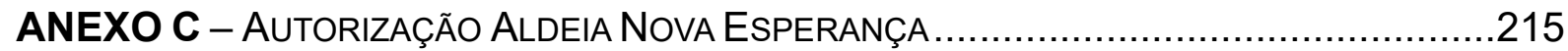

ANEXO D - PROJETO PolítICO PEDAGÓGICO - PPP .............................................216 


\section{INTRODUÇÃO}

A ciência da informação tem se preocupado com sua atuação enquanto mediadora da informação. Assim, novos estudos no âmbito científico têm se desenvolvido na área em busca de caracterizar e diagnosticar aspectos de atuação e desenvolvimento da mediação na atuação de seus profissionais.

As discussões que abarcam o uso do termo mediação e sua aplicabilidade crescem e vislumbram-se conquistas no que tange à clarificação destas discussões.

Este trabalho tem a intenção de entender e explorar a possibilidade da mediação da leitura de mundo. A leitura de mundo pode ser definida como a leitura dos signos que o mundo nos apresenta. Assume-se que a leitura de mundo impacta na apropriação da informação e que, portanto, pode ser usada tanto como apoio para um trabalho mediador de qualidade, como para práticas de manipulação.

Como os aspectos de mediação, mediação da informação e mediação de leitura de mundo são dependentes de diferentes aspectos sociais, culturais, históricos e geográficos, para discuti-los é interessante manter uma perspectiva que leve em consideração tais fenômenos. A fenomenologia traz a possibilidade de encontrar na subjetividade exposta em realidades complexas a objetividade que não pode ser separada do fenômeno, mas que, separada dele não deixa de ser axioma da relação estabelecida. A fenomenologia caracteriza, portanto, um norte que visa explorar fenômenos sem desconsiderar uma cadeia fenomenológica que o impacta.

Assim, num cenário onde a mediação dentro da Ciência da Informação ainda não possui um aprofundamento teórico consistente quanto a sua natureza e amplitude, questiona-se: Qual a real natureza da mediação? Existe apenas uma natureza? É possível mediar uma leitura do mundo? É possível entender o impacto da leitura de mundo na construção do conhecimento?

Observou-se a impossibilidade de seguir questionamentos como os previamente mencionados por não se ter claro o âmago envolvido na mediação e, assim, suas possíveis limitações. O que se buscou, portanto, é um "ponto de vista" gnosiológico da mediação, para que se possa entender sua abrangência. 
Ressalta-se então neste projeto a principal problemática: Quando, como e em qual grau se inicia a mediação na vida das pessoas sob uma perspectiva fenomenológica?

Esse esclarecimento se torna vital pois, a partir dele, é possível ressaltar os pontos desenvolvidos na atuação profissional do ato "intuitivo" de mediar. Neste trabalho o termo "intuitivo" foi utilizado com a intenção de mencionar a mediação utilizada superficialmente, ou seja, sem um desenvolvimento mais elaborado. Ao entender esse possível impacto profissional, pode-se buscar na mediação a resposta para seu desenvolvimento enquanto impulsionador social, constituindo uma ferramenta fortemente influenciadora. Seria ela então a forma, o caminho, de estabelecer atividades que visem impactar no que se assume ser o âmago do potencializador do desenvolvimento humano - seu desenvolvimento de leitura de mundo.

A motivação para realização desta pesquisa surgiu durante o curso de mestrado em Ciência da Informação, com a exploração do tema "A mediação em projetos de incentivo à leitura: a apropriação da informação para construção do conhecimento e do pensamento crítico" (2013-2015), por meio do qual foi possível observar a real importância da mediação da leitura de mundo junto a leitura escrita, num processo complexo que, quando exercido amplamente, se mostra fundamental para a apropriação da informação e possibilita, finalmente, ocasionar um impacto na construção do conhecimento. Notou-se, porém, a insuficiência de estudos com o foco na perspectiva da leitura de mundo, como pode-se observar abaixo no resultado de um levantamento realizado em bases de Teses e Dissertações do Brasil, Portugal e Espanha: 
Quadro 1: Levantamento realizado em 12 de janeiro de 2015.

\begin{tabular}{|c|c|c|c|}
\hline BASE & TERMOS & REGISTROS & OBS \\
\hline \multirow{4}{*}{ Biblioteca Digital Brasileira de Teses e Dissertações (BDTD) } & mediação da informação & 11 & 2 teses e 9 dissertações \\
\hline & mediação da(e) leitura & 5 & 0 teses e 5 dissertações \\
\hline & leitura de mundo & 32 & 14 teses e 18 dissertações \\
\hline & mediação da leitura de mundo & 0 & \\
\hline \multirow{4}{*}{ Banco de Teses e Dissertações da Capes } & mediação da informação & 45 & 40 em Ciência da Informação \\
\hline & mediação da(e) leitura & 4 & 1 em Ciência da Informação \\
\hline & leitura de mundo & 20 & Oem Ciência da Informação \\
\hline & mediação da leitura de mundo & 0 & \\
\hline \multirow{4}{*}{$\begin{array}{l}\text { Estudo Geral - Repositório Digital da Universidade de } \\
\text { Coimbra }\end{array}$} & mediação da informação & 1 & \\
\hline & mediação da(e) leitura & 0 & \\
\hline & leitura de mundo & 1 & \\
\hline & mediação da leitura de mundo & 0 & \\
\hline \multirow{4}{*}{ DIALNET - Tesis doctorales } & mediação da informação & 23 & \\
\hline & mediação da(e) leitura & 8 & \\
\hline & leitura de mundo & 5 & \\
\hline & mediação da leitura de mundo & 0 & \\
\hline
\end{tabular}

Fonte: Elaborado pela autora.

A intencionalidade de explorar a leitura de mundo surge do objetivo de utilizar a visão complexa exposta por Morin, onde se há o esforço de "[...] não sacrificar o todo à parte, a parte ao todo, mas por conceber a difícil problemática da organização [...]. (MORIN, 1990, p. 29, tradução nossa)². Essa proposta é difícil porque somos historicamente encorajados a formas "mutilantes" de pensar. (MORIN, 1990, p. 157).

Nessa perspectiva, para desenvolver habilidades de leitura de códigos (como a escrita por exemplo), há de se atrelar a esse ensino um contexto complexo, que nesta proposta envolve a leitura inicial que é realizada por todos - a leitura de mundo (FREIRE, 2011), que surge carregada de influências culturais, históricas e sociais.

A proposta deste trabalho foi entender como aspectos subjetivos como a leitura do mundo podem (ou não) ser mediadas entre diferentes grupos, em realidades e necessidades diferentes, a fim de encontrar a natureza, o âmago, do ato de mediar. Com a possibilidade de trazer clareza a esse aspecto intrínseco à mediação, buscar-se-á delinear um norte à mediação no âmbito profissional (para a Cl propriamente).

Defende-se, por exemplo, a possibilidade de mediar uma leitura de mundo, de impactar na forma em que o outro vê a própria existência e sua relação com o meio, impactando assim no desenvolvimento intelectual e espacial de

\footnotetext{
${ }^{2}$ Texto original: "Il s'efforce non pas de sacrifier le tout à la partier, la partier ao tout, mais de concevoir la difficile problámatique de l'organisation [...]".
} 
determinada sociedade. Tal peculiaridade seria utilizada também para manipular indivíduos: quando o indivíduo cresce imerso em um sistema de ensino que ignora seu conhecimento cultural tácito e Ihe condiciona a absorver ensinamentos préfabricados por uma sociedade que não vê benefício no espírito indagador rebelde da natureza humana e que, por isso, faz tudo para reprimi-la - têm-se assim a formação de meros decodificadores de escrita, receptores de dados que aceitaram sua condição e pararam de refletir quanto ao seu impacto no mundo e na sociedade. (FREIRE, 1979; 2005; 2013).

Ao compreender a possibilidade da mediação ser utilizada com esse impacto, e ao explorar a possibilidade de um melhor relacionamento entre mediador e grupos mediados (sempre visando a apropriação), vislumbra-se a possibilidade de encontrar insuficiências em processos educativos atuais (especificamente a mediação da leitura), abrindo assim novos questionamentos sobre o seu uso (da mediação) para o benefício da sociedade por possibilitar o entendimento da necessidade de grupos específicos da comunidade (como pessoas com deficiência), adaptando-se a forma de ensino em diferentes realidades.

Porém, conforme discutido previamente, não é possível tecermos tais questionamentos e estudos enquanto não há uma clareza de aplicabilidade da mediação neste âmbito. Assim, os resultados obtidos poderão trazer luz quanto à importância da mediação e quais suas possibilidades de uso para a Cl. Caso haja a comprovação de que é possível mediar a leitura de mundo, por exemplo, isso pode promover a valorização da leitura de mundo no desenvolvimento do conhecimento e a possibilidade de usá-la com objetivo de ajudar a sociedade, contribuindo para projetos sociais, ressaltando também a necessidade de exploração de novos projetos e pesquisas na área que demonstrem interesse em aprofundar-se nesse tema. Em contrapartida, caso não seja possível encontrar evidências amplas de uso da mediação na área, as restrições podem consolidar as vertentes e aplicabilidades do conceito.

A perspectiva dessa pesquisa demonstra caráter multidisciplinar (por explorar aspectos de base filosófica e da educação) e visa ressaltar as dimensões social e humana que a $\mathrm{Cl}$ abarca. (SARACEVIC,1995).

O Objetivo Geral deste trabalho é analisar aspectos da natureza da mediação sob uma visão fenomenológica, buscando identificar e entender o momento 
em que o processo da mediação inicia e como se perpetua em diferentes realidades complexas.

Seus Objetivos Específicos são:

$\checkmark$ Conhecer as concepções e formas de se entender a mediação sob uma perspectiva fenomenológica;

$\checkmark$ Identificar aspectos da leitura de mundo;

$\checkmark$ Explorar possibilidades de se utilizar a mediação como aspecto de junção entre o contexto sócio-cultural-ambiental de indivíduos e sua construção de conhecimento (entendendo nuances da profissionalização da mediação, ou a aplicação propriamente da mediação da informação e da leitura), na intencionalidade de adequar materiais e atividades que visem o desenvolvimento cognitivo.

$\checkmark$ Entender se comunidades brasileiras e estrangeiras que possuam singularidades de relacionamento e mediação com seu meio podem ser beneficiadas com a mediação de leitura de mundo.

Tendo os objetivos citados como norte, no próximo capítulo - 2 Metodologia, se esclarece a metodologia utilizada, bem como os critérios de inclusão e exclusão; no 3 são expostas as discussões e explorações acerca das bases fenomenológicas utilizadas; no capítulo 4 se apresenta os pressupostos teóricos da mediação e mediação da informação que embasam este trabalho; no $5^{\circ}$ se expõe os aspectos identificados na análise da natureza da mediação a partir da base fenomenológica; o $6^{\circ}$ insere discussões de aspectos da educação, cultura e interculturalidade que impactam nos temas abordados na tese; no $7^{\circ}$ se concentram as observações e resultados obtidos em pesquisas de campo realizadas no Brasil (2017) e no $8^{\circ}$ as realizadas na Espanha (2018); e o $9^{\circ}$ apresenta as considerações e proposta de atuação sobre o conceito de Leitura de Mundo para a área da Ciência da Informação; seguidos dos capítulos de conclusão, referências e apêndices (onde estão disponibilizados os instrumentos de coleta de dados construídos). 


\title{
2 METODOLOGIA
}

A pesquisa possui natureza qualitativa, tendo em vista que tal abordagem pode ser utilizada para trazer significação a fenômenos e posições relativas, contemplando a proposta que se objetiva delinear. Silva, Gobbi e Simão salientam:

\begin{abstract}
A pesquisa social vem acompanhando a evolução da humanidade e à medida que se distancia da visão positivista das leis universais incorpora e aprimora pressupostos próprios da pesquisa qualitativa dentro do paradigma interpretativo. Isso ocorre pelo entendimento do homem como um agente social que influencia e é influenciado pela estrutura social, dotado de percepções peculiares da realidade que permitem uma interpretação própria da sua realidade. Esta poderá ser distinta de acordo com o observador e a posição do mesmo frente ao fenômeno estudado. (2005, p. 70).
\end{abstract}

Assim, busca-se ater ao entendimento de significação baseado na figura social do homem e a influência de seu meio e estrutura social em relação ao fenômeno em foco do estudo. (MAY, 2004).

A pesquisa foi delineada em consonância ao código Ethical Guidelines For Educational Research quanto a sua responsabilidade ética com seus participantes, patrocinadores, e em relação à comunidade de pesquisadores educacionais e profissionais da educação, formuladores de políticas e público em geral, a fim de manter-se em um desenvolvimento eticamente responsável e livre de preconceitos. (BRITISH EDUCATIONAL RESEARCH ASSOCIATION, 2011).

Foram realizadas duas etapas de pesquisa e análise, sendo a primeira bibliográfica e realizada com o apoio e orientações do método Análise Textual Discursiva, e a segunda de cunho Etnográfico, realizado com os instrumentos para coleta de dados: levantamento bibliográfico, entrevista semiestruturada e observação, analisados com o apoio da Análise de Discurso.

O objetivo da parte teórica da pesquisa foi explorar, sob uma perspectiva fenomenológica, como a mediação pode ser entendida, bem como entender aspectos da leitura de mundo e a possibilidade de uma mediação desta última; sua execução envolveu etapas realizadas no Brasil, na Universidade Estadual Paulista "Júlio de Mesquita Filho" e na Espanha, na Universidad de Salamanca. 
Posteriormente, realizou-se pesquisas de campo a fim de conclusivamente ser possível analisar, em determinados contextos, a validação de aspectos da pesquisa teórica, principalmente no âmbito da leitura de mundo. $O$ universo de pesquisa a ser utilizado nessa etapa é composto de expressões de pessoas que demonstrem especificidades culturais de leitura de mundo no Brasil e Espanha.

No âmbito brasileiro, a pesquisa foi aplicada com uma aldeia de povos indígenas e no âmbito Espanhol com um grupo de imigrantes. Para essa etapa o uso da etnografia se fundamenta em sua perspectiva de descrição de um povo, no sentido coletivo, visando o estudo de "pessoas em grupos organizados". (ANGROSINO, 2009, p. 16) em consonância aos objetivos de pesquisa.

A orientação etnográfica a ser delineada é o Interacionismo Simbólico, para o qual a "sociedade não é um conjunto de instituições entrelaçadas, como os funcionalistas pensavam, mas um caleidoscópio em constante mutação de indivíduos interagindo uns com os outros", caracterizando uma abordagem dinâmica com pressupostos que envolvem aspectos de significação, simbologia, e da importância das interações sociais inclusive na construção do self, e que visa "desvelar os significados que os atores sociais atribuem às suas ações". (ANGROSINO, 2009, p. 20).

Os princípios do Interacionismo Simbólico são definidos por Blumer (autor mais célebre em essa formulação), e compartilhada por diferentes autores que trabalham como o tema (como Mead, Dewey, Thomas, Znaniecki, Baldwin, Redfeld e Wirth):

[...] os seres humanos agem com as coisas com base nos sentidos que as coisas apresentam para elas; essas 'coisas' incluem tudo que os seres humanos podem perceber no mundo, como objetos físicos, categorias de objetos, instituições, ideais, atividades e situações; o sentido dessas coisas é derivado ou emerge da interação social que temos com nossos semelhantes; esses sentidos são manipulados e modificados por um processo interpretativo, usado pela pessoa ao lidar com as coisas que ela encontra. (NUNES, 2013).

Os interessantes discursos propostos nessa orientação, amplamente desenvolvida a partir da Escola de Chicago e que permeia diferentes discussões, especialmente em contextos filosóficos e sociais, traz os aspectos de ação social e 
identidade numa perspectiva mais ampla, quebrando uma perspectiva inicial cartesiana que pretendemos evitar.

As etapas serão descritas e justificadas em sequência.

\subsection{ETAPA 1}

$\mathrm{Na}$ pesquisa bibliográfica, os temas mediação, fenomenologia e leitura de mundo foram pesquisados na literatura disponível nas línguas portuguesa, espanhola, inglesa e francesa, na perspectiva de utilizar o conhecimento disponível em teorias publicadas para delinear discussões dos temas propostos.

As pesquisas centraram-se nas bases de dados: Portal Capes, Scientific Electronic Library Online (SciELO), Base de Dados Referenciais de Artigos de Periódicos em Ciência da Informação (Brapci) e E-prints in library and information science (e-LiS).

Para estudar as principais abordagens a compor a pesquisa no âmbito da natureza da mediação foi selecionado, em literatura direta ou indireta, os conceitos de Hegel, Weber, Vigotski e Marx. As áreas de filtro utilizadas foram Ciência da Informação, Filosofia e Educação. Para a análise dos dados obtidos foi utilizada a técnica da Análise Textual Discursiva (ATD) - método qualitativo que possibilita a fragmentação e organização de materiais pertinentes a fim de estabelecer um processo que possibilite novas e amplas compreensões de um tema proposto.

A escolha da ATD foi ancorada em sua proposta de proporcionar "duas reconstruções concomitantes: 1. do entendimento da ciência e de seus caminhos de produção; 2 . do objeto da pesquisa e de sua compreensão" e na argumentação de que ela "cria espaços de reconstrução, envolvendo-se nisto diversificados elementos, especialmente a compreensão dos modos de produção da ciência e reconstruções de significados de fenômenos investigados". (MORAES; GLIAZZI, 2006, p. 118).

De forma prática, o emprego da ATD envolve as etapas de 1 Desmontagem dos textos, 2 - Estabelecimento de relações e 3 - Captação do novo emergente. A primeira etapa envolveu uma fragmentação dos textos, o segundo a categorização e o terceiro e último a extração de compreensões emergentes dos processos anteriores. (MORAES, 2003, p. 191). 
O objetivo dessa fase foi extrair um quadro descritivo moderno da mediação da informação, com possíveis níveis, significações e aplicações, desenvolvidos a partir das concepções dos autores elencados. Os resultados obtidos nesta primeira etapa serão a base de análise dos dados obtidos na etapa 2.

\subsection{ETAPA 2}

A segunda parte da pesquisa tem como base o método etnográfico e foi dividida em três fases de coleta de dados: a primeira envolvendo um levantamento bibliográfico, a segunda entrevistas, e a terceira observações.

Conforme define Angrosino, "a etnografia é a arte e a ciência de descrever um grupo humano - suas instituições, seus comportamentos interpessoais, suas produções materiais e suas crenças" (2009, p. 30$)$.

A escolha específica dos grupos se pauta no objetivo de trabalhar com pessoas que possam demonstrar necessidades de pesquisas mais aprofundadas no tema (leitura de mundo) para que se possa entender o contexto em que vivem e como esse contexto influencia seu relacionamento com $o$ aprendizado e seu desenvolvimento sociocultural.

Como critério de inclusão e exclusão, no âmbito brasileiro, delimitouse a aplicação da pesquisa em moradores da aldeia Xavante Nova Esperança, localizada do Mato Grosso. A escolha dessa aldeia se baseou na seu envolvimento em negociações educacionais em nome dos povos indígenas, possuindo representantes que atuam diretamente com a Funai e que participam do fórum Tsihorirã A'uwẽ Uptabi, que é um evento que surgiu em decorrência de uma reunião ordinária do Conselho Estadual de Educação Escolar Indígena - CEEl, em setembro de 2015, a partir da necessidade da elaboração da Política de Educação Escolar Indígena para Mato Grosso. As entrevistas foram realizadas apenas com coordenadores e professores, durante uma visita à aldeia, na qual foi possível também conhecer a escola e a biblioteca da aldeia.

Como critério de inclusão e exclusão, no âmbito espanhol, delimitouse a aplicação da pesquisa em moradores da região de Almeria devido ao fato dessa região demonstrar expressiva concentração de imigrantes em nível nacional, principalmente nos nichos de estufas, sendo que essa concentração tem impactado 
no índice de natalidade da região e, consequentemente, ampliado questões socioculturais. A aplicação de entrevistas foi realizada apenas com pessoas em maioridade civil. As observações buscaram uma imersão no fazer cotidiano dos participantes e assim foram realizadas dentro de bairros onde vive uma maior concentração dessas pessoas, com foco em espaços de maior interação entre eles (bares e praças).

Os resultados obtidos nas pesquisas de campos foram analisados com o apoio dos resultados da pesquisa teórica.

Têm-se a intencionalidade de poder contribuir para a conscientização do ensino quanto a necessidade de uma visão complexa de mundo antes da preparação de materiais e atividades que visem o desenvolvimento cognitivo. Salientando que, conforme exposto por Borko, a "Ciência da informação como disciplina tem como objetivo fornecer um conjunto de informações que vai levar melhorias em diferentes instituições e procedimentos dedicados à acumulação e transmissão de conhecimento." (BORKO, 1968, p. 4, tradução nossa ${ }^{3}$ ).

O tópico 2.2.1 descreve e justifica as etapas de entrevistas e observação propostas.

\subsubsection{Entrevistas e observação}

Para a realização das entrevistas foram construídos roteiros (instrumento de coleta de dados), de forma semiestruturada, com foco nos objetivos geral e específicos deste trabalho e ancorados em resultados obtidos na análise bibliográfica (os documentos relacionados, bem como os próprios roteiros, encontramse no Apêndice A - Instrumentos de Apoio para Coleta de Dados das Pesquisas de Campo.

A escolha de entrevistas como técnica de coleta de dados se baseia na premissa de que elas permitem que o entrevistador possa "registrar informação qualitativa sobre o tópico em questão", já que haverá a possibilidade de "sondar além

\footnotetext{
${ }^{3}$ Texto original: "Information Science as a discipline has as its goal to provide a body of information that will lead to improvements in the various institutions and procedures dedicated to the accumulation and transmission of knowledge.
} 
das respostas e, assim, estabelecer um diálogo com o entrevistado." (MAY, 2004, p. 148).

Ainda quanto à técnica semiestruturada, May salienta:

Considera-se que esses tipos de entrevistas permitem que as pessoas respondam mais nos seus próprios termos do que as entrevistas padronizadas, mas ainda forneçam uma estrutura maior de comparabilidade do que nas entrevistas focalizadas. (2004, p. 148).

Essa oportunidade de manter a naturalidade das pessoas, porém sem desviar-se extensivamente dos objetivos de pesquisa são os principais pontos que levaram a escolha dessa abordagem.

No decorrer das entrevistas, as seguintes orientações são de importante ressalte:

\begin{abstract}
Algumas exigências devem ser consideradas no momento da entrevista: marcar com uma certa antecedência a hora e o local apropriados; garantir ao entrevistado o sigilo e o anonimato, caso seja necessário; utilizar vocabulário adequado ao informante; não apresentar questões que extrapolem o universo cultural do entrevistado; ouvir atentamente a resposta do informante; estimulá-lo a discorrer sobre o assunto e não forçar o rumo das respostas.

No decorrer da entrevista, o pesquisador tem que evitar a ocorrência de saltos bruscos em relação ao tópico abordado, colocar questões mais simples antes das complexas e, principalmente, manter flutuante a atenção para observar gestos, entonações da voz, hesitações e outros comportamentos que podem conter significados específicos. (LUDWIG, 2003, p. 66).
\end{abstract}

As exigências mencionadas são de extrema importância, pois garantem a boa execução do método, o que facilita no posterior tratamento dos dados e aumenta sua confiabilidade.

Para a aplicação das entrevistas no Brasil os sujeitos selecionados foram: representantes das comunidades pesquisadas que estão envolvidos em projetos que focam a educação para esses povos, conforme autorizações e com o uso de gravações em áudio para posterior análise. No caso das entrevistas na Espanha, os sujeitos foram imigrantes advindos de países da África Subsaariana que aceitaram participar, e foram registradas em áudio para posterior análise.

A observação nesse contexto de fenômenos sociais não é um processo narrativo puro, mas busca não a descrição e sim a constituição de fatos. Não podemos "fotografar", por assim dizer, "fatos crus", mas envolve a observação 
científica de fenômenos metodicamente escolhidos e isolados de outros, respeitando e assumindo suas complexidades que impossibilitam seu estudo em totalidade nos aspectos de detalhes e relações, constituindo assim uma grande dificuldade para o pesquisador. Para superar tais dificuldades, métodos e rigores de observação são necessários, com o nortear essencial da criticidade do método adotado. (MAUSS; FAUCONNET, 1901).

As fases de coleta de dados (análise bibliográfica e entrevistas) proporcionaram a familiaridade com o universo de pesquisa e facilitaram a imersão no ambiente de observação.

Durante a parte prática, como já mencionado, foi adotado o Interacionismo Simbólico, que descreve os diferentes papéis que podem ser adotados pelo pesquisador: participante completo (exige imersão completa e sem agenda); participante-como-observador (exige imersão, porém com ciência e autorização de sua pesquisa); observador-como-participante (permite um maior distanciamento da comunidade, com integração em momentos específicos); e completo observador (envolve a coleta de dados objetivos sem envolvimento ou anúncio de sua presença).

Devido a pesquisa não possuir completa orientação etnográfica foram adotas as posturas participante-como-observador e observador-como-participante, dependendo da abertura encontrada pelos grupos pesquisados.

A pesquisa realizada no Brasil foi avaliada e aprovada pelos conselhos de ética do país (Anexo A: Autorizações CEP-Unesp / CONEP), pela Funai do estado Mato Grosso (Anexo B - autorização FUNAl Regional Xavante MT), responsável pela tratativa com a aldeias Xavantes da Região de Barra do Garças MT - Brasil, e pelos indígenas da aldeia visitada (Anexo C - Autorização Aldeia Nova Esperança).

$\mathrm{Na}$ Espanha não há um órgão que acompanha esse tipo de investigação. A composição dos instrumentos, sua avaliação e aplicação, foram amparadas no apoio recebido pelo Sindicato Andaluz de Trabajadores/as (SAT). Os instrumentos estão disponíveis no Apêndice $A$-- Instrumentos de Apoio para Coleta de Dados das Pesquisas de Campo. Não foram utilizados termos de consentimento devido a impossibilidade de apresentar documentos formais aos participantes, já que a maioria se encontra ilegalmente no país e tem dificuldades com o idioma.

Em ambos os casos serão expostos os diários de campo. As entrevistas não serão publicadas na íntegra para proteção dos participantes, por 
questões éticas e de segurança, especialmente por se tratar de comunidades já imersas em contextos frágeis e/ou violentos. 


\section{FENOMENOLOGIA}

Se assumirmos a importância do envolvimento social e cultural no desenvolvimento da mediação, há de se trazer a percepção para nortear novos questionamentos, há de se apoiar o estudo em fenômenos.

A palavra 'fenômeno', do grego phainómenon, significa "aquilo que aparece", e se deriva do verbo grego phainomenai: "eu apareço". Apesar dessa relação com "o que aparece", com o "brilho", para a fenomenologia seu conceito tem como âmago o aparecer, o próprio fenômeno da consciência, o fenômeno subjetivo e compreende, de maneira simultânea, "[...] tanto o aparecer quanto aquilo que aparece: a relação indissociável entre o sujeito e o mundo, a consciência e seus objetos." Resumidamente, o que na maioria das vezes não se mostra seria então o único "fenômeno" que interessaria, e para identificá-lo é necessário o "retorno à consciência", não estabelecida por Husserl de maneira abstrata e ingênua, mas usada para explicitar a investigação do próprio acontecimento da consciência. (GALEFFI, 2000, p. 25).

O termo fenomenologia se constrói originalmente de duas palavras gregas: "Fenômeno", já comentado, e "Logia" que, derivada da palavra logos, tinha muitos significados, entre eles palavra e pensamento. Bello (2006) a traduz então como a "reflexão sobre um fenômeno ou sobre aquilo que se mostra.", sendo a busca de "o que é que se mostra e como se mostra". (BELLO, 2006, p. 17-18, grifo nosso).

Coltro esclarece que a fenomenologia "tem como objeto de investigação o fenômeno, ou seja, o que se mostra a si e em si mesmo tal como é." (2000, p. 39). Isso porque se acredita que

[...] as coisas são e estão dadas em si mesmas no fenômeno (Erscheinung) e em virtude do fenômeno; são ou valem, [...] como individualmente separáveis do fenômeno, na medida em que não importa este fenômeno singular (a consciência de estar dadas), mas, essencialmente são dele inseparáveis. (GALEFFI, 2000, p. 23).

Muitos autores trabalharam com diferentes abordagens para 0 conceito de fenomenologia, mas, conforme Zlatev destaca, assim como Husserl "pediu para 'voltar para as coisas em si', é necessário 'voltar para Husserl' para entender verdadeiramente o que a fenomenologia é sobre". (ZLATEV, sem paginação, 
2009). Por isso, os pressupostos de Husserl foram escolhidos como norteadores da discussão inicial deste capítulo.

Husserl traz a fenomenologia dentro de um contexto controverso entre os estudos do conhecimento, numa contraposição de significados e possibilidades de estudo dentro da perspectiva do próprio conhecimento - isto é, a problemática sobre a possibilidade de o conhecimento fazer contato com seu objeto, trazendo à tona as deficiências do pensamento positivista, as ineficiências das abordagens metafísicas e as incertezas da dúvida cartesiana. São as complexidades implicadas aos estudos da percepção, onde o objeto percebido deve ser dado imediatamente - ali está a coisa antes de nossos olhos as perceberem. Eu vejo isso; eu entendo isso. Mas se a percepção nada mais é do que uma experiência que me pertence, do sujeito que percebe - qual a objetividade contida na análise do objeto? (HUSSERL, 1999).

Numa proposta de retorno às "coisas mesmas", haveria uma superação do discurso metafísico que é considerado especulativo, assim como do raciocínio das ciências positivistas, colocando as pesquisas no "mesmo plano da realidade". Seria o encontro de uma "via média" em como pensar a natureza e suas nuances, numa nova rigorosidade filosófica que se liberta das antigas tradições e se atenta apenas à realidade em uma perspectiva gnosiológica. (DARTIGUES, 2003).

Assim, ideia da fenomenologia de Husserl nasce na problemática das ciências empíricas, que se referem ao mundo como dado, ao mesmo tempo em que são, elas próprias, elementos do mundo avaliado. Ela, então, não se adequa a nenhuma classificação filosófica já que as antecede, não necessariamente no conceito temporal habitual, mas no de questionamento e avaliação, "acabando" onde todas as demais começam, por sua expressa recusa em aceitar acriticamente muitos pontos de partida por muito tempo inquestionáveis na avaliação filosófica, como por exemplo percepções e fatos biológicos, sociais e ambientais. (SCHUTZ, 1970).

Ele busca rejeitar o que identifica como um "naturalismo", que condicionaria às ciências a tratar seus objetos como puramente físicos, confundindo causas exteriores de um fenômeno com sua própria natureza. As ciências humanas carregariam, nesse contexto, seu interesse e fraqueza simultaneamente, a saber, as atividades do homem, em especial seu conhecimento. (DARTIGUES, 2003).

Husserl coloca, além da percepção, também os aspectos da memória e expectativa como experiências subjetivas, assim como todos os demais chamados "atos de pensamento construídos sobre eles", que seriam as bases nas quais 
postulamos a existência real e determinamos qualquer verdade sobre tal existência. A questão seria como eu, enquanto sujeito do conhecimento, sei que o que posso saber (e saber com certeza), não é determinado apenas por minhas experiências, mas que esses atos do conhecimento são algo que realmente existe? Para ele "[...] somente os fenômenos são genuinamente dados ao sujeito cognoscente, e o sujeito conhecedor nunca vai além das interconexões de suas experiências de conhecimento". (HUSSERL, 1999, p. 17, tradução nossa ${ }^{4}$ )

Abandona-se o pensamento de que conhecer é algo diferente do objeto conhecido; que o conhecimento é dado, mas o objeto conhecido não é dado; e, no entanto, o conhecimento deve relacionar-se com o objeto, conhecê-lo. Isso porque como posso entender essa possibilidade? Já que eu só poderia entender se a relação em si pudesse ser dada, ser vista, e o objeto é e permanece algo transcendente - e se o conhecimento e o objeto são realmente separados, então certamente não podemos ver nada aqui, qualquer esperança em encontrar um meio de obter clareza tirando conclusões de pressuposições transcendentes são consideradas por Husserl como "obviamente tolas". (HUSSERL, 1999, p. 29). Assim, as problematizações de entidades transcendentais, sua existência ou não, assumem uma nulidade epistemológica, devido sua então irrelevância ao estudo.

Husserl ultrapassa o dualismo idealismo-realismo, e propõe:

1 - que quando uma pessoa recebe uma mensagem, esta pessoa é provocada por um acontecimento, para que esta pessoa se aproprie desta mensagem, deste acontecimento, é preciso antes de mais nada que ela se afaste, isto é, exerça o que é o gesto mais natural de uma pessoa - faça um gesto de hesitação para compreender o que vem ao seu encontro, 2 - que esse acontecimento de apropriação, realizado por uma pessoa, mostra que o acontecimento, o fato, o mundo, a natureza, o universo, as outras pessoas, a própria pessoa, só são o que são, isto é, cada uma dessas realidades apontadas aqui, a partir de uma pessoa que as testemunha, que as nomeia, que as percebe e que Ihes atribui um sentido. Sem a presença da consciência intencional o mundo não é um objeto intencional ou intencionado. Portanto, para Husserl, o estabelecimento de um mundo significativo é correlativo de uma consciência significante, 3 - que o significado apreendido pela consciência intencional precisa ser rigorosamente pensado e repensado a partir de observações e atos imaginativos até se alcançar o que Husserl chama de essência, isto é, o sentido de ser um determinado e definido objeto que uma consciência apreende e não de outro objeto qualquer [...], 4 - [..] a apreensão do sentido de ser, no interior de uma correlação consciência mundo se dá a partir de

\footnotetext{
${ }^{4}$ Texto original: "[...] only phenomena are genuinely given to the knowing subject, and the knowing subject never gets beyond the interconnections of its ow experiences".
} 
um afastamento, de uma redução fenomenológica. (DICHTCHEKENIAN, 2013).

Nesses parâmetros, Husserl abandona o idealismo, que tornaria as coisas mesmas uma ficção, e o realismo, "que atribui uma impossível consciência de si as coisas mesmas e considera o sujeito uma ilusão", e se volta para as coisas mesmas, então alcançadas em seu sentido próprio, "por um esforço e um cuidado de uma consciência destinada a receber em si o que não é ela mesma”, e por isso o próprio conhecer para Husserl é identificado como uma transcendência, um ultrapassar de limites próprios, que contem em si uma nova possibilidade de ser. Ele apresenta a ontologia de que "[...] a essência de tudo que pode ser é inesgotável, multifacetada e que cada faceta revelada não nega as outras mas vem se somar as já reveladas e é o homem na sua maneira não determinada de ser, na sua peregrinação nesse mundo, o que recebe, ouve, um novo sentido de ser". (DICHTCHEKENIAN, 2013).

Os eventos passam então a ser avaliados como parecidos, mas nunca exatamente iguais, reconhecendo a complexidade do próprio ser humano como um ser impermanente. (ROSITO, 2006).

Husserl nos apresenta a fenomenologia como a "doutrina universal das essências, em que se integra a ciência da essência do conhecimento". (HUSSERL, 2008, p. 22). Nessa doutrina, o questionamento é apresentado como uma importante base, e amplia-se com base na perspectiva de busca do reconhecimento e entendimento dessas essências.

Esclarecendo que o que se busca encontrar por essência é "[...] estabelecer um horizonte dentro do qual o objeto pode variar sem perder sua identidade [...]" (GALLAGHER, 2012, p. 308).

O que a fenomenologia proporciona, portanto, é uma visão reducionista que não desconsidera a influência da habilidade do ser humano enquanto Ser em constante evolução e que possui livre-arbítrio que o possibilita manipular resultados, sempre agindo impactado por seu contexto histórico-socio-espacial, pois traz a luz sobre o fato de o mundo ser um "conjunto completo dos objetos da experiência possível e do conhecimento possível da experiência, dos objetos passíveis de ser conhecidos com base em experiências atuais do pensamento teórico correto." (HUSSERL, 2006, p. 2). 
Ao promover um então isolamento de fenômenos específicos sem desconsiderar a cadeia fenomenológica a que o objeto de estudo se encontra imerso, é possível "questionar e discutir os pressupostos tidos como naturais, óbvios, da intencionalidade do sujeito frente à realidade de sua ação." (COLTRO, 2000, p. 39). Os questionamentos são cruciais para a abordagem fenomenológica, considerada como "a ciência da dúvida", que busca uma verdade não reduzida ao "material”. (DÍAZ, 1973).

Husserl também salienta que o questionar um conhecimento não deve ser visto como uma dificuldade pois, para ele, "O conhecimento não se nega nem se declara em todo o sentido como algo de duvidosos pelo facto de " pôr em questão "”. (HUSSERL, 2008, p. 22). Ou seja, o abrir questionamento sobre um fenômeno não expõe fragilidade, mas sim a busca consciente e comprometida dessa natureza essencial do estudo.

O que buscamos é, portanto, encontrar a essência de um fenômeno e, para isso, podemos utilizar a redução fenomenológica (também chamada de epoché) que é proposta pela fenomenologia de Husserl e se caracteriza pela "busca do fenômeno enquanto algo puro, livre dos elementos pessoais ou culturais, e que, por conseguinte, promoverá o alcance da essência, ou seja, daquilo que faz com que o objeto seja o que é e não outra coisa". (COLTRO, 2000, p. 43).

Também, para conseguir de forma satisfatória tal redução, o autor apresenta as fases para se obtê-la: eliminação do subjetivo; a exclusão do teórico (exclusão momentânea de conhecimentos prévios); suspenção de tradições; busca de uma visão do "todo", generalista; e descrição e análise do objeto. (COLTRO, 2000, p. 43).

O processo envolve, como descrito, etapas que buscam um isolamento de variações por desconsiderar momentaneamente e conscientemente fatores de subjetividade, de conhecimentos anteriores e tradições, enquanto fatores que poderiam ser identificados como responsáveis pelas variações da essência. Depois dessa exclusão, viria então as etapas de ampliar a visão, considerar o todo sobre o fenômeno e, finalmente, descrever o objeto.

A redução propõe trazer como resultado, com a ajuda da intencionalidade, uma conexão ou correlação entre o eu penso e o objeto de pensamento, diferentemente da dúvida cartesiana, cujo retorno se foca no eu penso - não mais ego cogito, mas sim o ego cogito cogitatum. (DARTIGUES, 2003). 
Ainda, segundo Oliveira e Cunha (2008), no processo de descrição a busca de uma visão fenomenológica está imbricada em procedimentos que não sejam "mecânicos", mas que envolvam o pesquisador como um "encontro social". Isso porque:

[...] tanto o sujeito como fenômeno estudado está no mundo-vida. Sujeitos que participam de experiências vividas em comum, compartilham entendimentos, interpretações, comunicações, estabelecendo-se assim, a esfera da intersubjetividade. (OLIVEIRA; CUNHA, 2008, sem paginação).

Esse caminho de não cair em procedimentos mecânicos é importante pois "para a fenomenologia nada é objetivo, antes de ter sido subjetivo, ou seja, é a subjetividade que permite alcançar graus de objetividade" (OLIVEIRA; CUNHA, 2008, sem paginação). Os questionamentos que norteiam a epoché, portanto, reconhecem a existência e impacto da subjetividade dos fenômenos, mas busca o que não se altera frente a essas variações complexas dos encontros sociais.

Nesse contexto, e em uma perspectiva de análise de fenômenos com interferência humana direta (como o caso da mediação), outro questionamento importante é como distinguir o comportamento da experiência e, para Schutz:

A resposta é dada pelo uso comum. Uma dor, por exemplo, não é normalmente chamada de comportamento. Nem diriam que eu estou tendo algum comportamento se outra pessoa levantasse meu braço e, em seguida, o deixasse cair. Mas as atitudes que assumo em qualquer um destes casos são chamadas de comportamento. Eu posso lutar contra a dor, suprimi-la ou entregar-me a ela. Eu posso sujeitar-me ou resistir quando alguém manipula meu braço. Então o que temos são dois tipos diferentes de experiências vividas que são fundamentalmente relacionadas. Experiências do primeiro tipo são meramente "submetidas" ou "sofridas". Elas são caracterizadas por uma passividade básica. Experiências do segundo tipo consistem atitudes tomadas em relação as experiências do primeiro tipo. (1970, p. 65-66, tradução nossa). ${ }^{5}$

\footnotetext{
${ }^{5}$ Texto original: "The answer is supplied by ordinary usage. A pain, for instance, is not generally called behavior. Nor woul I be said to be behaving if someone else lifeted my arm and then let it drop. But the attitudes I assume in either of these cases are called behavior. I may fight the pain, suppress it or abandon myself to it. I may submit or resist when someone manipulates my arm. So what we have her are two different types of lived experiences that are fundamentally related. Experiences of the first type are merely "undergone" or "suffered". They are characterized by a basic passivity. Experiences of the second type consist of the attitudes taken toward experiences of the first type."
} 
Schutz visa exemplificar a diferença, num âmbito prático, da diferenciação entre comportamento e experiência em uma análise fenomenológica. $O$ autor traz a experiência de dor que, mesmo experienciada na mesma intensidade poderá ter, em pessoas diferentes, manifestações completamente divergentes (a dor da picada de uma agulha para uma pessoa pode ser apenas um desconforto, enquanto para outra pode ser considerada insuportável), que são respostas à experiências e estão condicionadas e especificidades que variam da percepção da dor (física e emocional) de cada um, mas que não mudam a essência do fenômeno da "dor" então provocada pela agulha.

Martins, faz a seguinte divisão teórica:

[...] o que é proposto pelo método fenomenológico é fazer a redução eidética para se encontrar aquilo que é o mais próprio do objeto e posteriormente fazer a redução transcendental para que se ache aquilo é o mais próprio do sujeito. (MARTINS, 2015, p. 31).

A redução eidética (que busca identificar as essências), se complementa, portanto, na busca do transcendental, que seria a perspectiva do sujeito sobre a essência - suas variações nos diferentes contextos sociais.

A transposição de matérias (ou em nosso caso aspectos empíricos relacionados à mediação e, por consequência, mediação da informação) do empírico para o racional pode proporcionar maior "amplitude" e "desempenho cognitivo-prático" para os pontos em estudo.

Ao trabalhar-se com a perspectiva fenomenológica, porquanto, buscou-se o entendimento da essência do que é o objeto que se busca compreender e suas diferentes expressões em realidades contextuais desse objeto com o meio social estudado, e assim será possível prever manifestações e limitações desse objeto. No caso dessa pesquisa, especificamente, possibilitará o entendimento dos fatores envolvidos no processo de mediação, suas possíveis variações e assim, abrangências e limitações a partir de uma perspectiva fenomenológica. 


\section{MEDIAÇÃO}

A mediação, vocábulo que entrou na língua portuguesa em 1670, pode ser "entendido como o ato ou efeito de mediar, ato de servir de intermediário entre pessoas, grupos, partidos, a fim de dirimir divergências ou disputas", e como "processo pelo qual o pensamento generaliza os dados apreendidos pelos sentidos" (GARCIA, 2004, p. 25).

Quando se propõe diferentes abordagens de mediações, como a mediação da leitura de mundo, encontra-se a lacuna anteriormente mencionada sobre o âmago e, por extensão, dos limites da mediação na atuação profissional. Neste momento surge a perspectiva de se voltar para uma visão da natureza da mediação. Objetivou-se neste trabalho explorar os conceitos de Hegel, tomado à dialética (BRAGA, 2004), Marx, voltado ao materialismo histórico (SILVA; SILVA; MARTINS, 2005) e Vigotski, com abordagens semióticas e psicológicas (MARTINS; MOSER, 2012), que trazem abordagens filosóficas nas quais o Ser apresenta relações mais complexas ao ato de mediar, no sentido de que esses autores levaram a mediação a um patamar mais amplo, partindo da existência e relacionamento estabelecido com o mundo e a cultura. O que se busca é entender em que local existencial e em qual essência a mediação é colocada nas diferentes vertentes trabalhadas pelos autores.

Hegel, em discussões que culminaram em desenvolvimentos teóricos que desembocam no que são considerados estudos do imaginário e pós-modernismo crítico, apresenta em sua obra A Fenomenologia do Espírito discussões e exposições que buscam problematizar e clarificar aspectos da ciência do Ser, passando por aspectos da existência da verdade, do conhecimento, da composição do absoluto, da negatividade, e, entre outros, de como a mediação é vista e usada nesse contexto. Em sua obra citada encontram-se as seguintes afirmações:

[...] a substância viva é o ser, que na verdade é sujeito, ou - o que significa o mesmo - que é na verdade efetivo, mas só à medida que é o movimento do pôr-se-a-si-mesmo, ou a mediação consigo mesmo do tornar-se outro. [...] O verdadeiro é o vir -a-ser de si mesmo, o círculo que pressupõe seu fim como sua meta, que o tem como princípio, e que só é efetivo mediante sua atualização e seu fim. [...]

O verdadeiro é o todo. Mas o todo é somente a essência que se implementa através de seu desenvolvimento. [...]

[...] a mediação não é outra coisa senão a igualdade-consigo-mesmo semovente, ou a reflexão sobre si mesmo, o momento do Eu para-si- 
essente, a negatividade pura ou reduzida à sua pura abstração, 0 simples vir-a-ser. O Eu, ou o vir -a-ser em geral - esse mediatizar , justamente por causa de sua simplicidade, é a imediatez que vem-aser, e o imediato mesmo. (HEGEL, [1807], p. 9-10)

A mediação poderia ser vista, dentro desse viés filosófico apresentado por Hegel, como uma mediação de e para si mesmo, na medida em que se busca um desenvolvimento e/ou adequação de si mesmo frente a universalidade e sua significação em um tempo social específico.

Ele usa o conceito também para explorar as concepções do elemento espiritual para a igreja cristã. Em sua obra Filosophy of History, Hegel traz o "princípio da mediação" como a "essência do princípio cristão". Ele explica que:

[...] O homem realiza sua essência Espiritual apenas quando conquista o Natural que se liga a ele. Essa conquista só é possível na suposição de que a natureza humana e a divina são essencialmente uma, e que o homem, na medida em que é Espírito, também possui a essencialidade e substancialidade que pertencem à ideia de divindade. A condição da mediação em questão é a consciência dessa unidade; e a intuição desta unidade foi dada ao homem em Cristo. $O$ objetivo a ser alcançado é, portanto, que o homem se apodere dessa consciência, e que ela seja continuamente nele estimulada. (HEGEL, 2001, p. 395, tradução livre ${ }^{6}$ ).

Ele explora como o conceito da hóstia que foi tida como objeto de adoração e, posteriormente, questionada durante a reforma Luterana, e ainda assim considerada com valor e de caráter espiritual. As concepções da igreja passariam por outras adaptações da mediação, como segue:

Esta é a dissidência absoluta em que a Igreja esteve envolvida durante a Idade Média: ela surgiu do reconhecimento do Santo como algo externo. O clero impôs certas condições, às quais os fiéis devem se conformar se quiserem ser participantes do Santo. Todo o desenvolvimento da doutrina, da visão espiritual até o conhecimento das coisas divinas, pertenceu exclusivamente à lgreja: ela deve ordenar, e os fiéis devem simplesmente acreditar: a obediência é seu dever - a obediência da fé, sem discernimento de sua parte. Essa posição de coisas tornava a fé uma questão de legislação externa [...].

\footnotetext{
${ }^{6}$ Texto original: "Man realizes his Spiritual essence only when he conquers the Natural that attaches to him. This conquest is possible only on the supposition that the human and the divine nature are essentially one, and that Man, so far as he is Spirit, also possesses the essentiality and substantiality that belong to the idea of Deity. The condition of the mediation in question is the consciousness of this unity; and the intuition of this unity was given to man in Christ. The object to be attained is therefore, that man should lay hold on this consciousness, and that it should be continually excited in him."
} 
A generalidade dos homens é assim separada da Igreja; e pelo mesmo princípio eles são separados do Santo em todas as formas. Pois pelo mesmo princípio segundo o qual o clero é o meio entre o homem por um lado e Deus e Cristo por outro, o fiel não pode dirigir-se diretamente ao Ser Divino em suas orações, mas apenas por meio de mediadores - seres humanos que conciliam Deus para ele, o Morto, o Perfeito Santos. Assim se originou a adoração dos Santos, e com ela aquele conglomerado de fábulas e falsidades de que os Santos e suas biografias foram investidos. [...]. (HEGEL, 2001, p. 395-396, tradução livre $^{7}$ ).

Essa mediação entre homem e Deus, chamada de "espírito negativo da igreja" culminou em uma espécie de comércio, onde a igreja estabelece o valor de "troca" para o bem divino, mediado pelos santos e os direcionamentos e penitências ordenados pela igreja (entre eles a presença em missas, confissões, orações identificados por Hegel como "cerimônias externas", e que influenciam todo o funcionamento do Estado e da ciência, gerando uma condição expressa como o "oposto da liberdade introduzida no próprio conceito de liberdade". (HEGEL, 2001, p. 397-398).

Já Marx traz a mediação na esfera do trabalho e produção, onde:

O trabalho enquanto produtor de valores-de-uso, enquanto trabalho útil, é, independentemente das formas de sociedade, condição da existência do homem, uma necessidade eterna, o mediador da circulação material entre a natureza e o homem [,isto é, da vida humana]. (MARX, 1867, p. 5)

[...] o objeto não é um objeto em geral, mas sim, um objeto bem determinado e que tem de ser consumido de uma maneira determinada, a qual, por sua vez, tem que ser mediada pela própria produção. A fome é a fome, mas a fome que é saciada com carne cozida e consumida com faca e garfo é diferente da fome do que devora carne crua e a come com a mão, com unhas e dentes. Por conseguinte, o que a produção produz objetiva e subjetivamente não

\footnotetext{
${ }^{7}$ Texto original: "This is the absolute schism in which the Church in the Middle Ages was involved: it arose from the recognition of the Holy as something external. The clergy imposed certain conditions, to which the laity must conform if they would be partakers of the Holy. The entire development of doctrine, spiritual insight and the knowledge of divine things, belonged exclusively to the Church: it has to ordain, and the laity have simply to believe: obedience is their duty - the obedience of faith, without insight on their part. This position of things rendered faith a matter of external legislation [...]. The generality of men are thus cut off from the Church; and on the same principle they are severed from the Holy in every form. For on the same principle as that by which the clergy are the medium between man on the one hand and God and Christ on the other hand, the layman cannot directly apply to the Divine Being in his prayers, but only through mediators - human beings who conciliate God for him, the Dead, the Perfect - Saints. Thus originated the adoration of the Saints, and with it that conglomerate of fables and falsities with which the Saints and their biographies have been invested."
} 
é só o objeto do consumo; é também o modo de consumo. A produção cria, pois, o consumidor.

[...] A produção proporciona não só um objeto material à necessidade, mas também uma necessidade ao objeto material. Quando o consumo emerge do seu primitivo caráter natural, imediato e tosco [...] passa a ser mediado como impulso pelo objeto: a necessidade que o consumo sente deste último é criada pela percepção do objeto. O objeto de arte - e analogamente, qualquer outro produto - cria um público sensível à arte e capaz de fruição estética. Deste modo, a produção não cria só um objeto para o sujeito; cria também um sujeito para o objeto. (MARX, [1859], p. 8)

Nos processos explorados por Marx vê-se a possibilidade de rompimento do caráter natural primitivo de sobrevivência pela mediação que acompanha os objetivos da economia.

Finalmente, em Vigotski encontra-se a abordagem da mediação dentro do contexto educacional, no qual o autor explora aspectos em atividades práticas, onde "[...] o processo simples estímulo-resposta é substituído por um ato complexo, mediado [...]" (VYGOTSKY, 1991, p. 30), o permitindo chegar a avaliações de atividades educativas onde, por exemplo, a criança: “[...] não dominou a lógica interna de usar um estímulo para mediar a resposta a outro [...]”. Vigotski apresenta a inclusão de estímulos em processos de solução de problemas lógicos com crianças, buscando entender como esses estímulos podem ser úteis para a solução de problemas e planejamento de ações futuras. (VYGOTSKY, 1991, p. 50).

Seus apontamentos influenciaram muitas pesquisas que buscam entender e aplicar aspectos do "papel dos sistemas semióticos no desenvolvimento mental, sobre o desenvolvimento da linguagem" dentro de estudos da mediação semiótica. (IVIC, 2010, p. 27).

Assume-se neste projeto a hipótese de que a mediação existe no mundo sine qua non. Ao assumir essa hipótese, é importante ressaltar a diferença entre mediação e relacionamento. É possível esclarecer nesse momento a importância da busca de um impacto ao conceito de mediação. Na mediação observa-se a existência de um $1^{\circ}$ elemento: sujeito principal (e não necessariamente individual, que será 0 foco do ato de mediar); um $2^{\circ}$ elemento: problema/exigência/necessidade/conflito/desejo (dependendo do contexto envolvido), aliados a um $3^{\circ}$ elemento (que figuraria o mediador), estando então esses três elementos envolvidos num processo mediador específico (de informação, de leitura, etc.) que busca um impacto sobre o $2^{\circ}$ elemento, e um $4^{\circ}$ elemento composto, por 
assim dizer, que é o produto (não necessariamente físico) mediado propriamente (uma informação, um livro, etc. com a composição do impacto implícito de seu produtor - o autor do livro, por exemplo). Já num processo de relacionamento, teríamos uma via de rotina, sem desejo de interferências, identificadas pela semiótica como o campo da primeiridade.

$\mathrm{Na}$ vida cotidiana, a mediação estaria presente como habilidade e sendo, portanto, passível de desenvolvimento. Qual seria então o principal diferencial impulsionador do desenvolvimento da mediação? Entende-se a práxis, enquanto envolvimento social, como impulsionador para tal desenvolvimento, sendo o uso do termo "impulsionar" no intuito de salientar que não haveria uma anulação da mediação sem ela, mas sim restrições no seu potencial.

Como exposto anteriormente, o que se busca não é retrabalhar as vertentes de mediação já utilizadas na área, mas sim encontrar um "ponto de vista" gnosiológico da mediação, para que se possa entender sua abrangência na $\mathrm{Cl}$, consolidando suas limitações e possibilidades. Vislumbra-se principalmente encontrar respostas relacionadas a possibilidade de explorar a mediação da leitura de mundo.

\subsection{Pressupostos De Mediação}

Os estudos que buscam debater os conceitos de três autores foram elencados para essa análise: Hegel, Marx e Vigotski. Com Hegel buscou-se uma visão filosófica, com Marx uma perspectiva social, e com Vigotsky uma abordagem psicológica educacional.

Para o desenvolvimento dos pressupostos de mediação, em todas as bases mencionadas, os metadados de pesquisa foram os termos: mediação com a variação: AND Hegel / AND Marx / AND Vigotski. Os idiomas de pesquisa foram português, espanhol, francês e inglês (havendo tradução dos termos para as respectivas pesquisas nas diferentes línguas).

Após a recuperação foi realizada uma planilha com todos os dados para excluir as duplicidades, tendo então os resultados (ordenados em ordem alfabética) para análise, totalizando 25 textos: 
Quadro 2: Textos recuperados.

\begin{tabular}{|c|c|c|}
\hline Autor & Título & Dados de Publicação \\
\hline Assalone, Eduardo. & $\begin{array}{l}\text { La crítica de la mediación hegeliana en } \\
\text { el segundo volumen de Enten-Eller (O } \\
\text { lo uno o lo otro) de Søren Kierkegaard: } \\
\text { ¿una crítica social? }\end{array}$ & $\begin{array}{l}\text { Las Torres de Lucca: revista } \\
\text { internacional de filosofía } \\
\text { política, 2014, Issue } 4, \\
\text { pp.63-84 }\end{array}$ \\
\hline $\begin{array}{l}\text { Bavaresco, Agemir } \\
\text { and Konzen, Paulo } \\
\text { Roberto }\end{array}$ & $\begin{array}{l}\text { Cenários da liberdade de imprensa e } \\
\text { opinião pública em Hegel. }\end{array}$ & $\begin{array}{l}\text { Kriterion, Jun 2009, vol.50, } \\
\text { no.119, p.63-92. ISSN 0100- } \\
512 X\end{array}$ \\
\hline $\begin{array}{l}\text { Berni, Regiane } \\
\text { lbanhez Gimenes }\end{array}$ & $\begin{array}{l}\text { Mediação: o conceito Vygotskyano e } \\
\text { suas implicações na prática } \\
\text { pedagógica }\end{array}$ & $\begin{array}{l}\text { XI Simpósio Nacional de } \\
\text { Letras e Linguística e I } \\
\text { Simpósio Internacional de } \\
\text { Letras e Linguística. } \\
\text { Uberlândia, 2006. p. 2533- } \\
2542 . \\
\end{array}$ \\
\hline $\begin{array}{l}\text { BOLAÑO, César } \\
\text { Ricardo Siqueira. }\end{array}$ & $\begin{array}{l}\text { Organização em rede, capital e a } \\
\text { regulação mercantil do elo social. }\end{array}$ & $\begin{array}{l}\text { Liinc em revista, v. 12, n. 1, } \\
2016 \text { (Revista-) }\end{array}$ \\
\hline Duarte, Newton & $\begin{array}{l}\text { A contradição entre universalidade da } \\
\text { cultura humana e o esvaziamento das } \\
\text { relações sociais: por uma educação } \\
\text { que supere a falsa escolha entre } \\
\text { etnocentrismo ou relativismo cultural. }\end{array}$ & $\begin{array}{l}\text { Educ. Pesqui., Dez 2006, } \\
\text { vol.32, no.3, p.607-618. } \\
\text { ISSN 1517-9702 }\end{array}$ \\
\hline Franko, M. & $\begin{array}{l}\text { Dance/Agency/History: Randy Martin's } \\
\text { Marxian Ethnography. }\end{array}$ & $\begin{array}{l}\text { Dance Research Journal, } 1 \\
\text { December 2016, Vol.48(3), } \\
\text { pp.33-44 }\end{array}$ \\
\hline Gama, Zacarias & $\begin{array}{l}\text { A categoria da mediação em Hegel, } \\
\text { Marx e Gramsci: para suprimir ruídos } \\
\text { conceituais }\end{array}$ & $\begin{array}{l}\text { Ciência \& Luta de Classes } \\
\text { Digital, } 47 \text {, ano I, v. } 2, \text { n. } 2 \text {, } \\
\text { p. } 46-55 .\end{array}$ \\
\hline $\begin{array}{l}\text { González Rey, } \\
\text { Fernando L. }\end{array}$ & $\begin{array}{l}\text { El lugar de las emociones en la } \\
\text { constitución social de lo psíquico: el } \\
\text { aporte de Vigotski. }\end{array}$ & $\begin{array}{l}\text { Educ. Soc., Jul 2000, vol.21, } \\
\text { no.71, p.132-148. ISSN } \\
0101-7330\end{array}$ \\
\hline $\begin{array}{l}\text { Hardt, Michael ; } \\
\text { Negri, Antonio } \\
\text { Hardt, Michael; } \\
\text { Brown, Nicholas; } \\
\text { Szeman, Imre. } \\
\end{array}$ & $\begin{array}{l}\text { What Is the Multitude? Questions for } \\
\text { Michael Hardt and Antonio Negri. }\end{array}$ & $\begin{array}{l}\text { Cultural Studies, May 2005, } \\
\text { Vol.19(3), pp.372-387 }\end{array}$ \\
\hline $\begin{array}{l}\text { Júlio Flávio de } \\
\text { Figueiredo } \\
\text { Fernandes; Mauro } \\
\text { Giffoni Carvalho; } \\
\text { Edson Nascimento } \\
\text { Campos }\end{array}$ & $\begin{array}{l}\text { Vigotski e Bakhtin: a ação educacional } \\
\text { como projeto dialógico de produção de } \\
\text { sentido. }\end{array}$ & $\begin{array}{l}\text { Bakhtiniana: Revista de } \\
\text { Estudos do Discurso [2176- } \\
\text { 4573] yr:2012 vol:7 iss:2 } \\
\text { pg:95 -108 }\end{array}$ \\
\hline Lessa, Sergio & $\begin{array}{l}\text { Trabalho, sociabilidade e } \\
\text { individuação. }\end{array}$ & $\begin{array}{l}\text { Trab. educ. saúde, Set } \\
\text { 2006, vol.4, no.2, p.231-246. } \\
\text { ISSN 1981-7746 } \\
\end{array}$ \\
\hline Murphy, Daniel. & $\begin{array}{l}\text { Levinas and Kierkegaard on Divine } \\
\text { Transcendence and Ethical Life: } \\
\text { Response to Donald L. Turner and } \\
\text { Ford Turrell's "The Non-Existent God". }\end{array}$ & $\begin{array}{l}\text { Philosophia, 2007, Vol.35(3), } \\
\text { pp.383-385 }\end{array}$ \\
\hline $\begin{array}{l}\text { NEVES, Barbara } \\
\text { Coelho. }\end{array}$ & $\begin{array}{l}\text { Formação e orientação: aspectos da } \\
\text { mediação no universo da inclusão } \\
\text { digital. }\end{array}$ & $\begin{array}{l}\text { Inclusão Social, v. 5, n. 1, } \\
2011 \text { (Revista-ARTIG) }\end{array}$ \\
\hline
\end{tabular}




\begin{tabular}{|c|c|c|}
\hline $\begin{array}{l}\text { Novelli, Pedro } \\
\text { Geraldo Aparecido. }\end{array}$ & $\begin{array}{l}\text { O ensino da filosofia segundo Hegel: } \\
\text { contribuições para a atualidade. }\end{array}$ & $\begin{array}{l}\text { Trans/Form/Ação, 2005, } \\
\text { vol.28, no.2, p.129-148. } \\
\text { ISSN 0101-3173 } \\
\end{array}$ \\
\hline $\begin{array}{l}\text { Nunes, Leila Regina } \\
\text { d'Oliveira de Paula, } \\
\text { Braun, Patrícia and } \\
\text { Walter, Cátia } \\
\text { Crivelenti de } \\
\text { Figueiredo }\end{array}$ & $\begin{array}{l}\text { Procedimentos e recursos de ensino } \\
\text { para o aluno com deficiência: o que } \\
\text { tem sido disseminado nos trabalhos do } \\
\text { GT } 15 \text { da ANPED sobre estes temas? }\end{array}$ & $\begin{array}{l}\text { Rev. bras. educ. espec., Ago } \\
\text { 2011, vol.17, no.spe1, p.23- } \\
\text { 40. ISSN 1413-6538 }\end{array}$ \\
\hline $\begin{array}{l}\text { Prearo, Alice } \\
\text { Yamashita, Rizzato, } \\
\text { Agueda Beatriz } \\
\text { Pires and Martins, } \\
\text { Sueli Terezinha } \\
\text { Ferreira }\end{array}$ & $\begin{array}{l}\text { O ensino de pediatria na atenção } \\
\text { básica em saúde entre as fronteiras do } \\
\text { modelo biomédico e a perspectiva da } \\
\text { integralidade do cuidado: a visão dos } \\
\text { médicos supervisores. }\end{array}$ & $\begin{array}{l}\text { Interface (Botucatu), Dez } \\
\text { 2011, vol.15, no.39, p.1039- } \\
\text { 1052. ISSN 1414-3283 }\end{array}$ \\
\hline Prenkert, F. & $\begin{array}{l}\text { Tracing the Roots of Activity Systems } \\
\text { Theory An Analysis of the Concept of } \\
\text { Mediation. }\end{array}$ & $\begin{array}{l}\text { Theory \& Psychology, } 2010 \\
\text { Oct, Vol.20(5), pp.641-665 }\end{array}$ \\
\hline $\begin{array}{l}\text { Schwede, Gisele, } \\
\text { Barbosa, Nasser } \\
\text { Haidar and } \\
\text { Schruber Junior, } \\
\text { Julio }\end{array}$ & $\begin{array}{l}\text { Psicologia nos direitos humanos: } \\
\text { possibilidades de mediações } \\
\text { semióticas. }\end{array}$ & $\begin{array}{l}\text { Psicol. Soc., Ago } 2008 \\
\text { vol.20, no.2, p.306-312. } \\
\text { ISSN 0102-7182 }\end{array}$ \\
\hline $\begin{array}{l}\text { Silvia Maria Cintra } \\
\text { Da Silva; Célia } \\
\text { Maria de Castro } \\
\text { Almeida; Sueli } \\
\text { Ferreira. }\end{array}$ & $\begin{array}{l}\text { Apropriação cultural e mediação } \\
\text { pedagógica: contribuições de Vigotski } \\
\text { na discussão do tema. }\end{array}$ & $\begin{array}{l}\text { Psicologia em Estudo, } 01 \\
\text { June 2011, Vol.16(2), } \\
\text { pp.219-228 }\end{array}$ \\
\hline $\begin{array}{l}\text { Souza, Jamerson } \\
\text { Murillo Anunciação } \\
\text { de. }\end{array}$ & $\begin{array}{l}\text { Estado e sociedade civil no } \\
\text { pensamento de Marx. }\end{array}$ & $\begin{array}{l}\text { Serv. Soc. Soc., Mar 2010, } \\
\text { no.101, p.25-39. ISSN 0101- } \\
6628\end{array}$ \\
\hline Thiago Cabrera. & $\begin{array}{l}\text { A mediação histórica e a filosofia do } \\
\text { direito em Hegel: entre liberdade e } \\
\text { necessidade }\end{array}$ & $\begin{array}{l}\text { Lex Humana, } 01 \text { December } \\
\text { 2012, Vol.4(2), pp.157-168 }\end{array}$ \\
\hline $\begin{array}{l}\text { Umbelino, Janaina } \\
\text { Damasco }\end{array}$ & $\begin{array}{l}\text { A mediação em Vigotski: reflexões } \\
\text { sobre um conceito }\end{array}$ & $\begin{array}{l}\text { XVI ENDIPE - Encontro } \\
\text { Nacional de Didática e } \\
\text { Práticas de Ensino. } \\
\text { Unicamp, Campinas, } 2012 . \\
\text { p. 2374-2385. } \\
\end{array}$ \\
\hline $\begin{array}{l}\text { Turner, Terence } \\
\text { Turner, Terence }\end{array}$ & $\begin{array}{l}\text { Marxian value theory: An } \\
\text { anthropological perspective. }\end{array}$ & $\begin{array}{l}\text { Anthropological Theory, } \\
\text { March 2008, Vol.8(1), pp.43- } \\
56\end{array}$ \\
\hline $\begin{array}{l}\text { Wright, Erik Wright, } \\
\text { Erik }\end{array}$ & Race, Class, and Income Inequality. & $\begin{array}{l}\text { American Journal of } \\
\text { Sociology, May 1978, } \\
\text { Vol.83(6), pp.1368-1397 } \\
\end{array}$ \\
\hline $\begin{array}{l}\text { Zanolla, Silvia Rosa } \\
\text { da Silva }\end{array}$ & $\begin{array}{l}\text { O conceito de mediação em Vigotski e } \\
\text { Adorno. }\end{array}$ & $\begin{array}{l}\text { Psicol. Soc., Abr 2012, } \\
\text { vol.24, no.1, p.5-14. ISSN } \\
0102-7182\end{array}$ \\
\hline
\end{tabular}

Fonte: a própria autora. 
Durante o estudo dos textos alguns precisaram ser retirados da amostra para aplicação da ATD porque não continham nenhum trecho que esclarecesse o conceito abordado.

Alguns textos, por sua vez, trabalhavam os conceitos na abordagem de mais de um autor e, por isso, os textos analisados foram numerados sequencialmente para que o mesmo texto pudesse compor a análise de mais de um autor.

Ao final, 10 textos foram utilizados para a aplicação inicial da ATD:

Quadro 3: Textos utilizados.

GAMA, Zacarias. A categoria da mediação em Hegel, Marx e Gramsci: para suprimir ruídos conceituais. Ciência \& Luta de Classes Digital, 47, ano I, v. 2, n. 2, p. 46-55.

CABRERA, Thiago. A mediação histórica e a filosofia do direito em Hegel: entre liberdade e necessidade. Lex Humana, 01 December 2012, Vol.4(2), pp.157-168.

ASSALONE, Eduardo. La crítica de la mediación hegeliana en el segundo volumen de Enten-Eller (O lo uno o lo otro) de Søren Kierkegaard: ¿una crítica social? Las Torres de Lucca: revista internacional de filosofía política, 2014, Issue 4, p.63-84.

UMBELINO, Janaina Damasco. A mediação em Vigotski: reflexões sobre um conceito. XVI ENDIPE - Encontro Nacional de Didática e Práticas de Ensino. Unicamp, Campinas, 2012. p. 2374-2385.

ZANOLLA, Silvia Rosa da Silva. O conceito de mediação em Vigotski e Adorno. Psicol. Soc., Abr 2012, vol.24, no.1, p.5-14. ISSN 0102-7182.

BERNI, Regiane Ibanhez Gimenes. Mediação: o conceito Vygotskyano e suas implicações na prática pedagógica. XI Simpósio Nacional de Letras e Linguística e I Simpósio Internacional de Letras e Linguística. Uberlândia, 2006. p. 2533-2542.

FERNANDES, Júlio Flávio de Figueiredo; CARVALHO, Mauro Giffoni; CAMPOS, Edson Nascimento. Vigotski e Bakhtin: a ação educacional como projeto dialógico de produção de sentido. Bakhtiniana: Revista de Estudos do Discurso [2176-4573] yr:2012 vol:7 iss:2 pg:95 -108.

PRENKERT, F. Tracing the Roots of Activity Systems Theory An Analysis of the Concept of Mediation. Theory \& Psychology, 2010 Oct, Vol.20(5), pp.641665.

SILVA, Silvia Maria Cintra Da; ALMEIDA, Célia Maria de Castro; FERREIRA, Sueli. Apropriação cultural e mediação pedagógica: contribuições de Vigotski na discussão do tema. Psicologia em Estudo, 01 June 2011, Vol.16(2), pp.219228.

NEVES, Barbara Coelho. Formação e orientação: aspectos da mediação no universo da inclusão digital. Inclusão Social, v. 5, n. 1, p. 44-57, 2011 (RevistaARTIG).

TEXTO 1

Fonte: a própria autora. 
Os tópicos a seguir apresentam os pressupostos identificados e a aplicação da ATD em cada um dos autores (Hegel, Marx e Vygotsky).

\subsubsection{Pressupostos de mediação em Hegel}

Nesse tópico será exposto a aplicação da Análise Textual Discursiva nos textos que apresentaram aspectos da mediação de Hegel.

Quadro 4: Fragmentação de Texto e Estabelecimento de Unidade de Sentido: Hegel.

\begin{tabular}{|c|c|c|c|}
\hline Texto na íntegra & Fonte & $\begin{array}{c}\text { Fragmentação do } \\
\text { Texto }\end{array}$ & $\begin{array}{l}\text { Unidades de } \\
\text { Sentido }\end{array}$ \\
\hline $\begin{array}{l}\text { Para Hegel, logo no prefácio de a } \\
\text { Fenomenologia do Espírito, a } \\
\text { mediação é a passagem de uma } \\
\text { situação para outra; "um tornar- } \\
\text { se Outro; é uma mediação; } \\
\text { mesmo que seja apenas } \\
\text { passagem a outra proposição" } \\
\text { (1807). O que permite esta } \\
\text { passagem é a reflexão sobre si } \\
\text { mesmo. Tal passagem é } \\
\text { caracterizada pelo apossar-se de } \\
\text { dado objeto imediato pela } \\
\text { consciência e a mediação "seria } \\
\text { sinal de que não se está de posse } \\
\text { do objeto mesmo, mas de algo } \\
\text { que sofreu alguma influência por } \\
\text { parte da consciência" (Govoardi, } \\
2013, \text { p. 43) }\end{array}$ & $\begin{array}{l}\text { texto } 1 \\
\text { pág. } 48\end{array}$ & $\begin{array}{c}\text { A mediação é a } \\
\text { passagem de uma } \\
\text { situação para outra, que } \\
\text { permite a reflexão sobre } \\
\text { si mesmo caracterizada } \\
\text { como o apossar-se de } \\
\text { dado objeto imediato } \\
\text { pela consciência. } \\
\text { Mediação como sinal } \\
\text { que não se está de } \\
\text { posse do objeto mesmo, } \\
\text { mas de algo que sofreu } \\
\text { alguma influência por } \\
\text { parte da consciência. }\end{array}$ & $\begin{array}{l}\text { Passagem de uma } \\
\text { situação para } \\
\text { outra. } \\
\text { Envolve a } \\
\text { autorreflexão, que } \\
\text { se caracteriza } \\
\text { como o apossar- } \\
\text { se do objeto } \\
\text { imediato da } \\
\text { consciência. } \\
\text { Sinal de que se } \\
\text { está com posse } \\
\text { de algo } \\
\text { influenciado pela } \\
\text { consciência. }\end{array}$ \\
\hline $\begin{array}{l}\text { A mediação na perspectiva em } \\
\text { que Hegel a situa, tem, portanto, } \\
\text { o sentido de "reflexão sobre si } \\
\text { mesmo". O ser imediato, o } \\
\text { homem somente supera a sua } \\
\text { animalidade em um processo } \\
\text { constante de construção de } \\
\text { conhecimentos, de tornar-se } \\
\text { sujeito, em contínuo vir-a-ser-de- } \\
\text { si-mesmo. } \\
\text { mediações permitem quessivas } \\
\text { produza a si mesmo, que se torne } \\
\text { sermovente. No princípio é um } \\
\text { ser "essente simples e imediato"; } \\
\text { posteriormente, com a reflexão } \\
\text { que é capaz de realizar, é o ser } \\
\text { mediatizado, diferente e superior } \\
\text { ao que existia. Ocorre então a }\end{array}$ & $\begin{array}{l}\text { texto } 1 \\
\text { pág. } 48\end{array}$ & $\begin{array}{c}\text { Reflexão sobre si } \\
\text { mesmo } \\
\text { O homem somente } \\
\text { supera a sua } \\
\text { animalidade em um } \\
\text { processo constante de } \\
\text { construção de } \\
\text { conhecimentos. } \\
\text { Sucessivas mediações } \\
\text { permitem que se } \\
\text { produza a si mesmo. } \\
\text { Passagem de ser } \\
\text { essente, simples e } \\
\text { imediato, com a reflexão } \\
\text { que é capaz de realizar, } \\
\text { para ser mediatizado, }\end{array}$ & $\begin{array}{l}\text { Autorreflexão. } \\
\text { Superação de } \\
\text { animalidade com } \\
\text { o processo } \\
\text { constante de } \\
\text { construção de } \\
\text { conhecimentos. } \\
\text { Evolução. }\end{array}$ \\
\hline
\end{tabular}




\begin{tabular}{|c|c|c|c|}
\hline $\begin{array}{l}\text { sua passagem de um status para } \\
\text { outro. Ele que só lidava com as } \\
\text { coisas tal como existiam } \\
\text { naturalmente, modifica-se ao } \\
\text { observá-las conscientemente, } \\
\text { isto é, ao aplicar-se às operações } \\
\text { do entendimento produzindo } \\
\text { outro nível de consciência para si. }\end{array}$ & & $\begin{array}{l}\text { diferente e superior ao } \\
\text { que existia. } \\
\text { Aplicar-se às operações } \\
\text { do entendimento } \\
\text { produzindo outro nível } \\
\text { de consciência para si. }\end{array}$ & \\
\hline $\begin{array}{l}\text { Ele admite que a sociedade civil } \\
\text { é o espaço onde ocorre a } \\
\text { mediação entre elementos } \\
\text { considerados naturais (o conflito, } \\
\text { a luta, a concorrência) de uma } \\
\text { racionalidade negativa e o } \\
\text { aspecto ético-político da } \\
\text { racionalidade positiva do Estado. }\end{array}$ & $\begin{array}{l}\text { texto } 1 \\
\text { pág. } 49\end{array}$ & $\begin{array}{l}\text { Sociedade civil como } \\
\text { espaço onde ocorre a } \\
\text { mediação entre } \\
\text { elementos naturais } \\
\text { mediados: conflito, luta, } \\
\text { concorrência. }\end{array}$ & $\begin{array}{l}\text { Sociedade civil } \\
\text { como espaço de } \\
\text { mediação. }\end{array}$ \\
\hline $\begin{array}{l}\text { [...] a mediação é um processo } \\
\text { mental, abstrato, e construtor de } \\
\text { uma realidade que não é } \\
\text { verdadeira }[. . .]\end{array}$ & $\begin{array}{l}\text { texto } 1 \\
\text { pág. } 54\end{array}$ & $\begin{array}{c}\text { Processo mental, } \\
\text { abstrato, e construtor de } \\
\text { uma realidade que não } \\
\text { é verdadeira }\end{array}$ & $\begin{array}{l}\text { Processo mental. } \\
\text { Processo abstrato } \\
\text { Processo } \\
\text { construtor de uma } \\
\text { realidade que não } \\
\text { é verdadeira. }\end{array}$ \\
\hline $\begin{array}{l}\text { Em Hegel, não apenas a relação } \\
\text { pertence à coisa, mas também a } \\
\text { coisa pertence à relação, e de } \\
\text { modo necessário, quer numa, } \\
\text { que noutra direção. Assim, a } \\
\text { perspectiva hegeliana contrapõe- } \\
\text { se frontalmente ao relativismo, } \\
\text { que não reconhece senão a } \\
\text { imediatidade das relações, ao } \\
\text { desautorizar suas mediações } \\
\text { como mero conglomerado de } \\
\text { imediatos justapostos violenta e } \\
\text { ocasionalmente, sem autêntica } \\
\text { união, conciliação e integração. }\end{array}$ & $\begin{array}{c}\text { texto } 2 \\
\text { pág. } 159\end{array}$ & $\begin{array}{l}\text { Não apenas a relação } \\
\text { pertence à coisa, mas } \\
\text { também a coisa } \\
\text { pertence à relação. } \\
\text { Contrapõe-se } \\
\text { frontalmente ao } \\
\text { relativismo. }\end{array}$ & $\begin{array}{l}\text { Processo } \\
\text { recíproco de } \\
\text { pertencimento } \\
\text { entre relação e } \\
\text { coisa. } \\
\text { Contraposição ao } \\
\text { relativismo. }\end{array}$ \\
\hline $\begin{array}{l}\text { O sentido do ser só pode estar, } \\
\text { então na mediação dos } \\
\text { momentos, na dialética ou } \\
\text { Liberdade, que é a necessidade } \\
\text { do ser de libertar-se de si mesmo, } \\
\text { ou melhor, de suas finitudes, } \\
\text { assumindo-se apenas como } \\
\text { momentos parciais de si, até } \\
\text { reconhecer-se em unidade com o } \\
\text { Infinito. }\end{array}$ & $\begin{array}{c}\text { texto } 2 \\
\text { pág. } 160\end{array}$ & $\begin{array}{c}\text { Mediação dos } \\
\text { momentos como sentido } \\
\text { do ser. } \\
\text { Libertar-se de si } \\
\text { mesmo, de suas } \\
\text { finitudes, reconhecer-se } \\
\text { em unidade com o } \\
\text { Infinito. }\end{array}$ & $\begin{array}{c}\text { Sentido. } \\
\text { Autolibertação. } \\
\text { Reconhecimento } \\
\text { com o infinito. }\end{array}$ \\
\hline $\begin{array}{l}\text { Somos "os mesmos de sempre" } \\
\text { mas sempre e de novo } \\
\text { recauchutados por tantas e tão } \\
\text { variadas mediações, isto é, por } \\
\text { passagens de um novo imediato } \\
\text { a outro, transições em nossas } \\
\text { determidades } \\
\text { características), que muitas }\end{array}$ & $\begin{array}{c}\text { texto } 2 \\
\text { pág. } 160\end{array}$ & $\begin{array}{l}\text { Passagens de um novo } \\
\text { imediato a outro, } \\
\text { transições em nossas } \\
\text { determidades (ou } \\
\text { características). } \\
\text { Muitas vezes parece } \\
\text { que toda mediação só } \\
\text { resultou em }\end{array}$ & $\begin{array}{c}\text { Transição. } \\
\text { Perda. }\end{array}$ \\
\hline
\end{tabular}




\begin{tabular}{|c|c|c|c|}
\hline $\begin{array}{l}\text { vezes parece que toda essa } \\
\text { mediação só resultou em } \\
\text { esvaziamento, em perda. }\end{array}$ & & $\begin{array}{c}\text { esvaziamento, em } \\
\text { perda. }\end{array}$ & \\
\hline $\begin{array}{l}\text { O mediado é mais verdadeiro que } \\
\text { o imediato, mas é composto a } \\
\text { partir do imediato, e, assim, } \\
\text { encontra-se numa certa relação } \\
\text { de dependência interna para com } \\
\text { ele. A verdade do mediado se } \\
\text { perde, no entanto, se as } \\
\text { imediatidades nele } \\
\text { suprassumidas são esquecidas. } \\
\text { A mediação não deve aniquilar a } \\
\text { vida do imediato, mas ao } \\
\text { contrário, acrescentar-lhe valor e } \\
\text { intensidade pela relação com } \\
\text { outros imediatos. }\end{array}$ & $\begin{array}{l}\text { texto } 2 \\
\text { pág. } 161\end{array}$ & $\begin{array}{c}\text { O mediado é mais } \\
\text { verdadeiro que o } \\
\text { imediato, mas é } \\
\text { composto a partir dele } \\
\text { e, assim, encontra-se } \\
\text { numa certa relação de } \\
\text { dependência interna } \\
\text { com ele. } \\
\text { A mediação não deve } \\
\text { aniquilar a vida do } \\
\text { imediato, mas sim } \\
\text { acrescentar-lhe valor e } \\
\text { intensidade pela relação } \\
\text { com outros imediatos. }\end{array}$ & $\begin{array}{l}\text { Mediado mais } \\
\text { verdadeiro que o } \\
\text { imediato. } \\
\text { Mediado } \\
\text { construído a partir } \\
\text { do imediato. } \\
\text { Mediação } \\
\text { enquanto relação } \\
\text { de agregação e } \\
\text { não anulação. }\end{array}$ \\
\hline $\begin{array}{l}\text { A realidade, aos olhos de Hegel, } \\
\text { é estruturada fundamentalmente } \\
\text { por mediações. }\end{array}$ & $\begin{array}{l}\text { texto } 2 \\
\text { pág. } 162\end{array}$ & $\begin{array}{c}\text { A realidade é } \\
\text { estruturada } \\
\text { fundamentalmente por } \\
\text { mediações. }\end{array}$ & $\begin{array}{c}\text { Fundamenta a } \\
\text { realidade. }\end{array}$ \\
\hline $\begin{array}{l}\text { Em la obra de Hegel el concepto } \\
\text { de mediacíon permite explicar el } \\
\text { tránsito y la identificación de los } \\
\text { términos considerados } \\
\text { contradictorios. La mediacíon es } \\
\text { ese proceso dialéctico por el cual } \\
\text { conceptos contradictorios, los } \\
\text { "extremos", llegan a identificarse } \\
\text { o a "concluirse" uno em otro, por } \\
\text { acción de un "término medio" no } \\
\text { exterior con respecto a la relación } \\
\text { de contradiccín. Así, por } \\
\text { ejemplo, la singularidad y la } \\
\text { universalidad, considerados } \\
\text { opuestos absolutos - ya que cada } \\
\text { uno puede definirse por la } \\
\text { negacion del otro - acaban } \\
\text { identificándose gracias a la } \\
\text { mediácion de la particularidad. } \\
\text { Porque lo particular se encuentra } \\
\text { en la relacíon inmediata para } \\
\text { Hegel tanto con respecto a lo } \\
\text { singular como a lo universal, } \\
\text { puede ejercer entre ellos una } \\
\text { mediación, es decir, estabelecer } \\
\text { un vínculo mediato que supere su } \\
\text { oposición. }\end{array}$ & $\begin{array}{l}\text { texto } 3 \\
\text { pág. } 68\end{array}$ & $\begin{array}{c}\text { Processo dialético pelo } \\
\text { qual conceitos } \\
\text { contraditórios } \\
\text { (extremos) chegam a } \\
\text { identificar-se ou a } \\
\text { concluir-se um em } \\
\text { outro. } \\
\text { Opostos podem } \\
\text { estabelecer um vínculo } \\
\text { mediato que supere sua } \\
\text { oposição. }\end{array}$ & $\begin{array}{c}\text { Processo } \\
\text { dialético. } \\
\text { Possibilidade de } \\
\text { vínculo superando } \\
\text { oposição. }\end{array}$ \\
\hline
\end{tabular}

Fonte: a própria autora. 
A partir das unidades de sentido e do corpus, por meio do método indutivo, relacionou-se as unidades de sentido em categorias, identificadas em: Espaços sociais; Apropriação; Imaterialidade; Influência da consciência; Mudança; Sentido; Reciprocidade; Vinculação. Apresenta-se, então, o metatexto, que expõe as compreensões obtidas:

Quadro 5: Metatexto mediação em Hegel.

A mediação na teoria de Hegel demonstra imaterialidade com impacto na materialidade, abarcando espaços sociais e influenciando a apropriação, destacando o impacto desta na consciência, na atribuição de sentidos e nas próprias mudanças evolutivas, não perdendo um movimento recíproco de significação, vinculando signos.

Fonte: a própria autora.

\subsubsection{Pressupostos de mediação em Marx}

Nesse tópico será exposto a aplicação da Análise Textual Discursiva nos textos que apresentaram aspectos da mediação de Marx.

Quadro 6: Fragmentação de Texto e Estabelecimento de Unidade de Sentido: Marx.

\begin{tabular}{|c|c|c|c|}
\hline Texto na íntegra & Fonte & $\begin{array}{c}\text { Fragmentação do } \\
\text { Texto }\end{array}$ & Unidades de Sentido \\
\hline $\begin{array}{l}\text { [...] ele não nega a mediação } \\
\text { como reflexão sobre si mesmo, o } \\
\text { simples vir-a-se. O criticável para } \\
\text { ele é a mediação exclusivamente } \\
\text { como atividade cerebral, fechada } \\
\text { no ambiente mental e descolada } \\
\text { do mundo real. Para Marx, a } \\
\text { capacidade de que os homens e } \\
\text { as mulheres têm de transformar a } \\
\text { natureza está nas mediações que } \\
\text { podem fazer diante das coisas } \\
\text { que os desafiam. }\end{array}$ & $\begin{array}{c}\text { texto } \\
1 \\
\text { pág. } \\
50\end{array}$ & $\begin{array}{c}\text { Critica a mediação } \\
\text { exclusivamente como } \\
\text { atividade cerebral de } \\
\text { Hegel } \\
\text { A capacidade de que } \\
\text { os homens e as } \\
\text { mulheres têm de } \\
\text { transformar a natureza } \\
\text { está nas mediações } \\
\text { que podem fazer } \\
\text { diante das coisas que } \\
\text { os desafiam. }\end{array}$ & $\begin{array}{c}\text { Além da atividade } \\
\text { cerebral. } \\
\text { Capacidade de } \\
\text { transformar a natureza. } \\
\text { Mediação para traspor } \\
\text { desafios. }\end{array}$ \\
\hline $\begin{array}{l}\text { A concepção de mediação } \\
\text { marxiana não poderia ser } \\
\text { diferente porque o seu mundo é } \\
\text { terreno, material e concreto e se } \\
\text { opõe ao mundo idealizado do } \\
\text { romantismo hegeliano. }\end{array}$ & $\begin{array}{c}\text { texto } \\
1 \\
\text { pág. } \\
50\end{array}$ & $\begin{array}{c}\text { Acontece no mundo } \\
\text { terreno, material e } \\
\text { concreto. }\end{array}$ & Atividade concreta. \\
\hline $\begin{array}{l}\text { [...] [a mediação] decorre das } \\
\text { reflexões sobre a concretude do } \\
\text { processo de vida, das relações } \\
\text { que os seres humanos } \\
\text { estabelecem com a natureza e }\end{array}$ & $\begin{array}{c}\text { texto } \\
1 \\
\text { pág. } \\
54\end{array}$ & \begin{tabular}{|c|} 
Reflexões sobre a \\
concretude do \\
processo de vida e das \\
relações com a \\
natureza e com os \\
\end{tabular} & $\begin{array}{l}\text { Reflexões concretas } \\
\text { sobre o processo de } \\
\text { vida e relações sociais. }\end{array}$ \\
\hline
\end{tabular}




\begin{tabular}{|l|c|c|c|}
\hline $\begin{array}{l}\text { com os seus iguais, em suas } \\
\text { relações sociais. }\end{array}$ & $\begin{array}{c}\text { seus iguais, em } \\
\text { relações sociais. }\end{array}$ & $\begin{array}{c}\text { Reflexões concretas } \\
\text { sobre relações com a } \\
\text { natureza. } \\
\text { Reflexões concretas } \\
\text { sobre relações com } \\
\text { seus iguais. }\end{array}$ \\
\hline $\begin{array}{l}\text { A psicologia social marxiana, } \\
\text { como área da educação, } \\
\text { dialeticamente, encontra espaço } \\
\text { em um lugar que até então era } \\
\text { reservado à sociologia e à } \\
\text { filosofia; a possibilidade de } \\
\text { transformação epistemológica de } \\
\text { mentalidades, transformação } \\
\text { social via apreensão da realidade } \\
\text { [...]. }\end{array}$ & $\begin{array}{c}5 \\
\text { pág. }\end{array}$ & $\begin{array}{c}\text { Possibilidade de } \\
\text { transformação } \\
\text { epistemológica de } \\
\text { mentalidades e } \\
\text { transformação social } \\
\text { via apreensão da } \\
\text { realidade. }\end{array}$ & $\begin{array}{c}\text { Transformação } \\
\text { epistemológica de } \\
\text { mentalidades. }\end{array}$ \\
$\begin{array}{c}\text { Transformação social } \\
\text { pela apreensão da } \\
\text { realidade. }\end{array}$ \\
\hline
\end{tabular}

Fonte: a própria autora.

Mais uma vez, a partir das unidades de sentido e do corpus, por meio do método indutivo, relacionou-se as unidades de sentido em categorias, identificadas em: Apropriação; Imaterialidade; Materialidade; Objetividade; Relações sociais; Superação; e Transformação. Apresenta-se, então, o metatexto, que expõe as compreensões obtidas:

Quadro 7: Metatexto mediação em Marx.

A mediação na teoria de Marx não abandona os aspectos imateriais de sua influência e apresenta o ressaltar do seu impacto social em contextos materiais, trazendo concepções objetivas de atuação da mediação frente a necessidades de transformação e superação no ambiente e nas relações sociais e da importância da apropriação da realidade nesse processo transformador.

Fonte: a própria autora.

\subsubsection{Pressupostos de mediação em Vygotsky}

Nesse tópico será exposto a aplicação da Análise Textual Discursiva nos textos que apresentaram aspectos da mediação de Vygotsky. 
Quadro 8: Fragmentação de Texto e Estabelecimento de Unidade de Sentido: Vygotsky.

\begin{tabular}{|c|c|c|c|}
\hline Texto na íntegra & Fonte & $\begin{array}{c}\text { Fragmentação do } \\
\text { Texto }\end{array}$ & Unidades de Sentido \\
\hline $\begin{array}{l}\text { Chamamos a atenção para o } \\
\text { importante papel que Vigotski } \\
\text { emprega ao uso de instrumentos } \\
\text { e signos como elementos } \\
\text { mediadores entre os homens, e } \\
\text { entre os homens e a natureza. } \\
\text { Para o autor, o uso desses } \\
\text { recursos são essenciais para a } \\
\text { constituição de novas formações } \\
\text { psicológicas, e seu uso só foi } \\
\text { possível porque o próprio } \\
\text { homem, ao produzir sua } \\
\text { sobrevivência, produziu e os } \\
\text { tornou mais complexos. }\end{array}$ & $\begin{array}{c}\text { texto } 4 \\
\text { pág. } \\
2382\end{array}$ & $\begin{array}{l}\text { Instrumentos e signos } \\
\text { como elementos } \\
\text { mediadores entre os } \\
\text { homens, e entre os } \\
\text { homens e a natureza. }\end{array}$ & $\begin{array}{c}\text { Instrumentos e signos } \\
\text { mediadores. } \\
\text { Mediação entre os } \\
\text { homens. } \\
\text { Mediação entre os } \\
\text { homens e a natureza. }\end{array}$ \\
\hline $\begin{array}{l}\text { Os signos criados pelos homens } \\
\text { permitiram a transformação ativa } \\
\text { da natureza do homen, } \\
\text { promovendo sua adaptação de } \\
\text { maneira ativa, ou seja, ele se } \\
\text { adapta, mas também transforma } \\
\text { sua atividade, regula sua } \\
\text { conduta. O homem é quem cria } \\
\text { novas conexões, novos signos } \\
\text { externos, que atuam de forma } \\
\text { mais complexa na sua atividade } \\
\text { psicológica, proporcionando sua } \\
\text { mudança, a transformação de } \\
\text { sua natureza. }\end{array}$ & $\begin{array}{c}\text { texto } 4 \\
\text { pág. } \\
2382\end{array}$ & $\begin{array}{c}\text { Signos criados pelos } \\
\text { homens permitiram a } \\
\text { transformação ativa da } \\
\text { natureza do homen, } \\
\text { promovendo sua } \\
\text { adaptação de maneira } \\
\text { ativa. } \\
\text { O homem é quem cria } \\
\text { novas conexões, } \\
\text { novos signos externos, } \\
\text { que atuam de forma } \\
\text { mais complexa na sua } \\
\text { atividade psicológica, } \\
\text { proporcionando sua } \\
\text { mudança e a } \\
\text { transformação de sua } \\
\text { natureza. }\end{array}$ & $\begin{array}{l}\text { Homem criador de } \\
\text { novos signos. } \\
\text { Possibilidade de } \\
\text { transformação de sua } \\
\text { natureza. } \\
\text { Criação de signos } \\
\text { externos que atuam de } \\
\text { forma mais complexa. }\end{array}$ \\
\hline $\begin{array}{l}\text { [...] Vigotski resgata as ideias de } \\
\text { Marx e Engels ao apresentar sua } \\
\text { compreensão de que é nas } \\
\text { relações sociais, mediadas pela } \\
\text { cultura, construída pelo próprio } \\
\text { homem, que o fazem se constituir } \\
\text { como humano, que lhe imprimem } \\
\text { as características } \\
\text { especificamente humanas, e lhe } \\
\text { permitem produzir novas formas } \\
\text { de relações, cada vez mais } \\
\text { complexas. }\end{array}$ & $\begin{array}{c}\text { texto } 4 \\
\text { pág. } \\
2382\end{array}$ & \begin{tabular}{|c|} 
Relações sociais, \\
mediadas pela cultura, \\
construída pelo próprio \\
homem permitem se \\
constituir como \\
humano, lhe imprimem \\
as características \\
especificamente \\
humanas, e lhe \\
permitem produzir \\
novas formas de \\
relações, cada vez \\
mais complexas.
\end{tabular} & $\begin{array}{c}\text { Cultura como } \\
\text { mediadora de relações } \\
\text { sociais. } \\
\text { Possibilidade de } \\
\text { produzir relações cada } \\
\text { vez mais complexas. }\end{array}$ \\
\hline $\begin{array}{l}\text { Para Vigotski a mediação pode } \\
\text { se caracterizar por duas formas: } \\
\text { instrumentos e signos através } \\
\text { dos instrumentos, que seriam as } \\
\text { ferramentas que modificariam a }\end{array}$ & $\begin{array}{c}\text { texto } 4 \\
\text { pág. } \\
2383\end{array}$ & \begin{tabular}{|} 
Duas caracterizações \\
possíveis para a \\
mediação: \\
instrumentos; e signos \\
através dos
\end{tabular} & $\begin{array}{l}\text { Mediação como } \\
\text { instrumento. } \\
\text { Mediação como signo } \\
\text { através dos } \\
\text { instrumentos. }\end{array}$ \\
\hline
\end{tabular}




\begin{tabular}{|c|c|c|c|}
\hline $\begin{array}{l}\text { estrutura dos objetos, e teriam a } \\
\text { função de "[...] servir como um } \\
\text { condutor da influência humana } \\
\text { sobre o objeto da atividade [....] } \\
\text { (Vygotiski, 19888, p. 62). }\end{array}$ & & \begin{tabular}{|c|} 
instrumentos, como \\
ferramentas que \\
modificariam a \\
estrutura dos objetos, \\
como um condutor da \\
influência humana \\
sobre o objeto da \\
atividade.
\end{tabular} & \\
\hline $\begin{array}{l}\text { [...] podemos afirmar que a teoria } \\
\text { de Vogotiski enfatiza o caráter } \\
\text { mediador da atividade humana. } \\
\text { Através da mediação pelos } \\
\text { instrumentos criados pelo próprio } \\
\text { homem ao longo de sua história, } \\
\text { que os seres humanos menos } \\
\text { experientes irão se constituindo } \\
\text { enquanto homens, enquanto } \\
\text { humanos. Vão se apropriando de } \\
\text { características especificamente } \\
\text { humanas e transformando em } \\
\text { suas, características gerais que } \\
\text { acompanham o desenvolvimento } \\
\text { do homem desde seus } \\
\text { primórdios, assim r como } \\
\text { construindo sua própria } \\
\text { singularidade. }\end{array}$ & $\begin{array}{c}\text { texto } 4 \\
\text { pág. } \\
2384\end{array}$ & $\begin{array}{c}\text { Enfatiza o caráter } \\
\text { mediador da atividade } \\
\text { humana. } \\
\text { Instrumentos criados } \\
\text { pelo próprio homem } \\
\text { como mediadores para } \\
\text { seres humanos menos } \\
\text { experientes se } \\
\text { constituírem enquanto } \\
\text { humanos, se } \\
\text { apropriando delas e } \\
\text { construindo sua } \\
\text { própria singularidade. }\end{array}$ & $\begin{array}{l}\text { Atividade humana } \\
\text { como mediadora. } \\
\text { Criação de } \\
\text { instrumentos para } \\
\text { mediação. } \\
\text { Influência social. }\end{array}$ \\
\hline $\begin{array}{l}\text { [...] mediação como possibilidade } \\
\text { de transformação social na } \\
\text { contemporaneidade. }\end{array}$ & $\begin{array}{l}\text { texto } 5 \\
\text { pág. } 6\end{array}$ & $\begin{array}{c}\text { Mediação como } \\
\text { possibilidade de } \\
\text { transformação social } \\
\text { na } \\
\text { contemporaneidade. }\end{array}$ & $\begin{array}{l}\text { Mediação como } \\
\text { transformação social. }\end{array}$ \\
\hline $\begin{array}{l}\text { [...] o processo de aprendizagem } \\
\text { em estudos de Vigotski [...] } \\
\text { revelam a complexidade do } \\
\text { conceito de mediação e compõe } \\
\text { uma perspectiva dialética, com } \\
\text { ênfase nas possibilidades de } \\
\text { aquisição do conhecimento } \\
\text { advindas da elaboração do } \\
\text { conceito de zona de } \\
\text { desenvolvimento proximal. }\end{array}$ & $\begin{array}{l}\text { texto } 5 \\
\text { pág. } 6\end{array}$ & $\begin{array}{c}\text { A complexidade do } \\
\text { conceito de mediação } \\
\text { compõe uma } \\
\text { perspectiva dialética. } \\
\text { Ênfase nas } \\
\text { possibilidades de } \\
\text { aquisição do } \\
\text { conhecimento } \\
\text { advindas da } \\
\text { elaboração do } \\
\text { conceito de zona de } \\
\text { desenvolvimento } \\
\text { proximal. }\end{array}$ & $\begin{array}{c}\text { Complexidade. } \\
\text { Dialética. } \\
\text { Conhecimento pela } \\
\text { zona de } \\
\text { desenvolvimento } \\
\text { proximal. }\end{array}$ \\
\hline $\begin{array}{l}\text { [...] o fato de ele criar a zona de } \\
\text { desenvolvimento proximal; ou } \\
\text { seja o aprendizado desperta } \\
\text { vários processos internos de } \\
\text { desenvolvimento que são } \\
\text { capazes de operar somente } \\
\text { quando a criança interage com } \\
\text { pessoas e seu ambiente e } \\
\text { quando em cooperação com seus }\end{array}$ & $\begin{array}{l}\text { texto } 5 \\
\text { pág. } 6\end{array}$ & $\begin{array}{c}\text { O aprendizado } \\
\text { desperta vários } \\
\text { processos internos de } \\
\text { desenvolvimento que } \\
\text { são capazes de operar } \\
\text { somente quando a } \\
\text { criança interage com } \\
\text { pessoas e seu } \\
\text { ambiente e quando em }\end{array}$ & $\begin{array}{c}\text { Aprendizado } \\
\text { dependente de } \\
\text { interação com pessoas } \\
\text { e ambiente. } \\
\text { Depois de } \\
\text { internalizado passa } \\
\text { para o } \\
\text { desenvolvimento } \\
\text { independente. }\end{array}$ \\
\hline
\end{tabular}




\begin{tabular}{|c|c|c|c|}
\hline $\begin{array}{l}\text { companheiros. Uma vez } \\
\text { internalizados, esses processos } \\
\text { tornam-se parte das aquisições } \\
\text { do desenvolvimento } \\
\text { independente [...]. }\end{array}$ & & $\begin{array}{l}\text { cooperação com seus } \\
\text { companheiros. } \\
\text { Quando internalizados } \\
\text { tornam-se parte das } \\
\text { aquisições do } \\
\text { desenvolvimento } \\
\text { independente. }\end{array}$ & \\
\hline $\begin{array}{l}\text { Vigotski não abre mão do } \\
\text { processo de aprendizagem de } \\
\text { acordo com o conceito de } \\
\text { mediação para a aquisição de } \\
\text { funções superiores [...]. }\end{array}$ & $\begin{array}{l}\text { texto } 5 \\
\text { pág. } 8\end{array}$ & $\begin{array}{l}\text { Aprendizagem pela } \\
\text { mediação para } \\
\text { aquisição de funções } \\
\text { superiores. }\end{array}$ & $\begin{array}{l}\text { Mediação como } \\
\text { significante na } \\
\text { aquisição de funções } \\
\text { superiores. }\end{array}$ \\
\hline $\begin{array}{l}{[\ldots] \text { a mediação cria as }} \\
\text { possibilidades de reelaboração } \\
\text { (recriação) da realidade. } \\
\text { Realidade esta estabelecida, } \\
\text { segundo o próprio Vigotski, como } \\
\text { um elo de ligação em que o signo, } \\
\text { a atividade e a consciência } \\
\text { interagem } \\
\text { Imperativamente, a categoria de } \\
\text { mediação possibilita a aquisição } \\
\text { de funções superiores. }\end{array}$ & $\begin{array}{l}\text { texto } 5 \\
\text { pág. } 8\end{array}$ & $\begin{array}{l}\text { A mediação cria as } \\
\text { possibilidades de } \\
\text { reelaboração } \\
\text { (recriação) da } \\
\text { realidade. } \\
\text { Realidade como elo de } \\
\text { ligação em que o } \\
\text { signo, a atividade e a } \\
\text { consciência interagem } \\
\text { socialmente. }\end{array}$ & $\begin{array}{l}\text { A mediação cria } \\
\text { possibilidades de } \\
\text { reelaboração da } \\
\text { realidade. } \\
\text { Realidade identificada } \\
\text { como elo de ligação } \\
\text { em que o signo, a } \\
\text { atividade e a } \\
\text { consciência interagem } \\
\text { socialmente. }\end{array}$ \\
\hline $\begin{array}{l}\text { [a mediação] É o processo que } \\
\text { caracteriza a relação do homem } \\
\text { com o mundo e com outros } \\
\text { homens. Assim temos l: } \\
\text { instrumento; S: sujeito; O: objeto. } \\
\text { A mediação é vista como central, } \\
\text { pois é nesse processo que as } \\
\text { Funções Psicológicas } \\
\text { Superiores (FPS) - tipicamente } \\
\text { humanas - se desenvolvem. As } \\
\text { FPS relacionam-se com ações } \\
\text { intencionais - planejamento, } \\
\text { memória voluntária, imaginação, } \\
\text { enquanto as FPE (funções } \\
\text { psicológicas elementares) dizem } \\
\text { respeito ao que é biológico, nato, } \\
\text { extinto, reflexo. }\end{array}$ & $\begin{array}{l}\text { texto } 6 \\
\text { pág. } \\
2539\end{array}$ & $\begin{array}{c}\text { Mediação como } \\
\text { processo que } \\
\text { caracteriza a relação } \\
\text { do homem com o } \\
\text { mundo e com outros } \\
\text { homens. } \\
\text { No processo de } \\
\text { mediação as FPS } \\
\text { (Funções Psicológicas } \\
\text { Superiores) } \\
\text { relacionam-se com } \\
\text { ações intencionais - } \\
\text { planejamento, } \\
\text { memória voluntária, } \\
\text { imaginação. } \\
\text { As FPE (funções } \\
\text { psicológicas } \\
\text { elementares) dizem } \\
\text { respeito ao que é } \\
\text { biológico, nato, extinto, } \\
\text { reflexo. }\end{array}$ & $\begin{array}{c}\text { Mediação como } \\
\text { processo que } \\
\text { caracteriza a relação } \\
\text { do homem com o } \\
\text { mundo e com outros } \\
\text { homens. } \\
\text { No processo de } \\
\text { mediação as Funções } \\
\text { Psicológicas } \\
\text { Superiores se } \\
\text { desenvolvem, que se } \\
\text { relacionam com ações } \\
\text { intencionais como } \\
\text { planejamento, } \\
\text { memória e } \\
\text { imaginação. }\end{array}$ \\
\hline $\begin{array}{l}\text { [...] ZPD (zona proximal de } \\
\text { desenvolvimento) [...] Trata-se do } \\
\text { espaço de trabalho no qual uma } \\
\text { pessoa atua para ampliar os } \\
\text { conhecimentos do aprendiz. Para } \\
\text { tanto é necessário reconhecer o } \\
\text { que o outro pode realizar sem } \\
\text { ajuda (ZDR - zona do }\end{array}$ & $\begin{array}{c}\text { texto } 6 \\
\text { pág. } \\
2539\end{array}$ & $\begin{array}{l}\text { ZPD (zona proximal de } \\
\text { desenvolvimento) é o } \\
\text { espaço de trabalho no } \\
\text { qual uma pessoa atua } \\
\text { para ampliar os } \\
\text { conhecimentos do } \\
\text { aprendiz. }\end{array}$ & $\begin{array}{l}\text { Objetivo de que se } \\
\text { internalize habilidades } \\
\text { ampliadas para que } \\
\text { elas sejam realizadas } \\
\text { de forma autônoma. }\end{array}$ \\
\hline
\end{tabular}




\begin{tabular}{|c|c|c|c|}
\hline $\begin{array}{l}\text { desenvolvimento real) e o que } \\
\text { não pode. O objetivo, então, é } \\
\text { que a realização de algo feito na } \\
\text { ZPD possa, em breve ser feito na } \\
\text { ZDR, buscando a autonomia de } \\
\text { atuação dos sujeitos envolvidos. }\end{array}$ & & \begin{tabular}{|c|} 
O objetivo é que a \\
realização de algo feito \\
na ZPD possa ser feito \\
na ZDR (zona do \\
desenvolvimento real), \\
buscando a autonomia \\
de atuação dos \\
sujeitos envolvidos.
\end{tabular} & \\
\hline 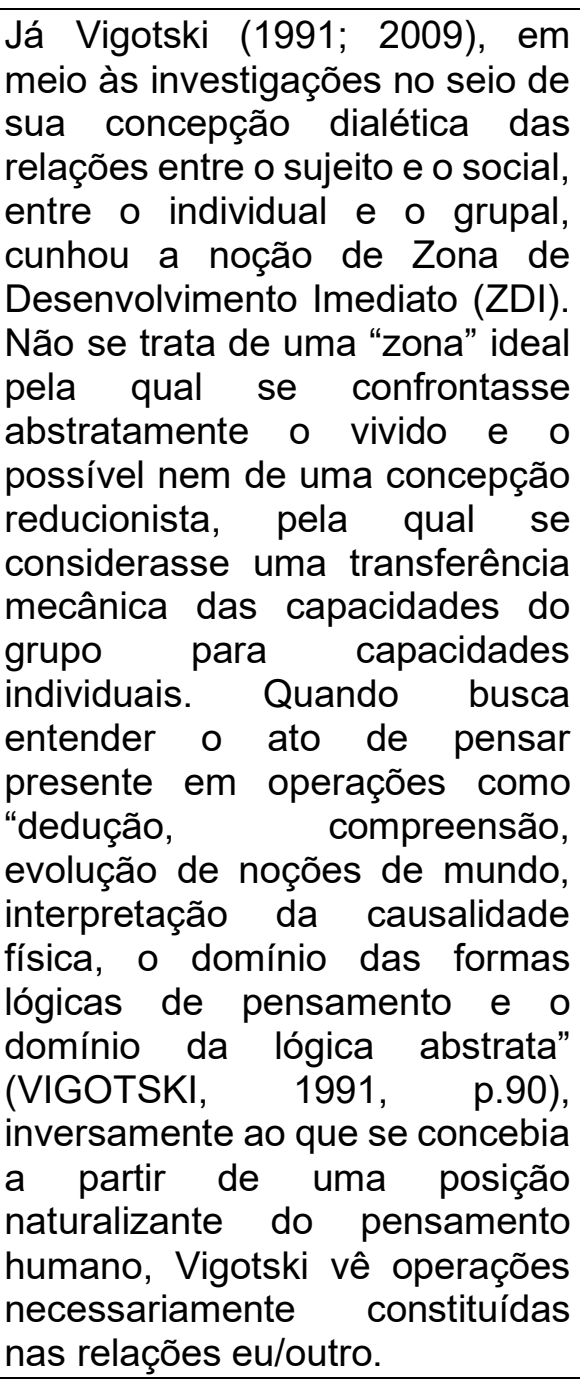 & $\begin{array}{c}\text { texto } 7 \\
\text { pág. } \\
97-98\end{array}$ & $\begin{array}{c}\text { Zona de } \\
\text { Desenvolvimento } \\
\text { Imediato (ZDI). } \\
\text { Busca entender o ato } \\
\text { de pensar presente em } \\
\text { operações como } \\
\text { "dedução, } \\
\text { compreensão, } \\
\text { evolução de noções de } \\
\text { mundo, interpretação } \\
\text { da causalidade física, } \\
\text { o domínio das formas } \\
\text { lógicas de pensamento } \\
\text { e o domínio da lógica } \\
\text { abstrata". } \\
\text { Inversamente ao que } \\
\text { se concebia a partir de } \\
\text { uma posição } \\
\text { naturalizante do } \\
\text { pensamento humano, } \\
\text { Vigotski vê operações } \\
\text { necessariamente } \\
\text { constituídas nas } \\
\text { relações eu/outro. }\end{array}$ & $\begin{array}{c}\text { Zona de } \\
\text { Desenvolvimento } \\
\text { Imediato (ZDI) - } \\
\text { operações } \\
\text { necessariamente } \\
\text { constituídas nas } \\
\text { relações eu/outro. }\end{array}$ \\
\hline $\begin{array}{l}\text { [...] Vigotski concebe uma } \\
\text { inusitada teoria do } \\
\text { desenvolvimento do pensamento } \\
\text { como elemento tensionado pelas } \\
\text { aprendizagens às quais os } \\
\text { sujeitos são submetidos ao longo } \\
\text { da vida, e não o contrário } \\
\text { (VIGOTSKI, 2009, p.336). }\end{array}$ & $\begin{array}{c}\text { texto } 7 \\
\text { pág. } \\
98\end{array}$ & $\begin{array}{c}\text { Teoria do } \\
\text { desenvolvimento do } \\
\text { pensamento como } \\
\text { elemento tensionado } \\
\text { pelas aprendizagens } \\
\text { às quais os sujeitos } \\
\text { são submetidos ao } \\
\text { longo da vida, e não o } \\
\text { contrário. }\end{array}$ & $\begin{array}{c}\text { Pensamento como } \\
\text { elemento tensionado } \\
\text { pelas aprendizagens } \\
\text { às quais os sujeitos } \\
\text { são submetidos ao } \\
\text { longo da vida. }\end{array}$ \\
\hline
\end{tabular}




\begin{tabular}{|c|c|c|c|}
\hline $\begin{array}{l}\text { One of the most important } \\
\text { characteristics of Vygotsky's } \\
\text { works is the idea of mediation } \\
\text { (Prenkert, 2006; Roth, 2007). } \\
\text { According to Vygotsky (1978), } \\
\text { this is the elementary feature } \\
\text { characteristic of human } \\
\text { consciousness. As activity is } \\
\text { consequence, human activats as } \\
\text { seen by activity theorists as } \\
\text { mediated through cultural } \\
\text { artifacts (Engeström, 1987; } \\
\text { Wertsch, 1994). This notion } \\
\text { stems from the Vygotskian root } \\
\text { model of mediated action } \\
\text { (Vygotsky, 1978, p. 40), where } \\
\text { humans act on an object through } \\
\text { the utilization of tools of various } \\
\text { kinds, such as material } \\
\text { instruments, signs, language and } \\
\text { mental models, and so on. }\end{array}$ & $\begin{array}{c}\text { texto } 8 \\
\text { pág. } \\
643\end{array}$ & $\begin{array}{c}\text { Característica } \\
\text { elementar da } \\
\text { consciência humana. } \\
\text { A atividade humana é } \\
\text { mediada por artefatos } \\
\text { culturais. } \\
\text { No modelo de } \\
\text { Vygotsky da ação } \\
\text { mediada, os seres } \\
\text { humanos atuam sobre } \\
\text { um objeto através da } \\
\text { utilização de } \\
\text { ferramentas de vários } \\
\text { tipos, como } \\
\text { instrumentos } \\
\text { materiais, sinais, } \\
\text { linguagem e modelos } \\
\text { mentais. }\end{array}$ & $\begin{array}{c}\text { Mediação como } \\
\text { característica } \\
\text { elementar da } \\
\text { consciência humana. } \\
\text { A atividade humana é } \\
\text { mediada por artefatos } \\
\text { culturais. } \\
\text { Os humanos atuam } \\
\text { sobre um objeto } \\
\text { através da utilização } \\
\text { de ferramentas de } \\
\text { vários tipos, como } \\
\text { instrumentos } \\
\text { materiais, sinais, } \\
\text { linguagem e modelos } \\
\text { mentais. }\end{array}$ \\
\hline $\begin{array}{l}\text { O professor que atua na ZDP } \\
\text { torna-se mediador do } \\
\text { conhecimento e da apropriação } \\
\text { da produção humana. Ao } \\
\text { afirmarmos isso nos reportamos } \\
\text { ao processo de mediação, que } \\
\text { mereceu especial atenção de } \\
\text { Vigotski ao abordar a questão } \\
\text { dos instrumentos de trabalho e } \\
\text { dos signos na constituição das } \\
\text { funções psicológicas superiores. } \\
\text { Conforme Vigotski (2000), assim } \\
\text { como os instrumentos mudam } \\
\text { operações de trabalho, os signos } \\
\text { - instrumentos psicológicos - } \\
\text { alteram a estrutura psicológica; } \\
\text { ou seja, as palavras, os números, } \\
\text { os recursos mnemotécnicos, } \\
\text { símbolos algébricos, obras de } \\
\text { arte, sistemas de escrita, mapas, } \\
\text { diagramas, etc., são artefatos } \\
\text { sociais que modificam a } \\
\text { organização mental humana e } \\
\text { ressoam no contexto em que o } \\
\text { sujeito vive, portanto são } \\
\text { mediadores dos processos } \\
\text { psicológicos. }\end{array}$ & $\begin{array}{l}\text { texto } 9 \\
\text { pág. } \\
222\end{array}$ & $\begin{array}{l}\text { O professor que atua } \\
\text { na ZDP torna-se } \\
\text { mediador do } \\
\text { conhecimento e da } \\
\text { apropriação da } \\
\text { produção humana. } \\
\text { Assim como os } \\
\text { instrumentos mudam } \\
\text { operações de trabalho, } \\
\text { os signos - } \\
\text { instrumentos } \\
\text { psicológicos - } \\
\text { alteram a estrutura } \\
\text { psicológica. } \\
\text { Artefatos sociais } \\
\text { modificam a } \\
\text { organização mental } \\
\text { humana e ressoam no } \\
\text { contexto em que o } \\
\text { sujeito vive e, portanto } \\
\text { são mediadores dos } \\
\text { processos } \\
\text { psicológicos. }\end{array}$ & $\begin{array}{c}\text { Os instrumentos } \\
\text { mudam operações de } \\
\text { trabalho, os signos - } \\
\text { instrumentos } \\
\text { psicológicos - } \\
\text { alteram a estrutura } \\
\text { psicológica. } \\
\text { Mediadores dos } \\
\text { processos } \\
\text { psicológicos: artefatos } \\
\text { sociais que modificam } \\
\text { a organização mental } \\
\text { humana e ressoam no } \\
\text { contexto em que o } \\
\text { sujeito vive. }\end{array}$ \\
\hline $\begin{array}{l}\text { Vigotski destacou, ainda, outra } \\
\text { forma de mediação: a que se dá } \\
\text { por meio de outra pessoa } \\
\text { (Kozulin, 1994, p.116). Como } \\
\text { apontamos anteriormente, é na } \\
\text { relação com o outro que se }\end{array}$ & $\begin{array}{l}\text { texto } 9 \\
\text { pág. } \\
222\end{array}$ & $\begin{array}{l}\text { Outra forma de } \\
\text { mediação: a que se dá } \\
\text { por meio de outra } \\
\text { pessoa. } \\
\text { É na relação com o } \\
\text { outro que se constitui }\end{array}$ & $\begin{array}{l}\text { O outro (homem) } \\
\text { como mediador, como } \\
\text { signo. } \\
\text { Toda e qualquer } \\
\text { função psicológica }\end{array}$ \\
\hline
\end{tabular}




\begin{tabular}{|c|c|c|c|}
\hline $\begin{array}{l}\text { constitui o plano interpsicológico } \\
\text { do desenvolvimento cultural do } \\
\text { indivíduo. Neste sentido, o outro } \\
\text { é signo mediador de condutas, } \\
\text { gestos, sentimentos } \\
\text { pensamentos, valendo lembrar } \\
\text { que toda e qualquer função } \\
\text { psicológica superior foi social } \\
\text { antes de tornar-se interna ao } \\
\text { indivíduo. }\end{array}$ & & \begin{tabular}{|c} 
o plano \\
interpsicológico do \\
desenvolvimento \\
cultural do indivíduo. \\
O outro é signo \\
mediador de condutas, \\
gestos, sentimentos e \\
pensamentos. \\
Toda e qualquer \\
função psicológica \\
superior foi social \\
antes de tornar-se \\
interna ao indivíduo.
\end{tabular} & $\begin{array}{l}\text { superior foi social } \\
\text { antes de tornar-se } \\
\text { interna ao indivíduo }\end{array}$ \\
\hline 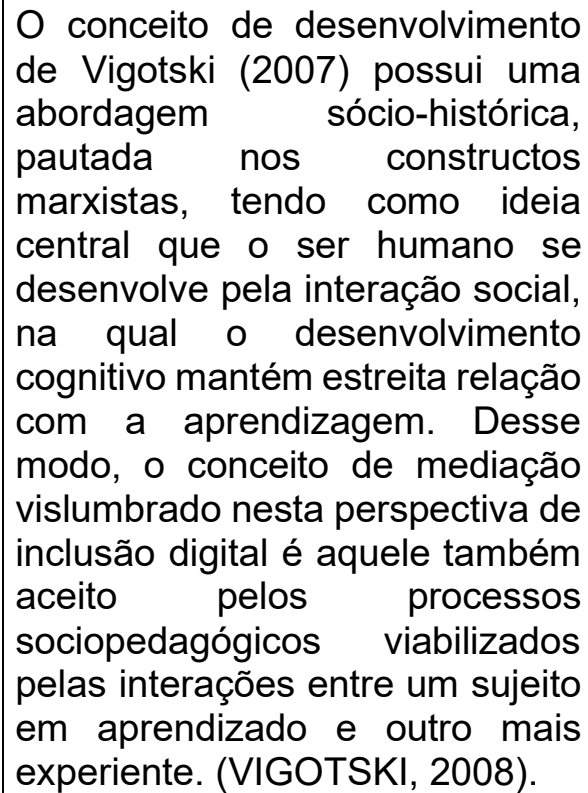 & $\begin{array}{l}\text { texto } \\
10 \\
\text { pág. } \\
53\end{array}$ & $\begin{array}{c}\text { O ser humano se } \\
\text { desenvolve pela } \\
\text { interação social, na } \\
\text { qual o } \\
\text { desenvolvimento } \\
\text { cognitivo mantém } \\
\text { estreita relação com a } \\
\text { aprendizagem. } \\
\text { Interações entre um } \\
\text { sujeito em } \\
\text { aprendizado e outro } \\
\text { mais experiente. }\end{array}$ & $\begin{array}{l}\text { Na interação social o } \\
\text { desenvolvimento } \\
\text { cognitivo se relaciona } \\
\text { estreitamente com a } \\
\text { aprendizagem. }\end{array}$ \\
\hline
\end{tabular}

Fonte: a própria autora.

Finalmente, relacionou-se também as unidades de sentido dos textos do quadro 6 em categorias, identificadas em: Apropriação; Autotransformação; Complexidade; Cultura como mediação; Cultura; Desenvolvimento; Homem como signo; Humanidade; Imaterialidade; Interação social; Natureza; Objetivação; Reflexão no ambiente; Relação social; Sentido; Significado; Signos; Superação; Transformação; e Vinculação. Apresenta-se, então, o metatexto, que expõe as compreensões obtidas:

Quadro 9: Metatexto mediação em Vygotsky.

Os trabalhos ancorados em Vygotsky apresentam sua teoria de fundamentos psicológicos, imateriais mas reflexivos na materialidade, que priorizam o estudo da mediação no viés do pensamento humano e o seu desenvolvimento, que possibilita a autotransformação, e estabelece zonas que objetivam sua expressão em processos complexos então identificados apenas na natureza humana. Seu trabalho traz a importância das relações 
sociais e da cultura, e propõe aspectos de desenvolvimento da mediação que proporcionem a superação e transformação, vinculando a mediação com o meio e com a natureza, trabalhando com aspectos de signos, sentidos e significados, apresentando o próprio homem como signo e a cultura como mediação, expressando assim a importância da apropriação frente a interações sociais.

Fonte: a própria autora.

\subsection{A COMPLEXIDADE DA MEDIAÇÃO DA INFORMAÇÃO NA CIÊNCIA DA INFORMAÇÃO}

Repetidas são as vezes em que a mediação também é apresentada com relações sígnicas e, nesse ponto, é possível utilizar a teoria de Peirce para clarificar alguns aspectos, reconhecendo sua grande contribuição para o entendimento da cadeia infinita de relacionamentos signo-objeto-qualidadeinterpretante-objeto-relação (PEIRCE, 2005), que um ser humano estabelece na natureza com outros seres, fazendo-se assim um signo imerso nesse relacionar infinito, onde se relaciona com diferentes representações e altera assim sua própria representação.

Peirce apresenta também a natureza dos objetos na semiótica: eles podem ser divididos em Objetos Dinâmico e Imediato, sendo o primeiro o "real" objeto representado pelo signo, e o último a "forma" dessa apresentação da realidade. Como o objeto imediato é uma apresentação do dinâmico, uma representação dele, podese dizer que ele não esgota sua existência e por isso, para conseguir uma exposição clara das coisas, muitas vezes é necessário percorrer inúmeras vezes o caminho da busca da compreensão dos objetos dinâmicos do mundo e universo. Também, por ser uma forma comum e rápida de disponibilização da realidade, o objeto imediato pode levar consigo uma grande perda, ou manipulação, do objeto dinâmico.

A escolha da visão de Pierce para o entendimento dessas relações entre objetos e significações também foi feita por sua proximidade com a teoria fenomenológica de Husserl, trazendo questionamentos sobre a percepção de objetos (AJIBOYE, 2012, p. 15).

Com esses aspectos esclarecidos, destacamos que nos entendimentos e abordagens para o conceito de mediação na Ciência da Informação há dois núcleos de embasamento, um deles apresenta a mediação como sinônimo de transferência, na qual informações são enviadas de um ponto a outro e que, 
figurativamente, podem ser representados como um processo de ponte (MAIA et al., 2011); o segundo traz uma perspectiva mais complexa, atrelada aos interesses da relação entre a informação e seu impacto na sociedade (ALMEIDA JÚNIOR, 2015).

O primeiro, identificado como um processo de ponte, apresenta, principalmente, foco em vertentes da tecnologia, nas quais a transferência de dados por meio de determinado suporte são o destaque, ou seja, o transportar de dados de um ponto a outro em suportes tecnológicos, e engloba suportes físicos como determinantes do foco de trabalho do profissional da informação, pois a informação se apresenta então dependente de materialidade.

Com base nessa abordagem, serviços e produtos são desenvolvidos com a preocupação de manter os suportes adequados e atualizados frente ao rápido desenvolvimento tecnológico que impacta na área. Nesse aspecto, estudos são pautados na necessidade de manter a interoperabilidade e a capacitação dos profissionais, resultando na recorrência de pesquisas fragmentadas, muitas vezes com foco na organização e tecnologia, ainda em uma visão voltada para práticas técnicas.

A segunda perspectiva, pautada em concepções da relação entre Informação e Sociedade, objetiva expor a necessidade de uma visão mais complexa desse processo, trazendo inclusive discussões divergentes quanto as responsabilidades da área e das abordagens do trabalho a ser desenvolvido. Essas discussões abarcam até que ponto os profissionais da área têm a responsabilidade de se preocupar com questões sociais. Um questionamento maior pode então ser ressaltado: o de se alguma área do conhecimento pode se constituir sem essa preocupação social, já que não existe área científica dissociada da sociedade.

Por não haver um consenso quanto a responsabilidade social da profissão, instituições ao redor do mundo que se destacam com um trabalho mediador em um âmbito social acabam por serem questionadas quanto a esse envolvimento do profissional, e até sofrem uma defasagem profissional devido ao desinteresse ou desconhecimento dos profissionais da área quanto a essa perspectiva de atuação. (OLIVEIRA, 2014).

Essa realidade demonstra que talvez nos próprios cursos de graduação e/ou pós-graduação em Biblioteconomia, Arquivologia e Ciência da Informação tal abordagem ainda não tenha sido incluída de forma expressiva nos 
currículos e atividades e/ou que ainda existem poucos modelos de atuação nesse âmbito.

A mediação da informação que se encontra na esfera Informação e Sociedade apresenta um diálogo com os aspectos da apropriação significativa objetivo de tal mediação - e, nessa transição, abre discussões como, por exemplo, a importância e significância da cultura no relacionamento estabelecido com a informação.

Porém, mesmo nessa perspectiva apresentada, um estudo aprofundado, que traga em ressalte as concepções do social e da complexidade, perpassa por discussões mais completas, como das contraposições entre: mediação versus disponibilização e mediação versus colonização. A complexidade amplia a problemática dos impactos que a mediação terá ou deve ou não buscar.

Quando se trabalha o acesso apenas, tem-se o aspecto da disponibilização retomado, voltando-se para a perspectiva de ponte previamente mencionada: a preocupação do profissional seria o propiciar o contato, tendo o receptor a responsabilidade de transcorrer os demais caminhos de construção do conhecimento sozinho. Esse profissional assume a grande preocupação com os formatos padrões e gerais de organização, gestão e atendimento em unidades de informação, passando aos "não usuários" a responsabilidade de não utilizar das disponibilizações expostas, ou seja, aqui uma biblioteca vazia, por exemplo, seria o resultado de um público que não se interessa pelos serviços por ela disponibilizados, e isso se caracterizaria como um problema deles (usuários), e não da biblioteca e seus serviços.

A concepção de mediação enquanto colonização moderna, por sua vez, tem-se mostrado um interessante ponto para discussão em estudos de mediação por ter se mostrado uma ferramenta importante de destruição cultural, intencional ou não. Essa concepção utiliza-se das bases da mediação enquanto processo complexo, porém em uma visão excludente, do "ou" e não do "e" em suas ofertas de serviços e concepções. Isso significa que o que se apresenta é uma imposição de que determinados relacionamentos com a informação são melhores e que por isso precisam ser incorporados em todos os espaços de mediação, ignorando-se as especificidades culturais do ambiente original desses espaços. Isso se torna claro quando é questionado sob a ótica de quem o trabalho é gerenciado, pois normalmente parte-se da concepção de que há uma "cultura melhor", e então desenvolve-se a oferta 
de trabalhos nessa perspectiva, na tentativa de sobrepor a outra cultura (ou seus aspectos) considerados ruins. (OLIVEIRA, 2014).

Culturas têm sofrido com essa sobreposição, e o resultado tem sido a perda de línguas e costumes milenares e, naturalmente, um distanciamento familiar entre jovens e anciãos, no qual importantes aspectos podem ao fim serem lançados ao esquecimento pela corrente do tempo, restando apenas dejetos de uma memória negligenciada. Uma colonização tão cruel quanto as demais, porém aceita e legalizada. (OLIVEIRA, 2014).

A intenção de trabalhos desenvolvidos nesse âmbito costuma ser positiva (assim como as demais), porém podem ser consideradas uma ameaça devido ao seu carácter excludente.

Há de se trazer a necessidade de reflexão sobre quais as preocupações que devem embasar um processo mediador para que ele consiga abarcar a complexidade de seu processo sem cair nas armadilhas da colonização. (MORIN, 2007).

A atuação do profissional da informação abarca diferentes espaços e abrangências, englobando etapas de gestão, organização e compartilhamento de informação em plurais suportes. A mediação da informação tem norteado estudos da área com objetivo de esclarecer complexidades envolvidas no desenvolvimento da atuação desse profissional enquanto mediador. A ética, por sua vez, aparece nesse contexto imersa nas relações sociais então estabelecidas pela profissão.

Tem-se assim a importância da expectativa de apropriação da informação em um processo mediador, ressaltando que esse aspecto apresenta o sujeito que recebe a mediação de forma ativa, em uma posição analítica e crítica, sendo ele mesmo um dos fatores que impactará na informação apresentada, mesmo que não condicionado a significar.

Oliveira (2015, p. 53) ressalta:

No âmbito da apropriação pode-se expor: o viver é o propósito que permeia a busca de significação; o que gera apropriação resulta em ganhos e perdas - a ampliação do conhecimento gera felicidade e descontentamento simultaneamente, já que o resultado é sempre novas lacunas que se abrem com a ampliação de horizontes cognitivos; essas lacunas tornam as batalhas recorrentes, numa guerra infinda, já que o próprio ser humano é infindo; quando estagnado na concepção de vida, as batalhas por conhecimento se tornam desnecessárias e/ou se algum dado não faz parte de seus 
propósitos ou anseios, muitas vezes acaba por passar despercebido, perdida na primeiridade.

Essa preocupação com a apropriação que possibilita a abertura de novas lacunas proporcionará ao profissional da informação a real postura mediadora, e tal atuação volta-se de modo consciente nos âmbitos social e ético da profissão pois demonstra uma atuação consciente e abrangente.

Porém, a possibilidade de apropriação é suficiente para um impacto positivo na vida das pessoas? Seria essa a lacuna para o seu desenvolvimento?

Partimos aqui da ideia de que a apropriação da-se não só de maneira consciente, mas de maneira inconsciente. A não apropriação, a ausência de apropriação, quer consciente ou inconsciente, vincula-se a um não sujeito informacional. O sujeito que se relaciona com a informação pode ser um sujeito real, quando se apropria da informação (sempre de maneira parcial, uma vez que a informação está em constante construção e recebendo significados, também de maneira constante); pode ser um sujeito em potencial, quando seu repertório de experiências e conhecimentos the permite uma apropriação limitada; e, como visto, pode ser um não sujeito informacional, aquele que, por vários problemas e obstáculos, quer físicos ou não, quer educacionais ou culturais, é impossibilitado de se apropriar da informação.

A informação causa conflitos informacionais, conflitos do conhecimento da pessoa. Tais conflitos geram, necessariamente, uma desestabilização das certezas presentes no sujeito informacional, levando-o a buscar novas explicações para o mundo, novas formas de olhar e entender o mundo, os outros e a si mesmo. O impacto positivo da apropriação da informação é a exigência de uma reestruturação do conhecimento individual desse ser informacional. Qualquer desenvolvimento - e isso abarca também, em nível micro, o sujeito - só se concretiza no conflito.

Atualmente vê-se a necessidade de exploração de mais um ponto: a ética. Vive-se no Brasil e em grande parte do mundo uma crise ética onde o uso da informação apropriada encontra problemas - ou não se pode usá-la por impedimento ético da sociedade, ou se a usa de forma antiética.

Barquero (2011) expõe 3 pontos importantes para a mediação no contexto pedagógico: ética, psicológico e ecologia. $\mathrm{O}$ autor explora que a ética se faz 
clara nesse processo porque "sem um reconhecimento pleno do outro [...] nenhuma mediação estará completa" (BARQUERO, 2011, p. 172, tradução nossa ${ }^{8}$ ) e, traz a concepção da empatia enquanto fator impactante do psicológico no processo mediador, fundamentando-se na complexidade do ser humano exposta por Morin.

A ética representa então a capacidade de "ver o outro", se centra no mediando, no que, para a Ciência da Informação figura o apropriar-se. Barquero ressalta a importância das consequências da ação do mediador sobre o outro: "[...] quando se trata de relacionamentos entre pessoas, todos os nossos atos contam, e até mesmo o menor deles, como um olhar fugaz de reprovação, por exemplo, pode fazer a diferença." (BARQUERO, 2011, p. 174, tradução nossa ${ }^{9}$ ).

A empatia, por sua vez, abarca a "experiência do holístico":

[...] pela empatia sinto que sou vida, vida que vive na vida, que nada me separa da árvore que é vida, do rio que é vida, do pássaro que é vida, que sou um com o pássaro, com o rio, com a árvore, e que quando eu digo eu é o mesmo que se dissesse nós. É uma questão de nos abrir. Nos abrir para ver, para ouvir, para tocar, para sentir. Se nos abrimos, a empatia, que é meio e fim ao mesmo tempo, é nutrida com cada ato da vida. (BARQUERO, 2011, p. 174, tradução nossa ${ }^{10}$ ).

$E$, finalmente, no âmbito da questão ecológica, o autor esclarece que "[...] trata-se de buscar sempre as relações e inter-retro-ações entre todo fenômeno e seu contexto, as relações recíprocas entre o todo e as partes: como uma modificação local afeta o todo e como uma modificação do todo afeta as partes." (BARQUERO, 2011, p. 174, tradução nossa ${ }^{11}$ ). Nesse aspecto a complexidade de Morin aparece, na perspectiva de um "contexto planetário":

Ao mesmo tempo, trata-se de reconhecer a unidade dentro do diverso, o diverso dentro da unidade; reconhecer, por exemplo, a unidade humana através das diversidades individuais e culturais; as

\footnotetext{
${ }^{8}$ Texto original: "sin un reconocimiento pleno del otro [...] ninguna mediación va a estar completa".

${ }^{9}$ Texto original: "cuando de relaciones entre personas se trata, todos nuestros actos cuentan y hasta el más pequeño, una fugaz mirada de reprobación, por ejemplo, puede marcar la diferencia."

${ }^{10}$ Texto original: "[...] por la empatía siento que soy vida, vida que vive en la vida, que nada me separa del árbol que es vida, del río que es vida, del pájaro que es vida, que soy uno con el pájaro, con el río, con el árbol y que cuando digo yo es lo mismo que si dijese nosotros. Es cuestión de abrirnos. Abrirnos para ver, para escuchar, para tocar, para sentir. Si nos abrimos, la empatía, que es medio y fin a la vez, se nutre con cada suceso de la vida."

${ }^{11}$ Texto original: "[...] se trata de buscar siempre las relaciones e inter-retro-acciones entre todo fenómeno y su contexto, las relaciones recíprocas entre el todo y las partes: cómo una modificación local repercute sobre el todo y cómo una modificación del todo repercute sobre las partes."
} 
diversidades individuais e culturais através da unidade humana. (BARQUERO, 2011, p. 175, tradução nossa ${ }^{12}$ ).

Claro que a ética, quando apoiada na capacidade de "ver o outro", de "entender o outro", vive, por um lado, com a busca, a procura, a tentativa de olhar esse outro em sua plenitude e, por outro, com a impossibilidade de que esse "entender o outro" em sua plenitude de fato possa se realizar. O diálogo, mesmo que sem a presença física dos sujeitos, ameniza essa impossibilidade. A ética nos espaços da informação deve considerar os personagens do processo de apropriação da informação como seres plenos, que carregam para a interação todo seu acervo de conhecimentos e experiências, suas vivências, seus modos de ver, entender e explicar o mundo, e isso torna a ética sempre um passo além da possibilidade de se dominá-la.

Os 3 pontos levantados pelo autor demonstram a complexidade da dialogia do processo mediador que, ancorado no Ser enquanto receptor do ato de mediar, não pode desconsiderar os diferentes aspectos que compõem a existência do Ser-no-mundo.

Essa dialogia se manifesta porque

Toda experiência humana é dependente das práticas de comunicação, como também da transmissão cultural, que constituem o locus da mediação, envolvendo um processo de compartilhamentos objetivo e intersubjetivo por meio dos quais os sujeitos envolvidos nesse compartilhamento sempre geram significações. Por esta razão a ação mediadora é compreendida como uma ação essencialmente pautada na dialogia. Ainda que na ação mediadora estejam envolvidos sujeitos cujo grau de clareza acerca do processo limite essa compreensão e também o sucesso da ação, a dialogia sempre estará presente. (GOMES, 2014, p. 47).

Nesse amplo contexto, o mediador da informação depara-se com questionamentos como: Há informação ruim, "desinformação", ou informação falha? Como mediar informação de forma ética e quais as implicações disso?

Conforme destacado por Gomes, os estudos em Ciência da Informação

\footnotetext{
12 Texto original: "Al mismo tiempo, se trata de reconocer la unidad dentro de lo diverso, lo diverso dentro de la unidad; reconocer, por ejemplo, la unidad humana a través de las diversidades individuales y culturales; las diversidades individuales y culturales a través de la unidad humana."
} 
[...] têm se ocupado da abordagem conceitual, dos fundamentos teóricos, do delineamento dos tipos de mediação, das categorias de atividades de mediação e do papel mediador do profissional da informação. $O$ tratamento dos últimos dois tópicos, em especial, parece convocar a comunidade da área ao enfrentamento de novos desafios para que se possa fazer avançar a formação dos profissionais da área, focalizando certas particularidades da ação mediadora. (GOMES, 2014, p. 47).

Essa nova abordagem de estudo, ainda segundo a autora supracitada

[...] ganha revelo um objetivo implícito da mediação da informação: o desenvolvimento do protagonismo social. Por outro lado, ao se compreender a mediação como uma ação voltada ao protagonismo, até mesmo por ser dependente do processo dialógico como método possível para o estabelecimento da aproximação de pólos, observase que o sucesso da ação mediadora é também dependente do nível de concientização do agente dessa ação quanto ao seu próprio papel protagonista. O profissional da mediação da informação age, constrói e interfere no meio, portanto, é também um protagonista social, e nessa condição se constitui em sujeito da estética, da ética e da produção humanizadora do mundo. (GOMES, 2014, p. 47).

O mediador consciente de seu impacto busca então a tratativa informacional de forma ética, com objetivos de ajudar a sociedade que anseia por conhecimento.

Acerca do conceito de informação, Rockembach esclarece:

Habitualmente, a informação é somente retratada pelo seu aspeto positivo, onde está ligada diretamente a construção de conhecimento e saber humano. Entretanto, outros aspetos são igualmente importantes, como quando a informação gera uma apreensão manipulada da realidade consensual, de forma intencional (desinformação ou disinformation) ou não intencional (falha na informação, ou misinformation). (ROCKEMBACH, 2012, p. 31).

O autor expõe assim que a informação também pode possuir caracteríticas identificadas como desinformação ou informação falha, podendo ser utilizada de forma manipulada (intencionalmente ou não) negativamente.

Segundo Floridi (1996), a desinformação ocorre quando há falta de objetivo, completude ou pluralismo, de forma combinada ou não, e que no ambiente da Internet a possibilidade da desinformação é ampliada pela facilidade e velocidade da criação de documentos, ressaltando que a gestão da informação é sempre passível de influência nesse processo. 


\section{Esponda explora que:}

A ética profissional estuda as normas e a conduta moral do homem no exercício de sua profissão, as quais devem embasar-se em princípios básicos de responsabilidade e em códigos de valor, que embora não estejam registrados regem as diretrizes a serem seguidas. O campo das ciências da informação, por abranger disciplinas cuja prática é uma tarefa destinada a favorecer o desenvolvimento humano individual e coletivo através de seu objeto de estudo; obriga a relação direta com as pessoas, portanto, não pode ignorar a ética como teoria ou ciência do comportamento moral do homem. (ESPONDA, 2013, sem paginação). ${ }^{13}$

Portanto, pela característica de proximidade da Ciência da Informação com o desenvolvimento humano, o que estabelece, segundo o autor supracitado, uma obrigatória relação direta, a ética apresenta-se como uma importante base na atuação profissional da informação que objetiva evitar a desinformação e/ou o compartilhamento de informações falhas, principalmente num contexto de grande imersão em ambientes web que maximinalizam essas ocorrências.

No âmbito da mediação de leitura faz-se pertinente entender também as características amplas que podem ser encontradas no processo de ler, perpassando por uma leitura contextual de acontecimentos, trazendo a inclusão do contexto do mundo dos eventos na construção da significação do leitor, na qual os "sinais" podem ser lidos a partir de um aprendizado muitas vezes resultante do próprio envolvimento social, como os ensinamentos passados por gerações familiares.

A clareza quanto a abrangência das possibilidades de leitura expressas, que perpassam a natureza da leitura do texto escrito expõe que o contato com o texto escrito não abarca todo o processo de leitura, mas sim que esse processo, em sua complexidade, tem etapas de uma leitura de mudo que o antecede e que impacta na significação do leitor sobre o texto.

Assim, Oliveira (2015, p. 71) ressalta que "A mediação da leitura analisa as opções do leitor, seu conhecimento adquirido em vivências ou estudo, bem

\footnotetext{
${ }^{13}$ Texto original: La ética profesional estudia las normas y la conducta moral del hombre en el ejercicio de su profesión, las cuales deben estar fundadas en principios básicos de responsabilidad y en códigos de valor, que aunque no estén escritos rigen pautas a seguir. El campo de las ciencias de la información, por abarcar disciplinas cuya práctica es un quehacer destinado a favorecer el desarrollo humano individual y colectivo a través de su objeto de estudio; obliga a la relación directa con las personas, por tanto, no puede estar ajena a la ética como teoría o ciencia del comportamiento moral del hombre.
} 
como sua imersão em diferentes mídias, procurando chegar ao seu principal objetivo - a apropriação da informação [...]".

O processo de mediar a leitura configura então uma atuação mediadora do profissional da informação que carrega, como objetivo implícito da área, a oportunidade de atuar no contexto social, e que pode exercer um impacto positivo se construído em conformidade com a ética profissional.

Se a mediação da leitura só acontece quando é realizada visando a apropriação, que por sua vez impactaria na construção do conhecimento e, além dessa face encontramos a expressão de um outro lado da moeda - a desinformação ou falha na informação, que também será apropriada, é necessário que se reanalise as abordagens desse material compartilhado pelo viés ético.

A mediação ética da leitura implica, portanto, o reconhecimento do impacto pessoal no processo mediador, e o reconhecimento de que a informação pode ser manipulada. Essa ciência, atrelada ao comprometimento ético da profissão, pode ser o caminho para atenuar a mediação da desinformação ou informação falsa.

Ao proporcionar a mediação da leitura considerando fatores éticos o profissional traz a perspectiva social para primeiro plano, ampliando a abordagem da apropriação em consonância à complexidade desse processo dialético.

O mediar a leitura eticamente deve pautar-se em projetos a serem desenvolvidos em concordância com diferentes realidades em que se buscará atuar, dirimindo conceitos de atividades e materiais massificados e com consciência de que a mediação trará um impacto, uma consequência e que, por isso, deve-se desenvolver este trabalho com responsabilidade, consciência e respeito.

O desconsiderar desses aspectos pode resultar em uma tentativa de sobreposição cultural - anular uma cultura anterior por uma outra que o profissional julga superior ou melhor. Tal afirmação pode parecer radical, porém utilizar qualquer outra abordagem seria um eufemismo da mesma realidade, afinal, o que é a promoção da cultura escrita de forma massificada senão um colonizar de que o acesso a escrita, por si só, é o fim do trabalho e o suficiente para compor ambientes culturalmente igualitários? Essa massificação se pauta no discurso hegemônico de que o acesso deve ser promovido, e o que o indivíduo faz com esse acesso não é mais responsabilidade do profissional da informação pois as condições serão então igualitárias e, portanto, dependentes de meritocracia. Tal postura pode ser 
considerada antiética por desconsiderar o sujeito e sua realidade, bem como o impacto do processo mediador.

No trabalho mediador de leitura há de se trazer diferentes vertentes para a construção de significado, e então explorar diferentes formas de atuação que complemente, por exemplo, uma cultura atual imersa também em redes de computadores nos quais "a todo instante são incluídas vozes com narrativas" e que perpassam por "cenas coletivas" de oralidade que formam uma "cadeia de voz" manifestada coletiva e espontaneamente. (BORTOLIN; ALMEIDA JÚNIOR, 2014, p. 187).

Uma inquietação resultante deste trabalho diz respeito a necessidade de dar um outro nome à informação quando essa assume um contexto negativo quando há a necessidade do uso de outro termo para designar esse conceito assumese então uma negação da negatividade dele? A informação seria então apenas boa? Já que quando se lhe é atribuída a negatividade se agrega a ela uma outra denominação, pode-se questionar: o que há de informação na desinformação ou na informação falha? 


\section{FENOMENOLOGIA DA MEDIAÇÃO}

Observou-se, após a junção das análises e construções dos metatextos expostos no capítulo 4 , que os estudos de mediação demonstram focos diferentes, porém estabelecem relações claras.

Os trabalhos ancorados nas teorias dos três autores investigados (Hegel, Marx e Vygotsky) trazem o foco do conceito da mediação ao desenvolvimento no âmbito imaterial da consciência e do processo cognitivo humano, atribuindo à mediação uma potencialidade em atingir transformação, evolução e/ou superação, ressaltando a importância de espaços sociais (mesmo que em diferentes perspectivas), da apropriação, e dos impactos recíprocos ou reflexivos materiais da mediação (também com diferentes abordagens).

Mantêm-se, assim, e a partir da tríade teórica norteadora básica elencada, o ressaltar de que a mediação se ancora na busca do impacto no desenvolvimento humano, e que esse desenvolvimento é dependente de interações espaço sociais, e que também é reflexivo.

Assim, suspendendo aspectos que independente do contexto surgiriam (como por exemplo influências anteriores e/ou externas ao processo e interferências por sua inerência), e sem analisar aspectos subjetivos (como bem/mal e positivo/negativo), identificou-se essencialmente um processo que exige uma interação entre ao menos dois seres, e um fator de impacto sobre ao menos um deles, com reflexão material. Observa-se que é um fenômeno essencialmente humano, ancorado em aspectos sociais.

Dentro dos padrões situados, alguns questionamentos foram então elencados e respondidos:

1. Se retiramos o mediador, como pessoa que conscientemente busca um impacto em outro a mediação ocorre? Não.

2. Se retiramos o mediador, materialmente junto ao outro, o processo ainda ocorre? Sim.

3. Se retiramos a intencionalidade no impacto no desenvolvimento humano, o processo ainda ocorre? Não. 
Reaproximando os fatores essenciais com as possíveis subjetividades, na construção inversa que não desconsidera a essência, e aliada à aspectos materiais de apoio à mediação (tecnologias), pode-se desenhar as seguintes possibilidades de interação dentro da concepção geral de mediação:

Figura 1: Mediação natural.

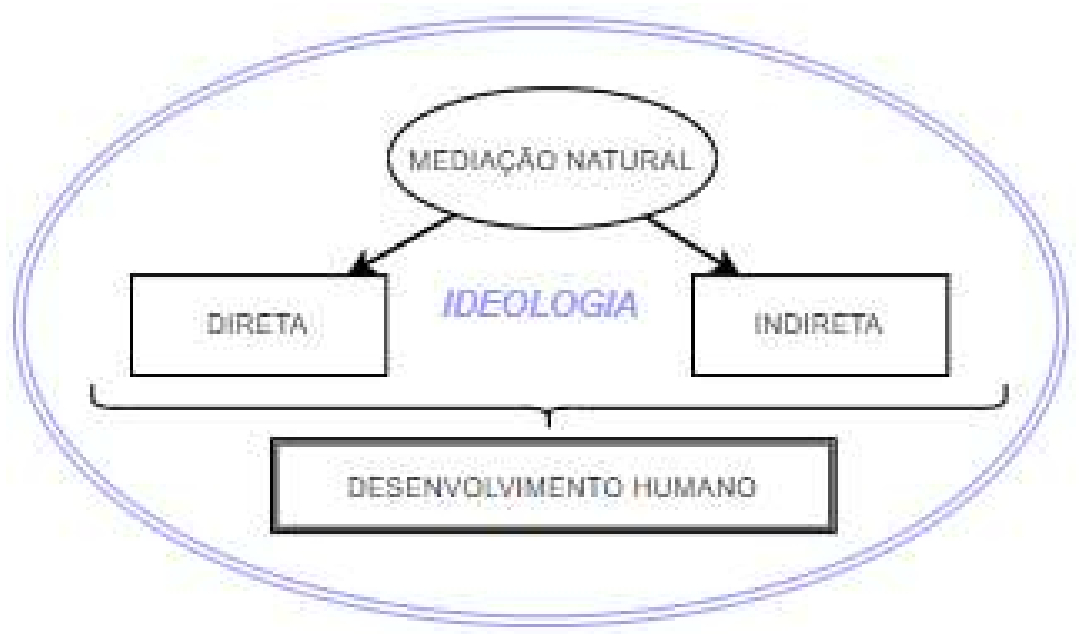

Fonte: elaborada pela autora.

A mediação, porquanto, se diferenciaria do processo de comunicação habitual especialmente por sua complexidade que envolve o impacto que busca exercer no desenvolvimento humano, na "espera" de um resultado específico, e não uma "transmissão" padrão comunicacional, cujo esquema seria, como no modelo de Shannon, a relação de transmissão de uma mensagem entre fonte/transmissor/receptor/destino, com uma preocupação ancorada no recebimento da mensagem propriamente, ainda que passível de análises de fatores externos, ruído etc. Esse salto de complexidade se materializa, seja na expressão social, seja na construção do conhecimento que modifica os envolvidos.

A figura visa explicitar que todo o processo se desenha no viés ideológico que permeia a sociedade na qual ele existe. Num primeiro momento espera-se a inclusão de aspectos que identificaríamos como natural (para interações habituais de relacionamento humano) e artificiais (para interações construídas, com uso de tecnologias), mas essa polarização foi considerada complementar e não exatamente determinante no âmbito da essência do fenômeno, podendo ser incluída em aspectos externos de apoio ao processo pois, ainda que fortemente impactantes, não determinam a possibilidade do mesmo. 
Os aspectos de ocorrência direta (no âmbito de interrelação pessoal entre todos os seres envolvidos) ou indireta (quando essa interrelação não acontece) foram incluídos como determinantes porque, diferentemente do natural/artificial, estaria imerso em todos os processos de mediação, uma vez que sempre haverá a possibilidade de imaterialidade no contato entre seres mediador/leitor, independentemente das questões materiais que permeiam a sociedade em questão, e levando em consideração que esse aspecto se repete e não o condiciona, ainda que seja necessário já que a existência do mediador consciente em um plano de fundo foi considerado o principal ponto, e não sua posição física propriamente. O processo, independentemente do "caminho" percorrido, culminaria no desenvolvimento humano (aqui exposto em aspecto neutro quanto a valoração desse impacto frente ao indivíduo e/ou sociedade), e ocorre dentro de aspectos ideológicos do espaço socio-temporal no qual se desenvolve e, por isso, optou-se pelo uso do termo leitor, enquanto exposição da característica construtiva cognitiva expressa no ser "foco", por assim dizer, do processo.

O processo seria dependente do contexto humano, um fenômeno essencialmente humano e, portanto, impossível de existir a partir de uma concretude antropomórfica, porém sem necessidade de contato imediato com o iniciador do processo, isso é - é possível que o mediador não esteja presente durante o processo, mas não é possível que o processo ocorra sem o mediador.

Espera-se que o aspecto da inconsciência pudesse ser inserido no esquema, porém, o caráter da intencionalidade que o conceito de inconsciência carrega fez com que ele precisasse ser excluído das possibilidades de interação já que, sempre que não há a intenção, várias complexidades que culminariam no objetivo de impacto definido na relação se anula ou se condiciona ao acaso - aspectos que não se buscava evidenciar.

Num exemplo prático e simplista desse aspecto excluído, analisou-se que seria como um fenômeno de "exercício versus alteração na forma física": uma pessoa que inicia uma rotina de exercícios buscando uma alteração na forma física passa por etapas e influências de rotinas complementares para conseguir ver, de forma material e inegável, uma alteração nesse corpo; já no caso de uma pessoa cuja rotina de exercícios tenha outro objetivo (como uma mudança de rotina, saúde ou ampliação de interações sociais), ainda é possível inferir que ocorrerão alterações nesse corpo, mas já não no mesmo âmbito do fenômeno anterior, já que nesse caso 
não se buscava a evidência ou potencialidade desse resultado, deixando-o ao acaso e não como aspecto determinante - a pessoa seguiria com a rotina ainda que não fosse possível uma identificação da mudança corporal expressiva.

Quando o foco do estudo é direcionado para o campo da Ciência da Informação, e atendo-se à mediação da informação como processo complexo, dentro da perspectiva da relação Informação e Sociedade, apresenta-se uma possível exploração do conceito englobando 4 aspectos principais: mediador, protoinformação, forma e leitor, didaticamente aqui representados nessa ordem, mas não se prendendo a ela em um processo linear propriamente, ou seja, na prática a ordem dos fatores pode variar e repetir-se. Esses 4 aspectos podem ser explicados/justificados como:

1. O termo mediador, para a Ciência da Informação, carrega em si a intencionalidade de exprimir que a mediação constitui uma ação intencional, que ele tem um norteador, e que não pode ser considerado imparcial pois todo agente não pode se dissociar de sua existência enquanto exerce suas atividades profissionais, nem uma instituição pode se dissociar de suas bases culturais, metas e objetivos. Esse profissional pode atuar em diferentes unidades informacionais, e em diferentes setores. A mediação da informação não se prende a setores de atendimento, mas está presente em todas as fases e setores da organização. (OLIVEIRA, 2015; ALMEIDA JÚNIOR; BORTOLIN, 2008).

2. O termo protoinformação visa sinalizar a importância da apropriação, já que se considera nesse processo que a informação só é informação no momento da apropriação, ou seja, ela se mostra dependente do sujeito e só é assim categorizada (consciente ou inconscientemente) por ele e, portanto, só é possível o trabalho com protoinformações, quais sejam dados consideráveis passíveis de apropriação, de significação. (ALMEIDA JÚNIOR, 2007);

3. O termo forma não se prende a questões materiais, mas sim expressa a forma assumida pela mediação, com base na relação protoinformação-leitor que se objetiva, podendo ser expressa em inúmeras variações como, por exemplo, um livro, uma oralidade, um sistema, uma interface, uma apresentação teatral, um prédio, um móvel, etc. O mediador analisará qual a melhor forma que deverá utilizar para promover protoinformações a seus leitores. 
4. Finalmente, a escolha do termo leitor em substituição a outros mais comumente utilizados na área, como usuário ou frequentador, visa ressaltar que a leitura em sua complexidade está intrinsicamente relacionada à existência humana, não sendo passível, portanto, a ideia de "não leitores", mas sim leitores de diferentes suportes e aspectos do mundo. Quando uma pessoa tem contato com a forma expressa da mediação, faria então sua leitura, meio pelo qual pode ou não ocorrer a apropriação; a leitura seria então o momento de avaliação e apropriação ou refutação. (OLIVEIRA, 2015).

O entendimento do envolvimento desses quatro pontos de base da mediação da informação na atuação do profissional da área esclarece a abrangência da necessidade de estudos do tema, para que então a prática de mediar possa ser consistente e responsável, pois os pontos perpassam todas as esferas de atuação, e cada um desses aspectos precisam ser considerados na complexidade que carregam.

A falta de diálogo e valorização de todos os aspectos apresentados enquanto complementares justifica porque é tão difícil que a mediação da informação possa ser colocada em prática ética e eficientemente. $\mathrm{O}$ mais comumente apresentado são abordagens que priorizam um ou alguns desses aspectos, deixando uma lacuna que pode resultar em problemas como falta de público em unidades informacionais, baixa abrangência ou aspectos de colonização. (OLIVEIRA, 2014; OLIVEIRA, 2015).

Um exemplo prático são centros culturais que, na perspectiva dos profissionais que os planejam e gerenciam, oferecem amplas e modernas bibliotecas, com acervos diversificados e sedutores, e que na prática ficam sem acesso, o que pode ser um indício de que houve uma desconsideração das características culturais das sociedades que desejam atender, bem como da necessidade de adaptação de serviços para tais leitores. Retoma-se aqui a questão: sob a ótica de quem o serviço é oferecido? (OLIVEIRA, 2014).

Quando se desconsidera a intencionalidade e influência por traz do objetivo da mediação fica mais difícil controlar o quanto esses aspectos influenciarão no resultado. Assumir que o mediador possui impacto, possui subjetividade, o auxilia a lidar com isso, tentando buscar a neutralidade conscientemente em sua atuação. (ILHARCO, 2003).

Quando se entende o mundo do leitor e tenta-se estabelecer uma negociação entre as culturas envolvidas, num processo construtivo e não de exclusão, 
têm-se a possibilidade de trabalhar a mediação em sua ampla complexidade e ética, criando novos significados e aprendizagens para a área da Ciência da Informação e para a Sociedade, numa construção significativa entre teoria e práxis. (OLIVEIRA, 2014; OLIVEIRA, 2015).

O processo de mediar a leitura escrita nesse âmbito, por exemplo, pode significar a inclusão de pessoas no reconhecimento da leitura escrita como processo habitual, aceitável, e não em sobreposição aos que já utiliza (como a oralidade), a ponto de tal hábito (escrita) ser incorporado culturalmente, tornando-se uma mediação natural, ou seja, o antes leitor que não tinha contato com a leitura escrita pode se tornar o novo mediador de leitura, pois ele poderá entender a importância de ambos os aspectos em sua vida (oralidade e escrita) e, principalmente, que um não deve se sobrepor ao outro, mas complementar-se, podendo então replicar essa nova "realidade" para outros envolvidos em seu círculo social. (SETZER, 2001; BORTOLIN, 2010; FREIRE, 2005; ALMEIDA JÚNIOR, 2007).

A mediação da informação, em sua complexidade, não possui um fim propriamente, e por isso a simples ideia de transposição precisa ser questionada, pois seu objetivo na apropriação da informação e construção do conhecimento segue caminhos pela busca de um pensamento complexo, iniciando uma corrente de novos questionamentos, e não finalização de questionamentos - é um descobrir e ampliar, e não um simples questionar e responder. 


\section{EDUCAÇÃO E INTERCULTURALIDADE}

Quando ressaltamos a necessidade de a mediação preocupar-se com a apropriação para a construção de conhecimento, falamos de um impacto além do âmbito cognitivo - falamos de um impacto cultural, já que a construção de conhecimento se dá de maneira intrínseca à realidade do ser enquanto ser inserido em sociedade.

Os estudos culturais assumem diferentes contextos nos estudos atuais e, especialmente no mundo globalizado, suas concepções complexas de embates, miscigenação, multiculturalidade e interculturalidade vêm sendo trazidos para essa discussão.

Os contextos de dominações territoriais, colonizações e globalização, entre outros, foram criando sociedades construídas e desenvolvidas em diferentes contextos temporais, porém tentando, ao mesmo tempo, igualar-se nesse âmbito. Os tempos de transposição modernidade-pós-modernidade deixam claro esse problemático ser num ser amplo que nos foi imposto com os fenômenos de aproximação desaproximada e hierárquica entre nações e povos.

Canclini ressalta que, nesses contextos contraditórios, assim como não funciona uma "oposição abrupta entre o tradicional e o moderno" também há conceitos como culto, popular e massivo que precisam ser desconstruídos, e que é necessário averiguar uma maneira conjunta de disciplinas que possam observar a "heterogeneidade multitemporal de cada nação", redesenhando planos de comunicação. (CANCLINI, 1989).

Os status de culto, popular e massivo são socialmente construídos e costumam protagonizar marginalizações em ambientes micro e macro, sem muitas vezes ter nenhuma aplicação factual passível de incorporação em determinadas culturas - o que vale mais: a arte de um pintor europeu, com suas tecnologias técnica e tintas, exposto em um museu, ou uma pintura realizada nos corpos de indígenas que neste momento fazem um ritual? São valores completamente distintos, cuja comparação, além de nula, é desnecessária, já que ambos expõem um contexto histórico-social complexo único, independente e rico em sua própria existência. 
Compartilha-se da visão de Geertz que apresenta o ser humano como:

[...] um animal amarrado a teias de significados que ele mesmo teceu, assumo a cultura como sendo essas teias e a sua análise; portanto, não como uma ciência experimental em busca de leis, mas como uma ciência interpretativa, à procura do significado. É justamente uma explicação que eu procuro, ao construir expressões sociais enigmáticas na sua superfície. (GEERTZ, 2003, p. 4)

Num emaranhado de significados, resultante do encontro das muitas teias existentes, a ciência interpretativa busca atos simbólicos que possibilite uma análise de discursos sociais, investigando a "importância não-aparente das coisas". (GEERTZ, 2003, p. 18).

A educação numa perspectiva humanizadora, que carrega em si a preocupação com a apropriação e que tem como alicerce expressões de amor, amorosidade, fé, esperança, desenvolvimento do pensamento crítico, entre outros aspectos abordados nos livros A Pedagogia da Autonomia, Pedagogia da Autonomia, e outros de Paulo Freire, apresenta-se escassa em nossos dias, com o agravar de uma perspectiva de aplicação ainda aprisionada na atual situação conturbada, política e economicamente.

Os que encontram a inquietação de nações mais justas e igualitárias vislumbram que em algum momento será possível que a educação seja amplamente difundida em todo seu potencial libertador, tão profundamente explorado por Paulo Freire, que também ressalta que "a história é tempo de possibilidade e não de determinismo, que o futuro [...] é problemático e não inexorável” (FREIRE, 2013, p. 20).

A agenda 2030 da Organização da Nações Unidas, ciente dessa realidade coloca, junto a outros objetivos, o objetivo sustentável 4 Educação de Qualidade, que explora a necessidade de "Garantir o acesso à educação inclusiva, de qualidade e equitativa, e promover oportunidades de aprendizagem ao longo da vida para todos". Dentro desse ponto encontramos as seguintes metas, a serem alcançadas até 2030:

$4.1[\ldots]$ garantir que todas as meninas e meninos completem o ensino primário e secundário livre, equitativo e de qualidade, que conduza a resultados de aprendizagem relevantes e eficazes 
4.2 [...] garantir que todos as meninas e meninos tenham acesso a um desenvolvimento de qualidade na primeira infância, cuidados e educação pré-escolar, de modo que eles estejam prontos para o ensino primário

$4.3[\ldots]$ assegurar a igualdade de acesso para todos os homens e mulheres à educação técnica, profissional e superior de qualidade, a preços acessíveis, incluindo universidade

4.4 [...] aumentar substancialmente o número de jovens e adultos que tenham habilidades relevantes, inclusive competências técnicas e profissionais, para emprego, trabalho decente e empreendedorismo

4.5 [...] eliminar as disparidades de gênero na educação e garantir a igualdade de acesso a todos os níveis de educação e formação profissional para os mais vulneráveis, incluindo as pessoas com deficiência, povos indígenas e as crianças em situação de vulnerabilidade

4.6 [...] garantir que todos os jovens e uma substancial proporção dos adultos, homens e mulheres estejam alfabetizados e tenham adquirido o conhecimento básico de matemática

4.7 [...] garantir que todos os alunos adquiram conhecimentos e habilidades necessárias para promover o desenvolvimento sustentável, inclusive, entre outros, por meio da educação para o desenvolvimento sustentável e estilos de vida sustentáveis, direitos humanos, igualdade de gênero, promoção de uma cultura de paz e não violência, cidadania global e valorização da diversidade cultural e da contribuição da cultura para o desenvolvimento sustentável

4.8 Construir e melhorar instalações físicas para educação, apropriadas para crianças e sensíveis às deficiências e ao gênero, e que proporcionem ambientes de aprendizagem seguros e não violentos, inclusivos e eficazes para todos

4.9 [...] substancialmente ampliar globalmente o número de bolsas de estudo para os países em desenvolvimento, em particular os países menos desenvolvidos, pequenos Estados insulares em desenvolvimento e os países africanos, para o ensino superior, incluindo programas de formação profissional, de tecnologia da informação e da comunicação, técnicos, de engenharia e programas científicos em países desenvolvidos e outros países em desenvolvimento

$4.10[\ldots]$ substancialmente aumentar o contingente de professores qualificados, inclusive por meio da cooperação internacional para a formação de professores, nos países em desenvolvimento, especialmente os países menos desenvolvidos e pequenos Estados insulares em desenvolvimento (ONU BRASIL, 2020, não paginado, grifo nosso).

Os pontos em destaque na citação são considerados importantes no contexto do desenvolvimentos dessa tese: a necessidade de garantia não apenas a determinado nível, mas a todos os níveis de formação para grupos vulneráveis; a 
relação da valorização da diversidade cultural, assim como a preocupação com o cultura de paz e não-violência, como impactantes diretos no desenvolvimento sustentável; a importância do espaço físico reafirmando e transparecendo as concepções de segurança, não-violência e inclusão; e a necessidade de atenção à formação especializada de professores.

E quais são as expectativas reais de aproximação ao cumprimento das metas no que tange à educação mundial? É importante ressaltar que a agenda faz uma grande aproximação dos objetivos com a superação da pobreza, isso porque a maioria dos desafios estão mais longe de superação quando traçamos a relação econômica envolvida.

É muito difícil falar de marginalização sem relacioná-la com a pobreza. Voltando-se ao ponto educacional, foco deste capítulo, pode-se ressaltar alguns dados gerais, como a avaliação das Nações Unidas (2019) que relataram que 55\% das crianças e adolescentes ainda não alcançaram as competências mínimas em leitura e matemática - sendo que dentro desse número há $1 / 3$ sem escolarização e 2/3 escolarizados porém sem conseguir o desenvolvimentos das competências mínimas dentro do aprendizado. A proporção desse desequilíbrio atinge $14 \%$ da Europa e América de Norte, contra uma média de mais de $80 \%$ para a população da África Subsaariana e Ásia Central e Meridional. (GARRIDO-RODRÍGUEZ, 2020).

Tem-se o registro de 262 milhões de crianças e adolescentes (entre 6 e 12 anos) ainda sem escolarização - número que equivale a 1/5 da população mundial dessa faixa etária. As cifras seguem incompatíveis com os objetivos de desenvolvimento justo, ampliando-se a todas as faixas etárias e níveis educacionais. Quando se analisa a situação de adultos, têm-se a cifra alarmante de que $75 \%$ das pessoas não alfabetizadas encontram-se concentradas em duas regiões do mundo: Ásia Meridional e África Subsaariana, sendo que os países considerados desenvolvidos concentram $5 \%$ da cifra mundial. Também, ainda que se encontre um aumento expressivo na alfabetização de mulheres nos últimos 25 anos, 2/3 das pessoas sem escolarização são mulheres. (GARRIDO-RODRÍGUEZ, 2020).

Outros informes, como o Informe Mundial da Infância (2019), também apresentam dados que demonstram o quanto estamos distantes da equidade educacional. Isso faz com que se considere que a taxa global de não escolaridade seja considerada inacessível e incomparável com os objetivos de um desenvolvimento justo, equitativo e sustentável que a Sociedade Internacional propôs como meta. Um 
aspecto prático de limitação que possa justificar esse contexto abismal são aspectos práticos de carência de infraestrutura, meios e instalações. Por exemplo, na África Subsaariana mais da metade das escolas de ensino primário e secundário tem acesso à água potável, energia elétrica, computadores e internet. (GARRIDO-RODRÍGUEZ, 2020).

A problemática do desequilíbrio econômico mundial, sem a necessidade de aqui explorarmos suas origens e desenvolvimentos, impactam não apenas nessa relação incomparável entre países, como também na própria ampliação da diversidade cultural na medida em que, em busca de uma libertação de um contexto sem expectativa, movimentos migratórios são impulsionados em busca de melhores condições de presente e futuro.

O frequente problematizador da escola enquanto facilitador de uma cultura intolerante mostra ainda mais a urgência da necessidade dessa reformulação no sistema de educação. É cada dia mais comum encontrar relatos de livros, trabalhos, abordagens de educadores, atividades, etc. que expõem crianças e jovens a um ambiente hostil, que naturaliza preconceitos e que, com a proteção da lei, continuam a ser reproduzidos no ambiente escolar mesmo após essas denúncias, numa mensagem clara de que ainda não há medidas realmente corretivas e impactantes desses aspectos de propagação de uma cultura intolerante no contexto da educação em muitos países. O resultado têm sido uma população que demonstra posturas de ódio, violência, intolerância, entre outros aspectos negativos, gerando também uma grande defasagem de alunos que são então vítimas diretas desse sistema intolerante (como gays, transexuais, negros, indígenas, quilombolas, imigrantes, e demais grupos negligenciados pela educação formal).

Garrido-Rodríguez (2019, p. 3) alerta para que, ainda que se reconheça o direito dos alunos em serem educados em condições de igualdade, essas condições só seriam possíveis se partíssemos de uma "integração educativa e social real", englobando medidas nos dois âmbitos. O autor esclarece que "a integração é fundamental na educação" assim como "a educação integral, inclusiva e de qualidade é fundamental na também para a integração". ${ }^{14}$

\footnotetext{
${ }^{14}$ Texto original: “[...] la integración es fundamental en la educación y al contrario, la educación integral, inclusiva y de calidad es fundamental también para la integración. [...]"
} 
Analisando o contexto Espanhol educacional e grupos imigrantes (grupo que fez parte de uma das pesquisas práticas dessa tese e cujos dados serão expostos no capítulo 8), Garrido-Rodríguez (2019) identifica interessantes fatores que dificultam esse contexto, dos quais destacam-se:

- limitações orçamentárias;

- concentração e segregação a estes coletivos por parte de centros púbicos de ensino;

- carências e necessidades advindas de contextos prévios;

- necessidade de melhora na formação inicial e contínua de professores; e

- implicações do contexto familiar (como precariedade econômica e vulnerabilidade social).

Em um contexto no qual a juventude espanhola tem demonstrado um crescimento preocupante de atitudes identificadas como "socialmente intolerantes, racistas e xenofóbicas", são considerados complicadores ao processo de integração:

- a falta de mediadores para as diferentes culturas;

- a baixa participação das famílias imigrantes nas Asociaciónes de Madres y Padres de Alumnos - AMPA (em tradução livre: Associações de Mães e Pais de Alunos);

- a necessidade de existência de programas de acolhida para recém chegados;

- serviços de apoio e assessoria para as famílias; e

- escassez de ações complementares para necessidades não estritamente curriculares. (GARRIDO-RODRÍGUEZ, 2019).

A responsabilidade desses atenuantes, conforme apontado pela sociologia da educação, recai sobre todo o sistema educativo (GARRIDORODRÍGUEZ, 2019) e, ainda que explorados dentro do contexto espanhol, parecem reproduzir-se também em diferentes países, e entre diferentes comunidades socialmente marginalizadas.

Os profissionais da informação, nesse contexto, dificilmente são vistos ou se assumem como profissionais educadores. As áreas da Ciência da Informação, Biblioteconomia e Arquivologia, de maneira geral, e sem desmerecer as importantes correntes que vêm tentado reverter isso, se isentam em seu currículo de uma formação humanizada, perdendo-se na técnica herdada de uma cultura tecnicista e que segue sendo propagada nas universidades dos cursos ofertados. Isso se agrava 
quando os poucos profissionais que, mesmo com essa barreira formativa, conseguem se ver na perspectiva humanizadora, encontram outra barreira posterior - a negativa receptividade dentro dos ambientes educacionais, que vêm essa intenção como ameaçadora ou inoportuna, ignorando ou mesmo hostilizando este profissional.

Focando na atuação de um desses profissionais, o bibliotecário, podese destacar que uma de suas principais funções no contexto escolar é a promoção da leitura e, devido a essa dificuldade de currículo e de trabalho conjunto com professores e demais membros desse ambiente, esse trabalho tem sido feito deficitariamente, sem se ater a necessidade que essa promoção na verdade deve ser uma mediação - um ato consciente e com objetivo claro: o objetivo de que os alunos se apropriem de informações relevantes para que se tornem seres questionadores, que desenvolvam um pensamento complexo.

O trabalho do mediador de leitura não é dirimir dúvidas ou apenas disponibilizar livros de maneira ordenada tecnicamente, mas ampliar conhecimento, dando assim origem a novas dúvidas, cada vez mais complexas, impactando em seu desenvolvimento pessoal; é facilitar e orientar o acesso a informações assertivas, éticas e confiáveis, motivando também o compartilhamento de informações; é ampliar suas atividades a toda a comunidade escolar com respeito e ética.

Para isso, é necessário que a identidade cultural de todos, sua leitura de mundo que antecede o texto escrito, entre outros aspectos, sejam valorizados nesse processo. O simples acesso a escrita não condiciona o leitor a um real entendimento e posicionamento crítico, por isso a prática de mediar deve ser exercida de forma ampla e coerente aos objetivos pedagógicos do espaço educador - objetivos esses que devem também ser estabelecidos conscientemente de sua política e objetivos.

Como explorado por Freire (1979, 2013, 2005), é muito importante que o acesso à escrita tenha objetivos de libertação, de desenvolvimento do pensamento crítico, e não se foque unicamente na decodificação do código da escrita propriamente. Também, o material escolhido para a promoção de leitura deve valorizar a leitura de mundo de cada aluno, e proporcionar uma visão humanizada da vida humana, dirimindo preconceitos e visões extremistas. Há de se apoiar uma política de liberdade e amor.

Toda mudança é incômoda porque implica em movimento, em ação, e nem todos estão dispostos a enfrentar as questões resultantes de mudanças - 
principalmente em um sistema corroído pela corrupção, desigualdade e preconceito. Nesse sistema, o educando lida diariamente com informações manipuladas para que ele reconheça "seu lugar", enquanto ser oprimido, ao qual só lhe resta aceitar a opressão e agraciar seus opressores, que se apresentam enquanto seres privilegiados por meritocracia. (FREIRE, 2013).

$\mathrm{Na}$ atuação docente, essas manipulações ideológicas se estendem por toda esfera escolar, e em muitas comunidades gera um ambiente de extrema potencialização da pobreza e de inúmeros preconceitos. O educador se vê imerso nesse contexto em tantas nuances e expressões que em algum momento pode começar a naturalizar esses fatos, se anestesiando frente a muitas injustiças e caindo no discurso fatalista de que "é assim mesmo", e que "a vida é mais fácil quando aceitamos". Numa sociedade opressora tal discurso favorece os opressores, que usam esses discursos como fortalecimento de sua dominação ideológica.

Frente a essa realidade o educador teria o desafio de buscar uma retidão ética, voltando a valorizar o ser humano enquanto ser presente ativo no mundo, e não amorfo, e assim reconhecer que ele tem voz, tem necessidades e desejos, tem história e faz história.

O ser é constantemente condicionado a complexas realidades sociais, mas essa não deve ser a determinação de sua vida. Ele pode e deve mudar sua realidade, agir frente sua historicidade, e o papel do educador nesse processo é primordial, pois ele poderá ser o impulsionador dessa consciência de liberdade e autonomia, desafiando o discurso hegemônico dominante em esferas educativas onde a educação seja exercida na concepção bancária e de manipulação dos oprimidos, estruturada para que estes se vejam como seres limitados. (FREIRE, 1979, 2013).

A prática educadora consciente das complexidades expressas por Paulo Freire $(2011 ; 1979 ; 2013 ; 2015)$, que busca o desenvolvimento de uma educação libertária, é considerada a mais coerente com a busca de superação dos processos educativos frente à sua necessidade de inclusão de grupos marginalizados e à superação de todas as metas apresentadas na agenda ONU 2030, já que traz como horizonte a perspectiva de mudar a vida de educandos, de os ajudar a ver todo seu potencial, seus direitos, e a importância de sua própria historicidade. Porém, sua aplicação pode constituir um desafio constante nos contextos estruturais vigentes, pois irá de encontro ao forte discurso opressor propagado. 
A manipulação midiática cresce sem precedentes, e engloba diferentes mídias e redes, dificultando a todas as pessoas um acompanhamento e criticidade sobre as informações. Nas madrugadas ou em plena luz do dia, a cada dia, novas leis que cancelam direitos e aumentam privilégios de opressores são aprovadas, e a divulgação destas costumam ser mascaradas com notícias que confundem e desesperam.

O educar com bom senso e democracia se torna, cada vez mais, uma prática a ser perseguida pelos governos que se beneficiam de uma educação bancária e superficial no apoio a manipulação ideológica. Assim, até mesmo educadores podem estar imersos nessa manipulação ideológica, o que pode resultar em uma perseguição dentro dos próprios ambientes educativos, e tornar a atuação do profissional que busca uma educação libertária cada vez mais desafiador.

Paulo Freire incentiva o entendimento da realidade, desvelando-a com amorosidade e bom senso, e lutando contra a domesticação alienante do sistema. E, em meio a "novos-velhos" tempos de perseguição da liberdade democrática, isso se faz com muita persistência e luta. Essa persistência envolverá o apego a práxis - buscar força em uma ideologia libertária para exercer uma prática condizente com ela.

Paulo Freire reforça a exigência do comprometimento e reconhecimento: o comprometimento com uma prática que tem profundo impacto social, e o reconhecimento do educador enquanto profissional que lidará não com conteúdos, mas com a vida das pessoas. A educação é, portanto, uma forma de intervenção no mundo e, assim, desempenha uma função social, muitas vezes desconsiderada pelo sistema educativo, reafirmando a concepção bancária de transferência, que ignora toda complexidade da existência e cultura humanas.

Com o desenvolvimento do pensamento crítico se pode ampliar a busca aos questionamentos, nos âmbitos macro e micro - questionar o outro, mas também a si, e ampliar a compreensão e acesso ao fazer ciência, ressaltando que o aprendizado transpassa a escola, compreendendo ressignificações e possibilidade de reescrever esse mundo.

Nessa complexidade da própria atuação de um educador, a educação é feita também com o corpo, numa espécie de apresentação que, sem palavras ou escritas, esclarece aos educandos o quanto se os reconhece, e o quanto se está aberto a eles - uma postura identificada como arrogante limita o acesso aos 
educandos. Essas nuances podem ser encontradas no conceito de amorosidade trabalhado por Paulo Freire que, muitas vezes reconhecido num âmbito poético, carrega em realidade a prática consciente que contrapõe o ódio e a distância propagados em uma forma programada de guerra e isolamento e e entre classes.

Essa preocupação com a realidade do outro se enquadra no que identificamos como "biblioteconomia crítica" e seus aspectos de inclusão dos direitos humanos nas esferas da informação e bibliotecárias. Esse movimento internacional inclui profissionais da área da Ciência da Informação que consideram que a condição humana e os direitos humanos estão acima de assuntos profissionais, tendo, portanto, uma base de respeito, valorização e reconhecimento da responsabilidade social de sua profissão.

Essa esfera da área reafirma que as bibliotecas são "[...] instituições sociais, políticas e culturais idôneas para gerar mudanças a partir de diferentes ângulos e em diversas latitudes. [...]". (MENESES-TELLO, 2017, p. 44, tradução nossa $\left.{ }^{15}\right)$.

A biblioteconomia crítica, portanto, aprofunda a teorização e tenta ampliar as abrangências dos discursos que veem permeando, já há muitos anos, investigações que discutem a necessidade de incluir as questões sociais e educativas nos estudos de informação e de seus compartilhamentos, entre outros.

Num contexto de mediação, pode-se afirmar que uma mesma informação é passível de várias classificações sígnicas de significado e pode, ou não, ter impacto em seu receptor. Em um contexto linguístico, desempenha a construção social de um ser, e impacta na sua construção de signos mentais que, do mesmo modo, podem ou não ter impacto em sua vida.

O homem aparece então na sociedade também como signo, influenciando toda cadeia ao seu redor. É uma existência de imersão em uma corrente de construção sígnica, através da qual somos aceitos em sociedade e construímos conhecimento.

A leitura, importante no fator de mediação, é uma manifestação sígnica de uma expressa língua. A leitura de um texto escrito, portanto, parte do

\footnotetext{
${ }^{15}$ Texto original: “[...] reafirma que las bibliotecas son instituciones sociales, políticas y culturales idóneas para generar cambios desde diferentes ángulos y en diversas latitudes. [...]"
} 
contato com a escrita e perpassa todos os contextos abordados, gerando novos signos mentais carregados de influências sociais, políticas, temporais e históricas.

A leitura exige a interação real do homem para que seja passível de construção de conhecimento, sendo que sua práxis e envolvimento linguísticos determinarão sua apropriação ou não, perpassando as categorias fenomenológicas em diferentes proporções (o mesmo texto trará o leitor para diferentes categorias de significação, porém essa interação é totalmente dependente de cada indivíduo que terá acesso ao mesmo conteúdo em questão).

As práticas que visam a promoção da leitura devem apoiar-se nessas discussões já em sua fase de planejamento, podendo em determinado momento serem até mesmo consideradas nulas, caso não tenham potencial de real interação com o público alvo. A complexidade do processo deve ser levada em consideração, para que a disponibilização da leitura não se torne um simples signo solitário.

Seja na Biblioteconomia, Arquivologia, Museologia, Ciência da Informação, ou qualquer outra área que assuma um potencial educador frente a uma sociedade complexa, diferentes aspectos que compõem uma sociedade construída por diferentes culturas devem ser trazidos para discussão, e algumas teorias apresentam caminhos nessa problemática.

Uma delas é o conceito de multiculturalidade, muito usado para tentar estabelecer práticas e projetos educacionais. O termo associado a uma determinada sociedade quer expressar que nela "convivem sistemas culturais inteiros distintos" (CAHEN, 2014, p. 25) e não, como algumas vezes utilizados, apenas para referir-se à existência de pessoas ou grupos isolados que são identificados como "diferentes", ou "de fora". A legislação costuma buscar a igualdade para todos, mas, ao considerar o igual desconsiderando as políticas do multiculturalismo enquanto teoria que estuda a situação multicultural, ela resultará em práticas de "isomorfismo" - "identificação exata entre uma língua, uma soberania, e um território" (CAHEN, 2014, p. 24).

$\mathrm{O}$ isomorfismo condena muitas culturas a serem sempre o outro, o diferente, o que precisa se adaptar a uma sociedade com traços culturais marcados como necessários para o acesso a cidadania, mas que o que realmente faz é propagar o racismo e deixar uma justificativa para ele (se uma determinada cultura não consegue se adequar aos padrões exigidos, ou se os resultados de seu contato intercultural não atinge os objetivos esperados pelo outro, seu então isolamento, ou 
qualquer perda de direitos, inclusive o da própria vida, fica condicionado a essa socialmente fabricada culpa pessoal de incapacidade de adequação).

Ainda que o conceito de multiculturalidade e multiculturalismo se encontrem ainda em voga, seja nos âmbitos de financiamento ou conceituais, eles passaram a serem considerados insuficientes quanto aos objetivos de implantação e, dessa insuficiência, os conceitos de interculturalidade e interculturalismo surgem na perspectiva de solucioná-los.

Para entender melhor a diferença entre ambos é primeiramente importante ressaltar que eles se amparam no paradigma do "pluralismo cultural" (novo paradigma que surgiu na década de 1960), que conota

[...] em primeiro lugar, a presença, coexistência ou simultaneidade de populações com diferentes culturas em um determinado âmbito ou espaço territorial e social, seja uma área civilizatória, uma entidade supranacional, um estado-nação, uma nação sem estado, uma região, um município, uma comunidade local, uma escola. Mas por 'pluralismo cultural' entende-se também [...] uma determinada concepção de diversidade cultural e uma determinada proposta sobre a forma legislativa, institucional, etc., nas quais se deveria abordar a prática. (ROMERO, 2003, p. 6-7, tradução nossa) ${ }^{16}$

O pluralismo cultural estabelece a premissa de que a diversidade cultural é um aspecto positivo na sociedade por ser enriquecedora, e advoga que ela não deve apenas ser aceita, mas também que essa diversidade deve ser respeitada, aproveitada e celebrada. Ele, resumidamente, apresenta que "[...] as pessoas são iguais em direitos, obrigações e oportunidades, e devem ser respeitadas em sua distintividade cultural, linguística e religiosa." (ROMERO, 2003, p. 8)

Tem-se então:

\footnotetext{
16 Texto original: “'Pluralismo cultural' connota, en primer lugar, la presencia, coexistencia o simultaneidad de poblaciones con distintas culturas en un determinado ámbito o espacio territorial y social, sea un área civilizatoria, una entidad supranacional, un estado nación, una nación sin estado, una región, un municipio, una comunidad local, una escuela. Pero por 'pluralismo cultural' también se entiende [...] una determinada concepción de la diversidad cultural y una determinada propuesta sobre la forma legislativa, institucional, etc, en que debería abordarse en la práctica."
} 
Figura 2: Modelos sociopolíticos frente a diversidade cultural.

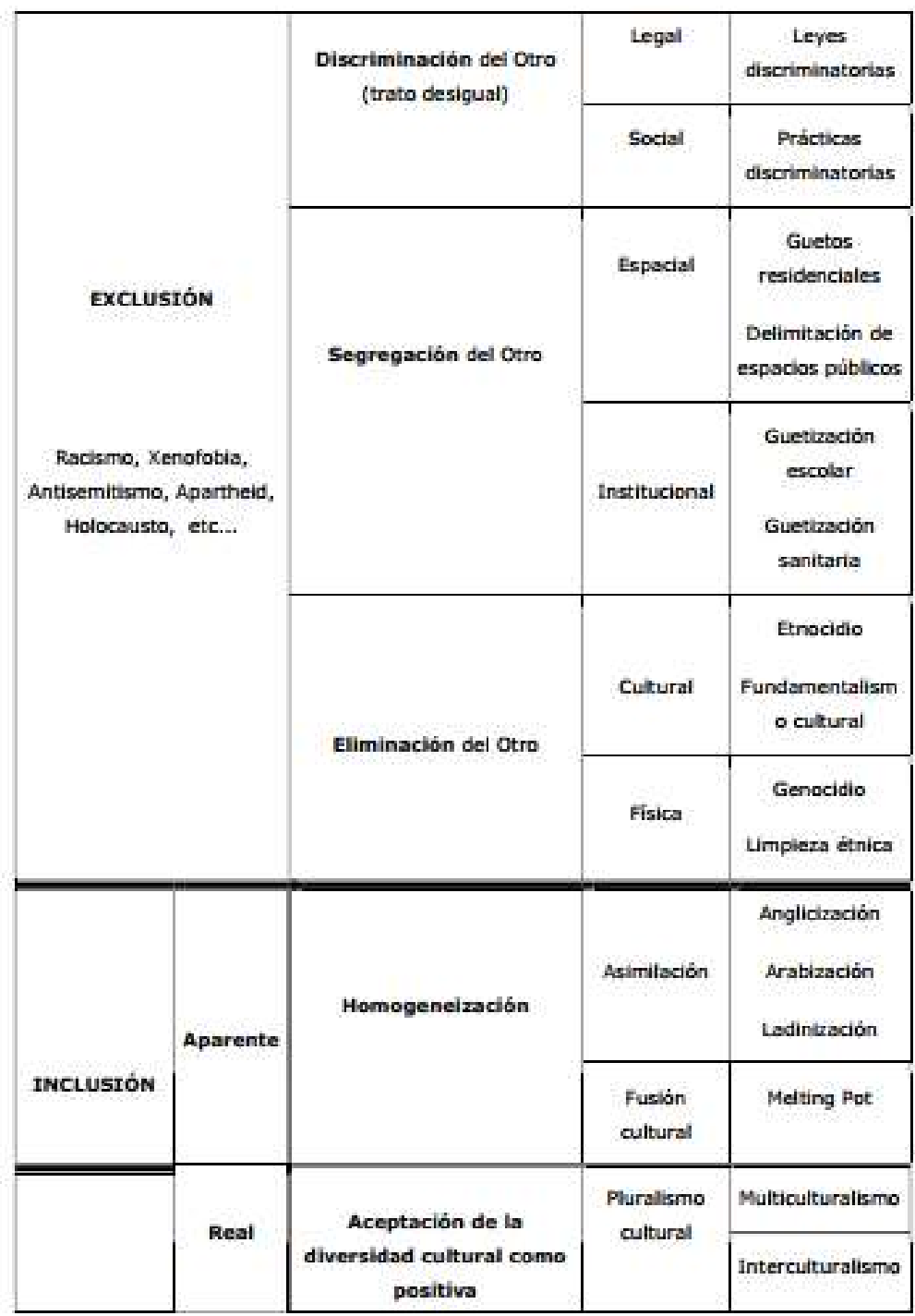

Fonte: Romero, 2003, p. 9-10.

Ambos os conceitos estão, portanto, embasados no mesmo paradigma de uma inclusão real, buscando não apenas a oposição ao racismo como a superação do isomorfismo, e assimilacionismo - um modelo de submersão para uma incorporação forçada dos aspectos culturais considerados aceitáveis, muito utilizado na década de 1970 com comunidades indígenas. (BETTIOL, 2017).

A interculturalidade é descrita pela Unesco como a referência à "presença e interação equitativa de diversas culturas e à possibilidade de gerar expressões culturais compartilhadas, adquiridas por meio do diálogo e de uma atitude de respeito mútuo. O conceito foi incluído na Convenção sobre a proteção e promoção da diversidade de expressões culturais, promovido em Paris, em 2005, tendo como um de seus objetivos o "fomento ao diálogo entre culturas a fim de garantir 
intercâmbios culturais mais amplos e equilibrados no mundo, em prol do respeito intercultural e uma cultura de paz". (UNESCO, 2005, sem paginação) ${ }^{17}$.

Num âmbito prático, o seguinte esquema é desenhado:

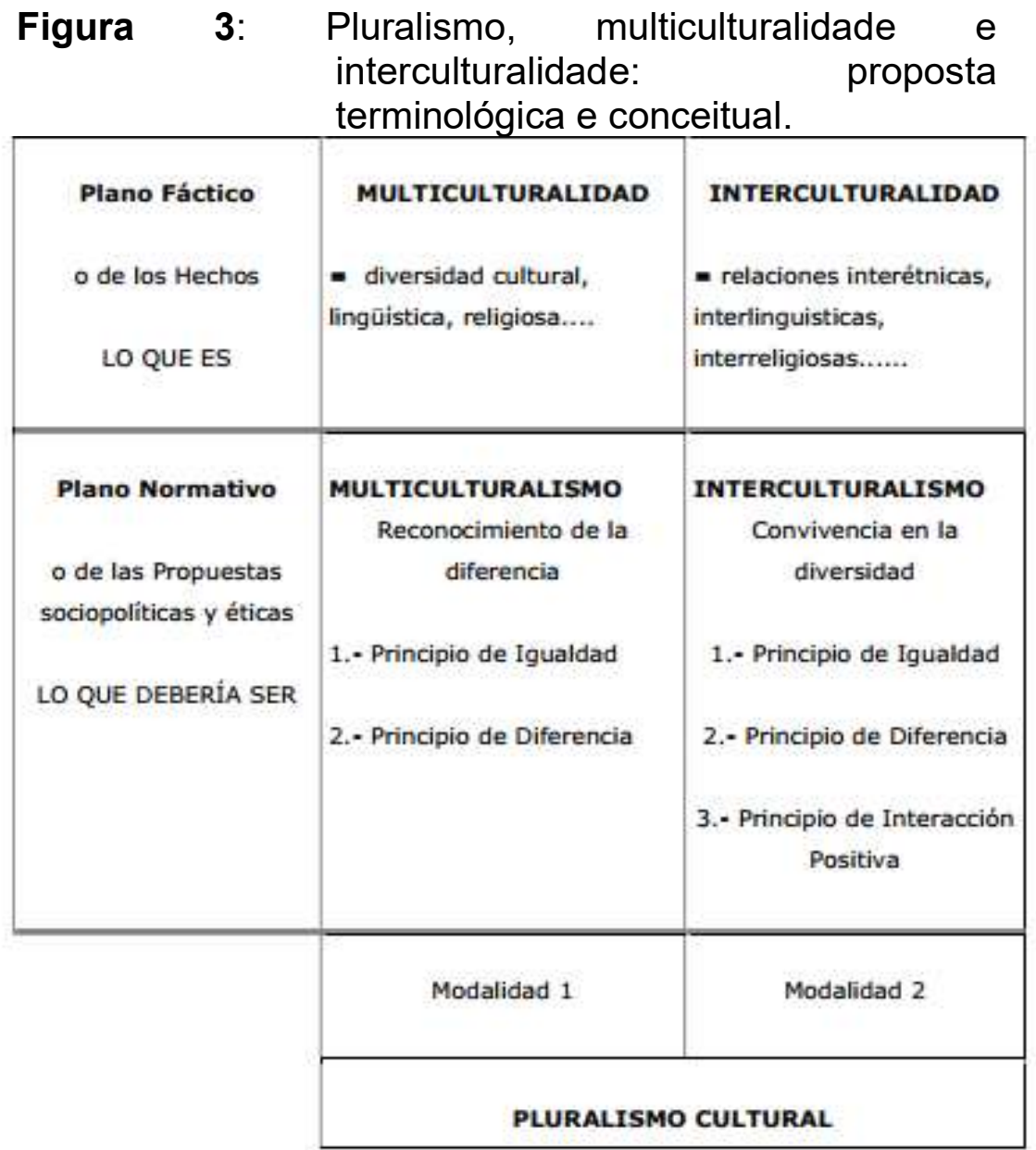

Fonte: Romero, 2003, p. 5.

Pode-se observar que a figura coloca o interculturalismo com a inclusão de um novo princípio - o de interação positiva, na intenção de superação das ineficiências ou limitações apresentadas pelo multiculturalismo, mas não uma negação de suas contribuições e construções.

O salto está em que em um contexto se reconhece a presença, intensidade e modos de expressão de diversidade cultural e se pode analisar as relações entre os diferentes sujeitos em função de identidades e culturais - sejam

\footnotetext{
${ }^{17}$ Textos originais: “La 'interculturalidad' se refiere a la presencia e interacción equitativa de diversas culturas y la posibilidad de generar expresiones culturales compartidas, adquiridas por medio del diálogo y de una actitud de respeto mutuo." / "c) fomentar el diálogo entre culturas a fin de garantizar intercambios culturales más amplios y equilibrados en el mundo en pro del respeto intercultural y una cultura de paz."
} 
positivas ou não - mas outro é que além das questões individuais se pode abordar como autoridades, partidos políticos, líderes sociais, profissionais, etc. consideram quais as melhores práticas para se abordar e tratar essa diversidade reconhecida. (ROMERO, 2003).

Estruturando a principal e concentradora crítica de que o multiculturalismo se "contenta" com e coexistência, enquanto o interculturalismo abarca volta sua atenção para a convivência, o seguinte quadro foi construído:

Quadro 10: Coexistência (multiculturalismo) versus convivência (interculturalismo).

\begin{tabular}{|l|l|}
\hline \multicolumn{1}{|c|}{ Coexistência } & \multicolumn{1}{c|}{ Convivência } \\
\hline Atenção a cada cultura individualmente. & Relação entre culturas. \\
\hline $\begin{array}{l}\text { A identidade de cada qual como um passo } \\
\text { absolutamente necessário para exigir } \\
\text { reconhecimento, e isso envolve a ênfase } \\
\text { nas diferenças. }\end{array}$ & $\begin{array}{l}\text { Convergências sobre as quais estabelecer } \\
\text { vínculos e pontos em comum. }\end{array}$ \\
\hline $\begin{array}{l}\text { Cultura e história próprios, os direitos de } \\
\text { cada um, o sistema jurídico de cada povo. }\end{array}$ & $\begin{array}{l}\text { Aprendizagem mútua, cooperação, } \\
\text { intercâmbio. }\end{array}$ \\
\hline
\end{tabular}

Fonte: Construído com base em Romero, 2003.

Essa diferenciação possibilitaria ao interculturalismo a incorporação de uma mensagem de "regulação pacífica de conflitividade interétnica", aspecto pouco ou nada tratado no multiculturalismo. Isso, para a educação, envolveria um salto quanto não apenas a formação de e para a diversidade, mas para a coesão social de uma convivência ativa e democrática. (ROMERO, 2003).

Como Garrido salienta, pode-se assumir que há um determinado acordo sobre a necessidade de melhorias em processos e estruturas educacionais, e que há assimetrias a se superar em muitos âmbitos, especialmente no que se diz respeito a grupos vulneráveis e marginalizados, porém há uma inconsistência quando se observa que não há um assumir das responsabilidades necessárias para atingir essas melhorias, especialmente em contextos econômicos. Há ainda, ademais dessa deficiência, questões qualitativas deficientes - se é necessário determinar o "quanto" se precisa melhorar, também é necessário o "como", e ambos estão interrelacionados. (GARRIDO- RODRÍGUEZ, 2020).

O modelo educativo intercultural foi considerado por GarridoRodríguez como o que 
[...] melhor satisfaz as necessidades de seu heterogêneo alunado, o mais coerente com o modelo de sociedade atual e o mais competente para cumprir com as garantias previstas pelo discurso positivo internacional de Direitos Humanos, paradigma legitimado pela via do consenso internacional e consolidado mundialmente. (GARRIDORODRÍGUEZ, 2019, p. 2, tradução nossa). ${ }^{18}$

A implementação das concepções de interculturalidade, e o desenvolvimento dos princípios do interculturalismo, portanto, podem ser um caminho coerente na busca pela superação dos desafios contextualizados neste capítulo, bem como uma proposta de possível aproximação com as metas da agenda 2030 para educação.

\footnotetext{
${ }^{18}$ Texto original: "Su estudio exhaustivo nos lleva finalmente a abogar por el modelo educativo intercultural por ser el que mejor satisface las necesidades de su heterogéneo alumnado, el más coherente con el modelo de sociedad actual y el más competente para cumplir con las garantías previstas por el discurso positivo internacional de Derechos Humanos, paradigma legitimado por la vía del consenso internacional y consolidado mundialmente."
} 


\section{PESQUISA DE CAMPO BRASIL: XAVANTES}

As diferentes colonizações, mais identificadas por muitos povos nativos como invasões, resultaram em grandes mudanças culturais nos diferentes países e continentes do mundo. Embora em larga escala, essas colonizações não atingiram todos os povos e, portanto, resistiram a comunidades inteiras que conseguiram permanecer em "isolamento" e outras cujo contato foi feito em momentos históricos posteriores, quando os impactos mais agressivos das colonizações foram superados ou menos minimizado, permitindo evitar, mas não completamente, a transposição imposta de uma cultura dominante.

A América Latina, no contexto da colonização, teve que conviver com dois mundos - o colonial e o moderno, resultando em uma instável construção da identidade de seu povo que hoje continua na busca pelo que ainda pode ser salvo de seus mundos. Castro e Castro (2018, p. 446) esclarecem que o

América Latina tornou-se [...] a primeira entidade histórica do mundo colonial/moderno e da modernidade, com o agravante de que, embora pioneira, continuou nos dois mundos - o colonial e o moderno, sem atingir o pleno desenvolvimento de suas potencialidades. $O$ passado colonial é considerado um fantasma histórico que precisa ser trazido à tona sob pena de continuar preso à colonialidade do poder e de sua dependência, não conseguindo chegar ao novo mundo.

É, além dessa luta constante, uma busca de manter-se a cultura entre a dissolução de um mundo cada vez mais globalizado. Para os países da América Latina, seis elementos podem ser identificados como chocantes no reconhecimento da identidade: o parasitismo metropolitano (que pode ser resumido na exploração dos recursos naturais, em uma visão de curto prazo e elitista); a já mencionada coexistência de dois mundos históricos; a Caixa vazia de Thorp (com etnia determinando a história, com falta de crescimento com equidade); a etnicidade como marcador de categorias sociais; a forma federativa do Estado e suas relações sociais (muitas vezes com uma postura exploradora e até tirânica e corrupta); e língua, cultura e racismo (que demonstram uma coexistência não respeitosa de diferentes etnias). (CASTRO; CASTRO, 2018).

Além desses aspectos, com o desenvolvimento global e tecnológico e a imigração constante, a sociedade tornou-se cada vez mais plural e, com isso, 
constantes são os desafios daqueles que buscam uma valorização do multiculturalismo e defendem o progresso que os respeite, principalmente no caso dos povos nativos. O Brasil, especificamente, tem enfrentado um grande desafio que impacta o mundo - suas questões de preservação ambiental.

As novas mudanças políticas mundiais, onde a valorização do capitalismo em detrimento da consideração da complexidade do desenvolvimento humano, e o potencial exploratório de sua expansão de mercado, orientaram novas frentes que passaram a atingir os atuais territórios que ainda estavam sob a proteção dos povos indígenas e que põe em risco toda uma esfera ambiental até então protegida por esses povos. Dentre os muitos retrocessos ambientais no Brasil, destaca-se que nos primeiros 6 meses do atual governo (janeiro a junho de 2018) houve a extinção de setores de proteção ambiental (como, por exemplo, as secretarias de mudanças climáticas, extrativismo e desenvolvimento sustentável e cidadania ambiental); o enfraquecimento de acordos internacionais de preservação e recuperação; imprecisões no licenciamento ambiental e da autonomia dos órgãos responsáveis por punir crimes ambientais; e liberação acelerada de agrotóxicos. (GREENPEACE BRASIL, 2019a).

Alguns dos resultados imediatos das mudanças mencionadas foram o crescente desmatamento da Amazônia e a invasão de terras indígenas. O sistema do governo brasileiro que realiza alertas de desmatamento registrou, apenas entre os dias $1^{\circ}$ e 28 de junho, a demolição de $769 \mathrm{~km}^{2}$ de florestas no Brasil, um número 88\% superior ao desmatamento do mesmo mês de 2018. (GREENPEACE BRASIL, 2019b)

Os indígenas, embora não sejam "ecologistas por natureza", têm consciência de sua dependência do meio ambiente e por isso desenvolveram formas de manejo dos diversos recursos naturais que se mostraram fundamentais para a preservação da cobertura florestal. Um levantamento do INPE (Instituto Nacional de Pesquisas Espaciais) demonstra que as Terras Indígenas aparecem como verdadeiros oásis de florestas em meio a regiões onde o desmatamento tem avançado mais rapidamente. (INSTITUTO SOCIOAMBIENTAL, 2019). 
Figura 4: Foto aérea de área de território brasileiro.

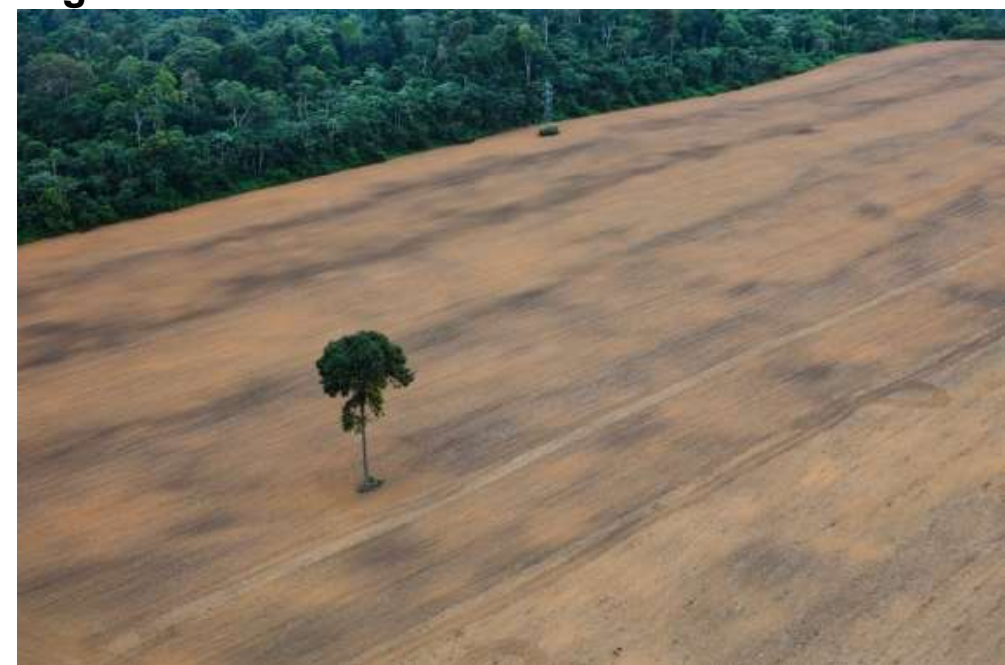

Fonte: Daniel Beltrá, 2019.

Figura 5: Desmatamento na Amazônia brasileira.

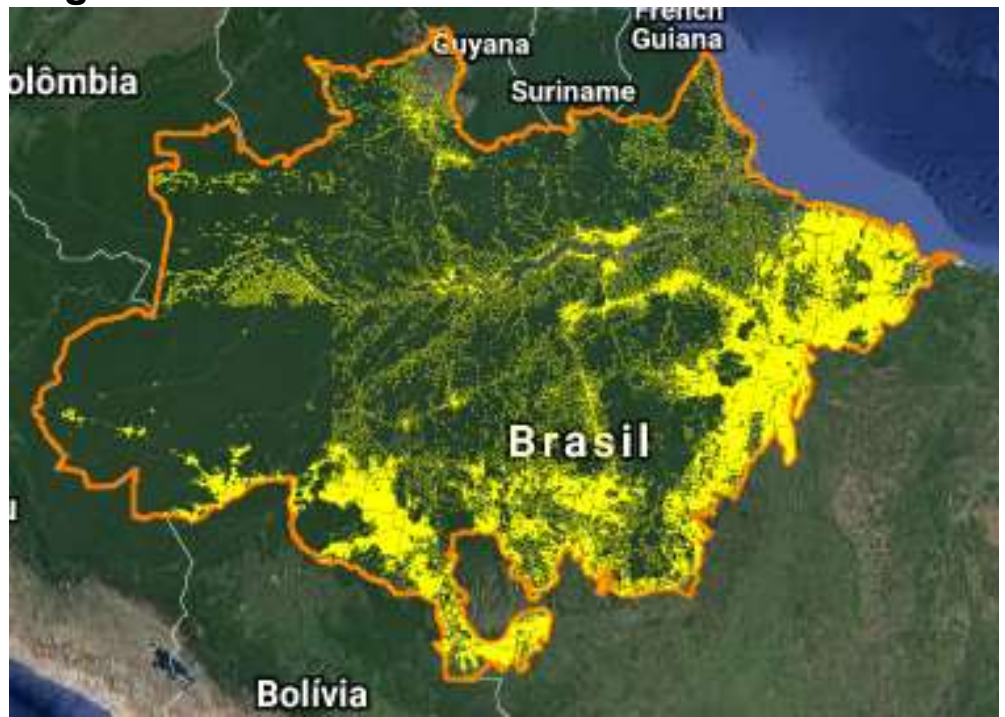

Fonte: Terrabrasilis, 2 de junho de 2019.

Na figura 4 se observa o contraste entre uma plantação de soja e uma área protegida por demarcação de terra indígena e, na figura 5, em amarelo, demonstra-se o desmatamento na Amazônia brasileira registrado em junho de 2019.

Dados de 2017 mostram que enquanto 20\% da Amazônia brasileira foi desmatada nos últimos 40 anos, dentro das terras indígenas somadas, o número é de apenas $2 \%$, destacando que dentro desse número também há desmatamento devido à invasão do território. Entre 2004 e 2008, 10 milhões de hectares da Amazônia brasileira foram demarcados como Terras Indígenas, e isso teve influência, junto com outros 20 milhões que estavam protegidos pelo Plano de Ação para a Prevenção e Controle do Desmatamento na Amazônia (PPCDAm), com queda de 37\% na taxa de 
desmatamento observada entre aqueles anos. Os povos indígenas também têm impacto na inibição da destruição da paisagem onde seus territórios estão inseridos: em um raio de $10 \mathrm{~km}$ de distância, observa-se $7 \%$ de área de floresta desmatada, enquanto em um raio de $25 \mathrm{~km}$ a proporção é de quase $12 \%$. Este efeito desempenha um papel importante na conservação da biodiversidade regional e dos sistemas hidrológicos da região. (INSTITUTO SOCIOAMBIENTAL, 2018).

Castro e Castro (2018) afirmam que, para o discurso da mídia brasileira, assim como para outros países da América Latina, os povos indígenas são infantilizados e / ou tratados como seres populares e, como resultado do racismo que sofrem, são vítimas de crimes fétidos, muitas vezes sem um julgamento justo. Assim, as pessoas acabam vivendo fora do conceito de cidadania em sua plenitude.

Em 2019 analisou-se o conteúdo que continha os termos "índio" e/ou "indígena" nas páginas web das 3 principais empresas de mídia brasileira: 1 - Globo (15,6 pontos); 2 - Registro (7,55 pontos); e 3-SBT (6,49 pontos) - cada ponto equivale a cerca de 254 mil casas e os dados são da avaliação do Painel Nacional de Televisão, sobre o primeiro trimestre de 2019 (OPOVOONLINE, 2019). O conteúdo recuperado, advindo de matérias televisivas transmitidas e de conteúdo textual publicado em jornais e ambiente web, foi analisado com base nas matérias recuperadas, assumindo-se a possibilidade de um contato mais direto com a população - mesmo que não leiam ou vejam as matérias completas, é difícil não ler / ver a manchete inteira.

Como resultados, elenca-se que:

- A frequente associação dos indígenas à violência, aos processos judiciais e ao resultado de "perdas" para grandes empresas, reafirma uma imagem de caráter complexo que costuma trazer mais mal do que bem. As notícias com manifestação conflituosa resultaram, respectivamente, em $61 \%, 67 \%$ e $75 \%$ dos resultados das 3 empresas.

- Não foi possível identificar manifestações positivas, no máximo conteúdo considerado categoricamente como de "promoção", onde encontrou-se um grande número de discursos ambíguos, que apresentam reafirmações folclóricas e polêmicas da realidade indígena, apenas com possibilidade de melhor análise com contato do noticiário completo, o que não foi analisado por não ser o objetivo do estudo. 
- Na esfera ambiental, a maioria enfoca questões de demarcação de terras e a necessidade de expansão agrícola, por isso foram totalmente identificados com manifestações políticas e econômicas, reafirmando o estereótipo de conflitos indígenas e indígenas. seu impacto negativo sobre a possibilidade de expansão econômica do país - já que a preservação foi na verdade um atraso para o desenvolvimento econômico do país.

- Com as manifestações identificadas, considerou-se que as informações rápidas veiculadas nos principais meios de comunicação analisados mantêm um discurso ambíguo ou negativo sobre questões indígenas e de preservação, e embora no conteúdo esses aspectos desse primeiro contato sejam corrigidos, ele depende do interesse da população para pesquisar o conteúdo completo - algo difícil de esperar em face dos conflitos exibidos com mais frequência. ${ }^{19}$

No contexto brasileiro, muitos indígenas se uniram em uma frente de luta por seus direitos, mas há o diminutivo apoio de outros membros da população e os estereótipos cada vez mais amplos e negativos dos indígenas na reprodução de um discurso culturalmente opressivo e colonizador, que inserido no "dia a dia" da população enfraquece a luta desses povos e valoriza a exploração agrícola de seus territórios (SURVIVAL, 2019; KRENAK, 2019).

O censo brasileiro de 2000 revelou um crescimento da população indígena bem acima das expectativas (de 294 mil para 734 mil pessoas em apenas nove anos). Esse aumento significativo foi entendido não apenas como um efeito demográfico, mas também para um possível aumento no número de pessoas, especialmente nas áreas urbanas do país, que se reconheciam como indígenas. (INSTITUTO BRASILEIRO DE GEOGRAFIA E ESTATÍSTICA, 2019).

Esse mencionado reconhecimento pode ser resultado de uma política que iniciava um melhor relacionamento com povos indígenas. Tais políticas foram interrompidas e atualmente estão sendo revertidas desde as grandes e drásticas mudanças governamentais no Brasil.

Também é importante ressaltar a diversidade dos povos indígenas brasileiros, muitas vezes apresentados como se houvesse uma miscigenação entre eles, contrariando a realidade de mais de 300 povos e etnias completamente distintas

\footnotetext{
${ }^{19}$ Os resultados completes da pesquisa foram apresentados no International Meeting of Information and Communication Researchers and Experts - ICOM 2019.
} 
e/ou isoladas, que possuem não só aspectos culturais completamente distintos, como também tempos de contato e relacionamentos incomparáveis entre sua(s) aldeia(s) / "parentes" (demais indígenas) / "não indígenas".

Neste trabalho os contatos de investigação foram feitos junto aos indígenas Xavantes, da aldeia Nova Esperança, localizada no interior do Mato Grosso e, portanto, as características de relação e cultura aqui apresentados possuem a riqueza própria desses povos e não são representativas dos demais, ainda que se possam, em determinados momentos, encontrar similaridades.

\subsection{Xavante / A'uwe}

O etnônimo Xavante foi o escolhido pelos waradzu ("brancos"), para denominar o grupo que, junto aos Xerente (autodenominados Akwe) do Estado do Tocantins, formam um conjunto etnolinguístico que é identificado na literatura antropológica como Acuen, da família lingüística Jê - tronco Macro-Jê. (INSTITUTO SOCIOAMBIENTAL, 2020).

É importante esclarecer que

Os Xavante não devem ser confundidos com os Oti-Xavante do oeste do estado de São Paulo e os Ofaié (Opaié)-Xavante do extremo sul do Mato Grosso, com os quais não compartilham nenhuma característica histórica ou sociológica em comum. Segundo a versão mais aceita, o nome "xavante" Ihes foi atribuído por não-índios visando sua diferenciação dos demais Acuen, particularmente, em relação aos "xerente", do qual se separaram por volta de 1820 ainda na Província de Goiás. (INSTITUTO SOCIOAMBIENTAL, 2020, não paginado).

Durante alguns anos grupos identificados por não-índios como "Xavantes" empreenderam travessias e refugiaram-se definitivamente no leste matogrossense, onde incorporaram a designação de "Xavante" para se referir a si próprio quando precisam falar com os waradzu, porém sua autodominação (em sua língua) é a'uwe ou a'uwe uptabi ("gente de verdade"). (INSTITUTO SOCIOAMBIENTAL, 2020).

Em fins da década de 1940, durante a campanha do Estado Novo no Brasil, os Xavantes "ficaram famosos" pela campanha de "pacificação" (eufemismo para "rendição") dos mesmos em prol da "Marcha para o Oeste", ainda que a pacificação, num primeiro momento, tenha ocorrido em apenas um grupo Xavante (em 
1946). Até meados de 1960 outros grupos foram contactados por diferentes representantes do waradzu, incluindo funcionários do Serviço de Proteção aos Índios - SPI (representante do Estado brasileiro), missionários católicos e protestantes. (INSTITUTO SOCIOAMBIENTAL, 2020; GORDON, 2014).

Figura 6: Troca de presentes entre grupos locais Xavante e o Serviço de Proteção ao Índio (SPI).

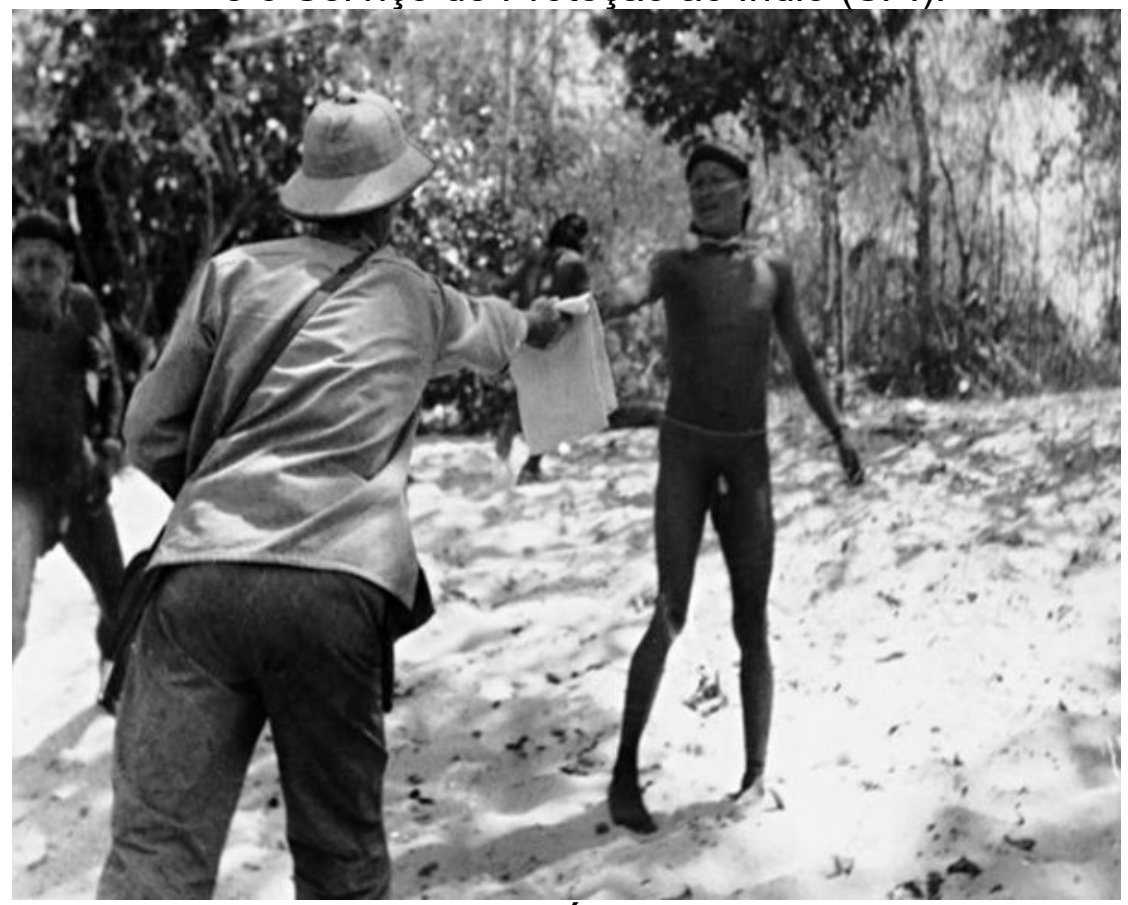

Foto: Lamônica/Museu do Índio (1951).

Fonte: Instituto Socioambiental, 2020.

Figura 7: Xavante vestido para festividade tradicional.

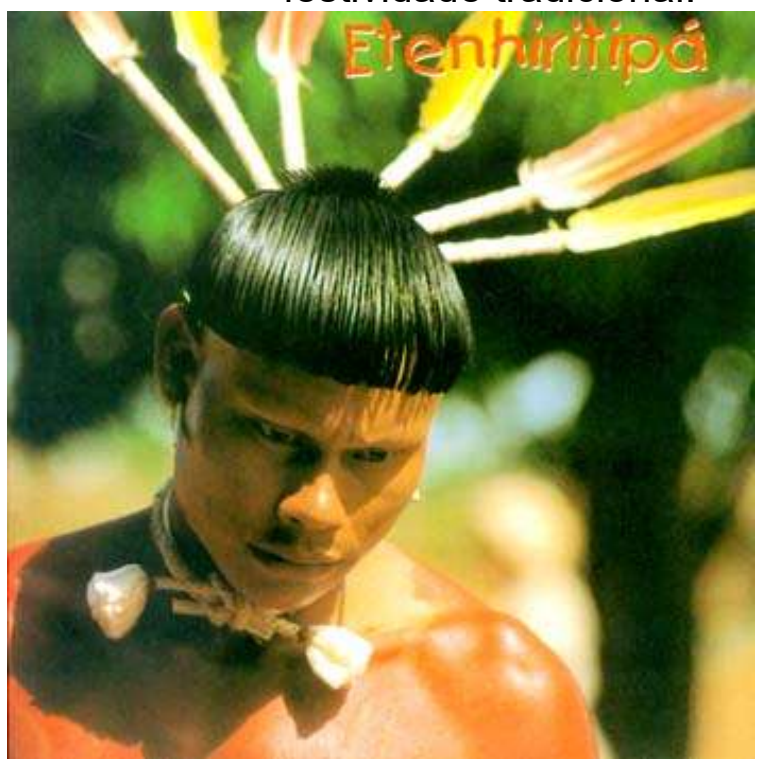

Fonte: FUNAI, 2020. 
Ainda que impactadas pelos referidos contatos, as comunidades Xavantes são politicamente autônomas, ainda que às vezes se unam em prol de objetivos comuns. Desde sua rendição foram obrigados a aceitar "os brancos" como uma "presença definitiva", e tentaram, assim como todas as demais etnias, evitar que essa rendição se tornasse "sujeição" ou "desaparecimento". (GORDON, 2014).

Como outros povos pertencentes ao ramo central da linguística Jê, ou sociedades Jê, os Xavantes possuem complexas e múltiplas oposições em sua sociedade, com uma formação dualística única composta de metades exogâmicas e ágamas, que impactam em seus pilares políticos e sociais. (GRAHAM, 2014).

\subsection{DIÁRIO DE CAMPO - VISITA À ALDEIA NOVA ESPERANÇA}

Fui até a aldeia Nova Esperança no dia 3 de setembro de 2017, acompanhada do indigenista Gustavo Gomes, da Funai. Saímos pela manhã da cidade de Barra do Garças, em torno de 8 horas, numa camionete alugada pela Funai, já que o carro deles havia ficado preso na aldeia (o que descobrimos depois). Viajamos por cerca de duas horas até chegar na aldeia, passando por um longo trecho de terra que embora tivesse pedaços com grandes buracos parecia bem cuidado e limpo, em grande parte pelo próprio trabalho da Funai, como me esclarecido.

Chegar na aldeia foi uma adrenalina interessante. É um ambiente no qual não sabia o que esperar. Era um espaço limpo no meio do cerrado, em formato claramente circular, onde as casas ficam na extremidade do círculo e há apenas uma construção ao centro. $O$ chão é completamente limpo, tendo apenas uma areia fina e clara, e as casas são feitas em sua maioria de palha nativa, mas todas em formato retangular, embora tradicionalmente as casas dos Xavantes fossem redondas. Havia também, em um dos extremos e longe das casas, duas pequenas construções de alvenaria - a escola e a biblioteca, e em outro extremo, mais próximo a algumas casas, uma caixa d'água.

Paramos o carro inicialmente do lado da casa do ancião da aldeia, o senhor Tobias. Ele nos recebeu com um sorriso, e já que éramos visivelmente esperados por todos. O presenteamos com peixes frescos e munição para caça. Ele se mostrou feliz e me presenteou com um cocar 
com uma linda pena bem longa, colocou em minha cabeça e pediu para eu usar em símbolo de que estava ali como amiga. Me deu um outro parecido, com uma pena menor, e disse que era para eu o levar de presente para São Paulo. Agradeci e cumprimentei as mulheres que então estavam se aproximando. O senhor Tobias é também pai do professor Xisto, Xavante que me convidou para ir até a aldeia.

Nosso presente foi guardado rápido, até porque um costume Xavante é que se você vê um presente que alguém ganhou e quer ficar com ele é só pegar, então os presentes são escondidos para que quem o ganhou não o perca.

Subimos novamente no carro e fomos para o centro da aldeia. Lá havia uma pequena construção com uma muretinha bem baixa feita de alvenaria, demarcando um espaço e segurando algumas poucas vigas de madeira que sustentavam a estrutura do telhado (feito com uma espécie nativa de palha). Uma construção que parecia integrar materiais de "fora" $e$ "dentro" da aldeia. Nesse espaço havia poucas cadeiras retiradas da escola, nas quais foi nos oferecido sentar.

As pessoas se aglomeram ao redor, algumas por curiosidade, outras ao serem chamadas. $A$ maioria na aldeia possui proximidades familiares, principalmente em uma aldeia pequena (em torno de 100 pessoas segundo o indigenista que me acompanhava), e se dividem em famílias, tendo um representante em cada família que se manifesta em nome de todos. As pessoas foram vindo até nós e se apresentando, falando a língua nativa. Poucas pessoas falam português com naturalidade na aldeia, a maioria tem muita dificuldade ou não entende nada, e por isso conversavam apenas em sua língua nativa.

Após as apresentações o ancião Tobias nos colocou gravatas Xavante, uma grande honra por ser um dos principais símbolos de sua cultura. Eu recebi uma própria para mulheres. Mulheres usam essas gravatas apenas em ocasiões especiais. Também recebemos cordas finas feitas de uma árvore e que foram trançadas pelo próprio Tobias. Ele amarrou uma corda em cada pulso meu, um costume Xavante que pode significar apenas adorno ou algo mais complexo. No nosso caso a simbologia tinha a perspectiva de nos "amarrar a aldeia", uma forma de criar laços.

Eles nos trouxeram artesanato feito por suas mulheres. As mulheres fazem joias para vender, no intuito de ajudar financeiramente suas famílias, mas não são adornos que realmente usam. A técnica que demonstram é muito grande, sendo as joias feitas com incriveis detalhes e lindas combinações de cores. Também trouxeram alguns objetos Xavantes para venda, como bolsas, arcos e cordas. Comprei algumas coisas. 
Eles então começaram uma dança especialmente para mim. Me convidaram para participar e aceitei. Fizemos uma roda e começamos a dançar. A maioria adolescentes e homens. Os homens cantam e dançam diferente das mulheres, mas todos dançamos em roda, dando as mãos. A postura de dança dos homens parece remeter a força e coragem, e das mulheres parece ser mais um acompanhamento.

O professor Xisto pediu que eu me apresentasse a todos. Seguindo a tradição Xavante para falar (na qual havia sido orientada pelos indigenistas da Funai antes), me coloquei em pé, evitando o olhar diretamente para os olhos das pessoas, e comecei dizendo que estava honrada em estar lá, agradecendo a receptividade e então falei um pouco sobre mim e minha pesquisa. Tentei ser breve e objetiva, principalmente para facilitar a compreensão de minha fala.

O ancião Tobias fez um longo discurso na língua Xavante, mas direcionado para mim. O professor Xisto o traduziu em linhas gerais, dizendo que ele estava perguntando o que minha pesquisa queria com eles, e se eu os poderia ajudar de alguma forma, principalmente porque agora eles querem iniciar um trabalho com turismo. Já havia sido instruída antes pelos indigenistas da Funai sobre não fazer promessas aos Xavantes, principalmente porque eles são literais e imediatistas nesse sentido, assim tentei em linhas gerais dizer que minha pesquisa queria entender algumas relações do povo Xavante com a Educação, e que eu tinha a complexidade da distância geográfica e do compromisso com a minha pesquisa que poderiam dificultar minha ajuda a aldeia nesse âmbito de promoção do turismo, mas que se houvesse algo que pudesse fazer remotamente ficaria feliz em ajudar.

O professor Xisto pediu então para que apenas os professores ficassem ali para conversarmos. Os demais adultos e algumas crianças então voltaram para suas casas, e algumas crianças ficaram por perto, brincando ao nosso redor. Embora houvesse outras pessoas o professor Xisto foi quem majoritariamente falou comigo, em parte por ter sido ele que me convidou, mas também por ser o coordenador da escola, e por se apresentar como "quem manda" na aldeia.

Pedi autorização para gravar nossa conversa, e após ele autorizar, liguei um gravador. Havia previamente estruturado questões objetivas, mas ali percebi que esse tipo de formalidade não funcionaria, tentei então fazer perguntas gerais nas quais em sua fala pudesse posteriormente tentar identificar os pontos que almejava. Ele me respondeu de forma calma e eloquente, sempre trazendo a importância da cultura de seu povo para destaque.

Estávamos lá há várias horas, tendo então já passado do horário do almoço e, assim, achei prudente finalizar a "entrevista", agradecendo grandemente a oportunidade. Pedi então para conhecer a estrutura da escola e da biblioteca, pedindo autorização para fotografar. Eles 
autorizaram e o ancião Tobias nos acompanhou até lá, ele guardava as chaves da biblioteca, e um professor guardava a chave da escola.

Primeiro entramos na biblioteca, sempre com a supervisão de Tobias, que nos explicou um pouco sobre como usavam o lugar. A biblioteca é um cômodo relativamente grande, fresco, de alvenaria, e com um acabamento rústico do lado de fora. As poucas estantes com livros estão juntas em uma extremidade do cômodo, e todos os livros por elas estavam bem sujos, sem marcas de uso, e sem nenhuma divisão ou organização. Os títulos claramente não possuíam uma política de escolha, mas pareciam ser provenientes de sobras e doações, incluindo livros didáticos, de direito e literatura. Um livro de ensino para indígenas estava entre os livros e, embora aparentemente interessante, era na verdade direcionado ao povo Bororo, e não Xavante (os dois povos possuem uma rixa territorial na região).

As estantes estavam bem perto uma das outras, claramente para deixar o restante do espaço livre. O restante do espaço contava com bancos feitos também em alvenaria, junto as duas paredes laterais; na parede extrema a que estavam os livros havia uma espécie de mesa principal, do tamanho de uma mesa de escritório grande, também de alvenaria. Atrás dessa mesa havia duas imagens católicas penduradas no centro da parede e, mais ao lado, encostada na parede, havia uma segunda mesa, menor e com outras imagens de santos e de um índio ameríndio. Tobias nos esclareceu que as imagens foram presentes, e que eles usavam aquele ambiente para danças também. A composição geral do espaço parecia um ambiente religioso, como que utilizado para orações.

Saímos e fomos para a escola, que fica a poucos passos da biblioteca. Lá encontramos uma pequena sala de aula e um pequeno cômodo identificado como cozinha (no qual não entrei). Na sala de aula me esperava o professor que abriu a sala, mas ele estava usando o celular para jogar e não parecia muito disposto a conversar. Respeitei e dei uma olhada no geral da sala. Havia muitas coisas embaladas empilhadas ao fundo da sala - livros didáticos, carteiras e cadeiras num grande amontoado, ainda em plásticos. No espaço utilizado da sala havia poucas carteiras e cadeiras, uma lousa, e uma mesa com computador com acesso à internet, usando principalmente para que os professores possam lançar as notas no sistema. Fazia muito mais calor naquele ambiente.

Saindo da sala de aula o ancião Tobias me chamou para arrumar minha gravata e me mostrou um bebedor cromado, me dizendo para tomar um pouco de água. Obedeci. Depois nos mostrou a árvore ao lado, dizendo que a utilizava para fazer as cordas, e nos mostrou um pé de fruta que havia próximo. Aproveitou a oportunidade para se dirigir ao indigenista que me acompanhava e começou a perguntar sobre algumas coisas e pedir outras. Voltamos ao centro da aldeia e por um tempo eu fiquei aguardado enquanto todos continuaram a conversa 
com o indigenista. Ao fim da conversa entre eles, paguei os artesanatos que havia comprado e então nos despedimos de todos e fomos embora.

Durante a visita fiz poucos registros fotográficos, e nos que fiz tentei não focar em pessoas (principalmente crianças), construções ou objetos que não faziam parte de nossas conversas, principalmente para evitar uma impressão de exploração. Os indígenas da aldeia usavam roupas, chinelos, e pouquíssimos adornos. Todos usavam a franja característica da cultura Xavante.

\subsection{OBSERVAÇÕES}

A intenção inicial dessa pesquisa de tese era ampliar as observações, a fim de conseguir se aproximar de aspectos identificados. Porém, inicialmente com necessidade de adequação do calendário das visitas com o calendário de festividades e rituais da aldeia, assim como com a necessidade de adequação ao calendário escolar e, posteriormente em virtude do impedimento de acesso à aldeia pela pandemia da Covid-19 durante o ano de 2020, as observações previstas foram inicialmente suspensas e, a partir da constatação da impossibilidade de executá-las dentro do cronograma possível de desenvolvimento da tese foram finalmente canceladas.

Figura 8: Sinalização de início de área indígena protegida.

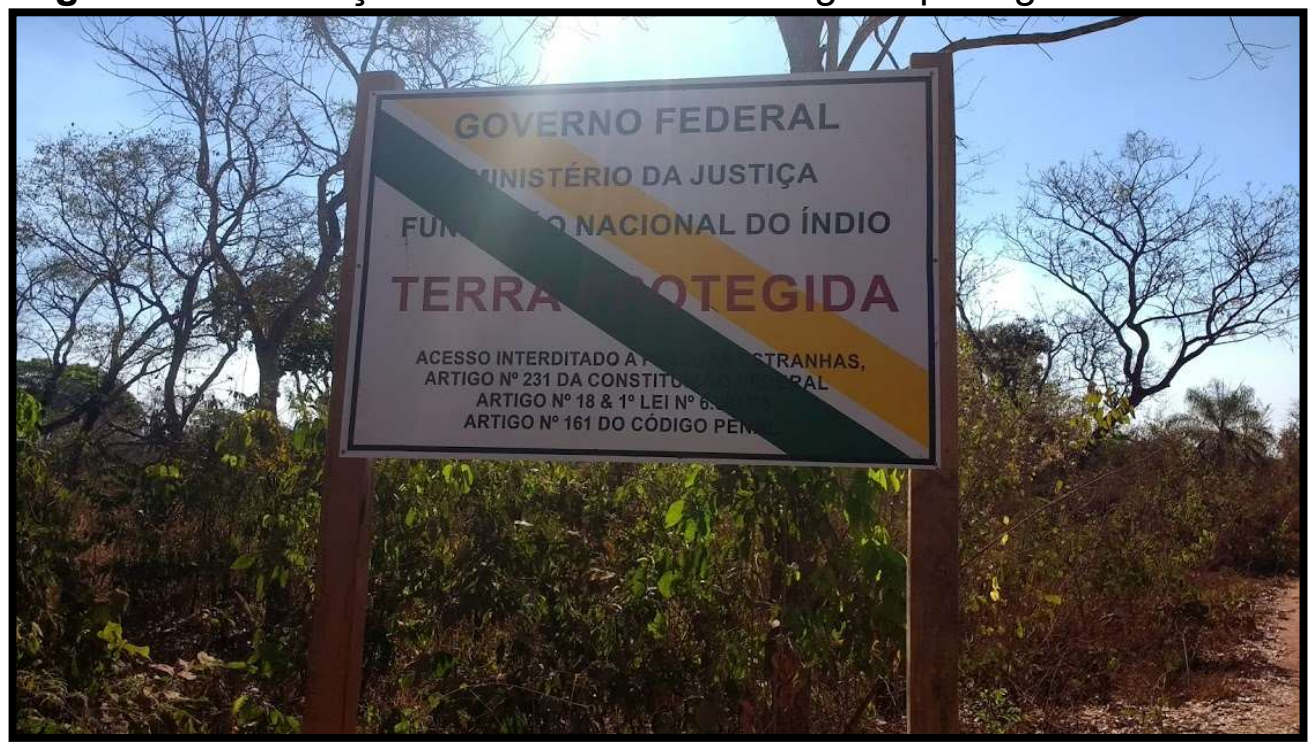

Fonte: acervo pessoal. 
As terras indígenas visitadas se encontram a uma distância de, em média, 30 minutos desde a cidade de Barra do Garças, no interior do estado de Mato Grosso, Brasil, utilizando um automóvel como transporte. O transporte foi cedido pela FUNAI, assim como a visita foi acompanhada por um indigenista.

A sinalização indica que a partir desse momento a área é protegida e os povos ali viventes têm autonomia legal sobre esse território, ao menos teoricamente.

Passamos por diferentes aldeias até chegar a uma das mais distantes, a Aldeia de Nova Esperança, onde éramos esperados.

Figura 9: Aldeia Nova Esperança 1.

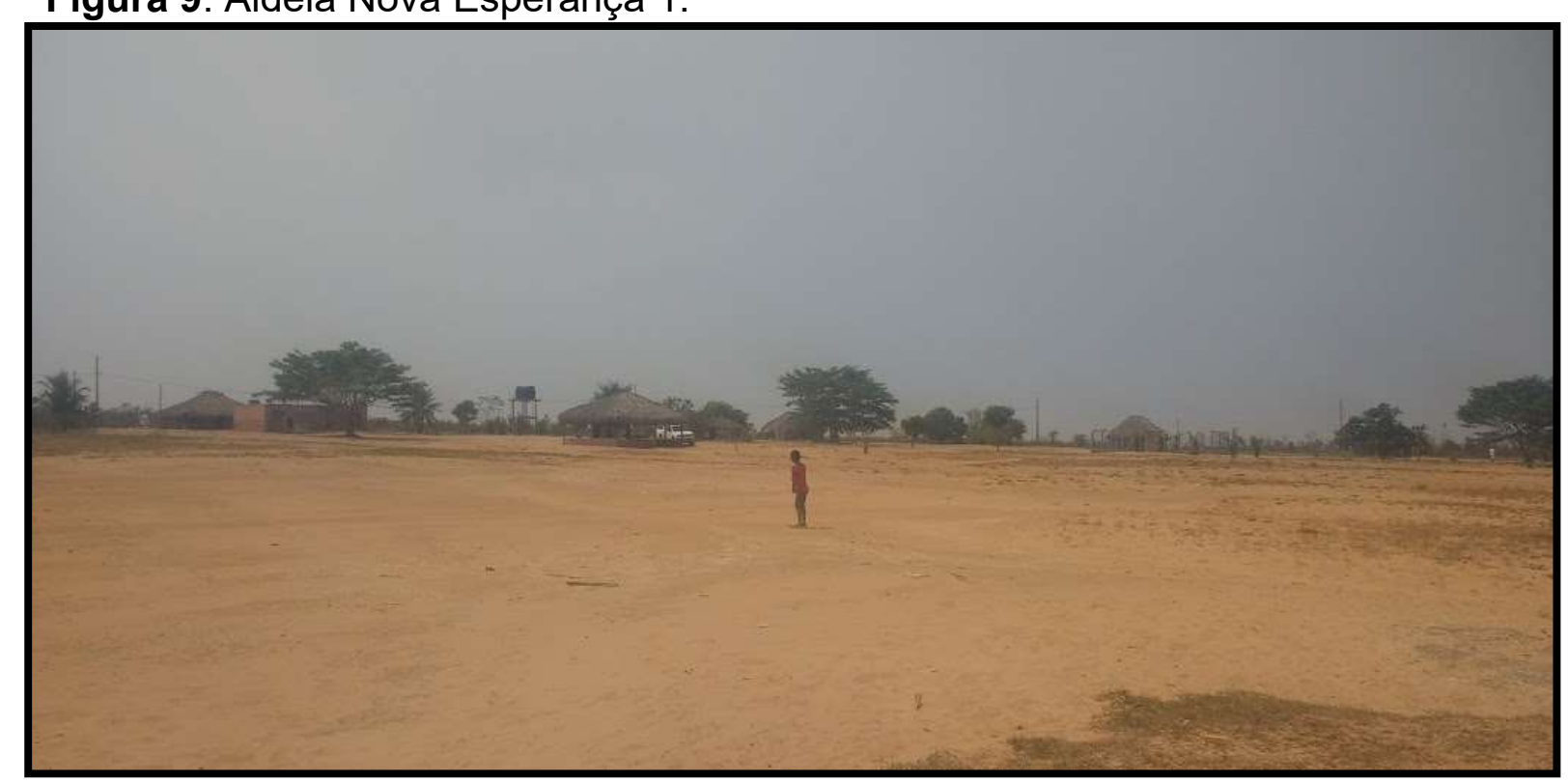

Fonte: acervo pessoal. 
Figura 10: Aldeia Nova Esperança 2.

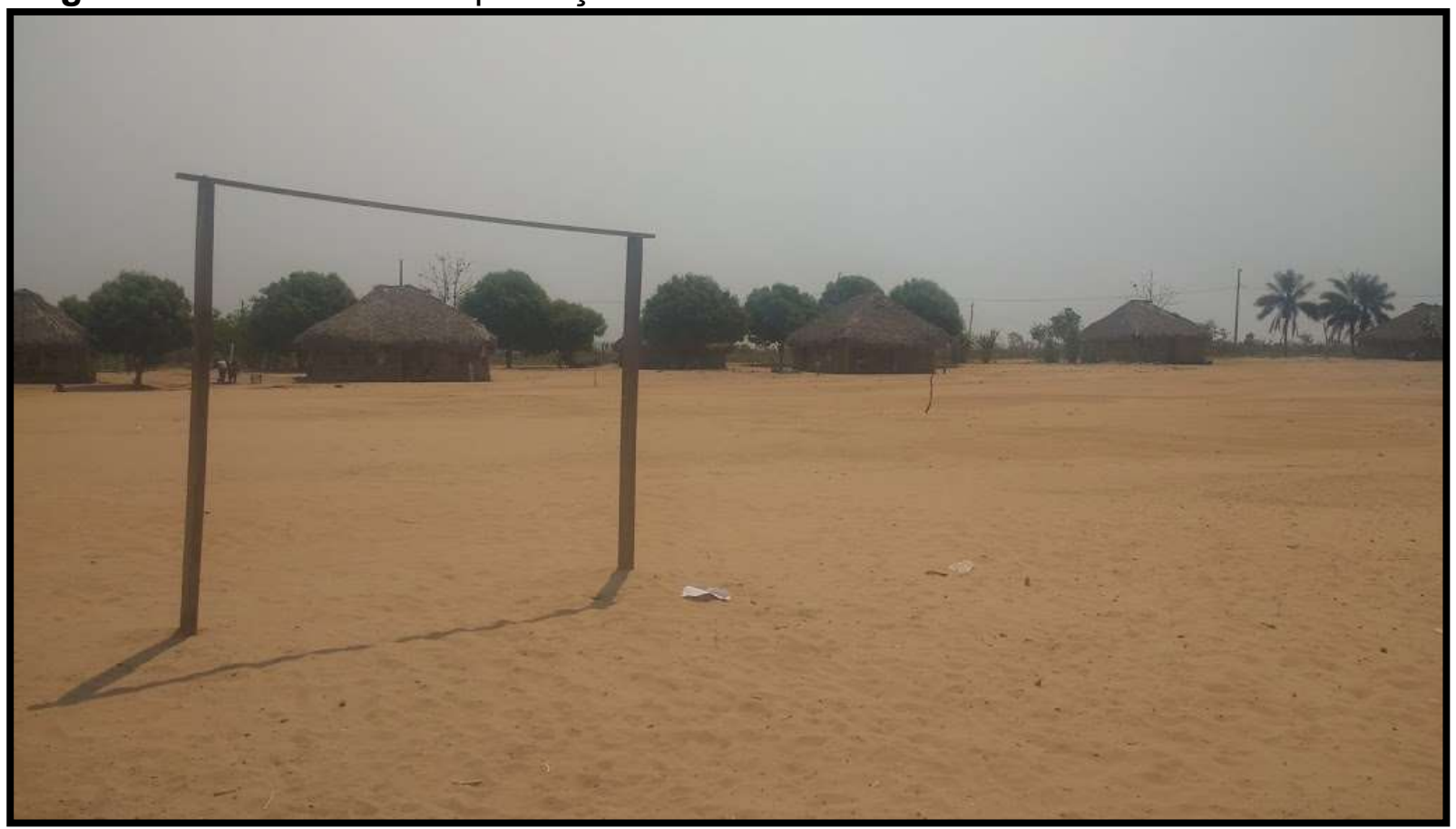

Fonte: acervo pessoal.

O local é limpo e ordenado dentro de uma lógica que se transparece pela posição das construções. O clima da região na época da visita é quente e seco.

Nessa perspectiva estão, na primeira foto, algumas casas ao fundo e ao centro, próximo ao carro da Funai, o local de reuniões (local onde foi realizada a entrevista).

Figura 11: Prédio da escola da aldeia.

Fonte: acervo pessoal. 
Figura 12: Frente de prédio da escola da aldeia.

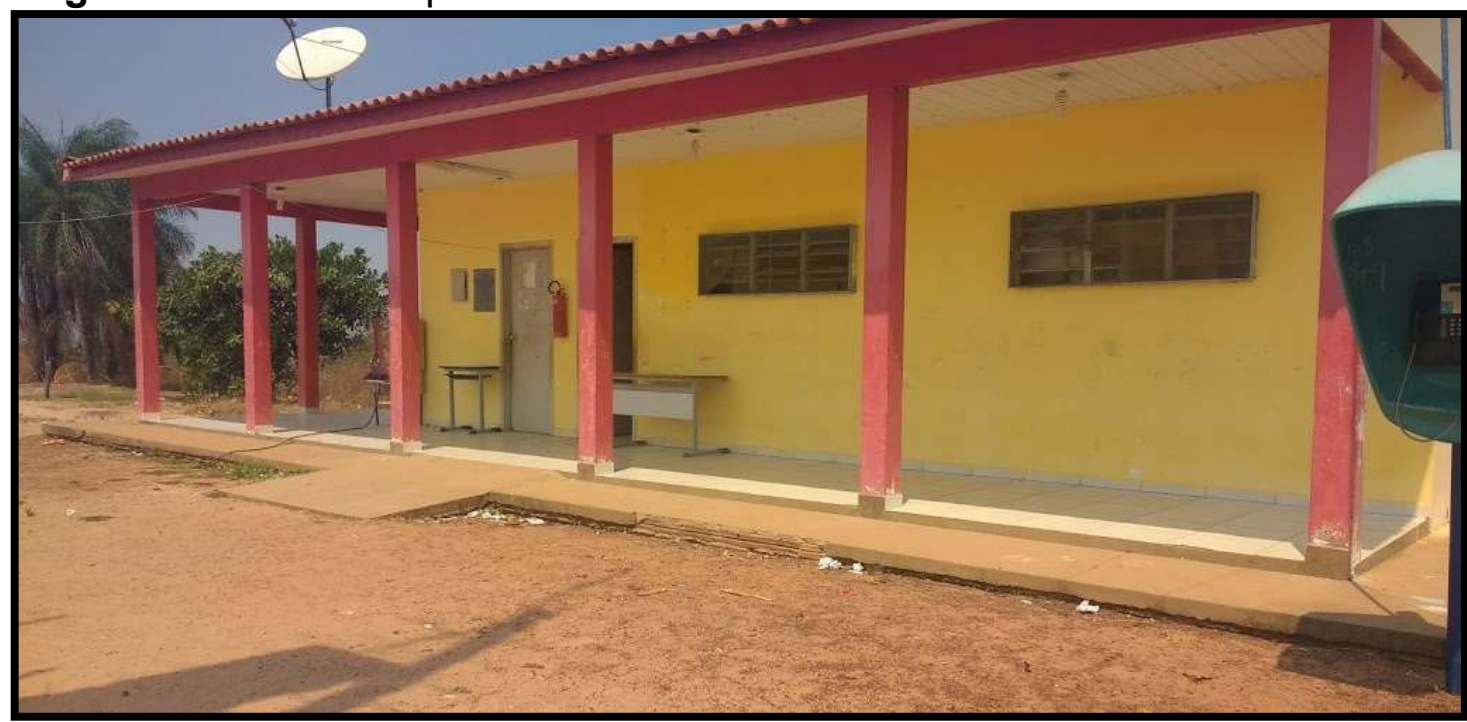

Fonte: acervo pessoal.

Os prédios da escola e da biblioteca se encontram na outra perspectiva da aldeia, em uma construção bem diferente das demais.

Sua construção foi uma iniciativa governamental e possui estruturalmente 1 sala de aula (com um computador com acesso à internet), 1 cozinha, 1 dispensa e 2 banheiros e, em seu entorno, um telefone público e um bebedouro.

Figura 13: Interna de sala de aula 1.

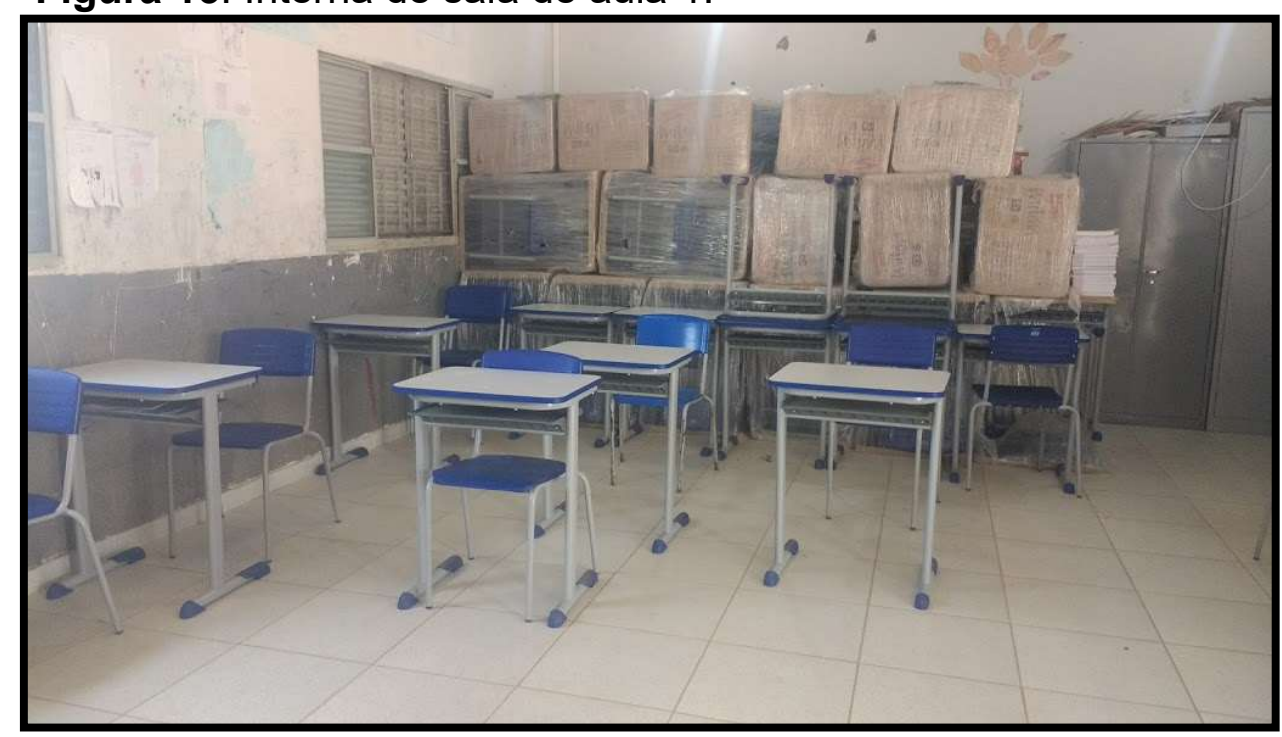

Fonte: acervo pessoal. 
Figura 14: Interna de sala de aula 2

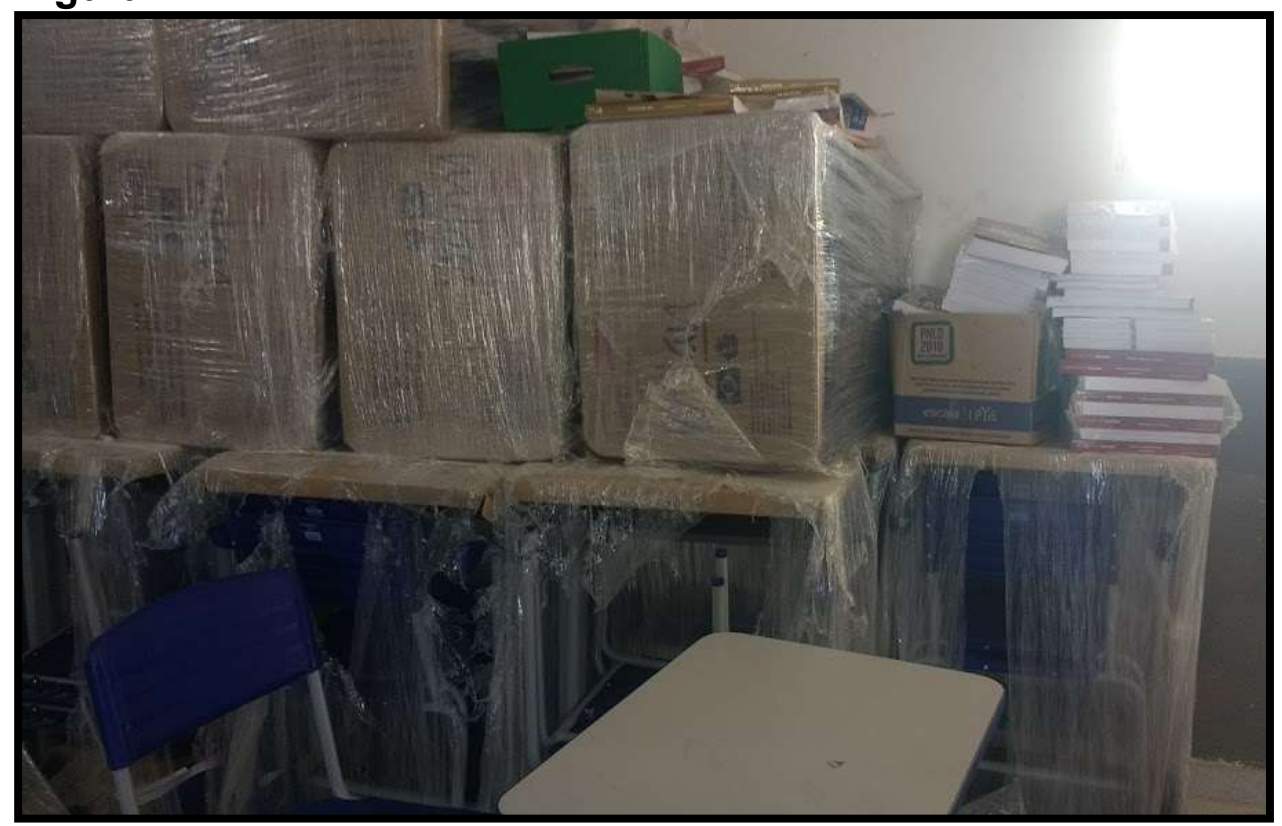

Fonte: acervo pessoal.

A disposição interna, sem muitos objetos, é a mesma encontrada na maioria das escolas públicas brasileiras.

O material ainda embalado ao fundo são móveis e materiais recebidos pelo governo e que não estavam sendo utilizados no momento.

A visita foi realizada em um dia não letivo. 
Figura 15: Lousa dentro de sala de aula.

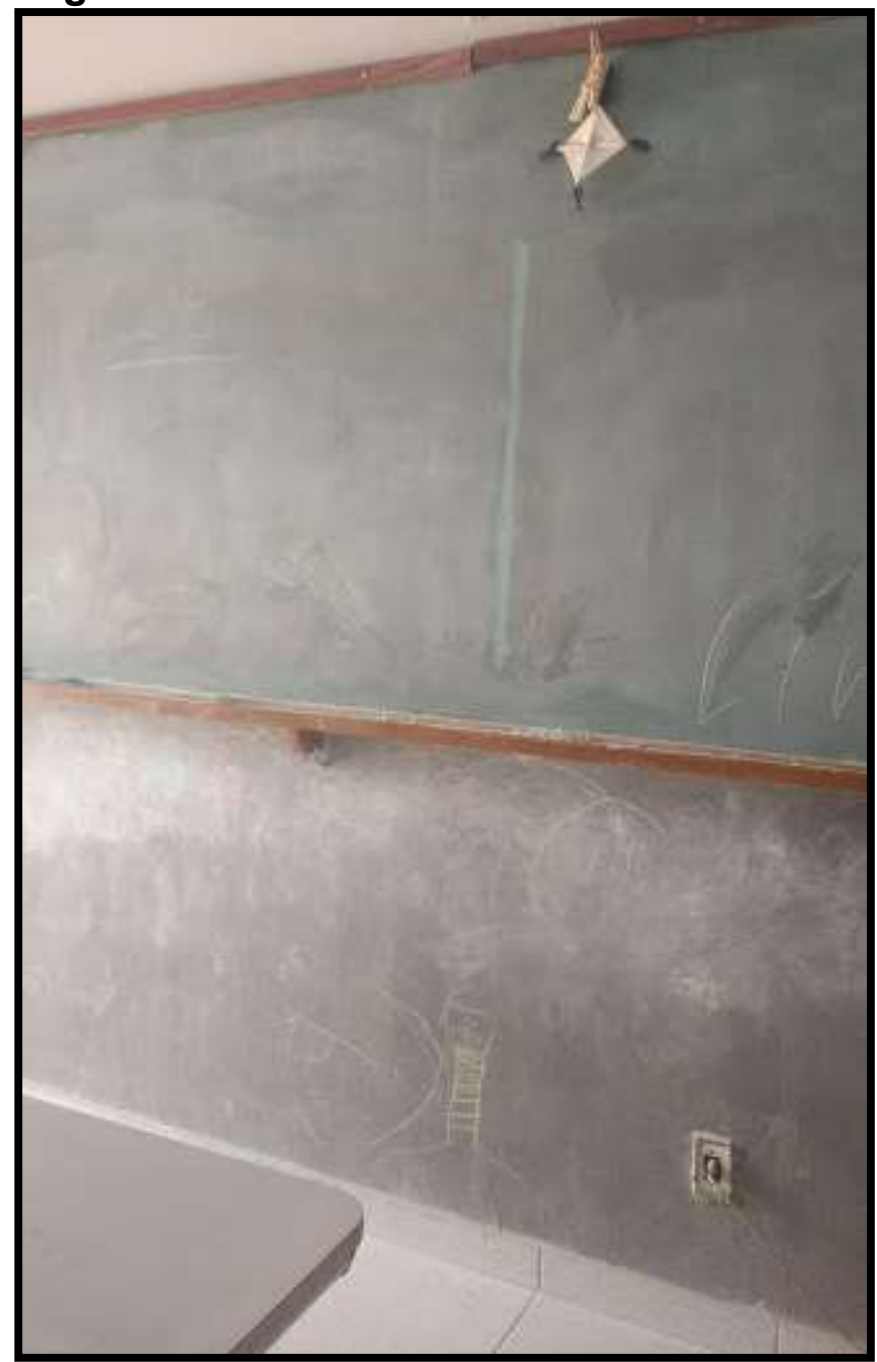

Fonte: acervo pessoal.

A lousa, localizada no outro extremo da sala, atrás da mesa do professor, possuía um artesanato pendurado em seu superior, e alguns desenhos realizados com giz em seu entorno. 
Figura 16: Prédio da biblioteca.

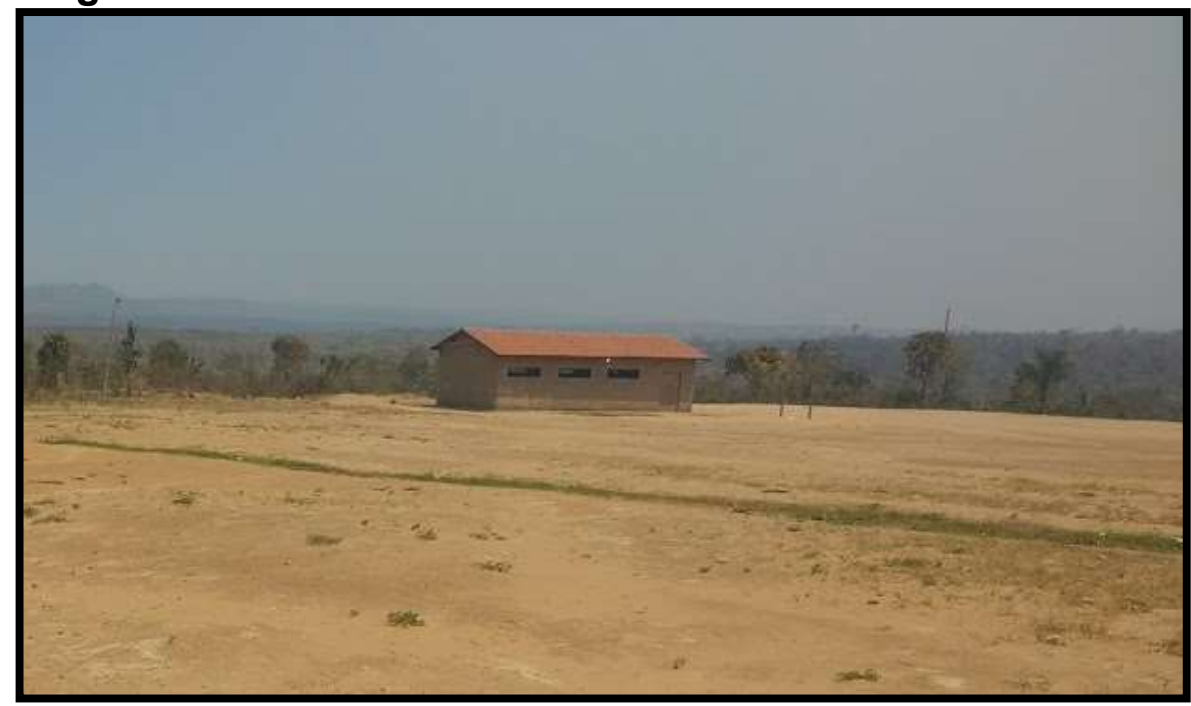

Fonte: acervo pessoal.

Na visita foi possível visitar a biblioteca da aldeia. Não era previsto na pesquisa que esse espaço já existisse.

O prédio, advindo de uma doação, é mais simples e o mais afastado das demais construções e, talvez pela sua cor, não obtém muito destaque no ambiente.

Figura 17: Espaço interno da biblioteca, com acervo ao fundo.

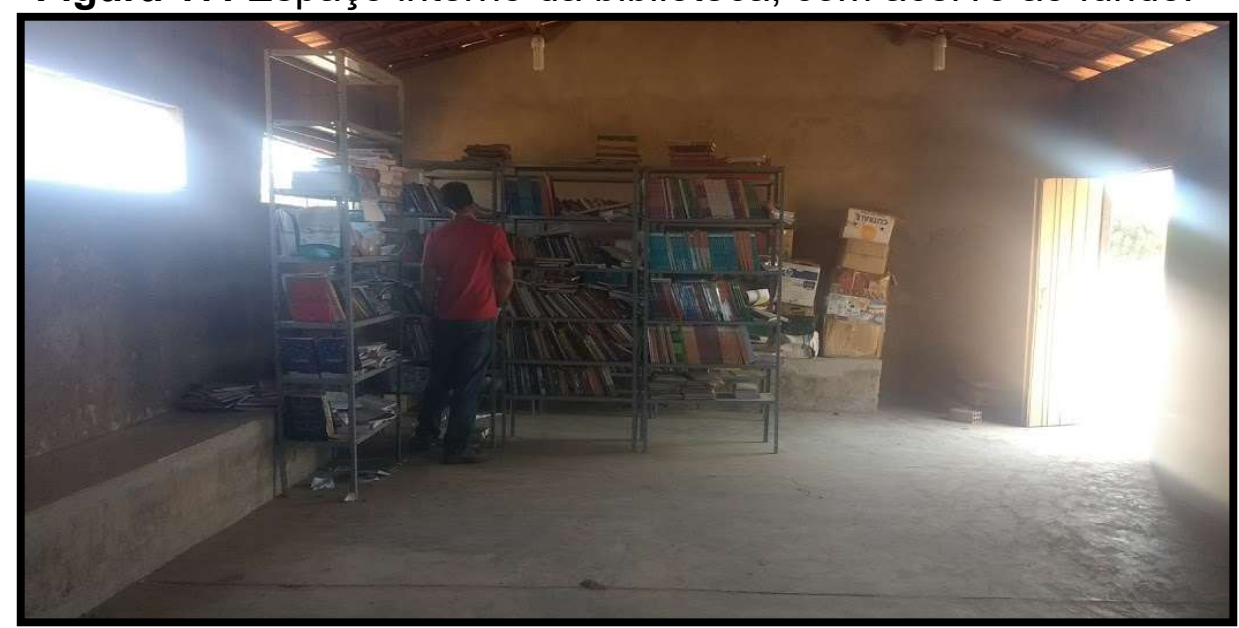

Fonte: acervo pessoal.

O acervo está concentrado em estantes dispostas logo na entrada do prédio. Ao fundo se observam caixas com livros, dispostas sobre um banco de alvenaria que contorna quase toda a construção internamente. 
Figura 18: Espaço interno da biblioteca.

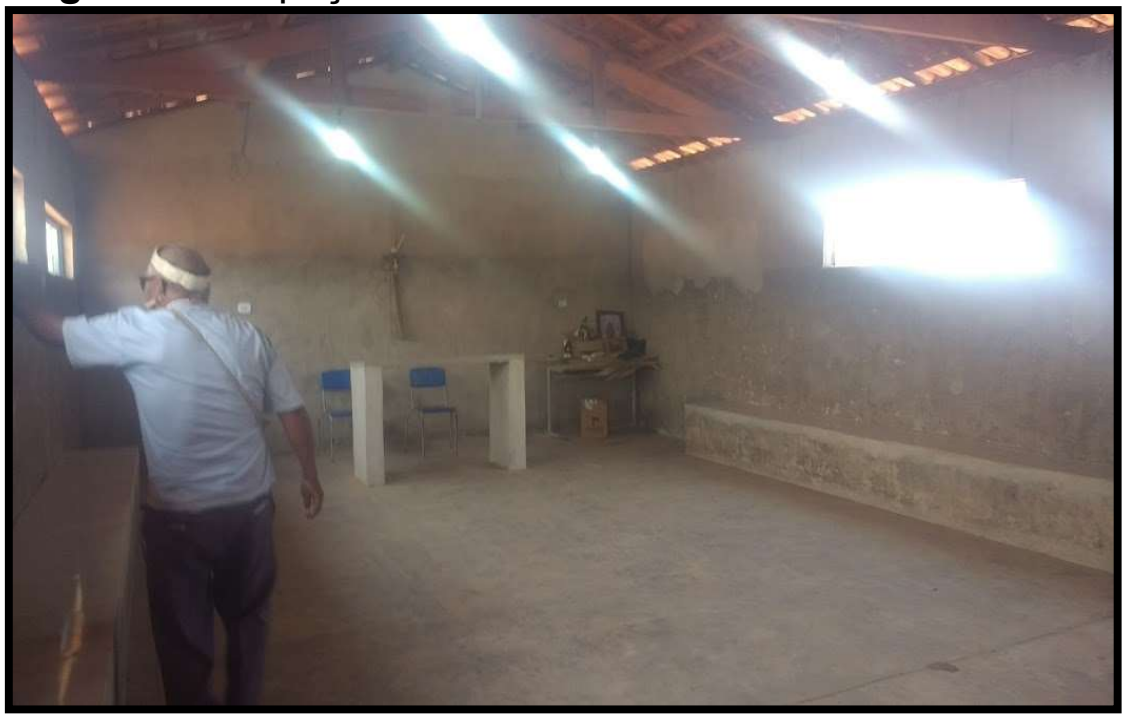

Fonte: acervo pessoal.

No outro lado observamos o maior espaço da biblioteca, onde há a mesa ao fundo com um pequeno altar religioso à sua direita.

Figura 19: Acervo da biblioteca.

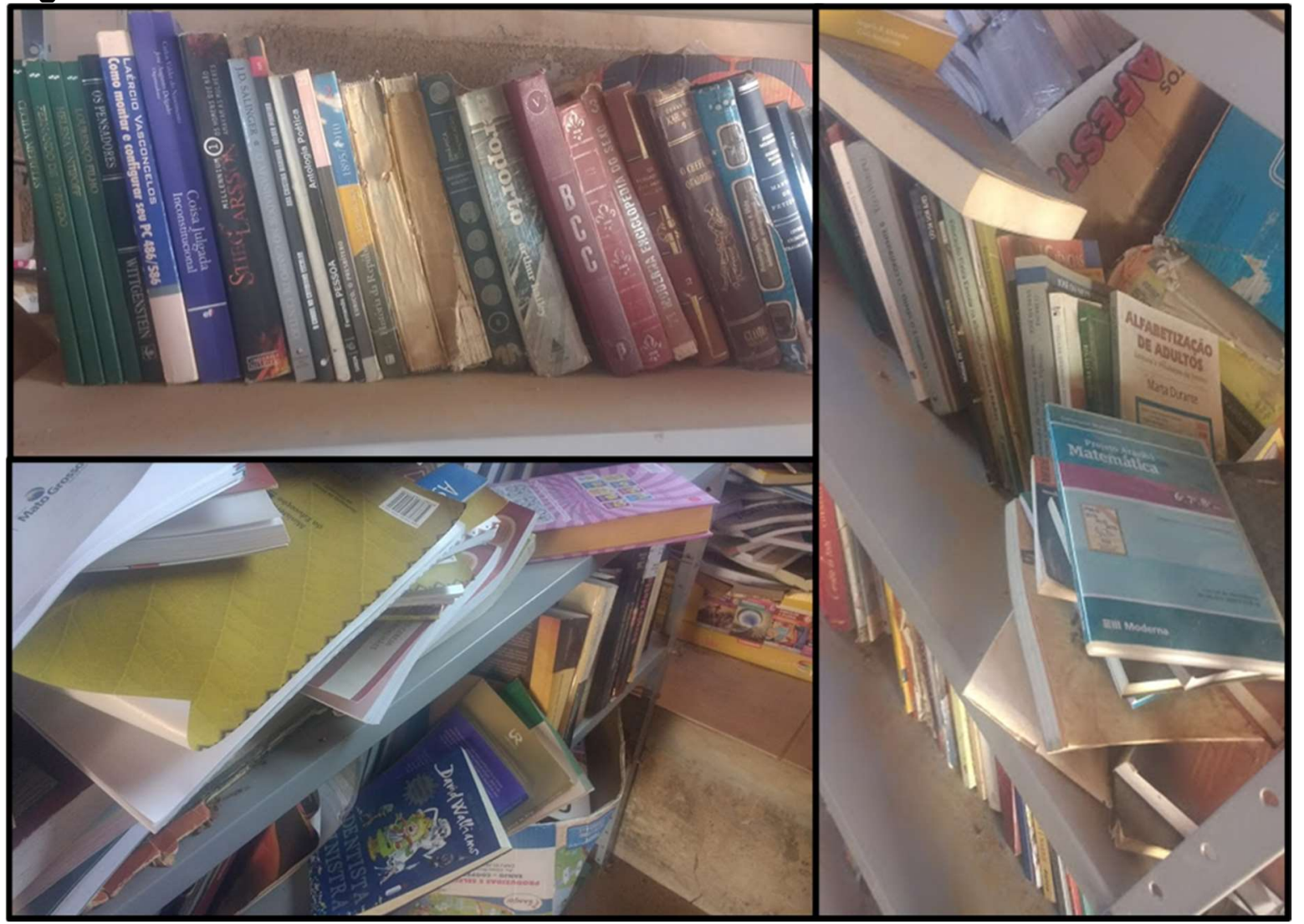

Fonte: acervo pessoal. 
É possível observar, ainda que sem um aprofundamento de análise do material que compõe o acervo, a existência de uma disposição desordenada e de títulos sem uma clara política de aquisição.

O espaço da biblioteca é de uso interessante para a aldeia, porém não necessariamente enquanto biblioteca propriamente. Nota-se, pela própria disposição do local, que o foco não é exatamente o material ou pesquisas que ali se desenvolvem. Porém, ao falar sobre o local, os indígenas que acompanharam a visita demonstraram interesse em sua adequação para que ele realmente pudesse ser utilizado para pesquisas.

A pessoa identificada como "bibliotecário responsável" é um indígena da comunidade, com o qual não tivemos a oportunidade de conversar.

\subsection{ENTREVISTA}

Nesse ponto apresenta-se alguns dos aspectos apresentados pelos professores indígenas e o ancião e cacique da aldeia. A entrevista foi realizada com todos, coletivamente, ainda que o principal interlocutor tenha sido um professor específico.

O momento de fala para os Xavante é muito respeitado e, assim, sempre que uma pessoa começa a falar ela não é interrompida até que termine seu raciocínio.

Os trechos abaixo relacionados são discursos transcritos em sua íntegra, sendo que as intervenções da pesquisadora estão sublinhadas e deslocadas do texto discursivo do entrevistado. A sinalização “***” demonstra material inaudivel/incompreensível para transcrição.

- Estamos tentando ainda a implantação plena do $P P P^{20}$, construída pela comunidade e não está sendo fácil porque essa colonização de sentar na fileira, na sala, introduzida, não está

\footnotetext{
${ }^{20} \mathrm{O}$ documento referido é o Projeto Político Pedagógico, construído com apoio do FORUM Tsihorirã no âmbito do Território Etnoeducacional A'uwẽ Uptabi (TEEAU - que envolve as Terras Indígenas Xavante: Pimentel Barbosa, Areões, Marãiwatsédé, Marechal Rondon, São Marcos, Sangradouro, Parabubure e Território Etnoeducacional A'uwẽ Uptabi Ubawawe; e tem o apoio das instituições parceiras: FUNAI, UFMT,UNEMAT, NPD, CEFAPRO/BGA/PVA, SUDE, SUFP, SAPE, UNEMAT, Assessorias Pedagógicas de Barra do Garças, General Carneiro, Campinápolis), a partir da necessidade da elaboração da Política de Educação Escolar Indígena para Mato Grosso, de forma participativa e consultiva dos povos indígenas e dos profissionais de educação.
} 
sendo fácil tirar da cabeça dos professores, até dos pais assim. Mas na nossa comunidade aqui temos costumes próprio, da aldeia, quer dizer, aproveita o nosso pai, ancião, o único ancião da aldeia, pra transmissão do conhecimento, e nessa aldeia não temos é implementação de membro para cerimonia própria, nós somos ligadas à aldeia mãe, quando, na participação da juventude a gente vai pra lá. Juventude é passagem. Ficamos lá 3 meses, 6 meses, porque eles ** complementa essa fase, então nós dependemos da aldeia mãe pra essa passagem, nós. E o cacique não autorizou ainda a construção do uho - nós precisamos construir uma casa de adolescente, aí vamos chamar os vizinhos pra participar, aí vai ter cerimonia mesmo, mas é um projeto cultural ${ }^{* *}$, tudo esse ritmo depende de algumas coisas, de ${ }^{* *}$, de padrinho, de adolescente, da juventude, então...

Mas, o PPP construído foi devido meu pai, transmissão da filosofia, mas estamos buscando a intervenção dele da prática, da prática. Então precisa explicar pro seu chefe que temos uma riqueza pra você citar na sua pesquisa. Por exemplo, essas meninas, tem sua participação filosófica, sociocultural dentro da comunidade, cacique também, como ancião, pré ancião ainda, ele também, temos essa participação dentro da cultura, meu pai já é o ancião do ancião, então a participação dele já é outra. Temos esse ciclo de vida já construída, assim, milenarmente. E, se puser incluir na sua pesquisa da justificativa da sua vinda, temos participação da FUNAl, que trabalha no setor da educação [ $\left.{ }^{* \star}\right]$.

Mas pra complementar é só com a gente mesmo, com o Xavante.

Estamos à disposição para colaborar com isso.

Até porque pelo meu caminho eu vejo que dão pouca importância pra essa questão, querem generalizar, globalizar a educação e não serve pra nós, não serve pra essa gente.

E a escola aqui, como funciona na prática? Vocês ministram aula para um grupo só com a educação que vem de fora? Tem separado a de vocês e a que vem de fora? Se é difícil, se é fácil... Em que etapa vocês estão da escola aqui?

- O estado tem seu sistema e nós também temos nosso sistema de educação. Então, o estado cobra muito da gente: horários, cotidiano né? mas, temos padrinho na cultura e é obrigatório participar pra dar ritmo na área de educação tradicional, a participação deles, então a gente quebra protocolo pra participação dos padrinhos. Até os alunos educando que participa assim como adolescente, então os professores têm que ir pra participar, eu não posso cobrar como diretor, mas é obrigatório que eles participem da cerimônia.

O estado cobra para o registro, o registro no diário eletrônico, mas nem todas as coisas a gente fala pra comunidade, tem coisas que só os homens podem saber. Então tem essas divergências, esses ** na educação e não é só que a gente educa, mas espiritualmente a gente educa também. Então ${ }^{* *}$ precisamos de isolamento, ${ }^{* *}$ então a gente fala que é o segredo dos homens, pra fortalecer ${ }^{* *}$ espiritual, então essas coisas a gente colocou no nosso calendário assim, como um acontecimento aleatório da cultura, e é incompreensível para o sistema. Então, nós atendemos público é até o ensino médio da educação básica, atendemos [é], educação de jovens e adultos, pra salas anexas, temos 5 salas anexas, algumas comunidades aqui. Então é muito difícil a gente trabalhar pedagogicamente porque temos transporte [é] eles dão combustível, mas o essencial, o transporte não tem, pra administração da escola. Até merenda a gente tem dificuldade, então tem essas coisas que a gente enfrenta. Acho que temos mais ou menos 20 professores, aqui das salas anexas acho que temos o que, 7 , na sede né, com 7 professores incluindo apoio também, com vigia, pra dar manutenção da escola, como parte elétrica, de agua né, até na limpeza também, faxineira, merendeira, temos aqui, temos 6 turmas aqui na sede e uma sala que é esta aqui [apontando para a construçãol, isso aqui é obra da FUNAI mas é da comunidade e o professor e essa casa da 
missão salesiana que construiu [apontando para a segunda construção], mas atende biblioteca, tá lá, então propriamente do estado é só aquele lá, uma sala de aula, cozinha, dispensa, dois banheiros, sala de professor não temos, administração não temos, o que dificulta o trabalho do secretário e a administração do diretor também. Para encontro do professor e sala do professor não tem, que é o trabalho pedagógico e é essa dificuldade de se trabalhar.

\section{- E pra vocês quando a educação começa?}

- Quando nasce. Primeiro ensinamos os pais, como se deve comportar quando o filho é criança, recém-nascido, o resgardo. Como o pai come muito dá gases pros filhos, não deve comer muito, qualquer coisa, não deve comer muito, come um prato bem, bem, assim, delicado, sem gordura, sem aquela comida que dá muito gases, pra que a criança não tenha gases, que ele cresça assim, é, sem problema, antigamente, num sei hoje, antigamente nossos pais banhavam a gente de manhã, mesmo quando criança, pra que nosso corpo reaja e se desenvolva mais, mas hoje com a educação da colonização previne que não se deve banhar a criança, que dá resfriado, mas nós somos xavantes, assim, eu, ele, que nossa mãe banha a gente de manhã, ** forte, então essa educação a gente recebe assim com medo de que as crianças adoeça, mas eu num falo assim pra minhas criança, olha eu tomava banho de manhã, eu ia lá no rio, e a gente voltava pra casa de manhã assim, tremendo de frio, mas é o prazer de tremer, o frio, então, a diferença da educação de hoje a gente não atende então primeiro as crianças a gente ensina a conhecer o membro da comunidade, os tios, os pais, tudo, e gente fala pra respeitar os outros, que a escola não ensina olha seu tio, seu avô, sua tia, conhecer todo mundo da aldeia. A escola não ensina isso, você tem que respeitar os mais velhos, isso é em casa, é família, até porque a criança é vista pela comunidade, toda comunidade percebe quem é aquela pessoa, tá todo mundo aqui educa a criança, ou seja, eu tenho que ser educado pra que a criança seja educada igual a mim. Tem que ter delicadeza na educação. Então, é, as vezes os professores da educação escolar está passando do limite também, em algumas comunidades grandes, que recebe mais, é mais formado academicamente, então passa dos limites com o cacique, até com a comunidade, tem bebida, tem já entrou droga, é, então, essa dificuldade as vezes o professor vai lá na escola, as crianças vê que ele bebeu naquele dia, então essa imagem que ele leva até a escola as vezes prejudica a consciência da criança né, então é o cuidado que a gente tá fazendo aqui mas é difícil essa globalização entra sem bater a porta. Então acho q é isso, quando chega na sala tem q sentar direitinho, todo no calado, é o limite do tempo também, porque pra nós não tem limite do tempo , é de manhã, a tarde a noite, [é] de acordo c o ritmo do tempo, então é se realizamos canto da noite, e esse canto da noite é serve pra gente aguentar o sono pra gente acordar de repente quando tá dormindo. Isso é para os homens. Nós aprendemos que aquele vai servir pra quando emergência a gente aguentar o sono né, se acontecer alguma coisa ele estar lá sem prejuízo do sono, pra estar atento a situação, então serve pra isso mas quem não aprendeu fica perdido, então toda essa pedagogia aqui no nosso trabalho a gente quer introduzir no nosso trabalho escolar, não tem como a gente conviver nessa globalização uma coisa separada mas a pergunta é, se eu trabalhar a educação, os professores, os indígenas aqui da região, se eu trabalhar a noite o estado vai me pagar aqui, da noite? Do turno da noite? Justo a FUNAI, ** realizamos o fórum, in loco né ** $e$ as perguntas vem saindo, uma riqueza de perguntas, então eu me comporto como líder da educação escolar indígena e veio percebendo essa compreensão, dos professores, principalmente né, e minoria dos não índios, com Gabriel, com Luciana, com a equipe dela, nada mais, porque o estado propriamente não quer entender, você já percebeu na sua pele que ninguém quer saber mas tamo aqui porque é nossa convivência, então a pergunta é, a dúvida que se paira no ar, é quem sou eu, nessa globalização da educação, ou qual é a minha participação, eu sou professor da escola ou membro da comunidade? Então, é, membro da comunidade eu não sou professor nem sou 
diretor, eu sou meramente membro da comunidade com participação na cerimônia como qualquer um, mas fora da cerimônia eu sou diretor, eu comando a escola, tenho meus funcionários, é uma coisa separada da outra, não tem como, não tem como, não está tendo como fazer junção, não está tendo, eu vivo a minha vida, culturalmente, eu vivo a minha vida assim de trabalho, eu tô aqui como membro da comunidade, eu uso poucas vezes a direção da escola, ser professor, quando eu estou conversando aqui com você, eu sou professor, quando eu vou na cidade == eu sou professor, mas até na minha formação eu percebi que eu tenho que me graduar mais, pra eu dialogar, ser igual aos profissionais da educação, se não for assim ninguém vai ouvir, ninguém, eu percebi isso ***. Então é isso Heloá, eu quero ano que vem fazer mestrado pra dizer isso, pra dizer isso, essa construção da PPP diferenciado, e me comporto como profissional da educação diferenciado, diferenciado porque tem a educação tradicional escolar, e tem a educação tradicional indígena, eu ando nesses dois mundos e me comporto como diferenciado. Eu sou professor ${ }^{* * *}$ diferenciado. E essa foi a minha deixa em algumas falas de discussão, as vezes a gente conta como o professor ou professora que não quer saber, e o professor que sabe demais, ó o indígena é assim, já fala, já propõe, mas eu falo "não, eu sou indígena, eu conheço a minha realidade, eu sou um profissional da educação diferenciado", pra calar a boca, porque ele não quer compreender, que vai dizer, ${ }^{* *}$ pode ir, que vai falar a mesma coisa, eu sou um profissional diferenciado, então a gente, eu tenho meu companheiro, colega, a gente tem enfrentado essas coisas, eu trabalhei na Seduc, na ** e a gente nas reuniões tem pessoas que sabem demais.

Não a gente enfrenta frente a frente a gente encara. Mas o governo muda a cada a cada quatro anos né, e nada de política permanece, política de governo em relação ao indígena e é difícil.

- Vocês acham que se as pessoas entendessem melhor, se todo mundo que trabalha com isso conseguisse entender melhor como é essa visão diferenciada, de vocês, isso seria bom pra vocês? Traria algum benefício?

- Eu sou um dos últimos que falaria isso, porque eu vejo que os professores esperam mais dos profissionais da cidade, como se a escola ** a educação escolar seja da cidade, do governo, do sistema. Então os profissionais, os colegas meus, indígenas, espera mais disso né, mais eu acredito que assim, muitos já tentaram contratar anciãos pra trabalhar nessa transição de crescimento escolar mas não conseguem porque o argumento do governo do sindicato é q não tem política dos indígenas, se for dos indígenas tem que pegar todos os estados do Mato Grosso, e é um problema, então se aproveitam disso também pra barrar as políticas indígenas.

- Então é assim, porque o sistema traz um pacote de disciplinas, de conteúdo de se trabalhar c carga horaria e tudo mais, e o currículo já feito, então o pessoal se acostumou a seguir aquele ritmo, os professores indígenas, os professores , mas não deixa de ser xavante, no nosso caso, ** sido praticado pelos professores pelos **, mas é, como se trabalhar na escola a filosofia indígena, principalmente a filosofia Xavante, ou seja dá uma qualidade, seja de crescimento da ${ }^{* *}$ indígena, seja da língua xavante, seja dos jargões existentes, seja da literatura, porque os livros distribuídos são nacionais, não tem especificidades, quando meu pai vai trabalhar essa transmissão de pensamento na sala de aula, como ele vai participar, então, é, nesse sentido eu vejo há necessidade da participação culturais na transmissão de conhecimento nas escolas. Assim, meu pai trabalhou, quando morava em São Marcos, na aldeia grande, ele conhece, a aprendizagem de artesanatos, então ele educou, ensinou, dentro da carga horária da aula, como se manuseia esse gravata, a cordinha, tudo, essa riqueza pra juventude e esses alunos dele já estão fabricando propriamente pra eles, pra geração deles, eu não participei, eu não sei fazer, então essa falta está me faltando muito porque eu já tenho meus netos eu já tenho meus filhos, essa utilidade que eu deveria aprender 
passou mas ainda dá tempo de aprender, então quando vai ter esse tempo? Já que a educação escolar tomou o tempo da educação tradicional, deve dá tempo dentro da sua grade, então é eu acho que é isso. Vai ser bom ou vai ser ruim? Vai ser pro sistema ou pro sistema da comunidade? Eu acho que vai ser bom para todo mundo, eu nunca vou deixar de ser xavante, nem pretendo para os meus filhos, para minha geração, porque esse ciclo de formação vai durar muito desde 1945, 1940, que é o nosso contato xavante, quanto tempo já temos preservando nossa cultura, então acho q é a necessidade de se implantar, de se discutir isso, mas isso, isso vai ser ==== porque quando sinalizamos esse desejo numa conferencia estadual o sindicato === a implantação do magistério indígena, quer dizer, essa política implantada dentro do sistema tem que passar por isso, e pra obter no sistema da educação estadual é específico para o povo indígena estadual - aí o sindicato. Isso vai gerar uma reestruturação dentro do nosso sistema, nosso sistema implantado, vai mexer com toda essa estruturação, o sindicato não deixou, então [é] nós precisamos de um político que abrace essa causa nossa, pra levar até a assembleia, dizer que há necessidade, mas esse nosso parlamentar que aparece na TV, com bolso cheio, com bolsa cheia né assim, não dá pra confiar, só se for indígena mesmo, não sei se, então, tem essa, essa barreira né, mas estamos aqui com xavante, praticando nossa cultura, essa queimada é nossa cultura, a gente cerca bicho e mata , e , vai ser assim, 50 anos, 100 anos, sei lá, mas estamos cercado de pasto aí, ele trabalha no pasto...

- E quando que um Xavante tem que sair pra estudar? Ele precisa? Atrapalha quando ele volta?

Muitos vai pra cidade pra sofrer, não sei por que, mas quanto líder na área de educação eu quero falar mais e não e fácil porque acho que cada um tem suas cabeças, suas filosofias...

\section{- E essa biblioteca? Vocês usam? Tem algum significado para vocês? Não é da cultura} Xavante mais a oralidade?

Não, essa implantação da biblioteca, eu acho que é necessidade, que tá sem uso, tá sem uso, mas eu gostaria que eles aprendessem, pra pesquisar, pra pesquisar. Nós temos que aprender a pesquisar, porque uma coisa que aprendi é ---- é ouvir e ouvir, eu gostava de ouvir meu pai, só que ele tá rezando muito, e aprendi a ouvir, gostaria que ele me ensinasse coisa tradicional, então essas coisas eu puxei ele através de um projeto de, tem um cara no estado do Mato Grosso que tem biblioteca itinerário, ele vai numa cidade pra outra, ele viaja dum estado num outro aí ele falou ô vem cá, você tem biblioteca? Não, não tenho não. Ó eu tenho acesso a embaixada posso buscar pra você, aí tenho um amigo irmão em Cuiabá, conversa com ele aí você me fala, tecnicamente. "A Xisto é assim, nós vamos trabalhar com o estado do Mato Grosso, aí é, vamos montar um projeto pra biblioteca, beleza, faz um projeto, quero porque a porta é aberta." Fizeram um projeto mandaram pra embaixada, a embaixada aprovou, mandou recurso, comprou livro, material, aí o estado reconheceu e implantamos ali, tem espaço ali, montamos ali, contratou um bibliotecário, também tem esse benefício, tá lá, aí falo com os professores pra fazer pesquisa lá, ficar lá um tempo. As crianças têm que aprender a ler, gostar de ler, mas os professores não tão usando, pesquisar, temos que aprender a pesquisar na leitura, explorar mesmo - interpretar o texto, então tem essa finalidade a biblioteca. 
Nós trabalhamos eixos temáticos

Um exemplo mais fácil, não sei se você conhece timbó, é um cipó, cipó, que a gente conhece que tem veneno, aí a gente tira, leva no córrego e a gente bate ali, extrai veneno, joga no córrego assim, ai o peixe vai atordoando, a gente flecha ele, consome. Então a gente leva a criança pra conhecer essa leitura, quando criança a gente só observa, a gente deseja ... deseja ficar com fome só pra flechar peixe, essa leitura de passar fome, flechar, bate, quando eu quero mais já pergunto meu pai, o peixe tá correndo assim, espera mais um pouquinho... então tem esse tipo de leitura que se ensina.

Essa queimada, as criança não vai, mas a juventude vai acompanhar, quem tem esse dom de caça já aprende logo, já entra assim, já mata, quem é divagar... tem esse ritmo de pedagogia , ninguém é obrigado a aprender tudo, tem pessoas que tem habilidade de cantar, de cantar, nós realizamos no Huara, aí lá reúne, discute, tudo, ali aprende a discussão, tudo é discutido, é ouvido, toda essa pedagogia tem seu ritmo de acordo com seu ritmo de crescimento. Tem pedagogia para caçadores...

Mas a educação escolar, por exemplo, a biblioteca, a gente ainda não aprendeu fazer essa leitura da escrita, eu acho que eu respondi essa diferença de leitura.

Esse é nosso ritmo de aprendizagem, aprender brincando, eu aprendi brincando. Quando a gente entra na sala de aula, professor quer que eu sente assim, quietinho, acho que tem mais prazer de aprender brincando, sem perceber que eu tô aprendendo, então não sei como fazer isso. Acho que eu, eu vi o professor sabe o professor que alfabetizo - crianças no ritmo deles aí eu perguntei --- faz tempo que eu queria perguntar a ele, agora que eu perguntei. "Olha você não precisa obrigar eles a prender, não precisa, eles que vão aprender sozinho" ele falou assim pra mim. Mas como? "coloca o nome deles, eles querem aprender o nome deles" --olha a metodologia dele, depois deslancha, vai uma palavra, uma oração... olha só o segredo dele. Todo mundo quer aprender seu nome.

Um único professor, ele não se exalta, --- ele sempre é humilde. Professores que se exalta, que eu conheço ---, não fazem isso. Fala muito. Não vi a esse desenvolvimento por parte deles, só fala muito. Quer dizer, esse cara sempre desejei perguntar a ele, como trabalhar igual a ele.

\subsection{PRojeto Político Pedagógico - PPP}

Os objetivos do documento mencionado (composto por 46 páginas e disponível no Anexo D), são:

Objetivo geral: Apresentar diretrizes que subsidiem a construção e implantação da Política de Educação Escolar Indígena para o Estado de Mato Grosso.

Específicos:

- articular a organização escolar com o ciclo de formação, tempos e espaços Xavante; 
- propor a inserção do profissional da Educação Xavante na carreira do magistério;

- indicar demandas de Formação profissional em nível inicial, continuada, contínua e desenvolvimento profissional;

- fortalecer o Território Etnoeducacional A'uwe Uptabi.

O documento, bem fundamentando legal e teoricamente, apresenta o contexto dos povos ali representados, com suas preocupações e contribuições para atingir seus objetivos anteriormente mencionados.

Destaca-se alguns pontos do documento:

Conforme diagnóstico apresentado pela Funai sobre o tempo e espaço, a escola não está voltada para o movimento do corpo, mas o contrário. A criança por exemplo, o movimento dela não sendo considerado pela escola, muitas vezes ocasionando indisciplina delas (gritaria). Nem o tempo e nem o espaço da escola estão adequados para a aldeia. Mas vários aspectos do cotidiano deve ser mudado por conta do calendário e da matriz curricular. Deve-se rever essa configuração que foi implementada pelo sistema educacional e que passou a impor o tempo da aldeia, mas que não concordam entre si. A escola está vindo para a comunidade e antes a comunidade é que ia para a escola. Até os projetos feitos pelos engenheiros e arquitetos são impostos sem considerar as sugestões da comunidade. (p. 24)

$[\ldots]$

No nosso Projeto Político Pedagógico já se discute a questão de tempo e espaço escolar e de como garantir uma educação diferenciada. O tempo de horas aula (quatro horas) não tem se mostrado eficiente para nós. É uma estrutura muito estranha porque vem de fora. Fomos questionados pelos anciãos pelo tempo/horas aula que nós queremos. $O$ tempo de horas aula que foi imposto tem influenciado o comportamento dos jovens de várias formas, entre outras coisas como o uso do uniforme, por exemplo. O jeito de educar o corpo também tem-se modificado.

Convém notar, que a dieta alimentar modificou-se completamente. Muitos estão hipertensos em decorrência do sedentarismo. Muitos estão deixando hábitos alimentares em troca de consumir alimentos que não sabem como foram preparados. $\dot{E}$ comum as crianças faltarem aulas na época das frutas de murici, buriti e caju e é bom senso não punir os alunos por causa disso porque estão aprendendo também. Nessa atividade e a caça não são medidas por horas correspondentes às quatro horas de aula, muitas vezes as atividades extrapolam as quatro horas; elas são consideradas aprendizados do modo de vida A'uwẽ. Trabalhamos muito

a importância da manutenção do ambiente em que vivemos sempre limpo. O que é mais importante, a qualidade do ensino ou formato de salas quadradas dela? Estamos discutindo com a SEDUC sobre um modelo arquitetônico sugerido de escola. A escola faz parte do Warã.

A escola não pode ficar desarticulada da organização espacial da aldeia.

O maior desafio da educação escolar indígena é conseguir um ensino de qualidade diferenciada, no sentido de atender as comunidades indígenas. Cabe ao estado se preparar para essa nova dinâmica, pois se tratam de 44 povos indígenas em Mato grosso, com suas filosóficas correspondentes.

Ensinamos nossos alunos conhecimentos dos não índios desde cedo na escola, e não temos materiais didáticos específicos voltados para a realidade da comunidade Xavante. Não temos uma didática de ensino especifica para as escolas Xavantes. $O$ 
governo incluiu saberes de inclusão sobre técnicas agroecológicas, tecnologias indígenas, e confecção de artesanatos.

As aulas devem ser ministradas na língua materna. Muitos alunos relatam que não conseguem assimilar o conhecimento em duas línguas. A escola organizada em ciclos traz desvantagens para nós porque muitos alunos passam de ano sem adquirir o conhecimento necessário para seu crescimento individual. A escola organizada por ciclo tem dificultado bastante o nosso trabalho. Antigamente o seriado era melhor, porque estudávamos muito com medo de reprovar. Influencia até mesmo os alunos chegam atrasados. Trabalhamos com conteúdos de concepção eurocêntrica. Temos que trabalhar conteúdos de acordo com a realidade Xavante.

Em síntese, queremos uma escola que valorize e fortaleça a cultura, língua e crença do povo A'uwe Uptabi. Para isso é necessário profissionais que sejam formados em mestrado, doutorado e também o sejam sua própria cultura, assim, promover o acesso ao conhecimento intercultural. Todos que queiram devem ter acesso à educação. As leis precisam ser cumpridas, garantindo os direitos e deveres constitucionais e o resguardo às formas de ensino e aprendizagem tradicional, do sistema de formação humana A'uwe Uptabi e ao mesmo tempo garantir aos estudantes e profissionais da educação o acesso aos conhecimentos e bens tecnológicos do mundo atual. (p. 24-25) [...]

Queremos ajudar a formar um aluno que respeite e vivencie as crenças e a identidade A'uwẽ Uptabi Xavante, participe da organização da comunidade, que busque os conhecimentos A'uwẽ, que produza histórias escritas na língua A'uwẽ Uptabi. E que também precisa ter conhecimento das línguas não indígenas e as relações interculturais: língua estrangeira, comércio, financeiro, artes, história geral, todas as ciências e tecnologia. E demais conhecimentos da cultura global.

Valores: amizade, companheirismo, respeito, amor ao próximo. (empenho e dedicação aos valores da cultura)

A partir desses valores cultivados na sociedade A'uwẽ acreditamos que a organização e o sistema de educação tradicional deve ser considerado na organização escolar. $A$ divisão dos grupos, os clãs, as funções nas cerimônias e a estrutura social e cultural. (p. 26)

[...]

Projeto Político Pedagógico

1- Garantir no PPP no que se refere a autonomia pedagógica das Escolas Indígenas Xavante: organização do tempo e espaço, conforme o ciclo de vida e sociolinguística da comunidade; estrutura social, as práticas culturais (como o luto, cujo o ritmo funeral fica por conta do pacificador, danhõno, darini, nominação das mulheres, entre outras) e sustentabilidade, a religião, a filosofia, a cosmologia e economia; o sistema próprio de aprendizagem, os saberes milenares e produção e publicação de material didático de interesse da comunidade.

2- Cada comunidade escolar deve construir o seu PPP seja ela da rede estadual ou municipal, mas a matriz curricular é a mesma.

3- O PPP deve ser construído com a participação da comunidade, junto com os técnicos indígenas que tem conhecimento sobre a educação do indígena e do warazu.

4- O PPP será construído no warã, onde a comunidade discute e avalia normalmente e onde toda comunidade participa, também foi colocado, que a indicação para direção da escola seja decidido no Warã no consenso da comunidade da aldeia.

5- Retomar o PPP das duas escolas de forma a garantir a gestão democrática, atendimento as demandas e indicações propostas pela comunidade. Focando em "Que aluno queremos ajudar a formar, e para isso que escola precisamos ter". (p. 32) 


\section{PESQUISA DE CAMPO ESPANHA: IMIGRANTES ADVINDOS DA ÁFRICA SUBSAAHRIANA}

O século $X X I$ incrementou a diversidade cultural em muitas nações, ocasionando uma sociedade imersa em uma crescente heterogeneidade, composta de identidades complexas resultantes de diferentes fatores, como migrações e imigrações crescentes, globalização, imediatismo nas comunicações e avanços tecnológicos nas mais distintas esferas.

Os movimentos migratórios sempre ocorreram no mundo, potencializados por diferentes razões e estendidos a diferentes regiões globais, gerados por uma combinação de necessidade e oportunidade e, portanto, não constituem um fenômeno recente. No entanto, a atual divisão de ocupação no mundo tem sido bastante explorada e o movimento humano é constantemente monitorado.

O direito de livre circulação entre países é defendido pela Declaração Universal dos Direitos Humanos (proclamada pela Assembleia Geral das Nações Unidas em Paris, em 10 de dezembro de 1948), em seu artigo 13, a mesma declaração cujo primeiro artigo garante que "todos os seres humanos nascem livres e iguais em dignidade e direitos", além de garantir a proibição da distinção entre pessoas por seu status político, legal ou internacional, ou por razões de "raça, cor, sexo, idioma, religião, opinião política ou de qualquer outra natureza, origem nacional ou social, posição econômica, nascimento ou qualquer outra condição" no artigo 2. (ORGANIZACIÓN DE LAS NACIONES UNIDAS, 1948). O Pacto Internacional sobre Direitos Civis e Políticos (artigo 2.1), expressa a proibição da discriminação e o Comitê de Direitos Humanos deixa claro que o princípio de igualdade da proteção, sem discriminação entre cidadãos e "não nacionais", se aplica a toda legislação dos Estados. (UNITED NATIONS - UN, 2014). Esses instrumentos e seus dois Protocolos Opcionais (um sobre procedimento de queixa e outro sobre pena de morte), compõem a Carta Internacional dos Direitos Humanos e têm expandido o corpo do direito internacional dos direitos humanos. (NAÇÕES UNIDAS BRASIL, 2020).

Em 2015, a ONU publicou informações sobre a existência de mais de 323 milhões de imigrantes internacionais em todo o mundo. O número de pessoas que, juntas, formaria o quinto país mais populoso do planeta e, também, a maior "população invisível" no campo dos direitos - o que é potencializado quando se 
observa a realidade daqueles que se encontram em situação irregular, que são os que mais sofrem discriminação e marginalização (UNITED NATIONS - UN, 2014).

O número de migrantes internacionais registrados segue em crescimento exponencial, como um fenômeno que não demonstra intenção de se retrair e que, portanto, deve seguir influenciando a pluralidade das nações:

Em 2017, o número de migrantes internacionais (pessoas que residem em um país diferente ao seu país de nascimento) alcançou os 258 milhões em todo o mundo, frente aos 244 milhões de 2015. As mulheres migrantes constituíram $48 \%$ desse número. Também, se estima que há 36,1 milhões de crianças migrantes, 4,4 milhões de estudantes internacionais e 150,3 milhões de trabalhadores migrantes. Aproximadamente, a Ásia concentra $31 \%$ da população de migrantes internacionais, Europa 30\%, Américas 26\%, África 10\% e Oceania 3\% (Dados do Portal Global de Dados Migratórios). (NACIONES UNIDAS, 2019, tradução livre). ${ }^{21}$

A partir dessa realidade, que vem ocasionando as chamadas "crises migratórias" na Europa, vieram à tona diferentes discussões, algumas contra outras favoráveis, sobre as políticas atuais dos países europeus, potencializadas por políticas controversas em escala mundial, especialmente em assuntos relacionados à responsabilidade social.

A União Europeia, por sua vez, se posiciona em seu atual programa de financiamento de investigações da União como enfrentando:

[...] enormes desafios econômicos que afetam de maneira significativa seu futuro comum, como a crescente interdependência econômica e cultural, o envelhecimento e mudanças demográficas, a exclusão social e a pobreza, a integração e desintegração, as desigualdades e os fluxos migratórios, o aumento da brecha digital, a sensação decrescente de confiança nas instituições democráticas e entre os cidadãos, dentro e fora das fronteiras [...]. (ESHORIZONTE2020, 2018, tradução livre). ${ }^{22}$

\footnotetext{
${ }^{21}$ Texto original: "En 2017, el número de migrantes internacionales (personas que residen en un país distinto al de su país de nacimiento) alcanzó los 258 millones en todo el mundo, frente a los 244 millones de 2015. Las mujeres migrantes constituyeron el $48 \%$ de estos. Asimismo, se estima que hay 36,1 millones de niños migrantes, 4,4 millones de estudiantes internacionales y 150,3 millones de trabajadores migrantes. Aproximadamente, Asia acoge el 31\% de la población de migrantes internacionales, Europa el 30\%, las Américas acogen el 26\%, África el 10\% y Oceanía, el 3\% (Datos recogidos de Portal Global de Datos Migratorios)". (NACIONES UNIDAS, 2019).

22 Texto original: "[...] se enfrenta a enormes retos socioeconómicos que afectan de manera significativa a su futuro común, como la creciente interdependencia económica y cultural, el envejecimiento y el cambio demográfico, la exclusión social y la pobreza, la integración y la desintegración, las desigualdades y los flujos migratorios, el aumento de la brecha digital, la sensación decreciente de confianza en las instituciones democráticas y entre los ciudadanos dentro y fuera de las fronteras [...]. (ESHORIZONTE2020, 2018)"
} 
O programa de financiamento Horizon2020, que é o maior projeto de financiamento europeu de pesquisa e inovação e compreende um período de 7 anos (2014-2020), apresenta o objetivo de, num mundo mutável, financiar projetos que busquem soluções para compreender a diversidade Europeia e apoiar sociedades inclusivas, inovadoras e reflexivas, no que eles identificam como um "contexto de transformações sem precedentes e crescente interdependência global". (ESHORIZONTE2020, 2018).

A coexistência e interação harmônicas seriam (frente a crescente complexidade de sociedades plurais, formadas por pessoas com distintas maneiras de viver, com suas próprias riqueza de costumes e visões de mundo), a base de uma força coletiva local e global, reconhecendo-a como um dos patrimônios da humanidade - e esta relação é chamada pela IFLA de multiculturalismo ou multiculturalidade. (IFLA, 2008).

No Horizon2020 são desenvolvidos projetos em colaboração entre países, dos quais podemos destacar, no âmbito da multiculturalidade (um dos temas frequentes de projetos que visam a integração de imigrantes), um crescente polo de investigações colaborativas de 3 países: Reino Unido, Alemanha e Itália ${ }^{23}$.

Na Espanha os fenômenos migratórios foram considerados como algo temporal e, assim, por muitos anos o país não se preocupou em rever suas leis migratórias - sua primeira lei, datada de 1985, só foi revista em 2000 , quando o volume de imigração no país se encontrava em volume considerável e mantendo pleno crescimento. Especialmente entre 2000 e 2010 o país passou por um importante processo de transformação entre país de migração para país de imigração. A lei de 2000 teve então quatro revisões, porém ainda sem conseguir um consenso político ou social sobre como a imigração deve ser gestionada no país. (GARRIDO, 2014).

A maior parte dos imigrantes recebidos na Espanha se fixa em objetivos laborais e a falta de uma legislação adequada para clarificar e garantir direitos dessas pessoas acaba por criar poucas possibilidades de imigrações legais. No contexto de ilegalidade um clima social começa então a instaurar-se no país, alimentados por políticas restritivas. (GARRIDO, 2014).

A falta de políticas sociais de integração para imigrantes seria uma das principais lacunas não preenchidas durante as expansões migratórias à Europa,

\footnotetext{
${ }^{23}$ Os dados dos projetos estão disponíveis para consulta no site https://cordis.europa.eu/.
} 
e essa deficiência não se restringe à Espanha, mas perpassa todos os países europeus que, com diferentes contextos e interesses, encontram dificuldade para estabelecer acordos no nível da união. (GARRIDO, 2014).

Individualmente, as políticas de integração que conseguem ser desenvolvidas centram-se em aspectos de aprendizagem da língua, orientações sobre o contexto social e formação e orientação para o trabalho. Já no nível europeu, tratados são criados visando contornar essa problemática - como os programas Tampere (19992004), La Haya (2004-2009) e Estocolmo (2010-2014). Os programas apresentam as prioridades a serem buscadas entres os estados membros, assim como metas de melhorias nesse contexto. (GARRIDO, 2014).

Na Espanha, assim como em Portugal e na Grécia, houve grandes reduções no financiamento para acesso a direitos sociais e medidas antidiscriminatórias (incluindo serviços de saúde), acompanhando uma linha que vincula direitos sociais a políticas de admissão, com a crença de que os benefícios são um atrativo para os imigrantes e que sua eliminação ou redução drástica poderia dissuadi-los. (LA SPINA, 2017).

No caso da Espanha, isso é exemplificado pelo decreto real 16/2012, que restringe a assistência médica a imigrantes em situação irregular (LA SPINA, 2017). A situação irregular dos imigrantes que já envolvia entre 15 e $20 \%$ - ou 30 a 40 milhões de pessoas em todo o mundo, do total de imigrantes internacionais em 2014 (UNITED NATIONS - UN, 2014).

É importante destacar que os imigrantes ilegais não são criminosos, mas que, como destaca a ONU:

A evidência mostra que eles não migram com o objetivo de enganar o sistema de seguridade social ou usar indevidamente os serviços do país de destino. É mais provável que eles estejam trabalhando em um hospital do que usando injustamente suas instalações. Eles tendem a trabalhar em setores sujos e perigosos, geralmente fazendo trabalhos que os trabalhadores locais não estão dispostos a fazer. De fato, governos têm interesse em promover e proteger os direitos humanos de todos os migrantes, inclusive migrantes irregulares, porque nenhuma sociedade pode desenvolver seu verdadeiro potencial quando barreiras legais, sociais ou políticas impedem que setores inteiros dessa sociedade contribuam para isso. (UNITED NATIONS UN, 2014, p. 2, tradução livre $)^{24}$

\footnotetext{
${ }^{24}$ Texto original: "The evidence shows that they do not migrate with the objective of cheating the social security system or misusing the services of the country of destination. They are more likely to be working in a
} 
O Migrant Integration Policy Index - MIPEX, é identificado como uma "ferramenta interativa e um manual de referência para analisar, comparar, e melhorar as políticas de integração de todos os países membros da UE" (JUNTA DE ANDALUCIA, 2018, tradução livre ${ }^{25}$ ), e é avaliado por La Spina junto à legislação espanhola. A autora ressalta que a integração de imigrantes no país é ameaçada e enfraquecida:

[...] em relação ao acesso à assistência social, educação e moradia, três direitos sociais que, embora não expressamente incluídos no MIPEX (exceto para a educação), tiveram restrições impostas a imigrantes ilegais ou residentes no contexto da crise econômica. De acordo com os dados do MIPEX, os quatro países têm taxas muito baixas de educação secundária ou universitária para estudantes imigrantes, o que afeta o recebimento de treinamento profissional para facilitar seu emprego ou integração. (LA SPINA, 2017, p. 18)

Encontra-se uma divisão entre nacionais, como cidadãos merecedores e imigrantes, exacerbados por canais irregulares devido às medidas cada vez mais austeras exigidas pela União Europeia para a imigração (LA SPINA, 2017). A regressão de direitos tem um impacto direto nos fatores de inclusão e exclusão, abandonando os imigrantes à margem da sociedade, que os assume como invasores e exploradores, ignorando os fatores complexos e terríveis pelos quais esses imigrantes podem ter sido motivados a deixar seu país de origem, assim como todas as contribuições que fazem, ou podem fazer, em seu novo país de residência, tanto em aspectos econômicos quanto culturais.

La Spina (2017) alerta para que, mesmo com as indicações da ONU de que todos os Estados membros deveriam reavaliar suas políticas de admissão e corrigir deficiências legislativas (levando mais em consideração a inclusão social e, assim,

\footnotetext{
hospital than unfairly using its facilities. They tend to work in sectors that are dirty and dangerous, often doing jobs that local workers are unwilling to do. Indeed, Governments have an interest in promoting and protecting the human rights of all migrants, including irregular migrants, because no society can develop to its true potential when legal, social or political barriers prevent entire sectors of that society from contributing to it".

${ }^{25}$ Texto original: "[...] herramienta interactiva y un manual de referencia para analizar, comparar, y mejorar las políticas de integración de todos los países miembros de la EU [...]"

${ }^{26}$ Texto original: "Other weaknesses and threats for integration occur in relation to access to social care, education and housing, three social rights that although not expressly included in the MIPEX (except for education), have had restrictions placed on them for illegal immigrants or residents in the context of the economic crisis. According to the MIPEX data, the four countries have very low rates of secondary or university education for immigrant students, which affects the receipt of professional training to facilitate their employment or integration".
} 
respeitando o acesso igualitário à habitação, emprego, educação e saúde, para que se possa buscar uma integração efetiva e não meramente simbólica), no campo jurídico, os estados do sul da Europa ajustaram seus sistemas com foco em seu bemestar em resposta à crise, excluindo certas categorias de imigrantes e mantendo um desenvolvimento de políticas para a integração de imigrantes lento e deficiente. Isso porque a variável do grau de integração social depende do status legal do imigrante (vinculado e dependente de políticas de imigração) e/ou da natureza do sistema de assistência social (associado especialmente ao princípio do mérito).

O que encontramos é uma fissura na filosofia liberal, uma vez que é observada a intervenção dos Estados, com o apoio de certos setores empresariais, com estratégias e parâmetros utilitários que criminalizam a migração, mas que também a utiliza para solucionar problemas, especialmente os de falta de mão de obra para determinados trabalhos. (SILVA, AMARAL, 2013).

Observamos que historicamente as legislações têm sido desenvolvidas buscando a incorporação de mão de obra qualificada de alto nível ou a incorporação em trabalhos braçais com péssimo retorno econômico, sendo guiados, portanto, por questões puramente econômicas e não de direito.

\subsection{IMIGRAÇÃO NA REGIÃO dE ALMERÍA - ESPAÑA}

Na Europa, a Espanha está entre um dos países que recebeu mais imigrantes. Os números registrados mostram um salto considerável no ano de 2017: 
Figura 20: Evolução de pessoas que chegaram ao território espanhol (terra e mar) pela fronteira Sul do país.

\section{Evolución del total de personas que llegaron a territorio español* por tierra y mar a través de la frontera Sur}

*Cuando hablamos de territorio español hacemos referencia a Península, Baleares, Canarias, Ceuta y Melilla.

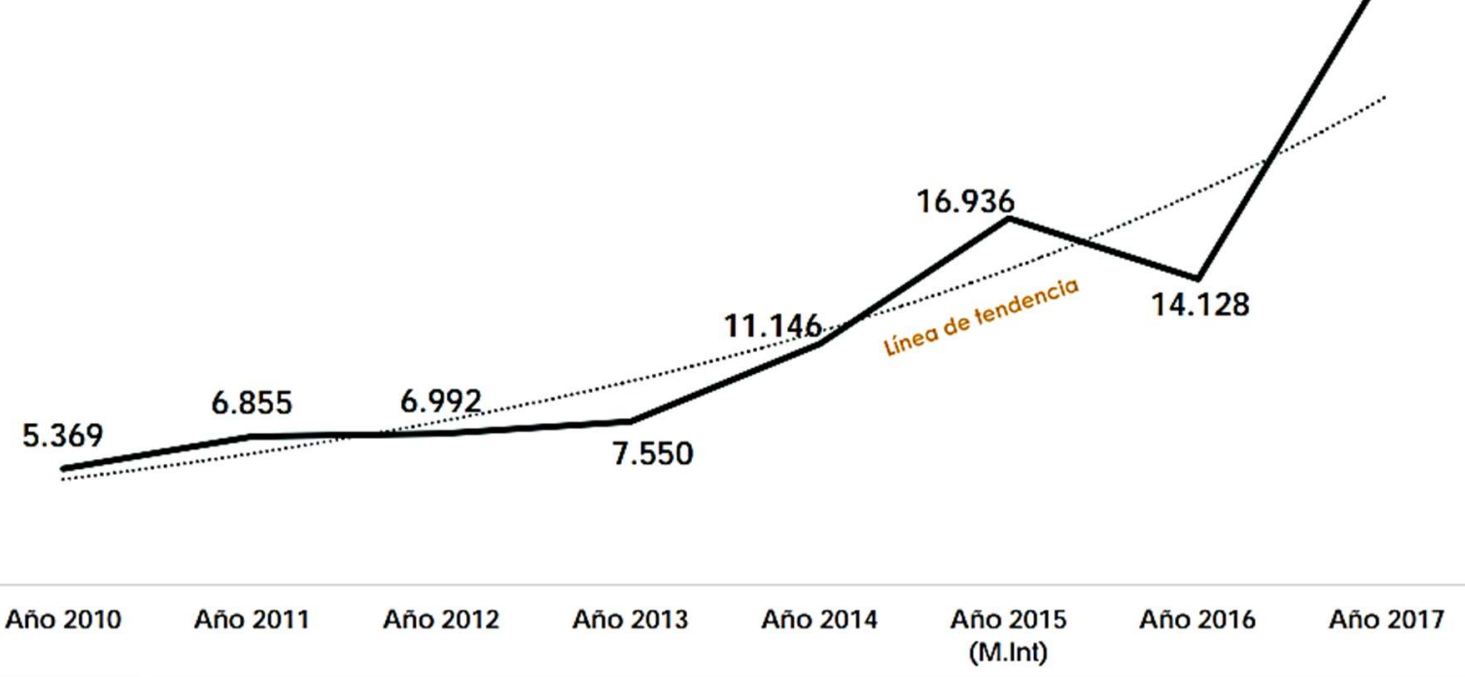

Fonte: Asociación Pro Derechos Humanos de Andalucía - APDHA, 2018.

São pessoas provenientes principalmente da África Subsaariana (49\%) e região Magrebe (região norte da África - formada por 48 países), com 39\%. Os $12 \%$ restantes são da Síria e outros países. (ASOCIACIÓN PRO DERECHOS HUMANOS DE ANDALUCÍA - APDHA, 2018).

A comunidade autônoma que recebeu o maior número de imigrantes na Espanha foi Andaluzia e, como mostra o gráfico da Figura 21, com uma expressiva diferença das demais: 
Figura 21: Entradas ao território espanhol (terra e mar) pela fronteira Sul segundo a zona geográfica.

\section{Entradas totales a territorio español por tierra y mar a través de la Frontera Sur según zona geográfica}

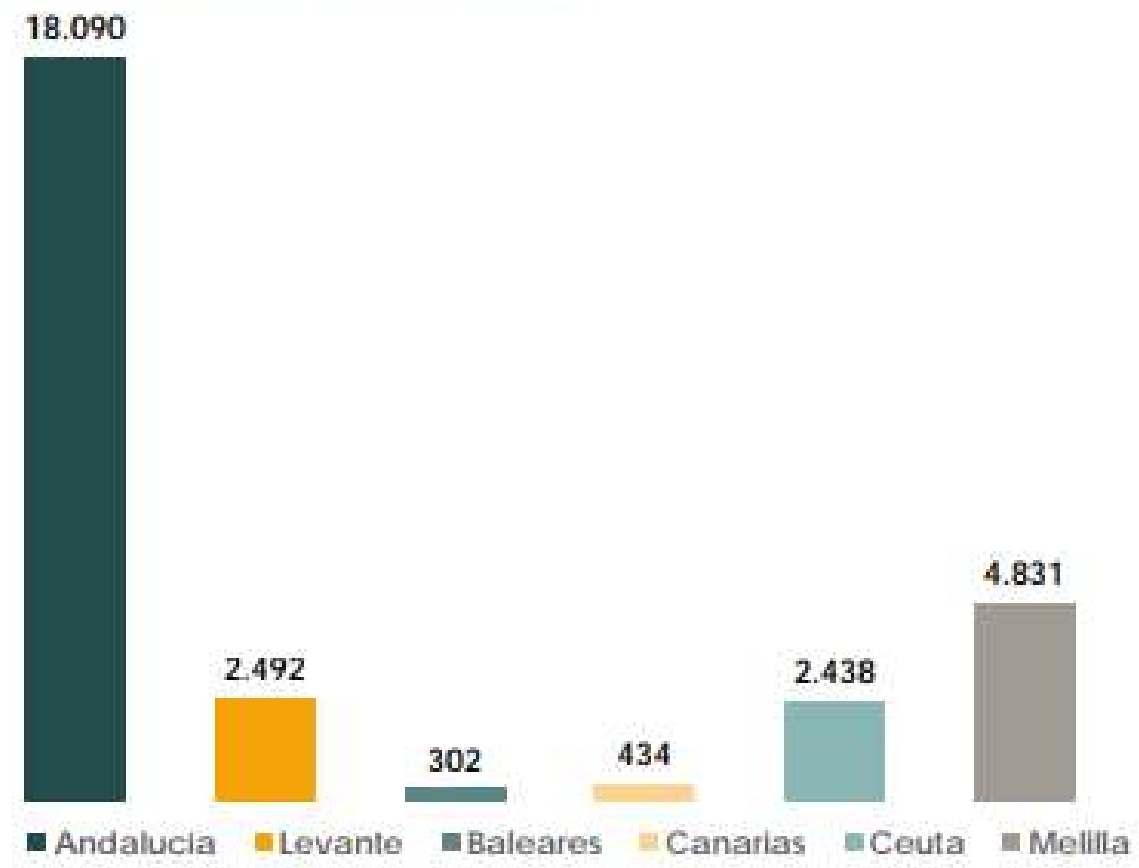

Fonte: Asociación Pro Derechos Humanos de Andalucía - APDHA, 2018.

Com o aumento constante e expressivo dos imigrantes, o problema é que "não existem estruturas ou meios adequados para dignificar aqueles que chegam após uma longa provação e respeitar seus direitos". (ASOCIACIÓN PRO DERECHOS HUMANOS DE ANDALUCÍA - APDHA, 2018). E, mesmo após a instalação, a problemática continua, permeando também aspectos sociais e culturais.

Almeria é uma das províncias que mais recebe imigrantes na comunidade autônoma de Andalucía, no sul da Espanha e que, sozinha, concentra mais de $63 \%$ da imigração recebida no país em 2017. (ASOCIACIÓN PRO DERECHOS HUMANOS DE ANDALUCÍA - APDHA, 2018).

Grande parte desses imigrantes escolhem a região em busca da garantia de trabalho - as vagas em estufas, que são uma importante esfera de produção de Andalucía e que contribuíram para o chamado "milagre econômico" iniciado na comunidade desde meados da década de 1970, e que envolve a grande mudança econômica responsável pela rápida e significativa melhoria no PIB da região, que passou de uma das províncias mais pobres da Espanha a assumir cifras superiores às médias de toda Andalucía. (CAUSSA, 2014, HERRERA, 2004). 
Parte desse milagre está relacionado à instalação das estufas na região, que mudaram drasticamente sua então realidade agrícola. Caussa (2014) esclarece que "este crecimiento era muy original: su motor era la agricultura de invernadero (y no la industria) y las protagonistas del mismo eran familias campesinas con explotaciones relativamente pequeñas (y no grandes propietarios o empresas capitalistas)".

O cultivo em estufas foi iniciado em uma vertente familiar, mas foi constantemente expandido e se tornou uma das principais opções de trabalho para imigrantes - inicialmente provenientes de outras regiões da Espanha, e que atualmente concentra majoritariamente imigrantes da África Subsaariana nos âmbitos de produção, mantendo sua origem familiar nas esferas administrativas. (ASOCIACIÓN PRO DERECHOS HUMANOS DE ANDALUCÍA - APDHA, 2018; CAUSSA, 2014, HERRERA, 2004).

Com o aumento da produção e diminuição da presença de proprietários familiares na esfera produtiva, e o aumento da presença de imigrantes, constituiu-se em Almería uma fonte constante de trabalho para imigrantes, cuja inserção nessa economia serviu também para aumentar os lucros, levando em consideração os baixos salários que recebem.

Segundo o governo andaluz, $7,38 \%$ da população registrada na comunidade é estrangeira (em Almería, o número total é equivalente a $19,66 \%$ da população e em Málaga, 14,48\%). Desse total da população estrangeira registrada, $49,17 \%$ são mulheres, o que representa um aumento de $2,53 \%$ em comparação com os $1,62 \%$ experimentado por homens. Jaén $(74,66 \%)$ e Sevilha $(69,23 \%)$ são as províncias com o maior número de pessoas que não são de países da UE-28. (JUNTA DE ANDALUCÍA, 2018).

Em 2017, $11.450(14,44 \%)$ é o número de nascidos vivos com pelo menos um dos pais com nacionalidade de um país estrangeiro (um aumento de $2,26 \%$ ), sendo que $48,62 \%$ deles têm dois pais da mesma nacionalidade e 4.863 pais mistos (um dos pais é nacional e o outro é estrangeiro). Nas províncias destacam-se Málaga (3.310) e Almería (2.623), além de Cádiz, não apenas pelo número (1.059 nascidos vivos), mas também pelo notável crescimento de $13,99 \%$ em relação ao período anterior.

No que diz respeito aos casamentos, em $2016 \quad 10,63 \%$ dos casamentos de Andalucía tiveram pelo menos um dos cônjuges de nacionalidade 
estrangeira e o maior volume ocorreu em Málaga (1.280 - 21,06\%). Dos cônjuges estrangeiros de casamentos mistos na Andalucía, 31,96\% provêm da União Europeia (UE-28) - 928 casamentos, 25,76\% de países sul-americanos (748) e 19,01\% do Continente africano (552).

Embora vejamos o aumento de estrangeiros registrados, casamentos e nascimentos mistos, houve uma queda anual de $76,94 \%$ na concessão de nacionalidades em 2017 (na Espanha esse número também diminuiu drasticamente: $72,35 \%$ ), a causa, segundo o Observatorio Permanente de Inmigración (OPI) é administrativa (JUNTA DE ANDALUCÍA, 2018).

Os primeiros 7 meses de 2018 já quase se igualaram ao número de imigrantes recebidos na mesma província em todo ano de 2017 , sendo que $80 \%$ deles vinham de países da África Subsaariana. (IDEAL, 2018).

Figura 22: Imigrantes chegando à costa de Almería após resgate.

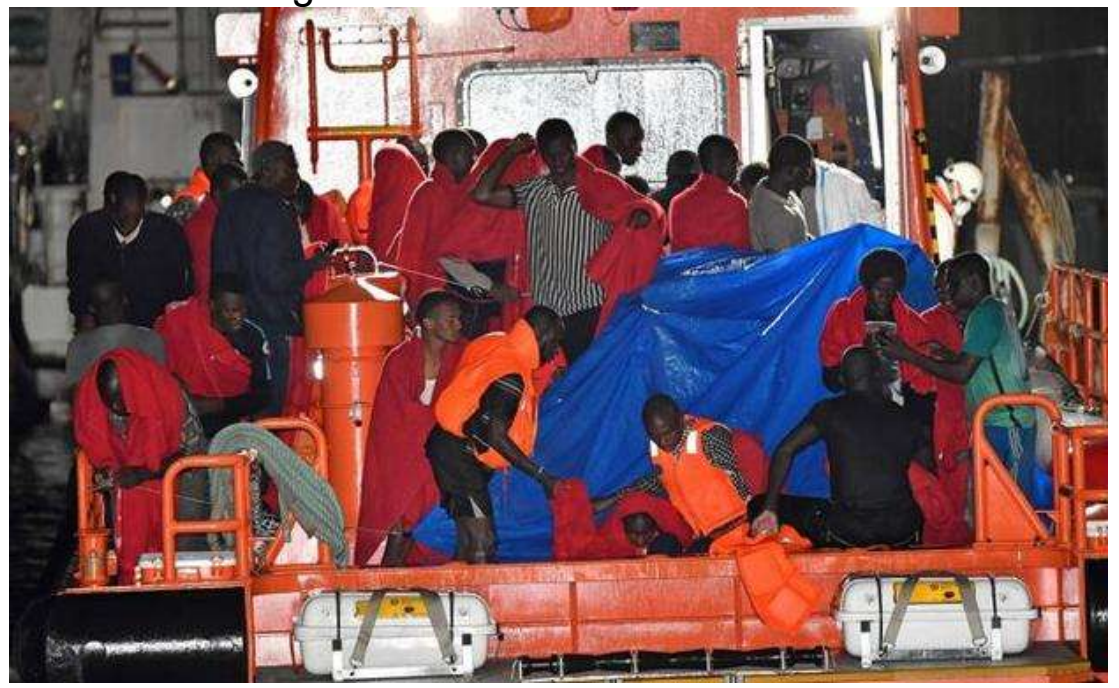

Fonte: Ideal, 2018.

Após chegar na região, muitos vão viver com contatos prévios, sejam familiares, conhecidos ou membros de associações. Esses contatos anteriores facilitam a adaptação ao novo espaço e especialmente a busca de trabalho e moradia.

Grande parte desse número de pessoas se concentra em trabalhos na produção das estufas, que costumam ter fácil inserção - o trabalho pode acontecer por indicação ou homens sem contrato de trabalho ficam em locais pré-determinados de encontro (como por exemplo rotatórias na entrada das cidades), onde os 
funcionários de estufas que precisam de mão de obra no dia passam para recolher o número de pessoas que precisam naquele dia.

A maioria dos empregos, ainda que envolva um vínculo frequente na mesma produção/empregador, não possui vínculo empregatício, o que dificulta o acesso a documentos de autorização de permanência no país para trabalho, já que não é possível comprovar os requisitos mínimos exigidos pelos escritórios de imigração. Há inúmeros relatos de patrões que mentem para os funcionários, dizendo que há um registro de trabalho e muitas vezes até mesmo pagam menos aos funcionários por isso - alguns desses trabalham anos nesse sistema e apenas quando já estão em idade mais avançada descobrem que não possuem nenhum direito porque na realidade nunca foram registrados como funcionários.

Figura 23: Estufas de Roquetas del Mar, Almería.

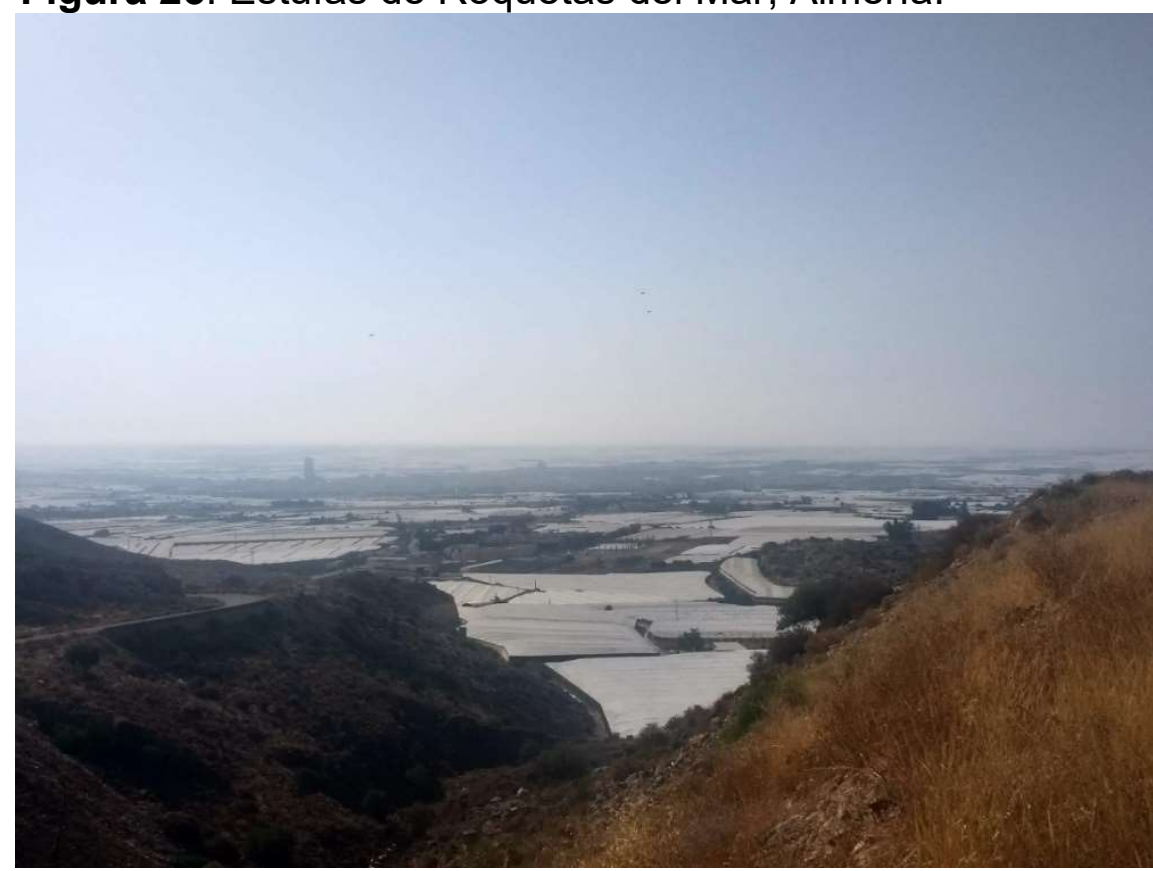

Fonte: acervo pessoal, 2018.

A paisagem da região, antes com vasta vegetação, alterou-se completamente, sendo difícil encontrar locais livres das estufas. A grande presença do material tem interferido consideravelmente no ecossistema, especialmente pela proximidade ao mar - local onde muitos detritos de plástico têm constantemente se acumulado. 
A cor branca que se ressalta na verdade não é a cor do plástico, mas sim de uma mistura que se usa para pintar as estruturas e ajudar no controle de temperatura e preservação.

Figura 24: Homens trabalhando na troca do plástico de uma estufa.

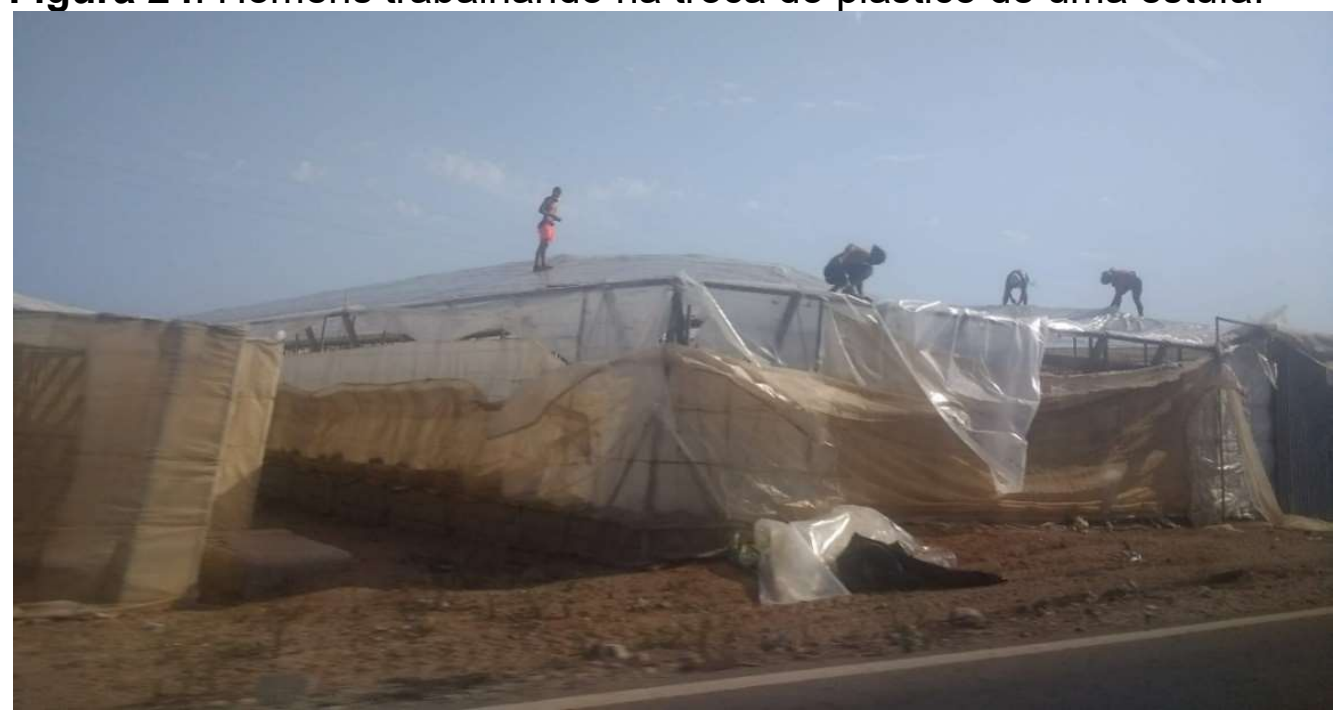

Fonte: acervo pessoal, 2018.

Os imigrantes trabalham não apenas no processo de produção das estufas, mas também em outras etapas e processos que envolvem sua estruturação e manutenção - como no exemplo acima, onde fazem a troca do plástico de uma estufa.

Figura 25: Homem trabalhando em estufa.

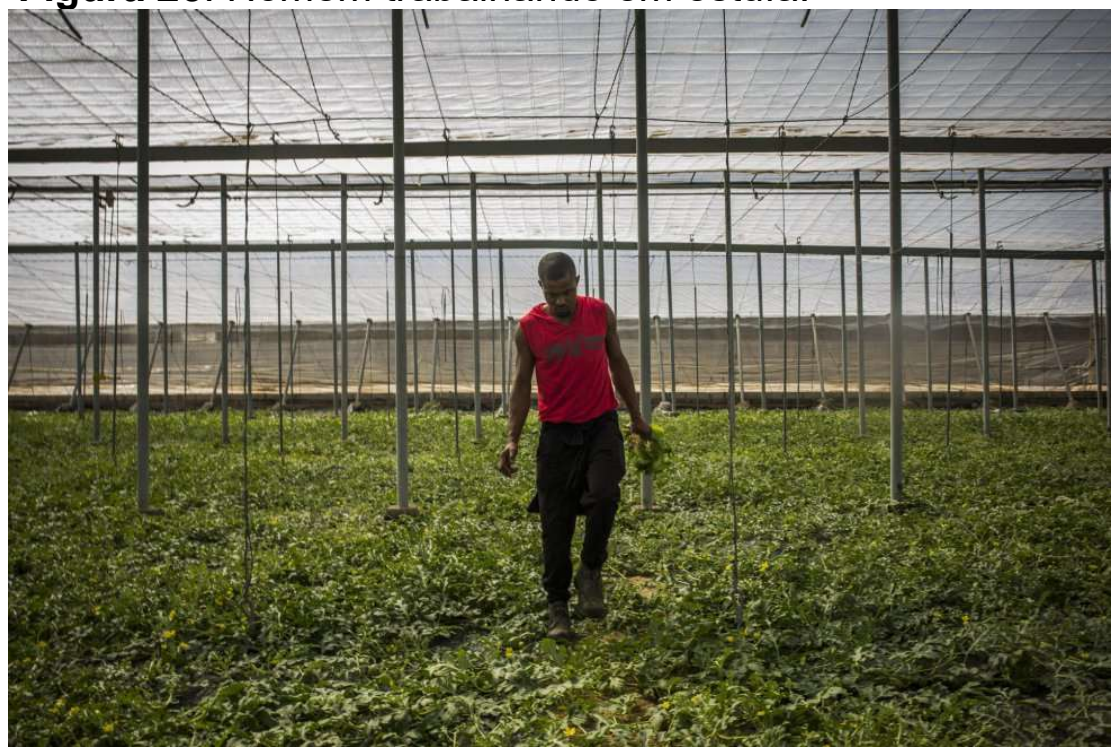

Fonte: El país. 
A parte interna das estufas passou a ser construída mais alta, segundo relato de entrevistados, especialmente para ampliar o tempo de trabalho dos imigrantes, que antes tinham que ficar sempre curvados e com isso se cansavam mais. Os cultivos são de diferentes espécies e usam diferentes tecnologias.

Os locais de moradia dos imigrantes variam de cidade e oportunidade, mas em sua maioria incluem espaços sem infraestrutura, divididos entre várias pessoas e normalmente incluem um cômodo amplo onde as pessoas improvisam todas as necessidades.

Figura 26: Imigrantes em sua casa improvisada.

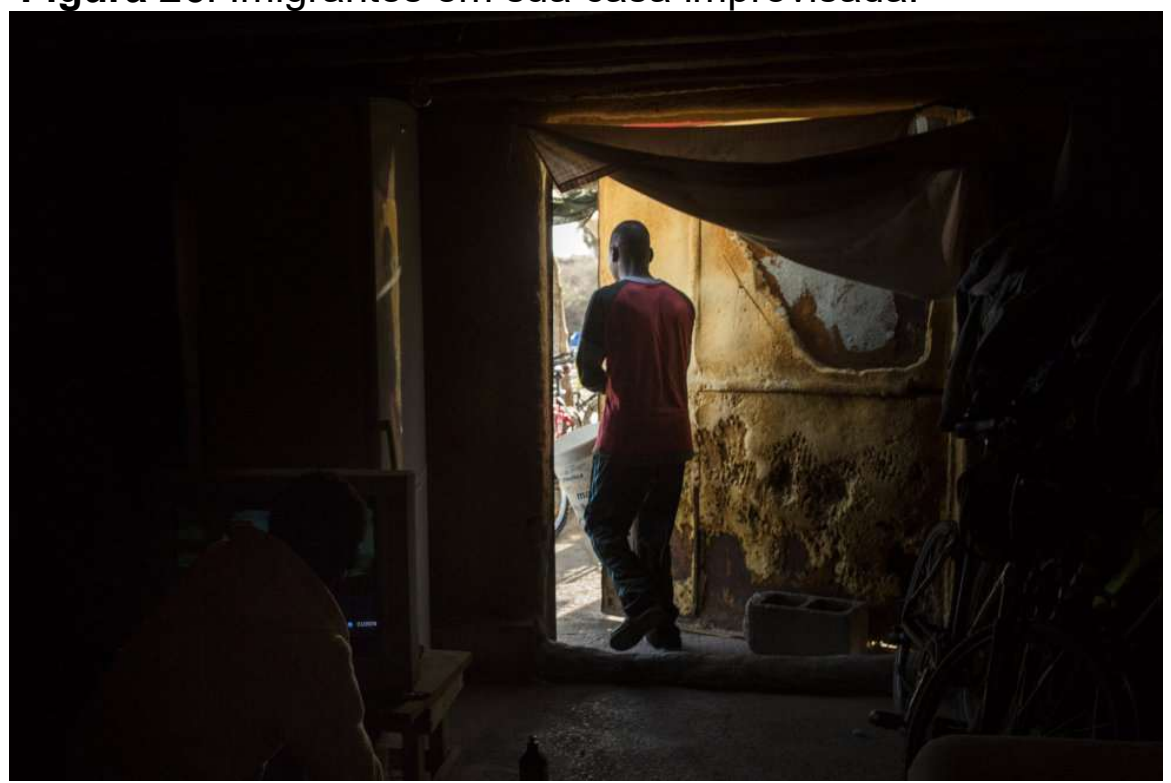

Fonte: El país.

As moradias variam de tipo de construção e, em algumas regiões, são improvisadas dentro das montanhas.

Os imigrantes que já se encontram no país a mais tempo e conseguiram os documentos de autorização para sua permanência têm o status de imigrante regular, o que os possibilita, ainda que com algumas restrições, o aluguel de casas mais estruturadas e em melhores localidades.

A dependência da ajuda de outros imigrantes e determinados preconceitos sofridos ocasiona uma concentração de imigrantes em determinados bairros e zonas, divididos também por religiosidade e procedência - é como os grupos se organizarem e estabelecerem um determinado monopólio na região, o que gera uma grande circulação, estrutura religiosa e de lazer, e comércio especializados concernentes com o entorno. 


\subsection{DIÁRIOS DE CAMPO}

\section{Dia 1 - Spitou Mendy}

O contato para falar com Spitou foi Leopoldo Frías, espanhol, que, além de seu trabalho habitual, tem uma atuação forte já há muitos anos junto a sindicatos que defendem o respeito ao trabalho dos imigrantes.

Encontrei com Spitou em um pueblo pequeno localizado em "El Parador", sem muito movimento ou ruídos nas ruas naquele dia, com uma avenida principal bem estruturada e arborizada, e se viam prédios relativamente bem construídos. É onde vive Spitou. A cidade parecia um local bom, com avenidas bonitas, flores, lojas e poucas pessoas na rua. Um dia de domingo que lembra a tranquilidade de um dia para descansar. Vestia roupas limpas, uma calça escura, uma sandália com tiras fechadas e uma camiseta branca.

Ele é sindicalista e conhecia nosso contato principal de atuações e programas do sindicato, onde se conheceram já há muitos anos. Ele e Leopoldo se cumprimentaram de maneira amistosa e terna. Leopoldo nos apresentou. Spitou me cumprimentou com alegria, com dois beijos no rosto, como é costume na Espanha, e com um grande e amigável sorriso, que levou quase todo o tempo em que estivemos juntos.

Entramos no carro para ir almoçar. Era cerca de 13h30. Assim que saímos com o carro Spitou já começou a me perguntar da pesquisa, sempre de forma direta e objetiva, mas também amistosa. Tentamos manter, ambos, um tom descontraído. "O que você quer saber de mim?" - ele me perguntou, Ihe respondi "tudo" - e rimos. Ele me disse que não havia muito, e eu disse que sabia que não era verdade. Me perguntou o que eu já sabia, e disse que sabia que eles vinham a Espanha para trabalhar e que sofriam, que eram explorados. Ele me respondeu que então eu já sabia tudo. Respondi que eu não tinha como provar, porque as pessoas diziam que não era assim, sobretudo em Salamanca (cidade da Espanha onde eu vivia naquele ano), e ele me disse que essas pessoas eram da "Europa, que eram muito cultas" para ver, e eu respondi que não achava que isso era cultura, mas sim viver uma mentira, e rimos de novo.

Spitou me contou que faz 18 anos que vive na Espanha, que veio com família, mas que agora vive sozinho. Sua mulher foi para a França, trabalhar. Tem filhos. Fomos no carro e ele foi contando algumas experiências, em geral de muita luta e busca por melhores condições de trabalho. Falou sobre a falta de políticas adequadas, o despreparo de autoridades (e comentou que muitas vezes foi até mesmo ofendido por essas pessoas). Tudo que contava tinha uma tranquilidade, uma segurança, passando uma clareza de que o assunto realmente faz parte de sua vida. 
Expôs que um dos maiores desafios é que as pessoas cedem ao medo e não se dispõem a lutar por melhorias, e deu exemplo de quando conseguiu dinheiro para aulas voluntárias de espanhol, mas que quase ninguém apareceu, ou de quando instrui as pessoas a denunciar as terriveis condições de trabalho e elas não o fazem porque dizem que serão punidos e/ou não trará resultado.

Baixamos do carro e fomos em direção ao restaurante. Spitou, no caminho, me afirma que já está acostumado com as adversidades que encontra.

No restaurante, mesmo com muito ruído, seguimos conversando, já com mais interações do Leopoldo, que também demonstra muito conhecimento sobre o assunto, fruto de sua atuação com o sindicato. Ele ressalta a importância do sindicato nas relações.

Spitou destaca que o mínimo de melhoria que houve nas condições de trabalho é relacionado a busca de aumento na produção, e não no bem-estar dos trabalhadores - por exemplo, o fato de subirem o teto dos invernaderos ${ }^{27}$ para que os imigrantes aguentem ficar ativos por mais tempo e que foi feito não por preocupação a sua qualidade de vida dentro do trabalho, mas sim pensando em melhorar a produção. Para ele a etapa mais dura do trabalho é plantar, pelo movimento repetitivo que "dói muito o corpo". Na primeira vez que trabalhou com isso, depois de 3 horas semeando quase não suportava a dor na coluna (a maioria deles são altos).

Seguimos conversando sobre várias das situações de vida que vive e acompanha, sobre os sindicatos e as relações de vida que possuem.

Quando falamos sobre uma integração possível ele me deu um de seus exemplos de vida, de quando um dia entrou em um bar "espanhol", para tomar um café. Pediu o café e o atendente Ihe serviu um. Perguntou quanto custava e a resposta foi " 5 euros" (o valor padrão de um café seria em torno de 1 euro).

\section{Dia 2 - Demais entrevistas com imigrantes}

O branco dos invernaderos domina quase todas as paisagens. A pintura utilizada para cobrir os plásticos e ajudar a protegê-los, bem como a manter seu microclima, dá cor ao "mar de plástico", que pode ser visto desde o espaço. O verde da paisagem resta apenas na memória dos que nasceram e cresceram ali e que, em poucos anos, viram o desfigurar de toda uma região. Os proprietários? "Qualquer um...". Pequenos agricultores que embarcaram na

\footnotetext{
27 Poderíamos traduzir a palavra invernaderos para estufas, porém, devido a características próprias de trabalho e estrutura desses ambientes na Espanha, optei por manter a palavra em espanhol.
} 
proposta de plantio e hoje vivem dele. Alguns, com mais propriedades, se tornaram extremamente ricos.

O carro adentra uma zona que começa a diferir das demais. O branco dos invernaderos aparece mesclado com casas que parecem abandonadas. As ciclovias começam a ser ocupadas por pessoas negras, que também começam a aparecer pelas ruas. Já não se vê quase nenhum branco. As casas seguem o padrão, simples, apartamentos baixos, com poucos andares. Nos bares e lojas há letreiros que indicam que são lojas de imigrantes, com dizeres e propagandas escritos em línguas diferentes. Pelas ruas, em sua maioria homens. Muitos conversando de maneira divertida entre si, no que parece ser diversas rodas de amigos. Vejo poucas mulheres.

Nos acercamos a uma praça onde há uma festa em um sindicato. Abordo algumas pessoas. A primeira um senhor com nacionalidade recém "conquistada", pela qual é felicitado. Ele demonstra gratidão ao "seu país". A segunda pessoa é uma mulher, mãe, que está com outras mulheres enquanto seus filhos brincam em um parquinho da praça. Ela fala perfeitamente espanhol e demonstra estar feliz vivendo na Espanha. Se coloca desconfiada com a abordagem, mas responde minhas perguntas. O terceiro, e último abordado naquele espaço, é um senhor que inicialmente aceita conversar comigo, mas na primeira pergunta me diz que não entende Espanhol, e depois diz de maneira hostil que na verdade não quer participar.

Seguimos para um bar, onde conversamos com a proprietária. Nacionalizada. Ela nos conta uma bonita história de quem foi uma das primeiras mulheres africanas a chegar ali para trabalhar. Sua trajetória de esforço, coragem e boa acolhida ela traduz finalmente como "orgulho".

Finalmente, vamos ao prédio da Associação, com quem tínhamos o inicial combinado. $O$ diretor nos esperava com alguns membros da associação, que visivelmente não tinham nem ideia do que eu queria. Nos adentramos ao prédio e meu contato me apresenta a eles e pergunta quem fala espanhol para poder falar comigo - apenas uma pessoa (que sublinha falar "um pouco"), e uma pessoa sinaliza que fala português. Começamos com o que falava espanhol, embora com dificuldade, e meu contato me ajudou fazendo de intérprete para nós dois quando necessário. O segundo eu pude entrevistar sozinha, já que ele falava português, tomando o cuidado de falar devagar para que ele me compreendesse da melhor maneira possível. Os dois entrevistados eram jovens e fortes, simpáticos e alegres, como a maioria dos jovens que encontrei por ali. A entrevista foi difícil, não apenas pela barreira linguística, mas também pelo ambiente - sempre havia outras pessoas na mesma sala enquanto conversávamos, alguns inclusive com uma postura vigilante. 
De maneira geral os entrevistados demonstraram um certo padrão de resposta que exprime satisfação e/ou conformismo. Esse padrão se mostrava contraditório quando eu pedia que me dissessem uma palavra que descrevesse sua vida na Espanha, já que o que ouvia sempre era algo que demonstrava negatividade, dificuldade ou superação. Quando eu perguntava qualquer coisa relacionado a educação: a pergunta soava absurda frente a realidade de trabalho (muitas horas, sem documentos).

O que eu identifiquei foi que as pessoas se aceitaram nesse lugar (figurativo) de oprimidos, e assim o ocupavam sem questionar muito, embora não estivessem plenamente satisfeitos com ele, numa espécie de felicidade programada, que se traduzia no concretar do objetivo primário: trabalhar.

A maioria dos espanhóis não entende seus dramas, não entende sua realidade, e os questionamentos nacionais são baseados em afirmativas como "se estivesse ruim eles não estariam aqui", "seu país natal é que os deve ajudar", "é uma invasão". As rádios na região de Almería traziam constantes debates sobre a situação de imigrantes e, principalmente, sobre os que naquele momento se encontravam entre a vida e a morte no chamado "grande cemitério" que se tornou o mar mediterrâneo. O uso de algumas expressões e exposição de alguns números as vezes incitava ainda mais o discurso de "invasão", que era, ao menos nos programas que ouvi, corrigidos em seguida, muitas vezes explicando a gravidade de expor esse tipo de comentário sensacionalista - uma contradição entre discursos que buscavam notificar o problema humanitário vivido.

A divisão entre imigrantes e espanhóis é clara. Nas cidades, nas ruas, nos comércios. Não se vê expulsões claras, nem ofensas expressas, mas a divisão se reforça em comportamentos e segregações. Você passa em um bar de espanhóis e é só o que encontra ali. Você passa em um bar de imigrantes e é só o que encontra ali. Numa rua onde os imigrantes caminham tranquilamente é uma rua onde eles vivem, e não os espanhóis, e vice-versa. São poucos (ou quase nenhum), os espaços em que há o mínimo de interação. Eu, sinceramente, não vi nenhum. Isso justifica o porquê minha presença era um estranhamento. Por onde eu passava notava um certo desconforto, o que é extremamente natural, dado essa divisão tão explícita.

As pessoas que encontrei e tive a oportunidade de entrevistar eram admiráveis. Os mais velhos traziam uma trajetória de superação e orgulho, e os mais jovens energia e força. Todos muito educados, mesmo estando em uma posição onde eu não figurava uma pessoa com quem eles se sentissem realmente à vontade. 


\subsection{VISITAS TÉCNICAS: BIBLIOTECAS}

As visitas ocorreram no ano de 2018 com autorização prévia das unidades visitadas. As fotos aqui divulgadas são de acervo pessoal e também foram previamente autorizadas atendo-se à exigência de não identificar as pessoas que estavam nos ambientes. Alguns espaços, especialmente os reservados ao estudo e leitura, encontravam-se com a presença de muitas pessoas e por isso não foi realizado nenhum registro fotográfico.

Em todas as bibliotecas visitadas não se encontrou fluxo de imigrantes no momento da(s) visita(s).

Todos os funcionários que participaram da recepção e/ou entrevistas foram muito atenciosos e receptivos à investigação, demonstrando interesse nos resultados e preocupação quanto ao tema no desenvolvimento da estrutura da unidade e de seus serviços, ressaltando que têm dificuldades sobre como trabalhar com a comunidade imigrante nesse espaço.

Algumas bibliotecas se cadastraram em um projeto de diversidade, promovido pela comunidade autônoma e disponibilizado para as bibliotecas que tivessem desejo de participar. O projeto envolveu a disponibilização de livros em outras línguas, como árabe. Os funcionários relataram que não receberam treinamento ou instruções sobre como trabalhar com essas obras ou com os imigrantes, simplesmente receberam as obras e, portanto, não consideraram o projeto muito impactante nas unidades participantes. Relataram também a dificuldade do tratamento técnico com obras em outras línguas.

\subsubsection{Biblioteca Municipal de Almería}

A biblioteca municipal é a maior biblioteca da província e tem o diferencial de receber mais recurso que as demais. A Biblioteca conta com diferentes espaços amplos, bem iluminados e equipados. 
Figura 27: Fachada da biblioteca de Almería.

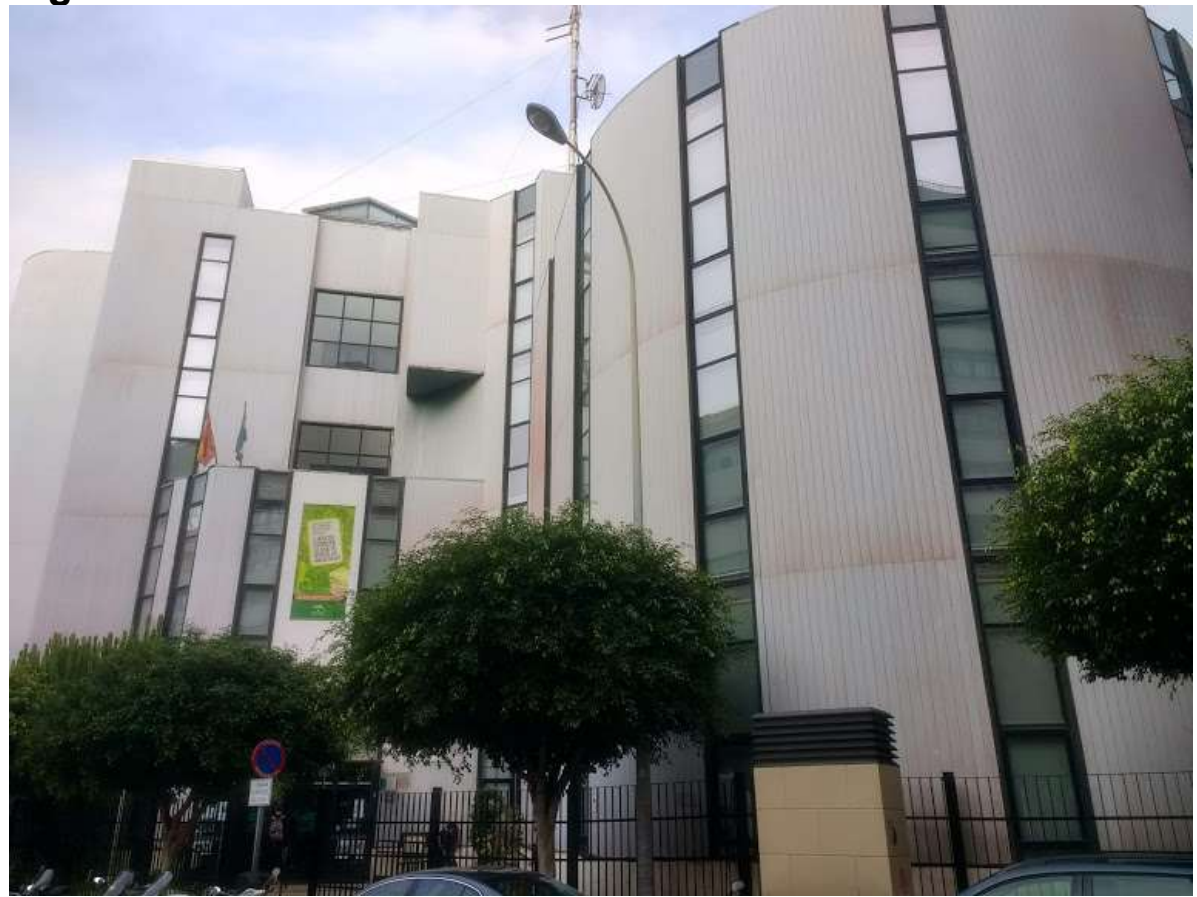

Fonte: acervo pessoal, 2018.

Figura 28: Interna da biblioteca de Almería.

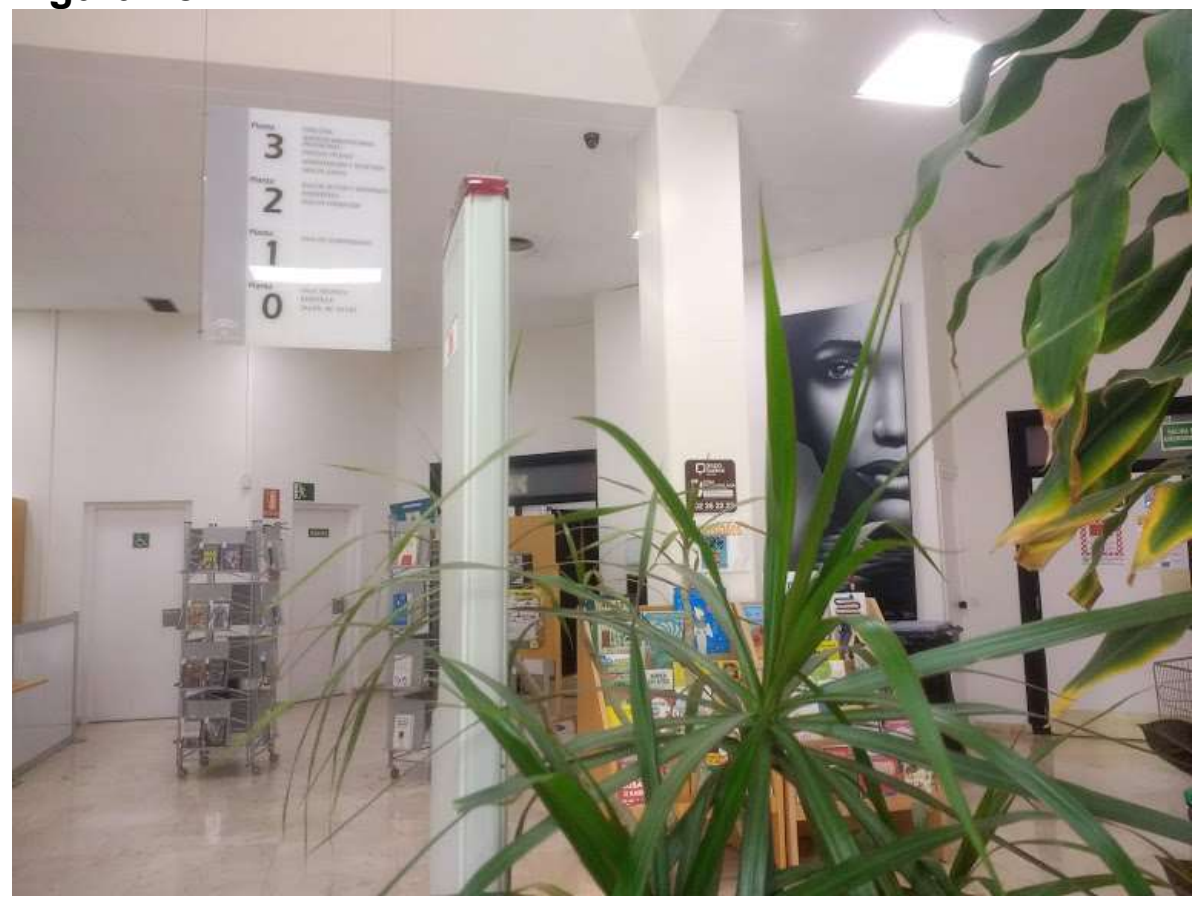

Fonte: acervo pessoal, 2018.

Os espaços internos são amplos, bem iluminados e decorados, e possuem placas de identificação que facilitam a informação sobre o conteúdo que se pode encontrar em cada andar. 
Um dos diferenciais que a biblioteca oferece é uma Bebeteca, que possui uma funcionária específica para o espaço.

Figura 29: Bebeteca da biblioteca de Almería.

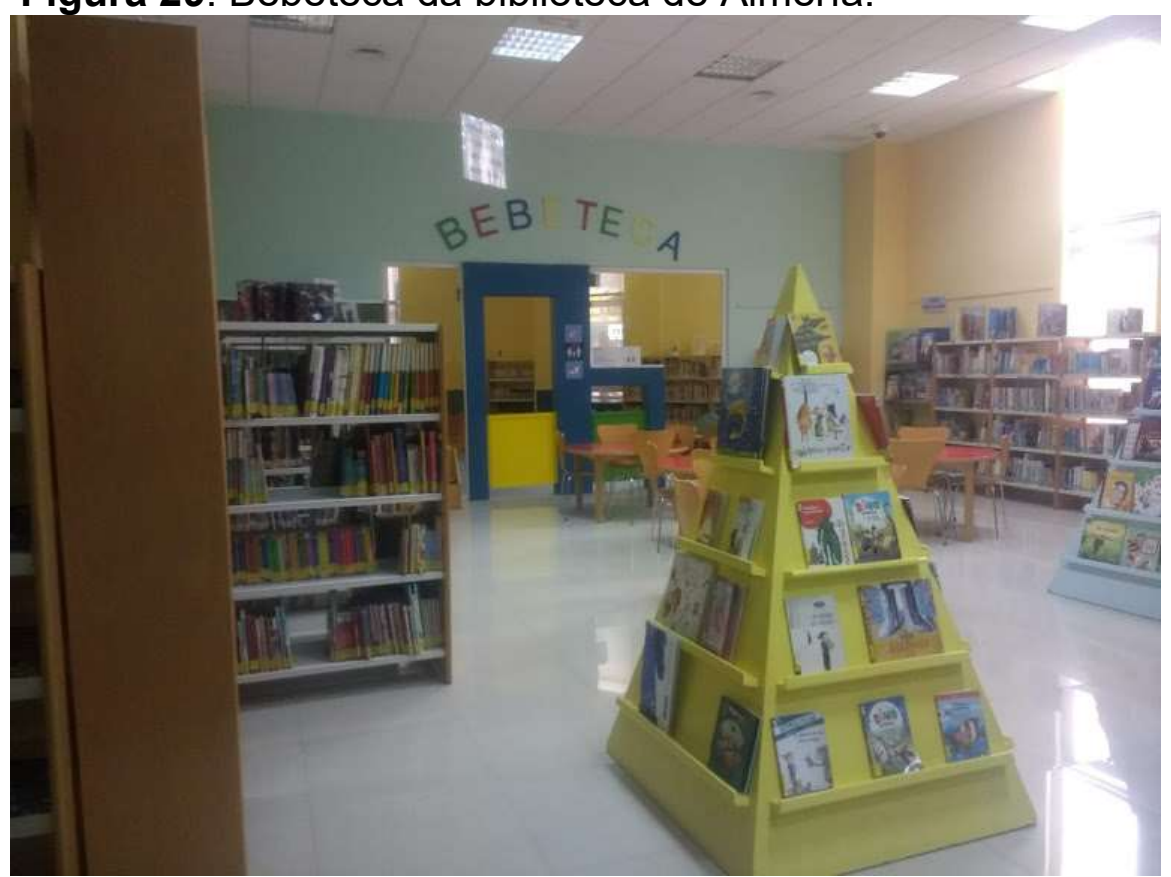

Fonte: acervo pessoal, 2018.

O espaço é lúdico e possui estrutura adequada a diferentes idades, porém funciona em um horário reduzido devido a necessidade da presença constante de uma funcionária especializada.

$\mathrm{O}$ acesso entre os andares pode ser feito por escadaria ou elevador. 
Figura 30: Escadaria entre andares da biblioteca de Almería.

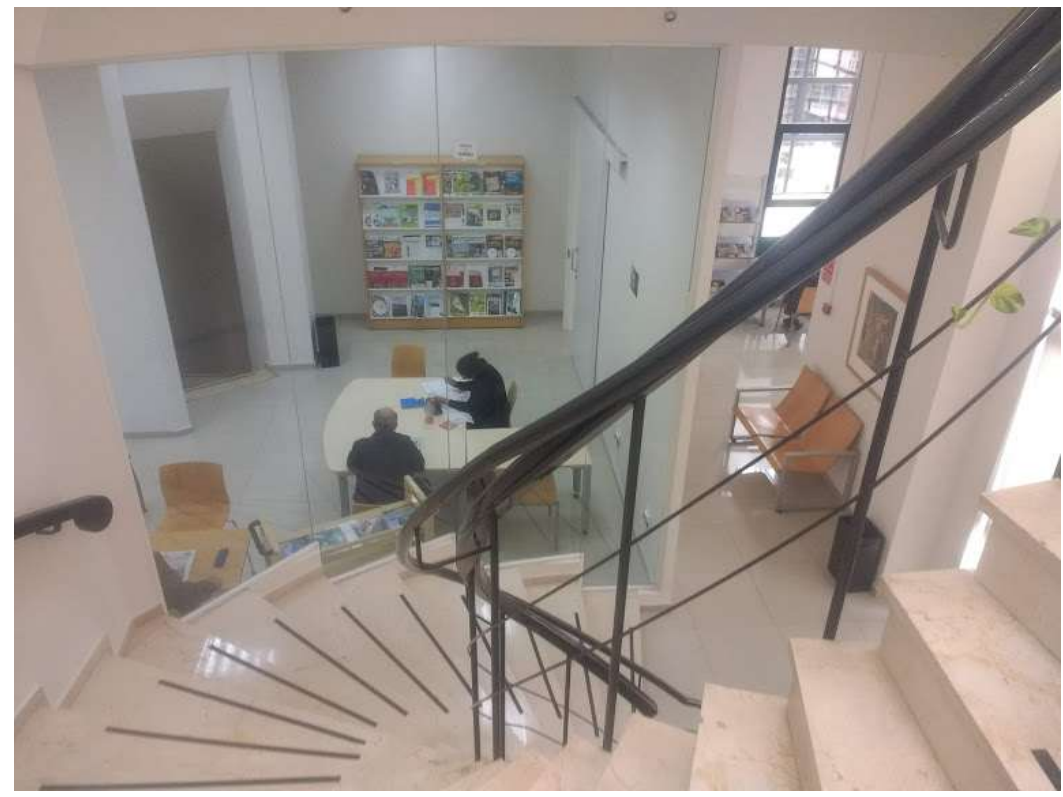

Fonte: acervo pessoal, 2018.

Figura 31: Acervo em destaque na biblioteca de Almería.

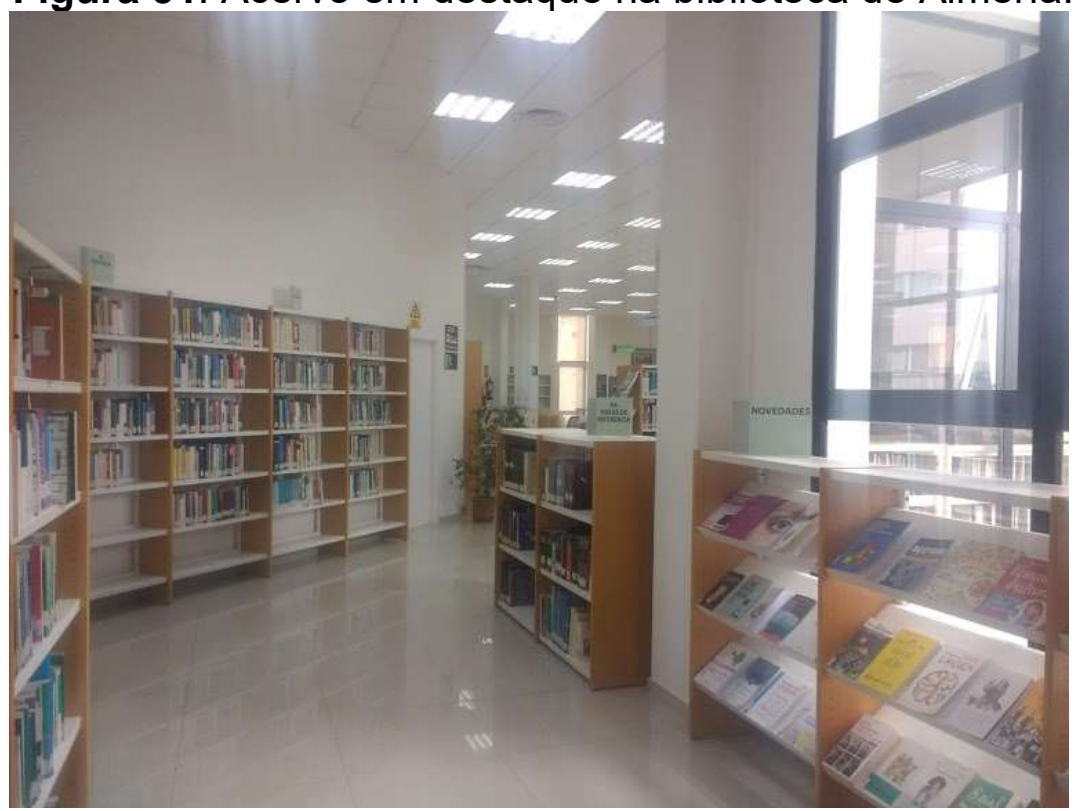

Fonte: acervo pessoal, 2018. 
Figura 32: Sala de periódicos da biblioteca de Almería.

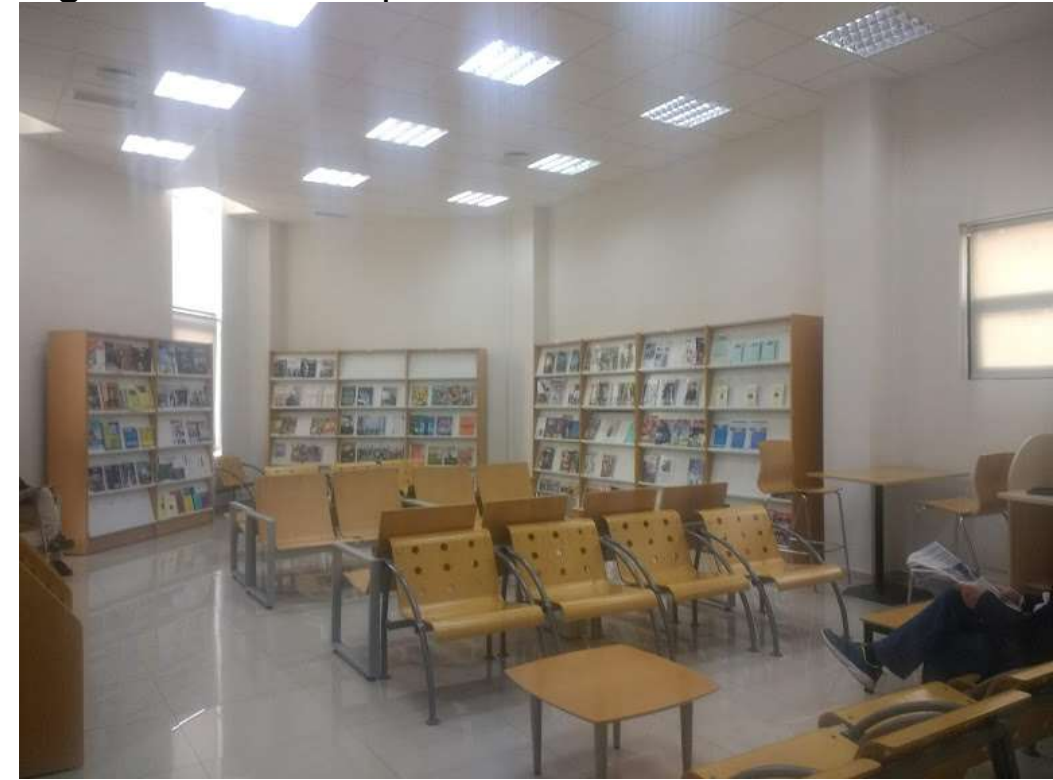

Fonte: acervo pessoal, 2018.

Figura 33: Salões de exposições.

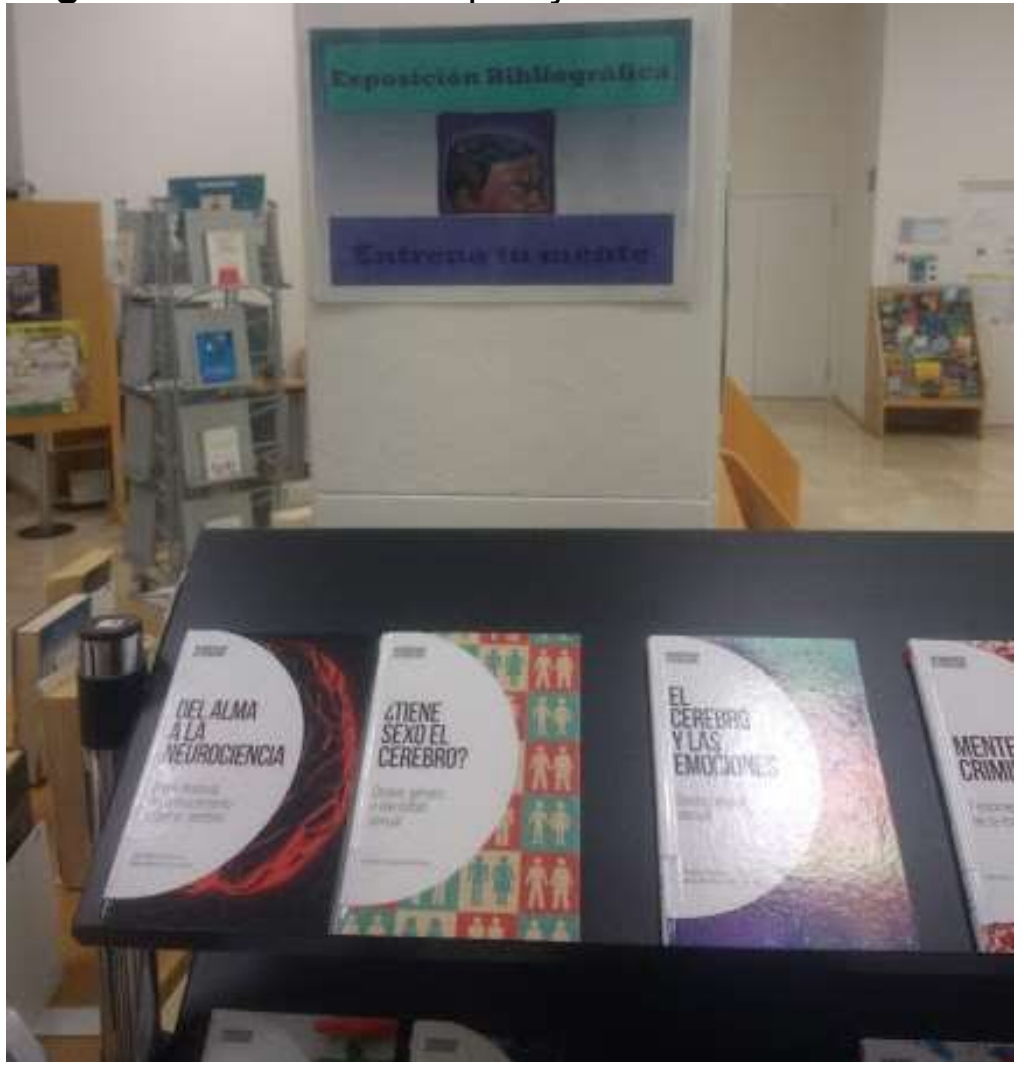

Fonte: acervo pessoal, 2018. 
Figura 34: Teatro da biblioteca de Almería

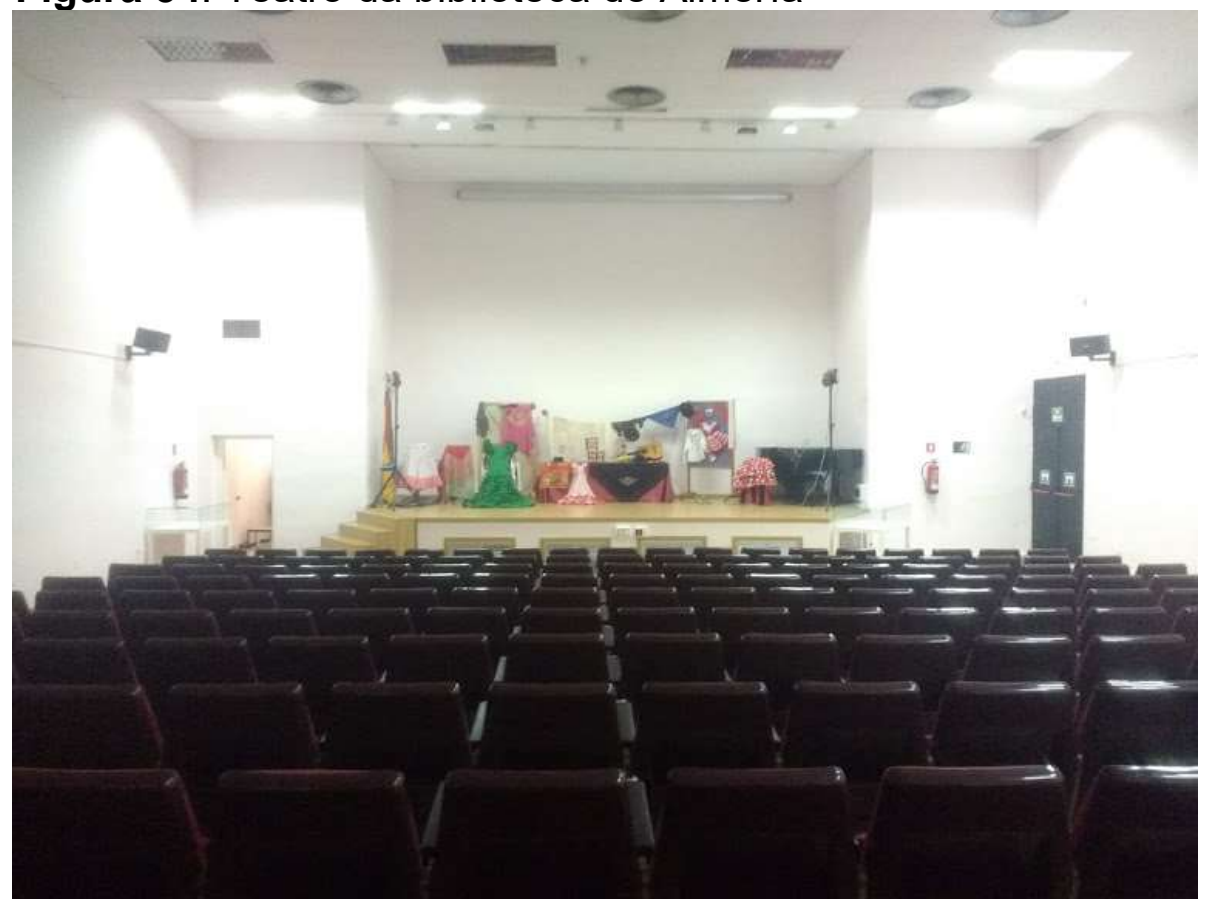

Fonte: acervo pessoal, 2018.

Durante a visita foi possível entender que a realidade da biblioteca municipal é bem diferente das demais, especialmente pelo apoio econômico. Esse aspecto foi mencionado várias vezes pelo funcionário responsável por acompanhar a visita.

Com um amplo espaço para atividades (incluindo salas de exposição/eventos e teatro) a biblioteca tenta aproveitar esse benefício para ampliar seus projetos.

O acervo possui livros com temáticas sociais em destaque, desde clássicos até livros mais recentes abordando diferentes problemáticas.

A comunicação e acervo são majoritariamente em espanhol, tanto no local quanto em mídias sociais e demais locais públicos.

Um aspecto importante ressaltado é que pela localização central da biblioteca ela é considerada geograficamente inoportuna para o uso por imigrantes, especialmente os ilegais, já que eles costumam morar em locais mais afastados e, portanto, as demais bibliotecas menores são mais frequentadas por eles. 


\subsubsection{Biblioteca de San Isidro}

A primeira biblioteca visitada em uma das pequenas cidades que possui maior presença de imigrantes foi a de San Isidro.

A pequena cidade, cercada por estufas, possui a biblioteca instalada em sua praça central.

A biblioteca, ainda que pequena, possui uma estrutura bem organizada e ampla. O bibliotecário responsável trabalha sozinho na unidade, e se reveza com outra profissional para atender outras unidades menores que funcionam em zonas de praia durante alguns períodos do ano.

Figura 35: Biblioteca de San Isidro.

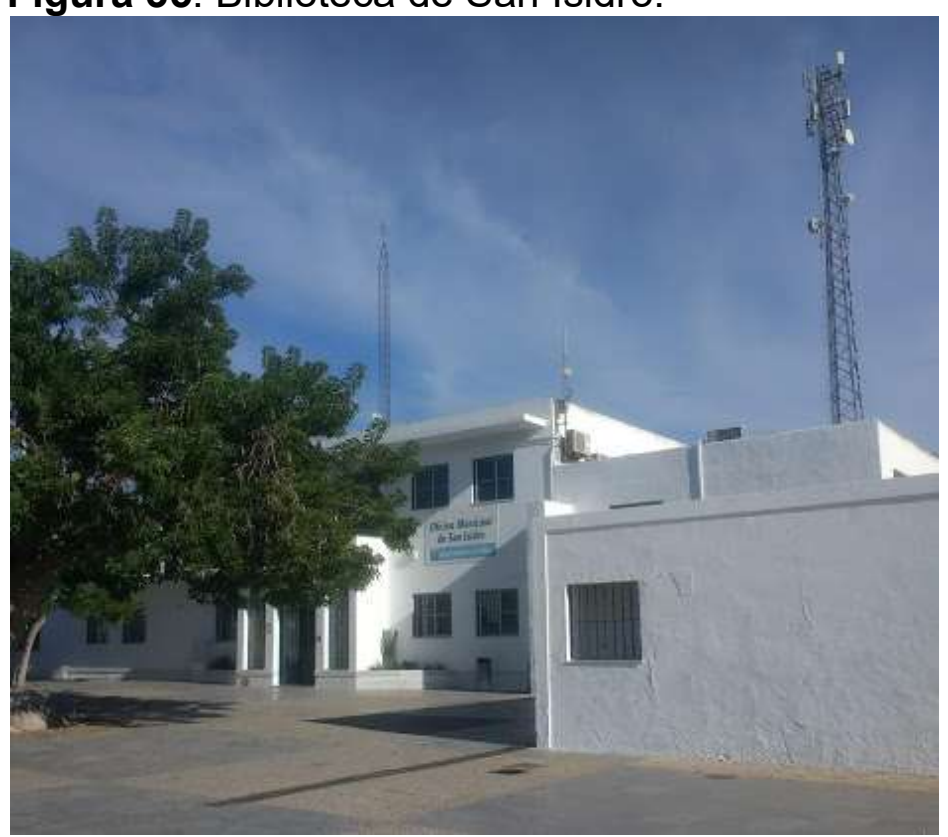

Fonte: acervo pessoal, 2018. 
Figura 36: Entrada da biblioteca de San Isidro.

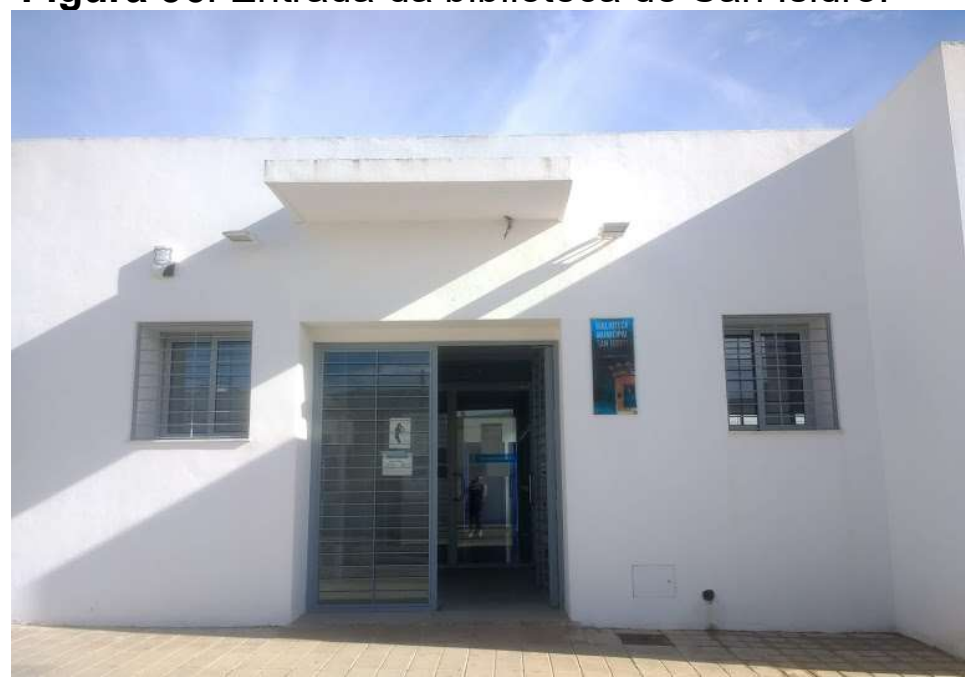

Fonte: acervo pessoal, 2018.

Figura 37: Imagem interna da biblioteca de San Isidro.

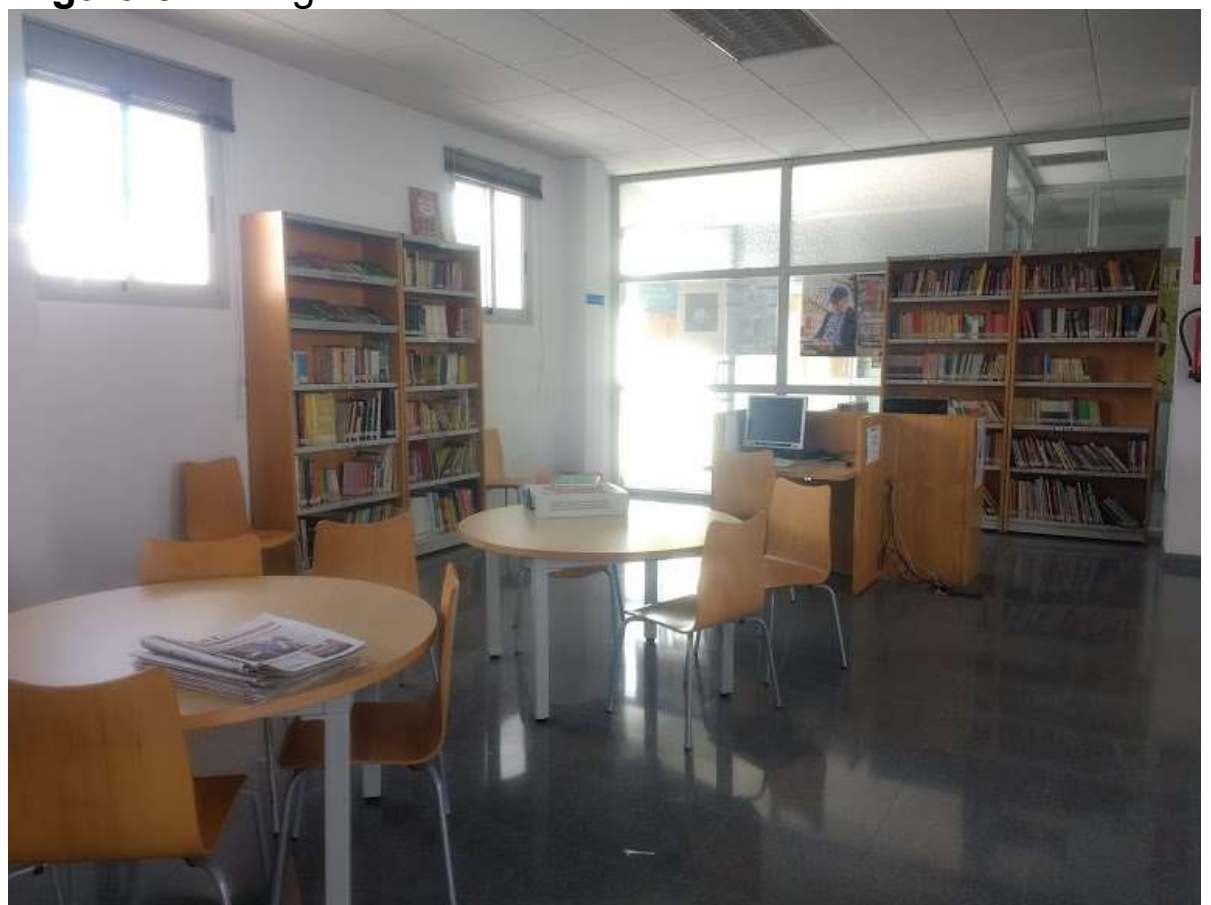

Fonte: acervo pessoal, 2018.

O bibliotecário responsável esclareceu que o uso do espaço pelos imigrantes costuma concentrar-se em poucos exemplares que ajudam no aprendizado do espanhol e no uso do wi-fi. 
Figura 38: Livros mais usados por imigrantes na biblioteca de San Isidro.

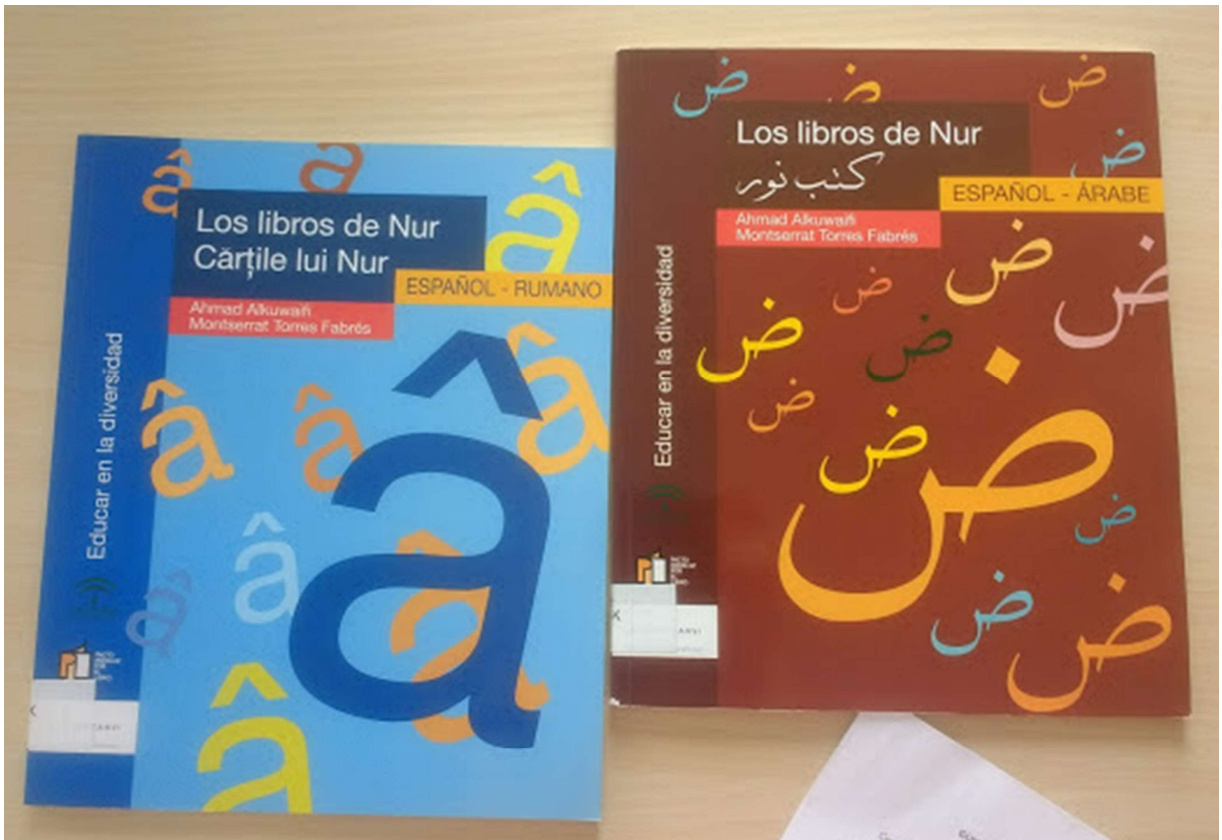

Fonte: acervo pessoal, 2018.

Figura 39: Exemplo de conteúdo interior de um dos livros mais usados por imigrantes na biblioteca de San Isidro.

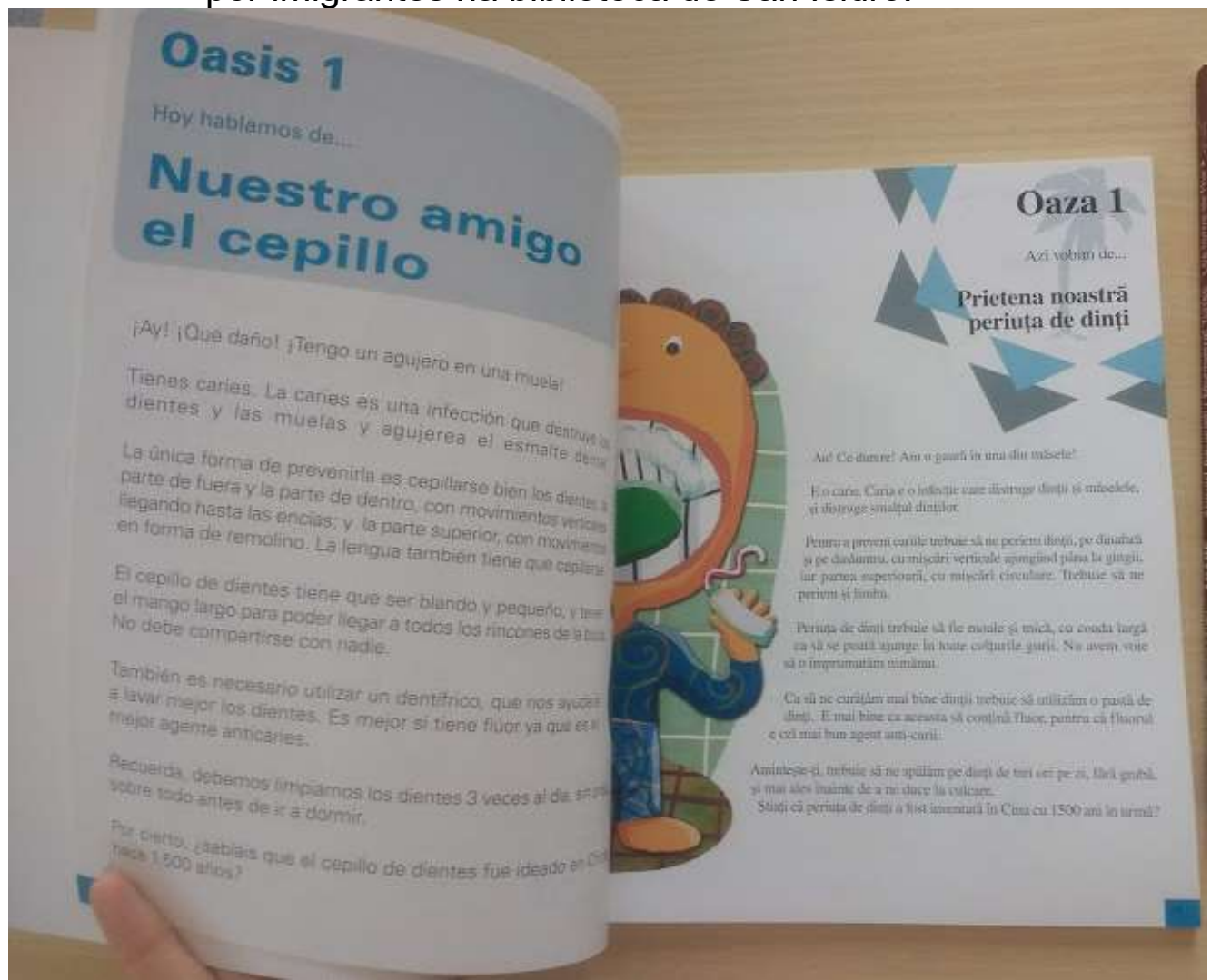

Fonte: acervo pessoal, 2018. 
Os livros mais consultados apresentam essencialmente histórias e palavras nas duas línguas - espanhol e romano ou espanhol e árabe - e um conteúdo simples e infantil.

\subsubsection{Biblioteca Roquetas del Mar}

A biblioteca visitada em Roquetas del Mar, uma das cidades com maior índice de imigrantes em Almería, encontra-se em um bairro considerado majoritariamente habitado e frequentado por imigrantes da África Subsaariana. Também se encontra em uma praça ampla e é esteticamente mais atrativa.

Figura 40: Fachada da biblioteca de Roquetas del Mar.

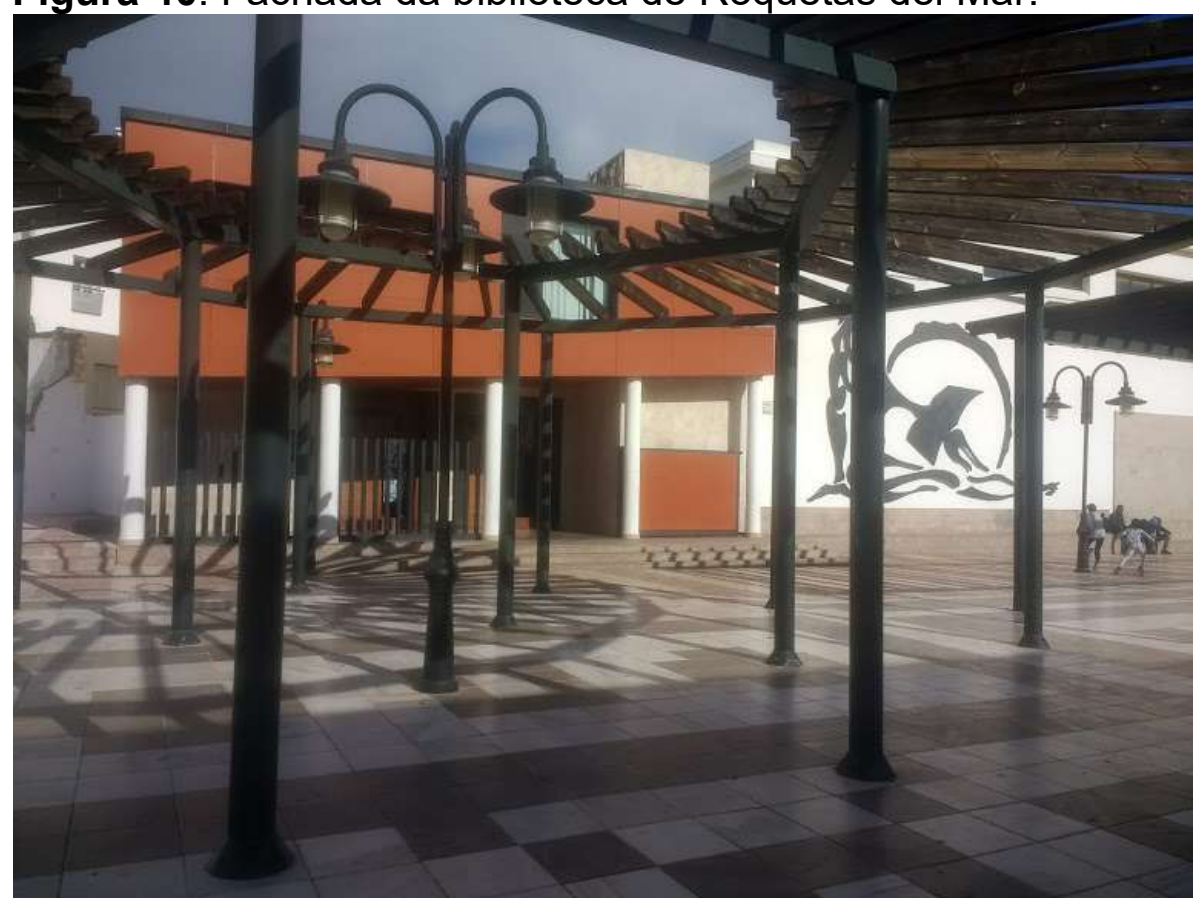

Fonte: acervo pessoal, 2018.

A entrada da biblioteca possui um amplo hall, onde eventualmente ocorrem eventos e exposições. 
Figura 41: Hall de entrada da biblioteca de Roquetas del Mar.

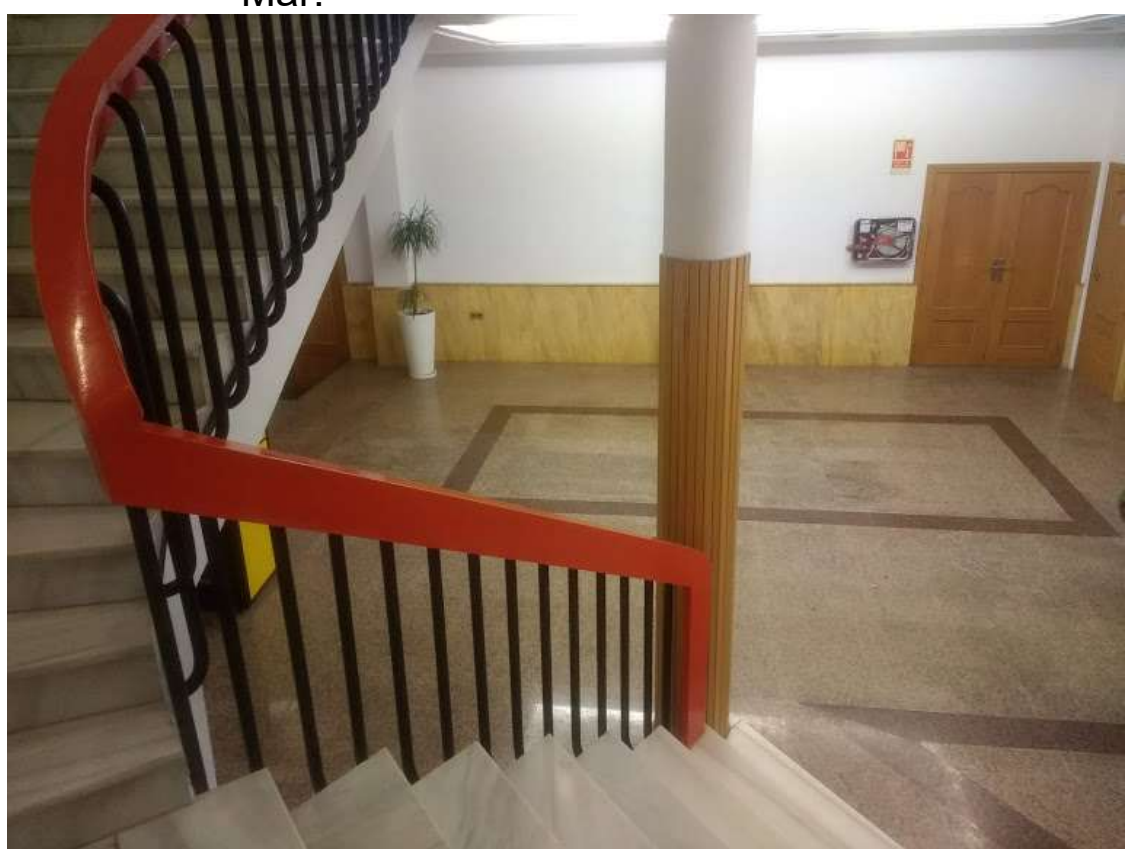

Fonte: acervo pessoal, 2018.

Subindo as escadarias encontramos o andar onde estão todas as demais instalações da biblioteca.

Antes de passar pelo balcão principal de atendimento e adentrar-se ao acervo propriamente, encontra-se um mural que, em espanhol, apresenta programações da biblioteca e anúncios. Há um espaço com poltronas, computadores para consulta ao acervo e pequenos projetos e uma mesa com livros para venda cujo lucro é revertido à associação Caritas (organização oficial da Igreja Católica que trabalha diretamente com projetos de caridade e assistência social). 
Figura 42: Quadro de anúncios da biblioteca de Roquetas del Mar.

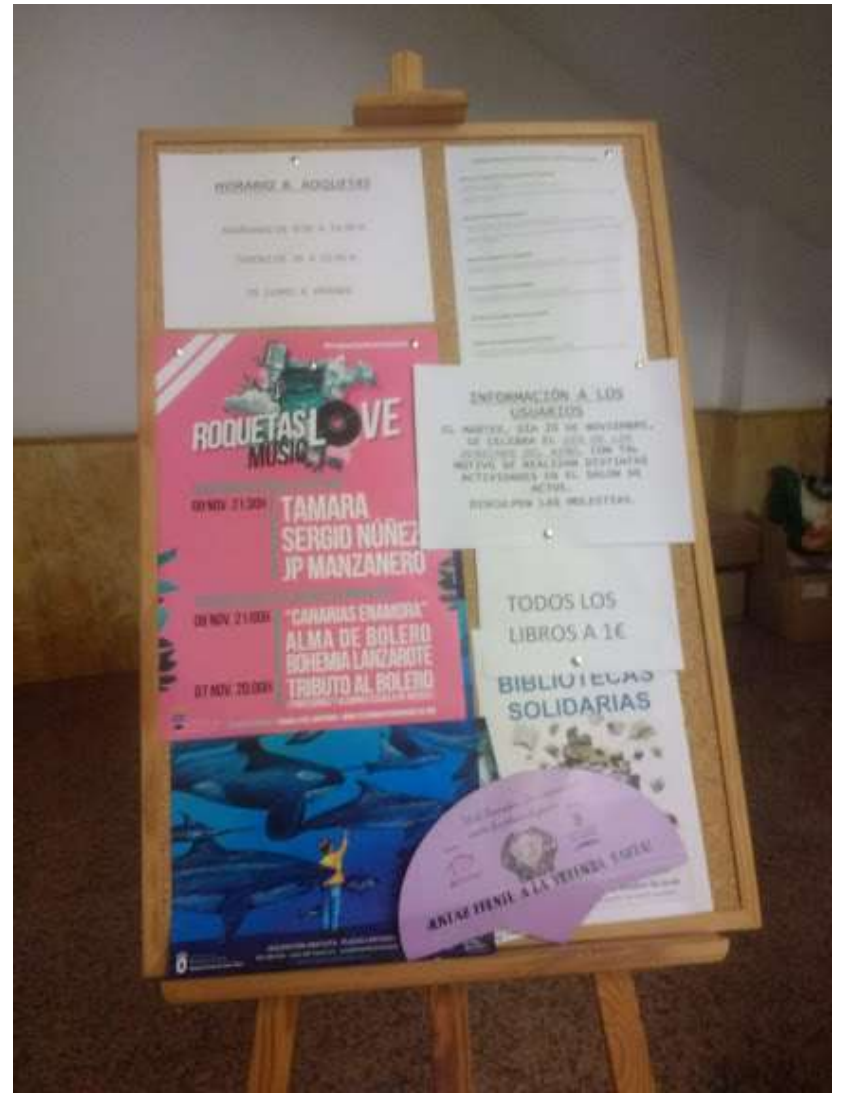

Fonte: acervo pessoal, 2018.

Figura 43: Poltronas na entrada da biblioteca de Roquetas del Mar.

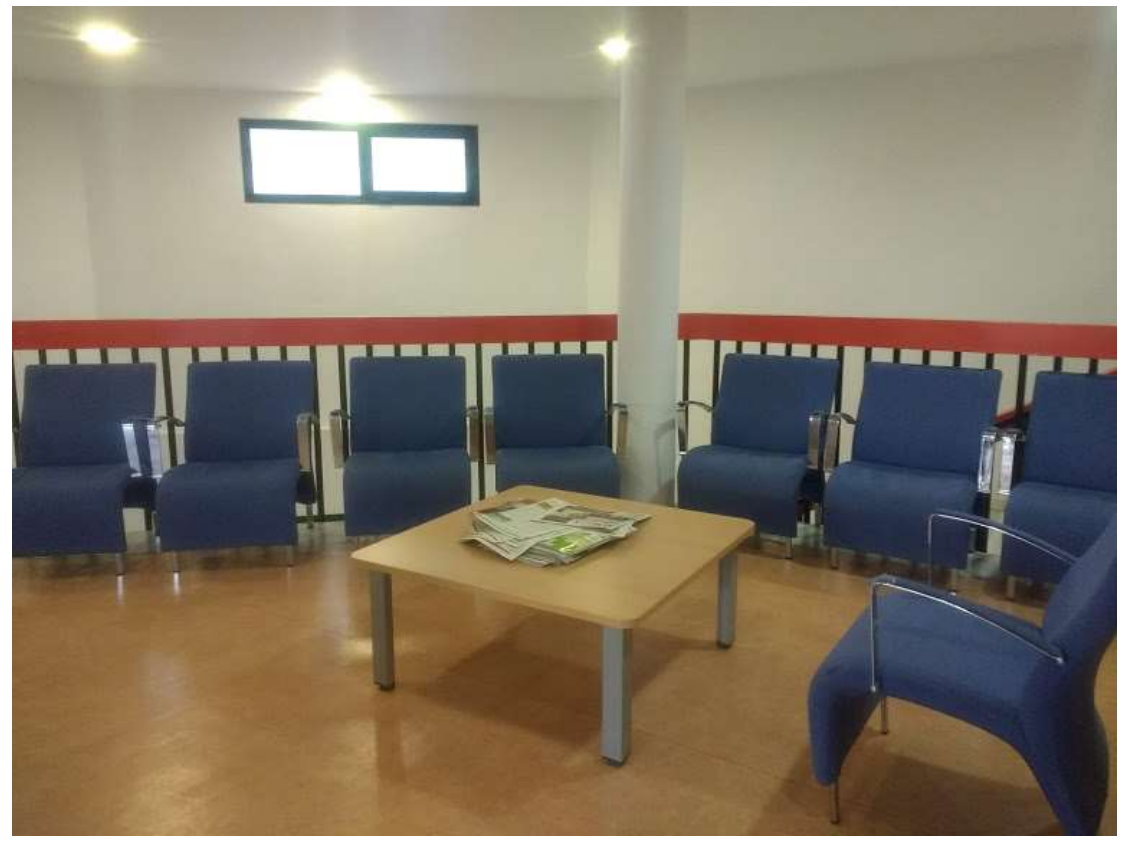

Fonte: acervo pessoal, 2018. 
Figura 44: Livros Caritas expostos na entrada da biblioteca de Roquetas del Mar.

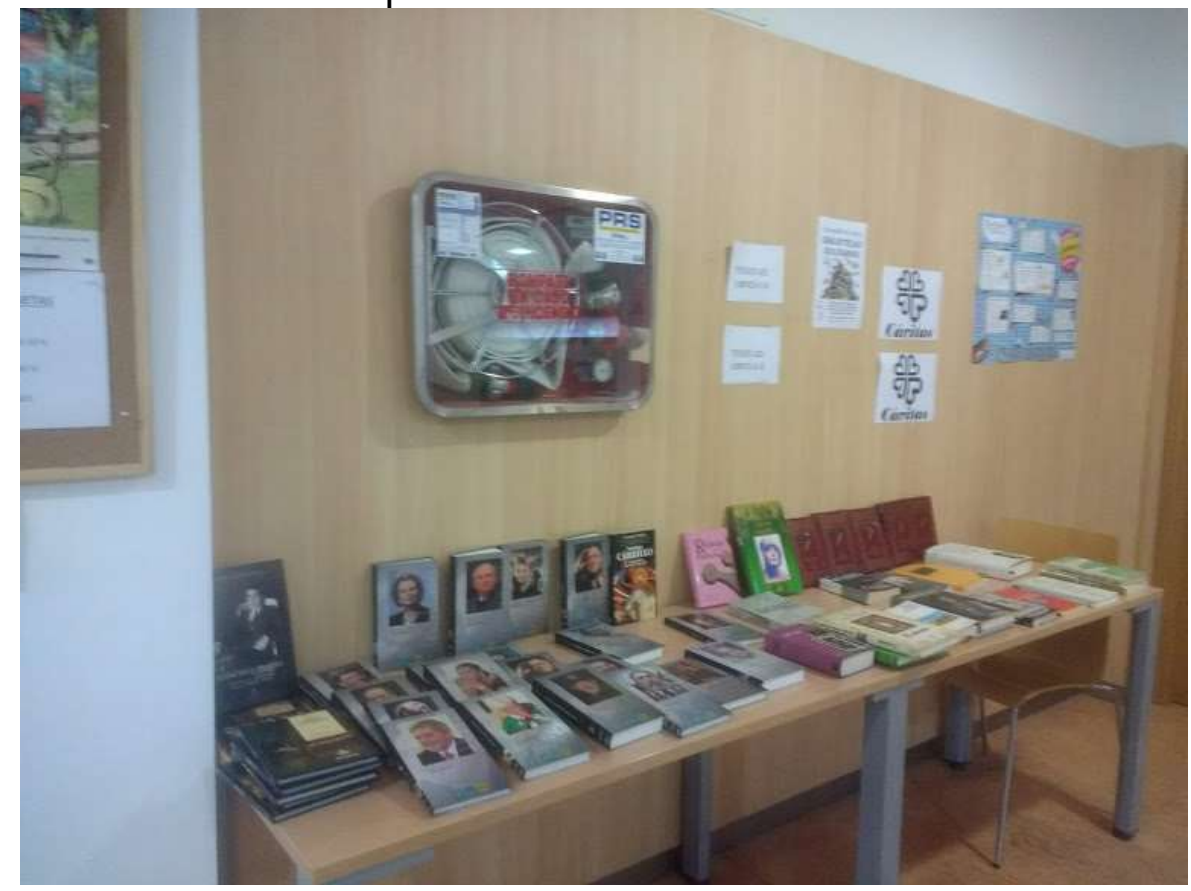

Fonte: acervo pessoal, 2018.

Figura 45: Acervo da biblioteca de Roquetas del Mar.

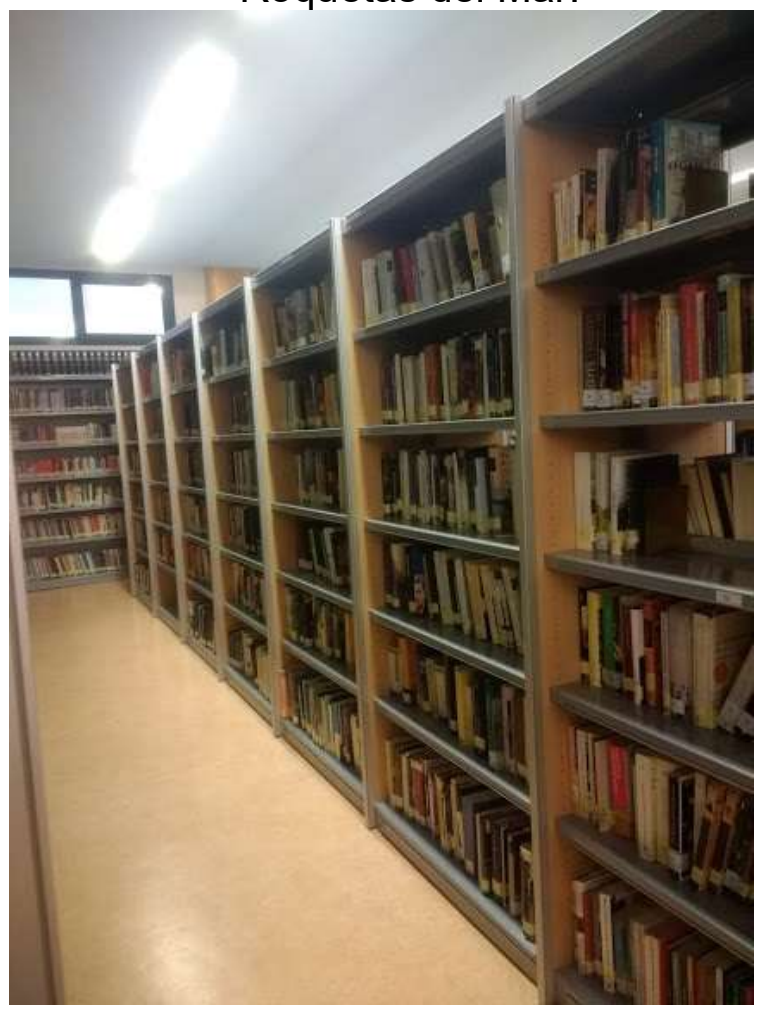

Fonte: acervo pessoal, 2018. 
A partir das entrevistas, realizadas com o apoio do roteiro disponível no Apêndice $A$, foram possíveis algumas inferências:

Contextualización del espacio y perfil de los funcionarios

- Horário de atendimento

Variou. Em algumas unidades mais abrangente, com manhã e tarde, outras em turnos e dias específicos (dependendo da disponibilidade de funcionários). Sempre fechando para almoço.

- Localização e estrutura física

Muitas bibliotecas são construídas em centros e locais de fácil acesso. Ainda que as estruturas não sejam tão grandes, os espaços costumam dar conta do número de frequentadores. $\mathrm{O}$ número de computadores foi um problema em algumas unidades por algum tempo, porém com a chegada do wi-fi esse problema diminuiu muito, já que muitos utilizam seus dispositivos móveis para acessar a internet.

\section{- Funcionários}

Todas as unidades possuíam um profissional responsável por cada unidade, porém, algumas vezes o mesmo profissional era responsável por mais de uma, tendo portando que fazer um rodízio para atender a todos. A existência de apenas um bibliotecário em algumas unidades trouxe um relato de sobrecarga em alguns momentos, especialmente quando a demanda de atendimento aumentava. Unidades de maiores centro costumam ter menos esse problema por possuírem mais funcionários, mas em todas foi demonstrado a necessidade de um trabalho conjunto para abarcar todos os setores, sendo que a ampliação do quadro de funcionários poderia ser vantajosa.

Alguns funcionários não possuem formação específica e contam, portanto, com o apoio de outros que mesmo não tendo a formação já trabalham a 
mais anos no local e por isso desenvolveram uma expertise prática, ou de bibliotecários regionais que sempre que possível vão até a unidade auxiliar nos pontos necessários.

- Línguas

Nenhuma unidade entrevistada recebeu treinamento ou investimento nesse âmbito para os funcionários.

Servicios y divulgaciones

- Projetos desenvolvidos ou em desenvolvimento com foco na comunidade imigrante

Todas as bibliotecas possuíam a intenção de atender a comunidade imigrante, mas não tinham projetos específicos para elas. Essa questão foi sinalizada como um desafio pela dificuldade de compreensão e acesso aos membros dessas comunidades.

Um projeto de apoio à diversidade foi proposto para algumas bibliotecas em uma chamada pública e algumas conseguiram se inscrever (a chamada foi considerada pouco divulgada - duas bibliotecas mencionaram não ter conseguido a inscrição porque só ficaram sabendo depois do prazo encerrado). As que conseguiram participar relataram que o projeto envolveu apenas a disponibilização de obras em outros idiomas, o que consideraram interessante, mas, como essas obras vieram sem nenhuma instrução aos funcionários ou qualquer treinamento ou apoio no sentido de como trabalhar com elas, também ineficiente.

- Adaptação do acervo

Todas as bibliotecas visitadas não consideravam seu acervo adaptado à imigrantes, tendo no máximo alguns exemplares advindos de doações ou do projeto mencionado.

Um fator interessante sobre as doações recebidas foi a dificuldade no tratamento técnico: muitos livros ficavam esperando por muito tempo para serem incorporados ao acervo porque nenhum funcionário conseguia fazer seu processamento técnico, especialmente por dificuldades linguísticas. 
- Contato com organizações/sindicatos ou representantes

Algumas unidades conseguiram apoio de organizações e escolas de idioma para ajudar com as dificuldades linguísticas mencionadas.

\section{- Experiências}

No geral as experiencias foram singelas e envolveram dificuldades no contato com os imigrantes.

Um bibliotecário relatou que os imigrantes buscavam na biblioteca uma forma de possuir um documento legal, porque achavam que ele poderia ter alguma validade, o que dificultou seu trabalho já que atendia muitos imigrantes que não tinham intenção nenhuma em usar a biblioteca e que, como trabalhava sozinho, isso the tirava muito tempo. Ele demorou para entender o porquê dessa procura constante pelos documentos e, assim que entendeu, passou a explicar-Ihes que não havia essa relação de documentos pessoais legais da Espanha com o cartão de usuário da biblioteca, e a exigir que apenas pessoas que realmente tivessem interesse em emprestar livros fizessem o cadastro.

Em todas as unidades visitadas foi relatado a busca pelo uso do wi-fi. As unidades não receberam instrução sobre como disponibilizar isso aos usuários, se deviam manter alguma restrição ou controle, mas salientaram que consideravam esse acesso uma grande ajuda aos imigrantes porque percebiam que era a forma que eles tinham para falar com familiares, e por isso tentavam manter esse acesso o mais fácil possível. Essa liberação acabou gerando alguns problemas em uma unidade, que destacou que eles faziam muito barulho e atrapalhavam os demais usuários do espaço e que, por isso, precisava estar constantemente monitorando isso, mas que mesmo assim não havia colocado empecilhos para o uso do sinal.

\section{- Expectativas}

Os funcionários relataram não possuir, no momento da entrevista, expectativas, porque não havia nenhum projeto em andamento, mas consideravam que qualquer iniciativa que os fosse apresentada no sentido de facilitar seu trabalho com essas comunidades como uma oportunidade interessante, já que consideravam um ponto muito complicado de trabalho. 


\section{MEDIAÇÃO DE LEITURA DE MUNDO}

Para falar sobre mediação de leitura de mundo explicitamente é, antes de tudo, primordial ressaltar as questões de que assume-se aqui que essa leitura mencionada envolve o reconhecimento do ser no mundo, como ele se relaciona com seu meio, significando-o e interferindo nas significações que outros possuem do mesmo mundo - essa teia de significações que se mostra pessoal e coletiva simultaneamente, na medida em que, independentemente do tamanho da comunidade em que nos encontramos, diferentes relações complexas são estabelecidas e que interferem na vida e desenvolvimento do ser em sociedade.

A leitura de mundo, portanto, ainda que seja individual, reconhece a coletividade desse ser que se desenvolve continuamente, com um universo informacional mutável e reflexivo.

Na medida em que se desenvolve, as diferentes leituras de mundo se entrelaçam e formam teias de comunidades formadas por indivíduos que assumem diferentes papeis nas sociedades dominantes e periféricas. Esses papéis impactam no próprio reconhecimento pessoal e da sociedade hegemônica, que tende a ditar regras específicas para os que consideram como "o outro".

Becker esclarece:

Todos os grupos sociais fazem regras e tentam, em certos momentos e em algumas circunstâncias, impô-las. Regras sociais definem situações e tipos de comportamento a elas apropriados, especificando algumas ações como "certas" e proibindo outras como "erradas". Quando uma regra é imposta, a pessoa que presumivelmente a infringiu pode ser vista como um tipo especial, alguém de quem não se espera viver de acordo com as regras estipuladas pelo grupo. Essa pessoa é encarada como outsider. (BECKER, 2008, p. 15).

O autor ainda esclarece que alguns aspectos considerados "errados", só o são quando expostos vexativamente, mas que sua existência "em segredo", por assim dizer, é aceita e tolerada. Também, a tolerância quanto à esses aspectos detêm-se muito ao grupo específico ao qual se aplica - como no exemplo do uso de maconha por grupos marginalizados e elitizados (ainda que a conduta seja a mesma, o tratamento recebido pelo grupo da polícia, mídia e comunidade no geral costumam ser expressamente divergentes). 
A existência desses grupos, com diferentes percepções de valores e prioridades, construídos em processos históricos-sociais, acentua-se quando as margens que os separam se vêm mais delineadas - normalmente incorporadas a grupos cuja exploração e marginalização possa ser utilizada como fonte de lucro pela sociedade hegemônica.

No grupo espanhol estudado (imigrantes da África subsaariana) foi possível observar algumas caraterísticas, das quais destaca-se:

1) Adaptação burocrática: ainda que falem a língua do novo país, os imigrantes demoram para incorporar a compreensão de aspectos burocráticos, como, por exemplo, entender quais documentos importantes precisam ou não ter e como consegui-los; e identificar como determinados espaços públicos (como bibliotecas) podem ser utilizados ou não por eles e seus familiares;

2) Exclusão laboral: independentemente de sua formação e experiência prévia, costumam ter trabalhos previamente estabelecidos para eles, normalmente vinculados ao cultivo de alimentos ou outros trabalhos exclusivamente braçais;

3) Exclusão social: mesmo que vivam ou transitem em espaços compartilhados com espanhóis recebem um tratamento diferenciado negativo, como cobranças mais altas ou negação expressa de atendimento/proximidade;

4) Segregação: incorporam-se a grupos e comunidades de imigrantes da mesma região, ainda que não falem a mesma língua;

5) Perspectivas futuras: demonstram foco na sobrevivência e, portanto, consideram aspectos de perspectivas de futuro como secundárias.

No grupo brasileiro (aldeia Xavante), destaca-se as seguintes observações:

1) Estrutura cultural familiar: a composição da aldeia se dá como um organismo familiar vivo, composto por famílias e seus representantes que falam por eles;

2) Caciques: a figura do cacique existe pela necessidade de contato com não-índios, e não por uma tradição da própria comunidade e, por isso, o peso dessa posição dentro da aldeia é menor do que o normalmente retratado;

3) Composição familiar e laboral: a escolha da profissão é muito pautada nas necessidades familiares (micro - necessidade de ter mais dinheiro na casa ou não, e macro - necessidade de determinado profissional na aldeia); 
4) Questões territoriais: possuem extrema dificuldade em manter-se nos espaços geográficos que lhes são determinados, já que a composição desses espaços desconsidera que sua composição (como fertilidade da terra, existência de nascentes e rios, e vegetação) impactam na sobrevivência;

5) Exclusão social: mesmo que vivam ou transitem em espaços compartilhados com não-índios recebem um tratamento diferenciado negativo, como cobranças mais altas ou negação expressa de atendimento/proximidade;

6) Segregação: incorporam-se a grupos e comunidades de indígenas, ainda que não sejam da mesma etnia (outros indígenas são identificados como "parentes");

7) Perspectivas futuras: demonstram foco na sobrevivência e preservação cultural, mantendo uma preocupação para como manter a sobrevivência da aldeia frente a sua marginalização e exclusão social.

Com base nas observações e investigações realizadas, compôs-se a seguinte imagem com a intenção de expor comportamentos identificados:

Figura 46: Influências da marginalização e preconceito sobre comunidades.
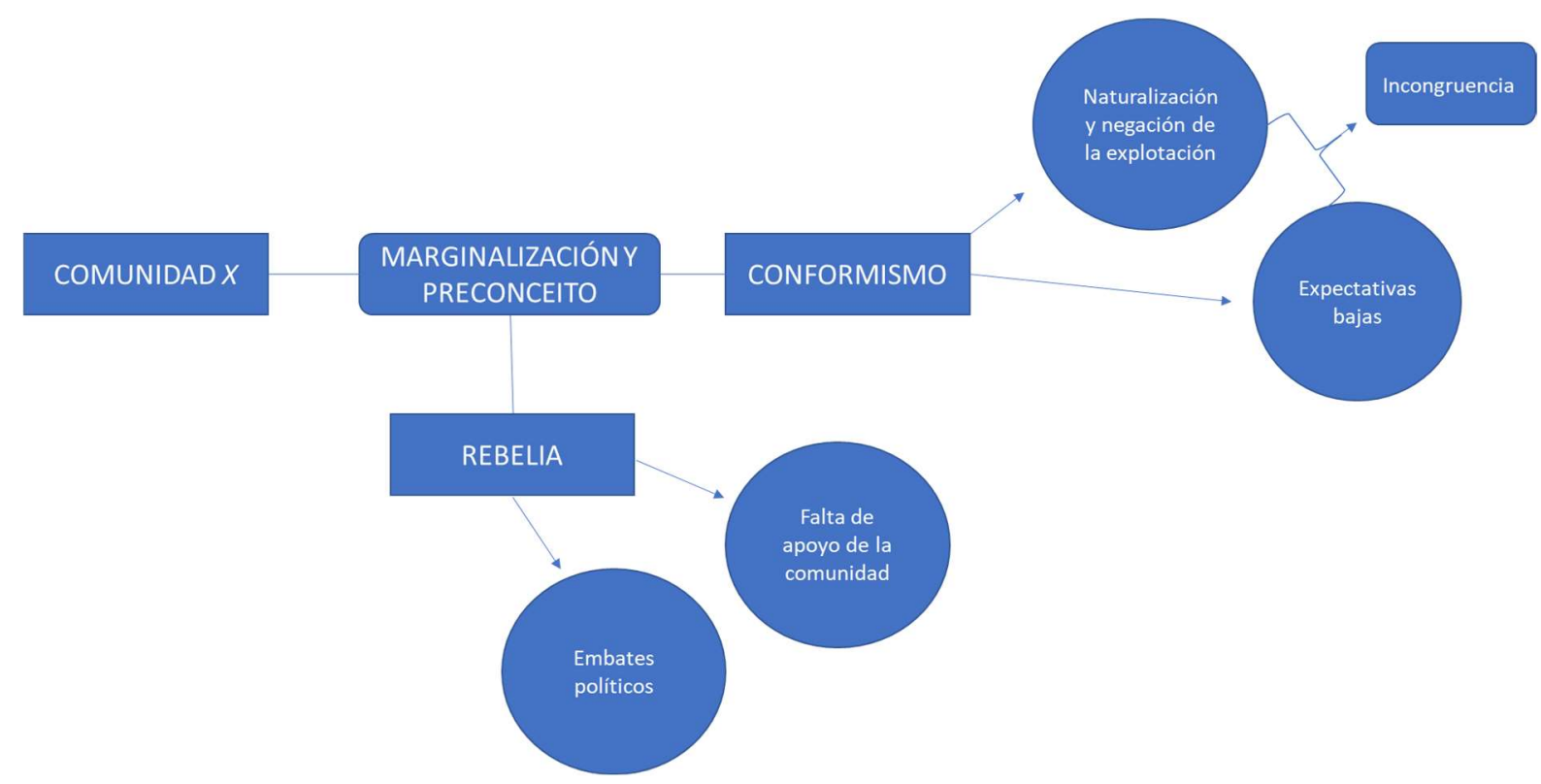

Fonte: a própria autora.

Os comportamentos, ancorados em contextos de marginalização (caracterizada especialmente pelo não acesso à cidadania e direitos básicos com a justificativa de incapacidade pessoal de não adaptação à regras sociais hegemônicas) e preconceito, costumam expor dois caminhos: o primeiro - conformismo - onde a 
pessoa aceita essa posição, e que pode ramificar-se na naturalização e/ou negação dessa posição ou na exposição de baixas expectativas pessoais, porém com ambas ramificações concentrando-se em aspectos de incongruência, resultando em discursos e atuações ambíguos e/ou controversos; e o segundo - rebeldia - onde a pessoa não aceita essa posição e rebela-se contra o sistema, com comportamentos normalmente resultantes em também duas ramificações, sendo uma determinada exclusão ou segregação dentro da comunidade ou grupo, ou a perseguição política, agravada pela falta de apoio comunitário. Embora os caminhos e ramificações sejam assim retratados, pela própria complexidade em que se encontram não são estáticos ou excludentes.

A composição de ideais que buscam a incorporação de diferentes culturas em um relacionar-se harmônico por muitas vezes falha nesse meio por, no lugar de buscar uma representatividade e compreensão da complexidade desse entrelaçar de visões, representar o discurso de que há um diferente, e que ele não se adequa a "nossa" realidade hegemônica e que ele deve ser visto e aceito dentro de um limite aceitável, e suas então "expressas limitações" por essa diferença enunciada passa a ser a justificativa de uma falsa incapacidade do outro em se adequar ao identificado como "mais civilizado", "mais adequado".

Isso quer dizer que o suposto enaltecer de comunidades que expressem uma diferença com a cultura hegemônica não significa sua real inclusão, mas sim uma forma de buscar uma aceitação leve frente a sociedade, minimizando diferentes preconceitos e fobias. É o processo de inserir algo ou alguém em determinado contexto, buscando assim uma representatividade, mas que, pelo total despreparo e falta de embasamento do contexto, gera um ambiente extremamente hostil que apenas reafirma que o "diferente é que não se esforça para fazer parte". É sempre o outro que não conseguiu se adaptar e, portanto, uma isenção da culpa.

O trabalho de mediação busca entender o outro para fornecer-lhe dados passíveis de atribuição de sentido, protoinformações que possam construir sentidos e proporcionar informação e conhecimento. Porém, e quando quem precisa da informação está do outro lado? E quando o que precisa ser mediado é o ser que precisa ser entendido para que governos, políticas, poderes e concepções possam ser construídos para eles? Note-se que não se fixa nesse momento a esfera de serviços informacionais, mas a que the antecede, afinal, como se pode desenvolver serviços informacionais amparados em conceitos de apenas uma via? Que sempre 
partem dos serviços aceitos que se dispõe e de como adaptá-los? Será sempre possível uma adaptação? Conseguimos comtemplar todas as complexas realidades existentes com os embasamentos teórico-técnicos que a $\mathrm{Cl}$ proporciona hoje?

O que se observa, com base na formação e desenvolvimentos atuais possíveis é a seguinte atuação:

Figura 47: Atuação de mediação - cenário 1.

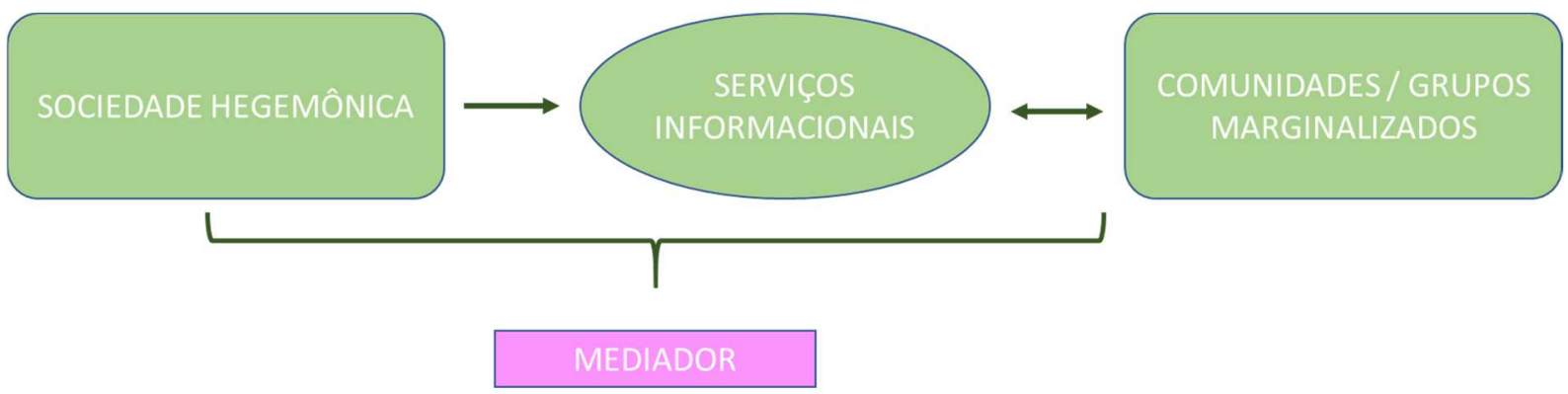

Fonte: a própria autora.

Nesse esquema observamos que, a partir da existência de normas e expectativas de uma sociedade hegemônica, espera-se a atuação do mediador que, no contexto de serviços informacionais desenhados "de dentro" dessa mesma sociedade, da qual o profissional faz parte, oferece esses serviços para as comunidades que se busca atender. Ainda que esse profissional esteja aberto para uma mediação consciente, trabalha com as limitações formativas e influências sociais e políticas que lhe são constantemente impostas, tanto do lado opressivo da sociedade hegemônica, quanto do lado segregado das comunidades/grupos.

A medida em que os instrumentos são apresentados e se trabalha com a necessidade de adaptá-los a determinadas realidades, o que fazemos é a transposição do "o outro tem que se adaptar" para o âmbito dos serviços informacionais, o que, conforme vimos na realidade das duas comunidades estudadas, não é possível já que há peculiaridades que o próprio profissional da informação não possui competência para trabalhar devido a suas limitações formativas e questões de políticas públicas que antecedem o próprio tratamento e disponibilizar da informação.

Além do aspecto que se relaciona diretamente com o acesso à informação indiretamente negado a determinadas comunidades devido a 
incapacidade de que existam serviços informacionais adequados a sua composição de mundo, no âmbito da interdisciplinaridade tem-se também o agravar da própria sociedade hegemônica que, fechada para essas "diferentes" leituras empobrece sua própria composição, limitando seu desenvolvimento a questões econômicas e políticas de aspectos capitalistas que frente a catástrofes mundiais já têm demonstrado o preço que está disposto a pagar para manter-se no poder, preço esse que começa a ser considerado caro demais e que tem feito grandes e diferentes nações ao redor do mundo rever suas prioridades e próprias concepções de desenvolvimento - concepções que, ironicamente, já foram questionadas pelas próprias comunidades que são marginalizadas por eles.

Há de se buscar, e esta é a proposta desse capítulo, a possibilidade de promoção do outro para que, numa real abertura e busca de crescer como ciência e sociedade, se possa transpor a aceitação de que "o diferente é complexo e não posso entende-lo" para o "eu sou o diferente e preciso saber explicar-me, conhecer e explicar o outro" - numa construção de mediação recíproca e infinda. Assim, mediar a leitura de mundo é muito mais que se fazer entender, é buscar genuinamente o entendimento e crescimento recíprocos, assumindo que ambos estão em patamares similares, superando a barreira de que um desenvolvimento, independente do âmbito (científico, social, tecnológico, etc.), possa se sobrepujar a outro e que, assim, se possa estabelecer uma convivência de aprendizagem, cooperação e intercâmbio.

Krenak (2019) relembra, ancorado também em narrativas de Eduardo Galeano, que povos indígenas têm resistido à imposição desse outro "melhor" que frequentemente lhes é proposto, mantendo características de diferentes etnias mesmo com o deslocar de seu espaço de origem e desrespeito às suas próprias concepções de existência.

Um ponto importante a superar é a própria concepção linguística na qual muitos dos serviços se embasam. A língua e concepções hegemônicas, muitas vezes representadas em códigos e suportes tecnológicos, pressupõem que as pessoas que os utilizarão terão domínio ou ao menos conhecimento dessa linguagem - mas é esse o caso sempre? As comunidades estudadas demonstraram que não. Muitos serviços que buscam promoção e conservação de determinadas nuances comunitárias, com boas intenções buscam a transposição de aspectos dessas culturas para a linguagem tradicional, ignorando que essa transposição pode, por si só, significar a deturpação do que se buscava promover ou conservar. É uma 
continuidade da história sendo contada pelos olhos dos vencedores - é a "minha" cultura sendo divulgada pela cultura do "outro", que não necessariamente a compreendo e/ou respeita.

Para ilustrar brevemente a gravidade que essa prática pode ocasionar: a gravação e transmissão de cerimônias secretas constituem uma violação da solenidade e próprio fundamento dessas cerimônias, sendo que tal divulgação pode simplesmente apagar o sentido de sua própria existência por corromper o âmago de suas regras - o segredo.

A fixação pelo registro têm guiado sociedades e forçado comunidades ágrafas e/ou de grande heranças orais e artísticas a repensar sua relação com o meio, obrigando-as a repensar toda sua composição de pensamento para adaptar-se a necessidade de escrita em uma língua que pode lhe ser estranha não apenas no âmbito da língua em si, mas da expressão que ela apresenta sobre a relação com objetos, cotidianos e sentimentos. Um grande movimento de registro de línguas indígenas percorre países buscando uma preservação, mas há de ressaltar-se que essa transcrição pode constituir uma descaracterização da língua originária e desvalorização da mesma à medida em que apresenta uma nova língua, que cabe no dicionário e assim pode ser explicada ao outro, e que portanto deve ser a então valorizada.

No âmbito de imigrantes, há o agravar da desconsideração da complexidade e gravidade da própria condição legal. No caso de imigrantes ilegais, por exemplo, a propostas de muitos serviços desconsidera a impossibilidade que eles podem ter em conseguir documentos básicos - como de identificação e de comprovação de endereço, bem como a limitação de tempo e escolaridade, que pode ocorrer dos dois lados: há imigrantes ilegais que podem ter uma excelente formação e experiência profissional que são perdidos na transição, seja pela impossibilidade de validação desse contexto, seja pelo próprio preconceito de mantê-los em atividades "aceitáveis", limitando sua expansão profissional, assim como há imigrantes que saíram muito cedo de seus países, sem ter a oportunidade de concluir os ensinos de base e que, pela sobrecarga de trabalho ou por inúmeras outras características pessoais complexas, dificilmente conseguirão tempo e/ou motivação para retomar os estudos, ainda que desejem fazê-lo. 
A fim de evitar manter o estudo num âmbito muito abstrato, das duas comunidades visitadas, destaca-se resumidamente os seguintes aspectos quanto a existência de bibliotecas:

1) No contexto espanhol, foi possível entrevistar os profissionais da informação que trabalhavam em algumas bibliotecas dos locais visitados, bem como observar o ambiente e seu entorno. As entrevistas e observações proporcionaram uma aproximação com a grande presença de imigrantes da África subsaariana, sujeitos da pesquisa, nos arredores, porém, uma mínima participação dos mesmos dentro da biblioteca ou como ativos participantes de serviços informacionais por elas propostos. O principal uso identificado foi do serviço do Wi-Fi, na maioria das vezes por celulares pessoais, e essa disponibilização evidenciou-se como uma manifestação individual dos profissionais ali atuantes, como uma cortesia e não exatamente como um serviço previsto. Todos os funcionários entrevistados demonstraram haver dificuldades de trabalhar com a comunidade de imigrantes, abarcando desde questões linguísticas (muitos não falam outra língua além do Espanhol e não recebem treinamento ou incentivo para ampliar esse aspecto) até questões de entendimento cultural (os imigrantes costumam ter dúvidas relacionadas a legislação e burocracia, já que não estavam habituados ao contexto espanhol, e possuem dificuldades que começam na própria identificação e porte de documentos básicos).

2) No contexto brasileiro, o contato foi com uma aldeia Xavante. A intenção inicial dessa tese era fazer uma investigação mais profunda dessa comunidade, a partir de um projeto mais amplo, aprovado pelo comitê de ética brasileiro e pela FUNAI, que daria oportunidade de imersão na comunidade para poder estudar melhor os aspectos que poderiam corroborar desenvolvimentos teóricos estudados, porém, em virtude da pandemia enfrentada no ano agendado para a maior etapa da prática (2020), priorizando-se questões de segurança da comunidade e por respeito às normas de contenção da pandemia apresentadas pela OMS, ela foi cancelada. Foi possível, no entanto, incluir os resultados de uma primeira etapa executada, de reconhecimento e familiarização, na qual foi realizada uma entrevista inicial e observações que possibilitaram, ainda que de maneira preliminar, algumas inferências. No âmbito da biblioteca, identificou-se a presença de uma estrutura 
física que representa a unidade de informação dentro da aldeia. Essa unidade, com poucos volumes, segundo nosso contato principal da aldeia, exemplifica também o desejo que eles possuem em ampliar investigações científicas dentro da aldeia. Foi relatado o desejo de utilizar esse espaço para a investigação científica dos indígenas, para que eles possam crescer cientificamente. Identificou-se, porém, uma grande inadequação no conteúdo das obras ali existentes, com a existência de materiais obviamente sem um critério de mediação e sem um treinamento de profissionais que poderiam atuar nesses espaços contribuindo para esse desejo de ampliação da pesquisa científica dentro das aldeias. Temos, portanto, a presença de uma estrutura física que figura um desejo informacional mais do que um sistema de informação que pudesse proporcionar a concretização desse desejo.

O que se propõe é a reorganização do esquema de atuação do mediador (cenário 1, exemplificado na figura 47) para:

Figura 48: Mediação da informação adaptada às concepções interculturais.

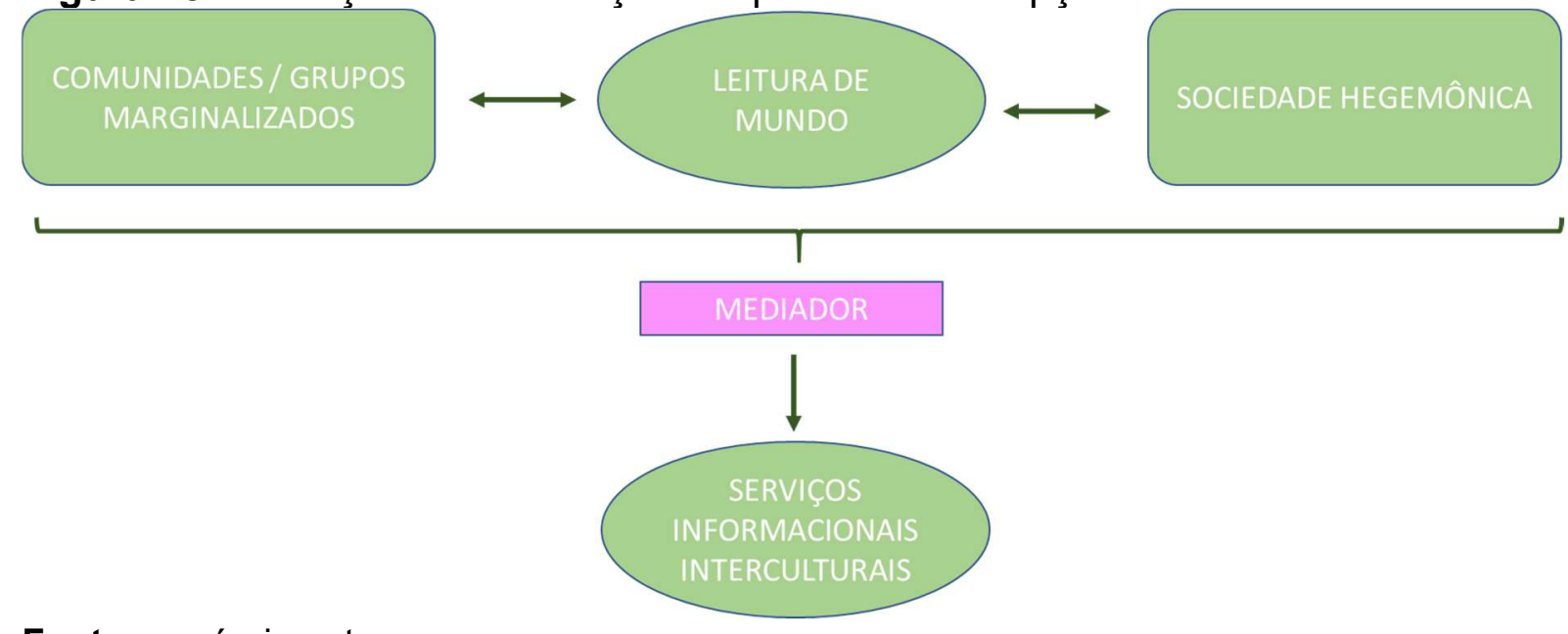

Fonte: a própria autora.

Nessa recomposição, por assim dizer, retira-se o protagonismo da sociedade hegemônica e realoca-se as comunidades/grupos marginalizados num primeiro plano, bem como amplia-se a atuação do mediador sobre todo o processo, assumindo-se a necessidade de consciência ativa de amplas complexidades envolvidas em todo o esquema de mediação. A leitura de mundo passa a ser o centro do esquema, já que se busca, antes, o entendimento de ambos os contextos e suas complexidades para, e apenas depois disso, ser possível a construção ou avaliação de serviços informacionais passíveis de desenvolvimento e incorporação. 
Para essa composição, inicialmente, se faz necessário avaliar:

A. Mediador em posição de atuação consciente: a atuação de mediação sem consciência não é considerada eficiente para a mediação da informação devido a necessidade de capacitação e responsabilidade necessários para trabalhar em contextos complexos como os apresentados. Sem a consciência de atuação é, no máximo, provável manter-se no esquema tradicional exposto na figura 47. Salientando que essa consciência deve incluir a própria consciência da interferência do inconsciente.

B. Mediador com formação capacitada: pela necessidade de compreender realidades complexas, bem como atuar criticamente frente sua própria atuação e formação, é provável que uma formação técnica tradicional seja insuficiente. Os aspectos de língua também podem ser considerados nesse caso, bem como a imersão em aspectos culturais dos grupos com os quais se busca trabalhar (sugere-se trabalhos de campo prévios).

C. Mediador com autonomia na construção e ampliação de serviços informacionais: Ainda que o profissional supere as barreiras $A$ e $B$, é necessário que essa autonomia seja respeitada para que seja possível a concretude e registro de seu trabalho, garantindo sua aplicação e continuidade.

D. Relação profissional/comunidade ou grupo: essa relação dificilmente será simples se o profissional da informação não fizer inicialmente parte do grupo/comunidade em questão. Porém, essa realidade não impossibilita o contato, nem determina restrições, apenas ressalta a necessidade de consciência, respeito e empatia que se deve demonstrar, especialmente com grupos que já foram vítimas de algum trabalho prévio que manteve-se no âmbito de colonização cultural que se busca evitar, e/ou de qualquer forma de exploração.

E. Relação profissional/sociedade hegemônica: não se pode ignorar a existência de uma sociedade hegemônica que, influenciando especialmente com sua força econômica, impacta diretamente a todos os grupos existentes. É necessário compreender essa força contextual a fim de poder estabelecer as estratégias de trabalho e desenvolvimento que se busca desenvolver tanto nessa sociedade como um todo, quanto nos grupos em atuações pontuais.

F. Serviços informacionais interculturais: A partir dessa construção complexa o mediador estaria habilitado para a composição de serviços informacionais interculturais, ou seja, serviços que pudessem propor a valorização da 
complexidade das realidades desses grupos/comunidades para contribuir com sua sobrevivência e superação de sua marginalização frente a sociedade hegemônica.

Relembrando que se estabeleceu a base fenomenológica da mediação no desenvolvimento humano (capítulo 5), e as características de um ambiente educativo intercultural, ancorado no paradigma do pluralismo cultural (capítulo 6) ; buscou-se, assim, transpor de forma prática como um trabalho mediador pode ser desenvolvido visando dirimir dificuldades de atuação frente a grupos marginalizados. 


\section{CONCLUSÃO}

O Objetivo Geral deste trabalho foi analisar aspectos da natureza da mediação sob uma visão fenomenológica, buscando identificar e entender o momento em que o processo da mediação inicia e como se perpetua em diferentes realidades complexas.

Quanto a isso, conclui-se que, a partir das concepções estudadas: Hegel (numa perspectiva filosófica), Marx (social) e Vygotsky (psicológica educacional), apresentadas e discutidas nos capítulos 4 e 5 , identificou-se que a atividade de mediar ancora-se se ancora na busca do impacto no desenvolvimento humano, "trabalhando", por assim dizer, no âmbito imaterial da consciência e do processo cognitivo humano - ela carrega características de transformação, evolução e/ou superação, ressaltando a importância de espaços sociais (mesmo que em diferentes perspectivas), da apropriação, e dos impactos recíprocos ou reflexivos materiais da mediação (também com diferentes abordagens).

Portanto, pode-se considerar que a intencionalidade é um ponto de partida para a mediação e assim, também uma condição para que um fenômeno seja considerado uma mediação.

Quanto aos objetivos específicos apresentados:

$\checkmark$ Conhecer as concepções e formas de se entender a mediação sob uma perspectiva fenomenológica.

A proposta de se trabalhar com autores distantes no âmbito temporal e de aplicação de pesquisas foi proposto com a intenção de que a redução fenomenológica aplicada pudesse ver mais claramente aspectos contextuais que não impactasse o fenômeno e, nesse sentido, considera-se que a escolha foi proveitosa.

A metodologia dessa pesquisa pode ser aplicada em análises de outros autores e contextos, confrontando-se seus resultados e assim enriquecendoos. 
$\checkmark \quad$ Identificar aspectos da leitura de mundo.

Foi identificado que a leitura de mundo, ainda que seja individual, reconhece a coletividade de um ser que se desenvolve continuamente, com um universo informacional mutável e reflexivo.

Como explicitado no capítulo 9 (Mediação de Leitura de Mundo), na medida em que se desenvolve, as diferentes leituras de mundo se entrelaçam e formam teias de comunidades constituídas por indivíduos que assumem diferentes papéis nas sociedades dominantes e periféricas. Esses papéis impactam no próprio reconhecimento pessoal e da sociedade hegemônica, que tende a ditar regras específicas para os que consideram como "o outro".

Analisando os diferentes aspectos que se mostraram durantes as investigações de campo (no Brasil e na Espanha), foi possível entender que sociedades marginalizadas, ainda que individualmente complexas e em constante evolução, possuem similaridades contextuais e que o entendimento sobre isso e seu impacto em comportamentos e necessidades podem auxiliar em um trabalho mediador.

$\checkmark$ Explorar possibilidades de se utilizar a mediação como aspecto de junção entre o contexto sócio-cultural-ambiental de indivíduos e sua construção de conhecimento (entendendo nuances da profissionalização da mediação, ou a aplicação propriamente da mediação da informação e da leitura), na intencionalidade de adequar materiais e atividades que visem o desenvolvimento cognitivo.

A possibilidade mais coerente identificada nessa tese envolve a adoção das concepções de interculturalidade à mediação, transpostas no modelo da Figura 48 - Mediação da informação adaptada às concepções interculturais (apresentada, justificada e discutida no capítulo 9 - Mediação de Leitura de Mundo), na qual se retira o protagonismo da sociedade hegemônica e realoca-se as comunidades/grupos marginalizados num primeiro plano, bem como amplia-se a atuação do mediador sobre todo o processo, assumindo-se a necessidade de consciência ativa de amplas complexidades envolvidas em todo o esquema de mediação. 
$\checkmark$ Entender se comunidades brasileiras e estrangeiras que possuam singularidades de relacionamento e mediação com seu meio podem ser beneficiadas com a mediação de leitura de mundo.

Tanto as comunidades visitadas, quanto os profissionais entrevistados (fizessem esses parte ou não das comunidades), externalizaram dificuldades de vivência e desenvolvimento devido a um contexto opressor que foi capaz de criar, na melhor das hipóteses, inserções de culturas em ambientes educacionais (e aqui inclui-se a biblioteca), mas não uma inclusão capaz de torná-los parte de uma sociedade plural em equidade.

Dentro das perspectivas essenciais da mediação aqui apresentadas (ancoradas exatamente no desenvolvimento humano e sua reflexibilidade), e das concepções de que o trabalho com a leitura de mundo pode iniciar uma transposição de algumas barreiras, assume-se que é possível, dentro de uma prática adequada e consciente, beneficiar essas comunidades, buscando um caminho para a exclusão de seu status de marginalizados.

Na já mencionada figura 48, como proposta de mediação, a leitura de mundo passa a ser o centro do esquema, já que se busca, antes, o entendimento de ambos os contextos e suas complexidades para, e apenas depois disso, ser possível a construção ou avaliação de serviços informacionais passíveis de desenvolvimento e incorporação (sendo esse o benefício que, dentro da Ciência da Informação, se busca alcançar).

Após essas clarificações e visando expor as experimentações vivenciadas em fases práticas da pesquisa, algumas considerações podem então ser delineadas:

Em um país de primeiro, segundo ou terceiro mundo, algo realmente se tornou claro - há muitas pessoas que vivem em um $4^{\circ}$ mundo, um upsidedown que, embora compartilhe o mesmo "plano" com os outros, permanece invisível, por mais expressiva que seja sua presença.

São pessoas que sobrevivem em uma realidade paralela, que não se encaixa nas descrições e objetivos do milênio. O tempo passa diferente entre os mundos. Eles coabitam, coexistem, mas de forma predatória - o $4^{\circ}$ mundo é o alimento 
dos demais - seu combustível. Ele existe porque serve aos outros e, se essa serventia não é justificada, sua existência também não.

Muitos de seus habitantes sabem sobre a negação de sua existência e, assim, sabem também que ninguém vai sentir falta do que nunca existiu, ou pelo menos ninguém com voz suficiente para ser ouvida, e por isso não têm outra alternativa que não seja o conformismo das barreiras que os cercam, da invisibilidade que os amaldiçoa, e então sobrevivem com o que a vida lhes propõe.

Outros, cientes dessa realidade e com a intenção de quebrá-la, aventuram-se em grandes batalhas em busca da quebra das barreiras que lhe são impostas e saem a exigir seus direitos. Porém, muitos são os desafios e até o momento têm-se visto que a sociedade tem conseguido abrir espaços de inserção, porém poucos de inclusão. Isso significa que as pessoas conseguem o direito de estar em espaços que por muito tempo não "os pertencia", mas que esses espaços ainda não são capazes de promover um ambiente de equidade inclusiva.

E quem subdivide os mundos? Se é o lugar de nascimento, porque os filhos do $4^{\circ}$ mundo nascidos nos primeiros ainda estão perdidos nessa linha paralela de existência? Se é a educação, por que encontramos nesse mesmo lugar pessoas com formação superior a uma grande parte da população das novas fronteiras que habitam? Se são os costumes, por que, mesmo depois de passar a maior parte de suas vidas imersos nos costumes locais dos "desenvolvidos", dos "brancos", ainda são ignorados e/ou julgados nesses mesmos costumes?

Por quanto tempo a sociedade ignorará que a escravidão tem sido o combustível de seu desenvolvimento, e que a incapacidade de desenvolver empatia e respeito pela vida continua sendo o maior inimigo da humanidade? A sobrevivência dessas pessoas, mesmo que pareça insignificante para a maioria de seus "senhores", é a mais forte expressão de resistência e luta: cada face, cada voz, não importa o quão vazia se considere, ressoa frente a realidade que a maioria quer esconder. $A$ existência dessas pessoas aponta a hipocrisia revolucionária do milênio, que prevê a inclusão, mas que tem alcançado apenas a inserção, em uma tentativa política de esconder a subexistência de pessoas que, literalmente com seu suor e sangue, nutrem a existência das grandes potências mundiais. $O 4^{\circ}$ mundo existe - e quem fechou suas portas? Ou ainda mais importante - quem ainda as mantêm fechadas?

A multiculturalidade já não é o caminho para a solução das desigualdades e desrespeitos entre culturas, até porque esse nunca foi o problema. 
Não é o costume que estranha. É a representação que fere. É a reprodução do discurso que violenta.

As pessoas continuam a ser vistas com os óculos sociais que as despreza e, crescidos nesse contexto, aceitam sua posição imposta. Os indígenas ainda levam as marcas que foram deixadas em suas testas por seus invasores, assim como os negros. Por quanto tempo essas pessoas ainda causarão estranhamento por sua simples existência?

Assim, o problema, a questão primordial, que se mostra dentre os inúmeros por quês que podemos lançar nessa questão, mantêm-se no cerne do início das conquistas - a proclamada necessidade de colonizar. As fronteiras foram cruzadas, a história foi se reescrevendo e reerguendo, mas transvestiu-se de uma nova cultura para impor a hegemonia de uma nova forma de dominação mais aceitável, palatável para a sociedade.

As pessoas continuam sem ser aceitas, mas muitas passaram a ser toleradas (inseridas e não incluídas) enquanto sua existência possui uma coerência ao mercado. Nessa linha, os imigrantes continuam sendo aceitos como força de trabalho, mas não como cidadão - esse rótulo não é fácil merecer. $E$ os indígenas, ainda que moradores originários dessas fronteiras, vão sendo apagados da história conforme seus territórios vão sendo os poucos tesouros restantes nessas terras de pouca fé, mas continuam sendo "vendidos" como folclore.

Foram identificadas grandes dificuldades de trabalho e desenvolvimento nos centros educacionais visitados (bibliotecas e abrigos) que trabalham com grupos com especificidades culturais da leitura do mundo (neste caso, com o grupo escolhido como representativo nesse contexto - imigrantes da África Subsaariana). Devido à complexidade do contexto estudado e das limitações formativas que se enfrenta, tais dificuldades podem ser consideradas previsíveis de reprodução em outros contextos similares.

A reorganização dos aspectos que compõem esses contextos, bem como o trabalho consciente nesse sentido, no âmbito profissional de atuação, é dependente de um treinamento adequado que ofereça caminhos e cenários com os quais esses profissionais devem estar preparados, ao menos psicologicamente, para lidar.

O desenvolvimento de propostas dentro do multiculturalismo possibilitou o reconhecimento da necessidade de convivência entre a pluralidade 
cultural que constitui o mundo, porém foi insuficiente em promover o convívio equitativo entre essas culturas, como observamos no caso de imigrantes na Espanha.

Já na perspectiva de ampliação para práticas do interculturalismo, depara-se com a complexidade de abrangência da consciência da existência da interculturalidade na sociedade, já que tal concepção quebra com a cultura hegemônica que, historicamente, têm conseguido manter sua soberania entre territórios e povos.

A proposta de uma mediação que busque nas sociedades marginalizadas um entendimento visa propor que essas comunidades tenham autonomia frente à determinação de necessidades informacionais.

Os esquemas propostos e suas discussões apresentadas (Figuras 46 - Influências da marginalização e preconceito sobre comunidades e 48 - Mediação da informação adaptada às concepções interculturais) visam propor um "ponto de partida" para profissionais da informação que se depararem com contextos plurais.

Considera-se que o reconhecimento do potencial facilitador do mediador da informação na composição de uma perspectiva que favoreça a interdisciplinaridade pode resultar numa aproximação entre sociedades marginalizadas e ambientes culturalmente hegemônicos e colonizadores, ressignificando serviços informacionais e, assim, contribuir para o desenvolvimento de uma sociedade intercultural.

Como forma de contribuição para os desafios de uma atuação junta a comunidades marginalizadas, apresenta-se a proposta de criação de um aplicativo que concentre diretrizes e modelos de práticas, voltados para profissionais da informação. Assim, o seguinte briefing é apresentado:

Proposta central: Desenvolvimento de um aplicativo móvel para smartphones.

Temática geral norteadora: Serviços informacionais desenvolvidos junto a comunidades marginalizadas.

Indicação: Profissionais da área da Ciência da Informação e demais envolvidos na criação e execução de serviços informacionais em contextos de comunidades marginalizadas.

Nome proposto: Mediando Mundos. 
Funcionalidades: Concentrar diretrizes, legislações e informações sobre projetos desenvolvidos e em desenvolvimento.

Plataforma: Optou-se pelo desenvolvimento para uso em smartphones devido a impossibilidade (econômica e/ou logística) que muitos profissionais podem encontrar para ter acesso a outro dispositivo.

Proposta inicial de layouts:

Figura 49: Tela principal.

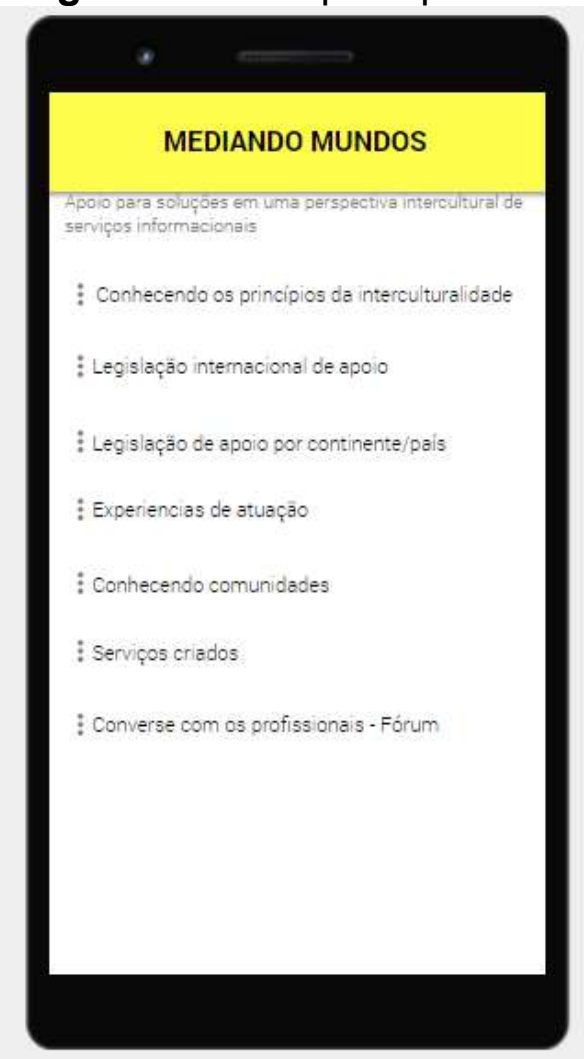

Fonte: A própria autora.

Exemplifica-se na tela os pontos que inicialmente se considera necessários para o desenvolvimento de um apoio significativo aos profissionais: a apresentação dos princípios da interculturalidade, a fim de contextualizar o desenvolvimento do aplicativo e situar o profissional quanto aos impactos dessa abordagem, suas significações e implicações; a exposição de legislação internacional de apoio, concentrando materiais que possam ampliar o conhecimento sobre o tema, ajudar na justificativa para o desenvolvimento de novos projetos, e auxiliar na visão geral que a comunidade internacional vem delineando; a concentração da legislação de apoio por continente e países, concentrando os documentos que possam ajudar 
nas especificidades regionais e nos âmbitos comparativos quali e quantitativos; experiências de atuação, concentrando os projetos já cadastrados e seus profissionais atuantes; conhecendo comunidades, integrando aspectos de comunidades que possam servir de estudo para o trabalho com diferentes realidades complexas, especialmente às em contextos de violência, onde o acesso e imersão podem se mostrar mais desafiadores; serviços criados, destacando os serviços e suas especificidades e/ou ressignificações, a fim de expor diferentes oportunidades imaginativas ancoradas na interculturalidade; e, finalmente, a exposição de um fórum, onde as pessoas poderiam expor problemas, tirar dúvidas, e/ou consultar os tópicos já abertos.

Figura 50: Tela com legislação.

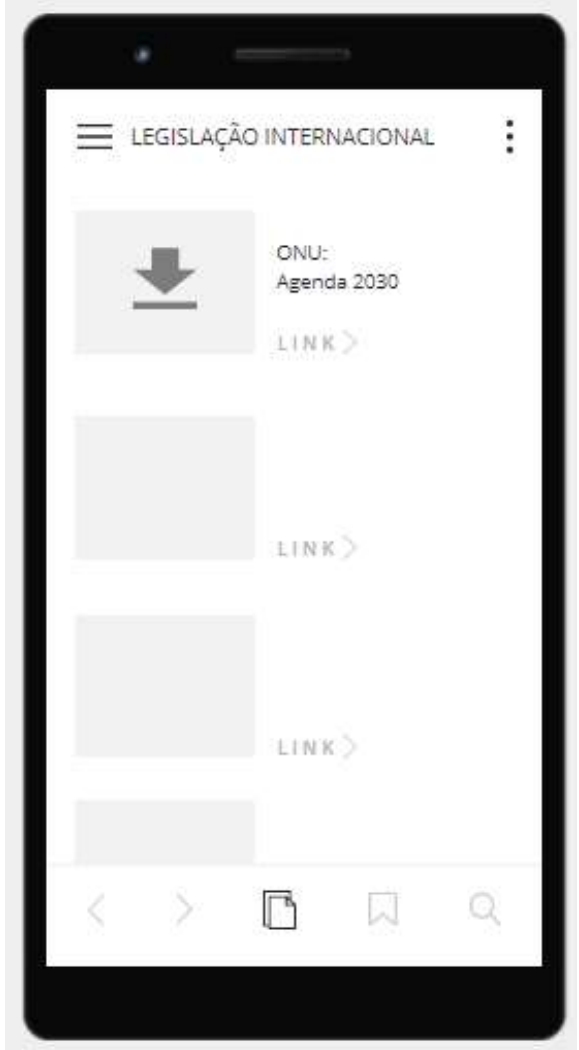

Fonte: A própria autora.

Assumindo a problemática de que alguns profissionais podem deparar-se com limitações de velocidade e/ou de franquia de dados para acesso ao aplicativo, na figura 50 exemplifica-se uma tela simples de download para documentos. A ideia é ressaltar a necessidade de não utilizar interfaces com muitos elementos, para favorecer uma navegação mais rápida e fluida. 
Figura 51: Tela para consulta de comunidades cadastradas.

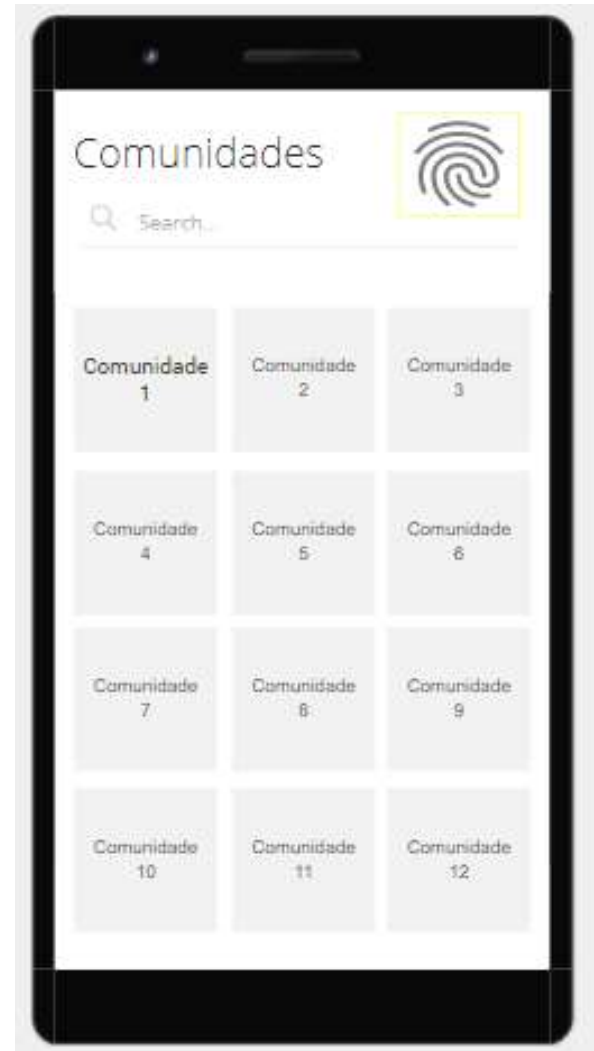

Fonte: A própria autora.

$\mathrm{Na}$ figura 51 observamos um exemplo, também simples, para exposição das comunidades cadastradas. O cadastro e consulta seriam restritos a usuários cadastrados, porém com a opção de contato privado com a administração do aplicativo para discutir a exposição de cadastros que necessitem proteção devido à contextos de violência, avaliando então caso a caso que se enquadre nessa especificidade. 

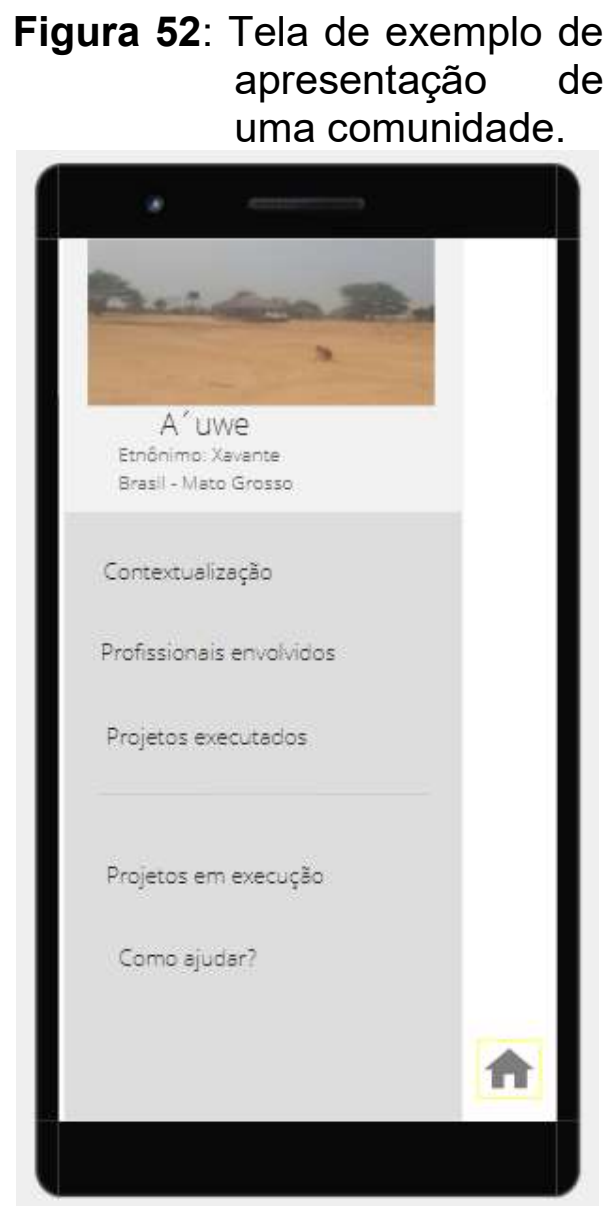

Fonte: A própria autora.

Na apresentação de uma comunidade (figura 52), predetermina-se as opções de cadastro: imagem, nome, etnônimo e localização para customização, e as abas de conteúdo: contextualização, informações dos profissionais envolvidos, projetos executados e em execução, e uma opção final de dar a oportunidade de contato entre profissionais que identifiquem a possibilidade de interagir com o projeto ou comunidade, oferecendo algum apoio, serviço ou sugestão. Nesse caso o profissional também deverá analisar os aspectos éticos de exposição da comunidade, trabalhando junto com eles para determinar qual conteúdo pode ou não ser incluído. No contexto de impossibilidade desse tratamento direto com a comunidade, seja por contextos de violência ou por limitações do projeto (por exemplo, no caso de um projeto em início, que não chegou na etapa de contato direto), pode-se disponibilizar apenas informações que não identifiquem especificamente a comunidade, ocultando aspectos até que seja possível seu tratamento ético. 
Finalmente, considera-se que a ampliação dessa pesquisa e proposta, culminando com o desenvolvimento prática do aplicativo apresentado, é a sugestão final deste trabalho para a execução de investigações futuras. 


\section{REFERÊNCIAS}

AJIBOYE, Olanrewaju Emmanuel. Social Phenomenology of Alfred Schutz and the Development of African Sociology. British Journal of Arts and Social Sciences, v. 4, n.1, 2012. Disponível em:

<http://www.bjournal.co.uk/paper/bjass_4_1/bjass_04_01_02.pdf>. Acesso em: mar. 2016.

ALMEIDA JÚNIOR, Oswaldo Francisco de. Leitura, mediação e apropriação da informação. In: SANTOS, Jussara Pereira dos (Org.). A leitura como prática pedagógica na formação do profissional da informação. Rio de Janeiro: Biblioteca Nacional, 2007. v. 1, p. 33-45.

. Mediação da informação: um conceito atualizado. In: BORTOLIN, Sueli; SANTOS NETO, João Arlindo dos; SILVA, Rovilson José da (Orgs.). Mediação oral da informação e da leitura. Londrina: ABECIN, 2015. p. 9-32.

ALMEIDA JÚNIOR, Oswaldo Francisco de.; BORTOLIN, Sueli. Mediação da informação e da leitura. In: SILVA, Terezinha Elizabeth da (Org.).

Interdisciplinaridade e transversalidade em Ciência da Informação. Recife: Néctar, 2008. p. 67-86.

ANGROSINO, Michael. Etnografia e observação participante. Porto Alegre: Artmed, 2009.

ASOCIACIÓN PRO DERECHOS HUMANOS DE ANDALUCÍA - APDHA. Balance Migratorio 2017: APDHA reclama vías seguras tras triplicarse las entradas por mar el pasado año. 2018. Disponível em: <https://www.apdha.org/balancemigratorio17/>. Acesso em: 10 dez. 2018.

BARQUERO, José Alberto Rubí. Una mediación ética, psicológica y ecologizante. Revista Electrónica Educare, Costa Rica, v. 15, n. 1, p. 171-176, 2011. Disponível em: <http://www.redalyc.org/html/1941/194118804014/>. Acesso em: 10 dez. 2018.

BELLO, Angela Ales. Introdução a fenomenologia. Bauru: Edusc, 2006.

BETTIOL, Célia Aparecida. A formação de professores indígenas na universidade do estado do amazonas: avanços e desafios. 2017. Tese. (Doutorado em Educação) Programa de Pós-Graduação em Educação da Faculdade de Ciências e Tecnologia, da Universidade Estadual Paulista UNESP/Campus de Presidente Prudente.

BORKO, Harold. Information Science: What is it? American Documentation, Washington, v. 19, n. 1, p. 3-5, jan. 1968.

BORTOLIN, S. Mediação oral da literatura: a voz dos bibliotecários lendo ou narrando. 2010. Tese (Doutorado em Ciência da Informação) - Faculdade de Filosofia e Ciências, Universidade Estadual Paulista de Marília, 2010. 
BORTOLIN, Sueli; ALMEIDA JÚNIOR, Oswaldo Francisco de. Oralidade e a ética na mediação da literatura. Informação \& Informação, Londrina, v. 19, n. 2, p. 171-190, 2014.

BRAGA, William Dias. Mediação e processos de compreensão intersubjetiva das representações sociais do Trabalho. DataGramaZero, Rio de Janeiro, v. 5, n. 3, p. A02, 2004.

BRITISH EDUCATIONAL RESEARCH ASSOCIATION. Ethical Guidelines for Educational Research. 2011. Disponível em: <https://www.bera.ac.uk/researchersresources/resources-for-researchers>. Acesso em: 10 dez. 2018.

BUFREM, Leilah Santiago; SANTOS, Sandra de Fátima. Ciência da informação e uso metodológico da etnografia. EDT - Educação Temática Digital, Campinas, v. 11, n. 1, p. 148-174, jul./dez. 2009.

CAHEN, Michel. Pode uma política de multiculturalidade existir sem uma grande narrativa? In: MACAGNO, Lorenzo. O dilema multicultural. Curitiba: Ed. UFPR; Rio de Janeiro: Graphia, 2014. p. 17-35.

CANCLINI, Néstor García. Culturas híbridas: estrategias para entrar y salir de la modernidad. Miguel Hidalgo: Grijalbo, 1989.

CASTRO, Rita de Cássia Marques Lima de; CASTRO, Paulo Sérgio.

Reconhecimento dos povos latino-americanos entre suas próprias nações: uma questão de identidade ou de interesse? In: PAREDES, Beatriz. O Mundo Indígena na América Latina: Olhares e Perspectivas. São Paulo: Edusp, 2018.

CAUSSA, Martí. Almería: el lado oscuro del milagro económico. Tribuna VIENTO SUR. 2014. Disponível em: <http://vientosur.info/spip.php?article8874>. Acesso em 15 ago. 2018.

COLTRO, Alex. A fenomenologia: um enfoque metodológico para além da modernidade. Caderno de Pesquisas em Administração, São Paulo, v. 1, n. 11, p. 37-45, 2000. Disponível em: <http://pablo.deassis.net.br/wpcontent/uploads/fenomenologia_modernidade.pdf>. Acesso em: 15 ago. 2019.

CONGRESSO BRASILEIRO DE BIBLIOTECONOMIA, 24., DOCUMENTACAO E CIENCIA DA INFORMACAO, 2011, Maceió. Anais... Maceió: CBBD, 2011. <http://www.portal.ufpr.br/Acessibilidade/O\%20Bibliotecario_como_Mediador_no_Pr ocesso_de_Transferencia.pdf>. Acesso em: 15 dez. 2018.

DÍAZ, Carlos. Introduccion a la fenomenologia. Madrid: Ed. Zero, 1973.

DARTIGUES, André. O que é a fenomenologia. 8. ed. São Paulo: Centauro Editora, 2003.

DICHTCHEKENIAN, Nichan. Curso de Introdução à Fenomenologia _Parte 1. 2013. Disponível em: <https://www.youtube.com/watch?v=u_A0-xxbogE> . Acesso em: 28 jul. 2019. 
ESHORIZONTE2020. Europa en un mundo cambiante, sociedades inclusivas, innovadoras y reflexivas. 2018b. Disponível em: <https://eshorizonte2020.es/retossociales/europa-en-un-mundo-cambiante-sociedades-inclusivas-innovadoras-yreflexivas>. Acesso em: 6 de nov. 2019.

ESPONDA, Esther Paredes. Ética de la información, los nuevos problemas de la ética. Un reto para el profesional de la información del siglo XXI. 2013. Disponível em: <http://www.revinfodir.sld.cu/index.php/infodir/article/view/9/13>. Acesso em: 28 jul. 2019.

FLORIDI, Luciano. Brave.Net.World: The Internet as a Disinformation Superhighway. The Electronic Library, Oxford, v. 14, n. 6, p. 509-514, 1996. Disponível em: <http://www.emeraldinsight.com/doi/abs/10.1108/eb045517>. Acesso em: 10 dez. 2018.

FREIRE, Paulo. A importância do ato de ler em três artigos que se completam. 51. ed. São Paulo: Cortez, 2011.

. Educação e mudança. São Paulo: Paz e Terra, 1979.

. Pedagogia da autonomia: saberes necessários à prática educativa. 45 . ed. São Paulo: Paz \& Terra, 2013.

Pedagogia do oprimido. 46. ed. Rio de Janeiro: Paz e Terra, 2005.

FUNAI. Etenhiritipá - Cantos da tradição Xavante. 2020. Disponível em:

$<$ http://www.funai.gov.br/index.php/indios-no-brasil/sons-indigenas/1165-etenhiritipacantos-da-tradicao-xavante>. Acesso em: 24 set. 2020.

GALEFFI, Dante Augusto. O que é isto - a fenomenologia de Husserl? Ideação, Feira de Santana, n. 5, p. 13-36, jan./jun. 2000.

GALLAGHER, Shaun. Taking stock of phenomenology futures. Southern Journal of Philosophy, Memphis, v. 50, n. 2, 304-318, 2012.

GARCIA, S. R. R. Um estudo do termo mediação na teoria da modificabilidade cognitiva estrutural de Feuerstein à luz da abordagem sócio-histórica de Vygotsky: um estudo teórico. Dissertação. (Mestrado em Psicologia) - Universidade de São Marcos, São Paulo, 2004.

GARRIDO, P. Inmigración y diversidad cultural en España: su gestión desde la bonanza económica a la crisis. Madrid: Editorial Fundamentos, 2014.

GARRIDO-RODRÍGUEZ, Pedro. Desafíos y oportunidades del sistema educativo ante la inmigración y la diversidad cultural. In: COLOQUIO INTERNACIONAL EDUCACIÓN E INTERCULTURALIDAD: INTERCULTURALIDAD E INMIGRACIÓN: IMPACTOS Y DESAFÍOS EN LA EDUCACIÓN, 2., 2019, Facultad de Educación de la USAL, Salamanca. Salamanca: Ediciones Universidad de Salamanca, 2019. p. 1-15.

El panorama internacional ante la educación y la pobreza. DYLE:

Revista sobre educación y liderazgo educativo, n. 5, 2020. 
GEERTZ, Clifford. A Interpretação das Culturas. São Paulo: LTC, 2003.

GOMES, Henriette Ferreira. A dimensão dialógica, estética, formativa e ética da mediação da informação. Informação \& Informação, Londrina, v. 19, n. 2, p. 46-59, maio./ago. 2014.

GORDON, Cesar. Os Xavantes e suas circunstâncias. In: COIMBRA, Carlos E. A.; WELCH, James R. (Orgs.) Antropologia e história Xavante. Rio de Janeiro: Museu do Índio - Funai, 2014. p. xii-xv.

GRAHAM, Laura R. Uma esfera pública na Amazônia? A construção do discurso colaborativo despersonalizado entre os Xavantes. In: COIMBRA, Carlos E. A.; WELCH, James R. (Orgs.) Antropologia e história Xavante. Rio de Janeiro: Museu do Índio - Funai, 2014. p. 123-155.

GREENPEACE BRASIL. Ações efetivadas. 2019a. Disponívem em: $<$ https://www.greenpeace.org.br/hubfs/Imprensa-2019/6meses GovernoBolsonaro_meioambiente.pdf?_ga=2.50817195.302455122.1562072001827094786.1562072001>. Acesso em: 1 jul. 2019.

Governo Bolsonaro confirma agenda antiambiental e de destruição da Amazônia. 2019b. Disponívem em: <Recuperado de https://www.greenpeace .org/brasil/blog/governo-bolsonaro-confirma-agenda-antiambiental-e-de-destruicaoda-amazonia/?fbclid=IwAROMPwY-

OdnF468MUKKF5feQxpSeCi6_eHCVGVJRkyCUqh_x52uwHeFZK3U>. Acesso em: 1 jul. 2019.

HEGEL, Georg Wilhelm Friedrich. Fenomenologia do Espírito. [1807]. Disponível em:

$<$ http://www.dominiopublico.gov.br/pesquisa/DetalheObraForm.do?select_action=\&c o_obra=2289>. Acesso em: 20 set. 2020.

Filosophy of History. Kitchener: Batoche Books, 2001.

HERRERA, Jerónimo Molina. El papel de la agricultura intensiva en la economía de la provincia de Almería. Revista De Humanidades Y Ciencias Sociales Del lea, Barcelona, n. 19, p .13-38, 2004.

HUSSERL, Edmund. A ideia da fenomenologia. 2. ed. Rio de Janeiro: Edições 70, 2008.

Idéias para uma fenomenologia pura e para uma filosofia

fenomenológica. Aparecida: Idéias\&Letras, 2006.

Volume VIII

The idea of phenomenology. Boston: Kur Academc Pulshs, 1999.

IDEAL. El $\mathbf{8 0 \%}$ de los migrantes recibidos en Almería son de origen

subsahariano. Miércoles, 15 agosto 2018. Disponível em:

<https://www.ideal.es/almeria/almeria/migrantes-recibidos-almeria-20180815220847ntvo.html>. Acesso em: 20 jan. 2019. 
ILHARCO, Fernando. Filosofia da informação: uma introdução como fundação da acção, da comunicação e da decisão. Lisboa: Universidade Católica, 2003.

INSTITUTO BRASILEIRO DE GEOGRAFIA E ESTATÍSTICA - IBGE. Estudos especiais: o Brasil Indígena. 2019. Disponível em:

$<$ https://indigenas.ibge.gov.br/estudos-especiais-3/o-brasil-indigena>. Acesso em: 4 jun. 2019.

INSTITUTO SOCIOAMBIENTAL. Índios e o meio ambiente. 2019. Disponível em: $<$ https://pib.socioambiental.org/pt/\%C3\%8Dndios_e_o_meio_ambiente. Acesso em: 2 jul. 2019.

Xavante. 2020. Disponível em:

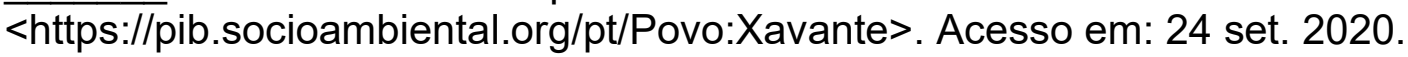

IVIC, Ivan. Lev Semionovich Vygotsky. Recife: Fundação Joaquim Nabuco, Editora Massangana, 2010.

JUNTA DE ANDALUCIA. Observatorio Permanente Andaluz de las Migraciones. 2018. Disponível em: <http://www.juntadeandalucia.es/justiciaeinterior/opam/es>. Acesso em: 20 jan. 2019.

KRENAK, Ailton. Entrevista. 2019. Disponível em:

$<$ https://deolhonosruralistas.com.br /2019/06/19/ailton-krenak-a-mentira-e-amanipulacao-colocam-a-vida-das-pessoas-integras-emrisco/?fbclid=IwAR3TATXM9VVny06u7pHcntSB34Rn9Yo9YwNy A8iTS9YiXkqrstJnJ2yE9nA>. Acesso em: 4 jun. 2019.

LA SPINA, Encarnación. Controlling Immigrant Integration in the Euro-Mediterranean Region: A Compelling Turnaround in Times of Economic Crisis. Revista Crítica de Ciências Sociais, [Online], n. 114, 2017. Disponível em: <http:// journals.openedition.org/rccs/6735>. Acesso em: 23 dez. 2017.

LUDWIG, Antônio Carlos Will. A pesquisa em educação. Revista Linhas, Santa Catarina, v. 4, n. 2, 2003.

MAIA, Maria Aniolly Queiroz et al. O Bibliotecário como Mediador no Processo de Transferência da Informação para Pessoas com Deficiência Visual. In:

MARX, Karl. O Capital: livro 1. [1867]. Disponível em: <http://www.dominiopublico.gov.br/pesquisa/DetalheObraForm.do?select_action=\&c o_obra $=4360>$. Acesso em: 21 set. 2020.

. Para uma crítica da economia política. [1859]. Disponível em:

<http://www.dominiopublico.gov.br/pesquisa/DetalheObraForm.do?select_action=\&c o_obra=2285>. Acesso em: 21 set. 2020.

MARTINS, João Paulo. Fenomenologia e neurociência: uma relação possível. Dissertação. (Mestrado em Filosofia). 2015. Programa de Pós-Graduação em Filosofia da Universidade Estadual Paulista "Júlio de Mesquita Filho" - UNESP, 2015. Disponível em: < https://www.marilia.unesp.br/Home/PosGraduacao/Filosofia/Dissertacoes/m_jp_me_mar.pdf>. Acesso em: 15 ago. 2019. 
MARTINS, Onilza Borges; MOSER, Alvino. Conceito de mediação em Vygotsky, Leontiev e Wertsch. Revista Intersaberes, Curitiba, v. 7, n. 13, p. 8-28, 2012.

MAUSS, Marcel; FAUCONNET, Paul. La sociologie, objet et méthode. Paris: Société anonyme de la Grande Encyclopédie, 1901. v. 30

MAY, Tim. Pesquisa social: questões, métodos e processos. 3. ed. Porto Alegre: Artmed, 2004.

MENESES-TELLO, Felipe. Información y bibliotecas em torno a los derechos humanos. Revista Brasileira de Biblioteconomia e Documentação, São Paulo, v. 13, n. 2, jul./dez. 2017.

MORAES, Roque. Uma tempestade de luz: a compreensão possibilitada pela análise textual discursiva. Ciência \& Educação, Bauru, v. 9, n. 2, p. 191-211, 2003.

MORAES, Roque; GLIAZZI, Maria do Carmo. Análise textual discursiva: processo reconstrutivo de múltiplas facetas. Ciência \& Educação, Bauru, v. 12, n. 1, p. 117128, 2006.

MORIN, Edgar. Introdução ao pensamento complexo. 3. ed. Porto Alegre: Sulina, 2007.

Science avec conscience. 9. ed. Paris: Fayard, 1990.

NACIONES UNIDAS. Migración. 2019. Disponível em:

<https://www.un.org/es/sections/issues-depth/migration/>. Acesso em: 6 de nov. 2019.

NAÇÕES UNIDAS BRASIL. A Declaração Universal dos Direitos Humanos. Disponível em: <https://nacoesunidas.org/direitoshumanos/declaracao/>. Acesso em: 29 jul. 2020.

NUNES, Jordão Horta. Interacionismo simbólico e movimentos sociais: enquadrando a intervenção. Revista Sociedade e Estado, Brasília, v. 28, n. 2, maio/ago. 2013

OLIVEIRA, Amanda Leal de. A negociação cultural: um novo paradigma para a mediação e a apropriação da cultura escrita. 2014. Tese (Doutorado em Ciência da Informação) - Escola de Comunicação e Artes, Universidade de São Paulo, São Paulo, 2014.

OLIVEIRA, Guilherme Saramago; CUNHA, Ana Maria Oliveira. Breves considerações a respeito da fenomenologia e do método fenomenológico. Cadernos da FUCAMP, Monte Carmelo, v. 7, n. 7, 2008. Disponível em: $<$ https://biblat.unam.mx/pt/revista/cadernos-da-fucamp/articulo/brevesconsideracoes-a-respeito-da-fenomenologia-e-do-metodo-fenomenologico>. Acesso em: 17 ago. 2019.

OLIVEIRA, Heloá Cristina Camargo de. A mediação em projetos de incentivo à leitura: a apropriação da informação para construção do conhecimento e do pensamento crítico. 2015. Dissertação (Mestrado em Ciência da Informação) Universidade Estadual Paulista “Júlio de Mesquita Filho", Marília, 2015. 
ONU BRASIL. Objetivo de Desenvolvimento Sustentável 4. Disponível em: <https://brasil.un.org/pt-br/sdgs/4>. Acesso em: 22 set. 2020.

OPOVOONLINE. Veja quais os canais de televisão mais vistos no Brasil 2019. 2019. Disponível em <https://www.opovo.com.br/divirtase/2019/04/23/veja-quais-oscanais-de-televisao-mais-vistos-no-brasil-em-2019.html>. Acesso em: 1 jul. 2019.

ORGANIZACIÓN DE LAS NACIONES UNIDAS. Departamento de Información Pública. Declaración Universal de los Derechos Humanos. 1948. Disponível em <http://www.un.org/es/documents/udhr/>. Acesso em: 18 nov. 2018.

PEIRCE, Charles Sanders. Semiótica. São Paulo: Perspectiva, 2005.

ROCKEMBACH, Moisés. Modelo de evidência da informação em plataformas digitais: estudo exploratório no âmbito da Ciência da Informação. 2012. Tese de Doutoramento. Porto: Faculdade de Letras, Universidade do Porto, 2012.

ROMERO, Carlos Gímenez. Pluralismo, Multiculturalismo E Interculturalidad:

Propuesta de clarificación y apuntes educativos. Educación y futuro: revista de investigación aplicada y experiencias educativas, Madrid, n. 8, 2003, p. 1-24. Disponível em: <https://red.pucp.edu.pe/ridei/wpcontent/uploads/biblioteca/100416.pdf>. Acesso em: 17 out. 2020.

ROSITO, Guilherme Augusto. Abordagem fenomenológica e metodologia de produção de conhecimentos. Revista Brasileira de Inteligência, Brasília, v. 2, n. 3, set. 2006. p. 23- 28.

SARACEVIC, Tefko. Interdisciplinarity nature of Information Science. Ciência da Informação, Brasília, v.24, n.1, p.36-41, 1995.

SAVE THE CHILDREN. Informe Mundial de la Infancia. London: Save the Children Federation, 2019.

SCHUTZ, Alfred Schutz. Phenomenology and Social Relations. Chicago: University of Chicago Press, 1970.

SETZER, Valdemar Waingort. Os meios eletrônicos e a educação: uma visão alternativa. São Paulo: Escrituras, 2001.

SILVA, Célia Regina da; SILVA, Luiz Fernando da; MARTINS, Sueli Terezinha F. Marx, ciência e educação: a práxis transformadora como mediação para a produção do conhecimento. Educação e Marxismo, Bauru, v. 1, n. 1, p. 7-18, 2005.

Disponível em:

<http://www2.fc.unesp.br/revista_educacao/arquivos/Marxismo_ciencia_e_educacao. pdf>. Acesso em: 13 abr. 2018.

SILVA, Cristiane Rocha; GOBBI, Beatriz Christo; SIMÃO, Ana Adalgisa. O uso da análise de conteúdo como uma ferramenta para a pesquisa qualitativa: descrição e aplicação do método. Organizações Rurais \& Agroindustriais, Lavras, v. 7, n. 1, p. 70-81, 2005. 
SILVA, Wanise Cabral; AMARAL, Nemo de Andrade do. A imigração na Europa: a ação política da União Europeia para as migrações extracomunitárias. Seqüência, Florianópolis, n. 66, p. 235-259, jul. 2013.

SURVIVAL. Derechos y responsabilidades. 2019. Disponível em: <https://www.survival.es/sobre/funai>. Acesso em: 4 jun. 2019.

UNESCO. Convención sobre la protección y la promoción de la diversidad de las expresiones culturales. 2005. Disponível em:

$<$ http://www.unesco.org/new/es/culture/themes/cultural-diversity/culturalexpressions/the-convention/convention-text\#: :text=todas\%20las\%20culturas,La\%20protecci\%C3\%B3n\%20y\%20la\%20promoci\%C3\%B3n\%20de\%20la\%20diver sidad $\% 20$ de $\% 20$ las,las $\% 20$ de $\% 20$ los $\% 20$ pueblos $\% 20$ aut $\%$ C3\%B3ctonos>. Acesso em: 22 set. 2020.

UNITED NATIONS - UN. The Economic Social and Cultural Rights of Migrants in an Irregular Situation. Geneva: UNO publications. 2014. Disponível em:

<https://www.ohchr.org/Documents/Publications/HR-PUB-14-1_en.pdf>. Acesso em: 17 nov. 2018.

VYGOTSKY, Lev Semyonovich. A formação social da mente. 4. ed. São Paulo: Livraria Martins Fontes, 1991.

ZLATEV, Jordan. Phenomenology and Cognitive Linguistics. In: GALLAGHER, Shaun; SCHMICKING, Dan (Ed.) Handbook on Phenomenology and Cognitive Science. Dordrecht: Springer, 2009. p. 415-446. Disponível em:

<https://www.researchgate.net/publication/226838531_Phenomenology_and_Cogniti ve_Linguistics>. Acesso em: 20 jan. 2017. 
APÊNDICES 


\section{APÊNDICE A}

ApÊndice A - InStrumentos de Apoio para Coleta de Dados das Pesquisas de

CAMPO

\section{Presentación - Objetivos}

\section{Objetivo general:}

Comprender cómo ha sido la adaptación de la vida de inmigrantes de la África Subsahariana en España, y cómo las Ciencias de la Información os puede ayudar en ese proceso.

\section{Objetivos específicos:}

- Conocer los posibles conflictos culturales que los inmigrantes encuentran para vivir en España;

- Entender sus objetivos, conquistas y frustraciones;

- Descubrir si es posible una actuación mediadora que os proporcione una mejor cualidad de vida.

Beneficios esperados: Dar visibilidad a los conflictos enfrentados por los inmigrantes y buscar modelos de acciones que os puedan auxiliar. 


\section{GUIÓN ENTREVISTAS INMIGRANTES}

\section{- Identificación (perfil)}

\begin{tabular}{|l|l|l|l}
$\square$ & Hombre & Mujer & No-binario \\
\hline
\end{tabular}

\begin{tabular}{|l|l|l|l}
\hline Ilegal & Legal & & Naturalizado \\
\hline
\end{tabular}

1. ¿Cuál es su país de origen?

2. ¿Cuántos años tiene?

3. ¿Cuál es su formación?

\section{- Contextualización}

4. ¿Cuánto tiempo lleva viviendo aquí?

5. ¿Ha vivido en alguno otro país?

6. ¿Ha vivido en otra ciudad en España?

7. ¿Cómo es donde vive? (la estructura física y se vive solo o con otras personas)

\section{- Cuestiones "problema"}

8. Una solo palabra que primero se le viene a la mente para "España":

9. ¿Cómo es la relacione qué tiene con las personas dónde vive? (en casa y/o en el barrio)

10. ¿Dónde trabaja? ¿Cómo es su relación con las otras personas en su trabajo?

11. ¿Cuáles son las principales diferencias que observa entre España y su país de origen? ¿Y cómo se siente en relación con estas diferencias? ¿Son positivas 0 negativas?

12. ¿Cómo te sientes en relación con la lengua española?

13. ¿Sigue estudiando en España? ¿Por qué?

14. ¿Siente que tiene desafíos para vivir mejor en España? ¿Por qué?

15. ¿Tienes acceso a un ordenador? ¿Y a la internet?

16. ¿El acceso a la Internet es (o sería) positivo para usted? ¿Por qué?

17. ¿Tiene la intención de seguir viviendo aquí? ¿Por qué?

18. Una solo palabra que primero se le viene a la mente para "la vida en España": 
ANEXOS 


\section{ANEXO A \\ AUTORIZAÇÕES CEP-UNESP / CONEP}

UNESP - FACULDADE DE
unesp
FILOSOFIA E CIÊNCIAS -
CAMPUS DE MARILIA

PARECER CONSUBSTANCIADO DO CEP

\section{DADOS DO PROJETO DE PESQUISA}

Titulo da Pesquisa: A natureza da mediaçao da informaçăo sob uma visao fenomenológica Pesquisador: HELOA CRISTINA OLIVEIRA DEL MASSA

Área Temática: Estudos com populaçoes indigenas;

Versão: 4

CAAE: 79781817.2 .0000 .5406

Instituiçăo Proponente:Faculdade de Filosofia e Ciéncias/ UNESP - Campus de Marilia

Patrocinador Principal: Financiamento Próprio

FUNDACAO DE AMPARO A PESQUISA DO ESTADO DE SAO PAULO

\section{DADOS DO PARECER}

Número do Parecer: 2.791 .875

\section{Apresentação do Projeto:}

Projeto centrado em analisar aspectos da natureza da mediaçăo sob uma visáo fenomenológica, buscando identificar e entender o momento em que 0 ato da mediaçå inicia e como se perpetua em diferentes realidades complexas. Pesquisa de natureza

qualitativa, incluira Analise Bibliográfica e coletas de dados baseadas no método etnográfico, e para análise dos dados será utilizando a Análise Textual Discursiva e a base fenomenológica.

Objetivo da Pesquisa:

O objetivo do estudo será analisar aspectos da natureza da mediaçao sob uma visăo fenomenológica, buscando identificar e entender o momento em que o ato da mediaçao inicia e como se perpetua em diferentes realidades complexas. Como objetivos secundários espera-se identificar aspectos da leitura de mundo; Analisar as influencias culturais, sociais e politicas que podem interferir em indwiduos durante sua leitura de mundo, e se essa leitura de mundo influencia no relacionamento com o aprendizado; Explorar possibilidades de se utilizar a mediaçăo como aspecto de junçăo entre o contexto sócio-cultural-ambiental de individuos e sua construçăo de conhecimento (entendendo muances da profissionalizaçăo da mediaçao, ou a aplicaçào propriamente da mediaçăo da informaçăo e da leitura), na intencionalidade de adequar materiais e atividades que visem o desenvolvimento cognitivo; e Entender se comunidades brasileiras e estrangeiras que possuam singularidades de relacionamento e mediaçácom seu meio podem ser

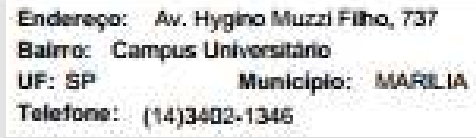




\section{UNESP - FACULDADE DE FILOSOFIA E CIÊNCIAS - CAMPUS DE MARILIA}

Continuagle de Persces: 2.791.875

beneficiadas com a mediaçao de leitura de mundo.

Avaliaçăo dos Riscos e Beneficios:

Nao há riscos previstos para os sujeitos da pesquisa. Os beneficios såo indiretos aos sujeitos da pesquisa, contribuindo para a área de pesquisa em mediaçao da informaçao.

Comentários e Consideraçóes sobre a Pesquisa:

Pesquisa bem estruturada e com tema relevante para a area do pesquisador responsavel.

Consideraçōes sobre os Termos de apresentaçâo obrigatória:

TCLE necessita de adequap̧es conforme recomendaçă do CONEP.

Conclusốes ou Pendências e Lista de Inadequaçóes:

Pendente de adequaçoes no TCLE conforme deliberaçăo do CONEP.

Consideraçôes Finais a critério do CEP:

Este parecer fol elaborado baseado nos documentos abaixo relacionados:

\begin{tabular}{|c|c|c|c|c|}
\hline Tipo Documento & Arquivo & Postagem & Autor & Situaçao \\
\hline $\begin{array}{l}\text { Informaçoes Básicas } \\
\text { do Projeto }\end{array}$ & PB_INFORMAÇOES_BASICAS_DO_P & $\begin{array}{c}13 / 03 / 2018 \\
13-28: 05\end{array}$ & & Aceito \\
\hline $\begin{array}{l}\text { TCLE / Termos de } \\
\text { Assentimento / } \\
\text { Justificativa de } \\
\text { AusAncia }\end{array}$ & $\begin{array}{l}\text { Termoconsentimentoresponsavel_corrigi } \\
\text { do_sinal.doc }\end{array}$ & $\begin{array}{c}13 / 03 / 2018 \\
13: 27: 31\end{array}$ & $\begin{array}{l}\text { HELOA CRISTINA } \\
\text { OLIVEIRA DEL } \\
\text { MASSA }\end{array}$ & Aceito \\
\hline $\begin{array}{l}\text { TCLE / Termos de } \\
\text { Assentimento / } \\
\text { Justificativa de } \\
\text { Ausencia }\end{array}$ & $\begin{array}{l}\text { Termoconsentimentoresponsavel_corrigi } \\
\text { do_limpo.doc }\end{array}$ & $\begin{array}{c}13 / 03 / 2018 \\
13: 27: 22\end{array}$ & $\begin{array}{l}\text { HELOA CRISTINA } \\
\text { OLIVEIRA DEL } \\
\text { MASSA }\end{array}$ & Aceito \\
\hline $\begin{array}{l}\text { TCLE / Termos de } \\
\text { Assentimento / } \\
\text { Justificativa de } \\
\text { Ausencia }\end{array}$ & $\begin{array}{l}\text { Termoassentimentomenor_corrigido_sin } \\
\text { al_doc }\end{array}$ & $\begin{array}{c}13 / 03 / 2018 \\
13: 27: 09\end{array}$ & $\begin{array}{l}\text { HELOA CRISTINA } \\
\text { OLIVEIRA DEL } \\
\text { MASSA }\end{array}$ & Aceito \\
\hline $\begin{array}{l}\text { TCLE / Termos de } \\
\text { Assentimento / } \\
\text { Justificativa de } \\
\text { AusAncia }\end{array}$ & $\begin{array}{l}\text { Termoassentimentomenor_corrigido_lim } \\
\text { po.doc }\end{array}$ & $\begin{array}{c}13,03 / 2018 \\
13: 26: 59\end{array}$ & $\begin{array}{l}\text { HELOA CRISTINA } \\
\text { OLIVEIRA DEL } \\
\text { MASSA }\end{array}$ & Aceito \\
\hline $\begin{array}{l}\text { TCLE / Termos de } \\
\text { Assentimento / } \\
\text { Justificativa de } \\
\text { Ausencia }\end{array}$ & TCLE_corrigido_sinalizado_doc & $\begin{array}{c}13 / 03 / 2018 \\
13: 26: 46\end{array}$ & $\begin{array}{l}\text { HELOA CRISTINA } \\
\text { OLIVEIRA DEL } \\
\text { MASSA }\end{array}$ & Aceito \\
\hline $\begin{array}{l}\text { TCLE / Termos de } \\
\text { Assentimento / }\end{array}$ & TCLE_corrigido_limpo.doc & $\begin{array}{c}13 / 03 / 2018 \\
13: 26: 34\end{array}$ & $\begin{array}{l}\text { HELOA CRISTINA } \\
\text { OLIVEIRA DEL }\end{array}$ & Aceito \\
\hline
\end{tabular}

Endereço: Av. Hygino Muzzi Fiho, 737

Bairroc Campus Universitanio

UF: SP

Municipio: MARELA

CEP: $17.525-900$

Telefone: (14)3402.1346

E-mail: cep.marliagunesp.tor 
UNESP - FACULDADE DE FILOSOFIA E CIÊNCIAS -

CAMPUS DE MARILIA

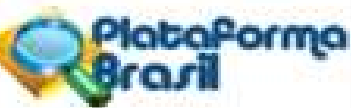

unesp
Continuageto a Pareciet: 2.791.875

\begin{tabular}{|c|c|c|c|c|}
\hline $\begin{array}{l}\text { Justificativa de } \\
\text { Auskncia }\end{array}$ & TCLE_corrigido_limpo.doc & $\begin{array}{c}13 / 03 / 2018 \\
13: 26: 34 \\
\end{array}$ & MASSA & Aceito \\
\hline $\begin{array}{l}\text { Projeto Detalhado I } \\
\text { Brochura } \\
\text { Investigador }\end{array}$ & $\begin{array}{l}\text { DelMassa_Projeto_corrigido_semsinaliz } \\
\text { acao.docx }\end{array}$ & $\begin{array}{c}08103 / 2018 \\
17: 38: 57\end{array}$ & $\begin{array}{l}\text { HELOA CRISTINA. } \\
\text { OLIVEIRA DEL } \\
\text { MASSA }\end{array}$ & Aceito \\
\hline Outros & carta_resposta_docx & $\begin{array}{c}08 / 03 / 2018 \\
17: 34: 01\end{array}$ & $\begin{array}{l}\text { HEL OA CRISTINA } \\
\text { OLIVEIRA DEL } \\
\text { MASSA }\end{array}$ & Aceito \\
\hline Outros & roteiro_entrevistas_2_prof.docx & $\begin{array}{c}08,03 / 2018 \\
17: 33: 08\end{array}$ & $\begin{array}{l}\text { HELOA CRISTINA } \\
\text { OLIVEIRA DEL } \\
\text { MASSA }\end{array}$ & Aceito \\
\hline Outros & roteiro_entrevistas_1_coord.docx & $\begin{array}{c}08103 / 2018 \\
17: 32: 12\end{array}$ & $\begin{array}{l}\text { HELOA CRISTINA } \\
\text { OLIVEIRA DEL } \\
\text { MASSA }\end{array}$ & Aceito \\
\hline $\begin{array}{l}\text { Projeto Detalhado I } \\
\text { Brochura } \\
\text { Investigador }\end{array}$ & $\begin{array}{l}\text { DelMassa_Projeto_corrigido_sinalizado. } \\
\text { docx }\end{array}$ & $\begin{array}{c}08103 \sqrt{2018} \\
17: 27: 29\end{array}$ & $\begin{array}{l}\text { HELOA CRISTINA } \\
\text { OLIVEIRA DEL } \\
\text { MASSA }\end{array}$ & Aceito \\
\hline Cronograma & CRONOGRAMA.docX & $\begin{array}{c}29 / 11 / 2017 \\
14: 30: 15\end{array}$ & $\begin{array}{l}\text { HELOA CRISTINA } \\
\text { OLIVEIRA DEL } \\
\text { MASSA }\end{array}$ & Aceito \\
\hline Outros & aut_aldeia_nossa_sra_gracas.jpg & $\begin{array}{c}29 / 11 / 2017 \\
14: 24: 34\end{array}$ & $\begin{array}{l}\text { HELOA CRISTINA } \\
\text { OLIVIRA DEL } \\
\text { MASSA }\end{array}$ & Aceito \\
\hline Outros & aut_aldeia_nova_esp.jpg & $\begin{array}{c}29 / 11 / 2017 \\
14: 24: 02\end{array}$ & $\begin{array}{l}\text { HELOA CRISTINA } \\
\text { OLIVEIRA DEL } \\
\text { MASSA }\end{array}$ & Aceito \\
\hline Outros & aut_aldeia_sao_marcos.jpg & $\begin{array}{c}29 / 11 / 2017 \\
14: 23: 34\end{array}$ & $\begin{array}{l}\text { HELOA CRISTINA } \\
\text { OLIVEIRA DEL } \\
\text { MASSA }\end{array}$ & Aceito \\
\hline Outros & aut_coord_reg_funai.jpeg & $\begin{array}{c}29 / 11 / 2017 \\
14: 21: 40\end{array}$ & $\begin{array}{l}\text { HELOA CRISTINA } \\
\text { OLIVEIRA DEL } \\
\text { MASSA }\end{array}$ & Aceito \\
\hline Folha de Rosto & folha_de_rosto_assinada.pdf & $\begin{array}{c}07 / 11 / 2017 \\
12-05: 39\end{array}$ & $\begin{array}{l}\text { HELOA CRISTINA } \\
\text { OLIVEIRA DEL } \\
\text { MASSA }\end{array}$ & Aceito \\
\hline
\end{tabular}

Situaçäo do Parecer:

Pendente

Necessita Apreciaçăo da CONEP:

Nao
Enderogo: Av. Hygino Muzzi Fitho, 73

Bairroc Campus Unhversitanio

UF: SP Municipio: MARLLLA

Telefone: [14]3402-1346
CEP: $17.525 \times 800$

E-mail: cep.maniliagunesp.br 


\section{UNESP - FACULDADE DE FILOSOFIA E CIÊNCIAS - CAMPUS DE MARILIA

MARILIA, 31 de Julho de 2018

Assinado por:

SIMONE APARECIDA CAPELLINI

(Coordenador) 
ANEXO B

AutorizaÇão FUNAI Regional XAVANTE - MT

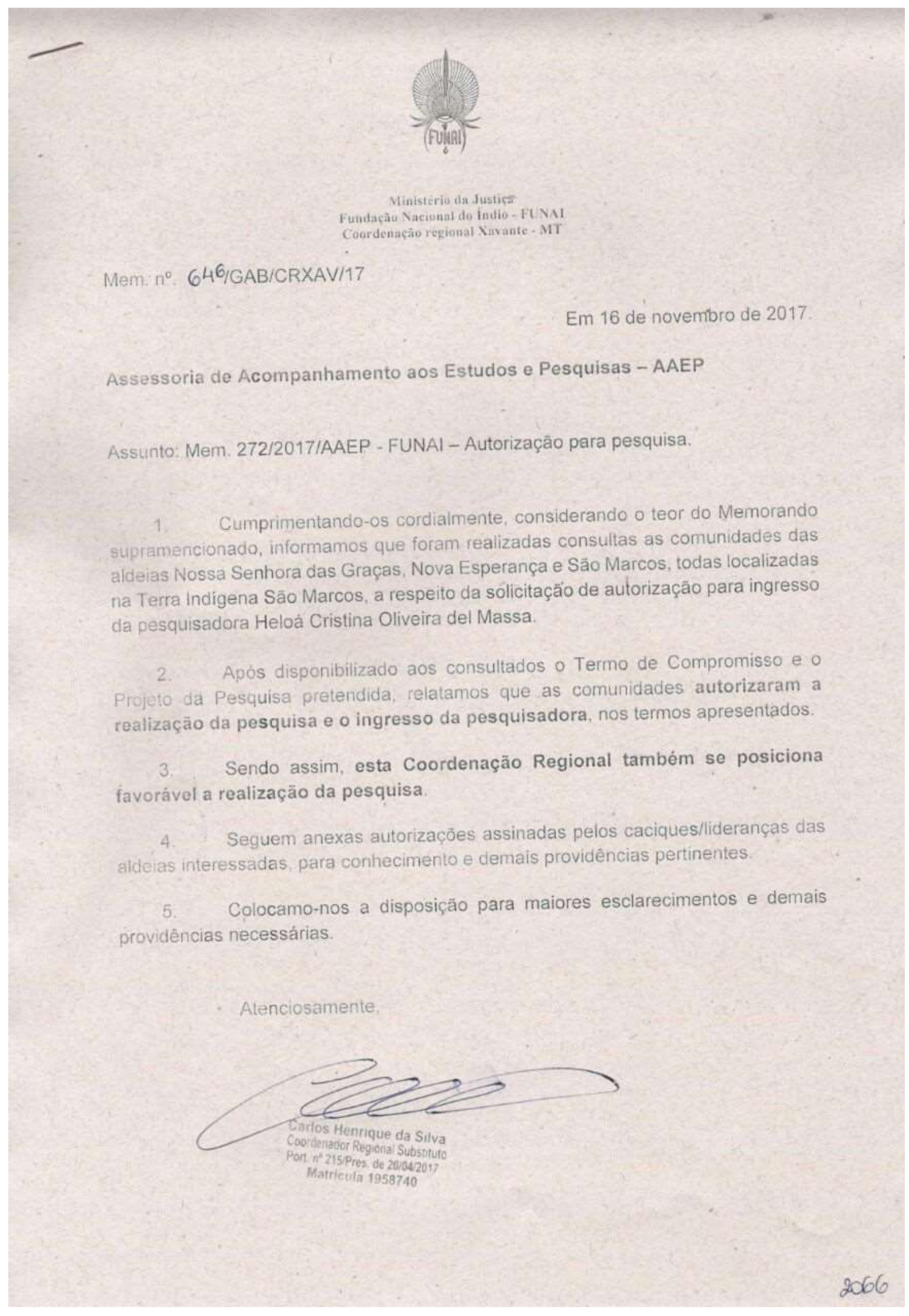


ANEXO C

\title{
AutorizAÇÃo Aldeia Nova EsperançA
}

\author{
Alieia Now Experafice \\ Torra indigura Säo Marcos \\ 09 de novembro de 2017
}

Assunto: Autorizaçāo de ingresso na aldeia para fins de pesquisa.

Nos, comunidade residente na aldeia Nava Esperança; Terra indigna Sâo Marcos tocalizada no municipio de Barta do Garças - Mato Grosso, fomos contultados gela Ccordenaçăo Regional Xavante a respeito do iogresso da pesquisadora Heloa

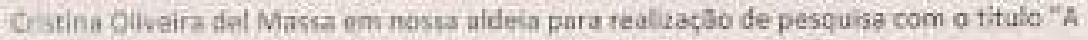

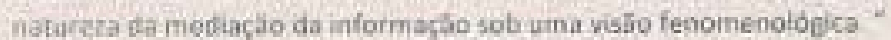

Agós leitura do Prajeto de Pesquisa e de Termo de Compromis5o, discutimos o assunto e decidimos por autorizat a realizaç̄o da Pesquisa, conforme nos foi upresentada.

Sendo asaim, redigimos o preserte documento, qug va assinado polas lideramsos do aldeia.

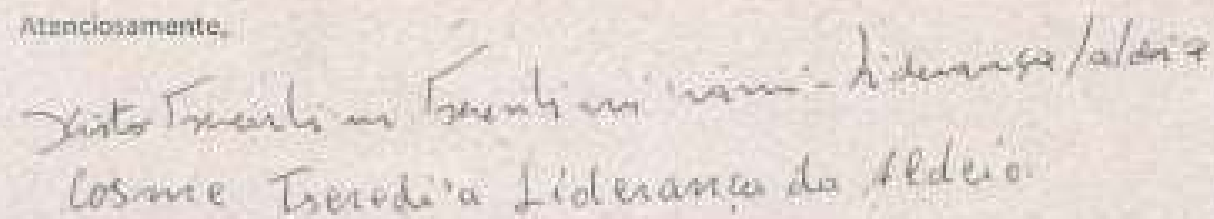


FORUM TSIHORIRÃ

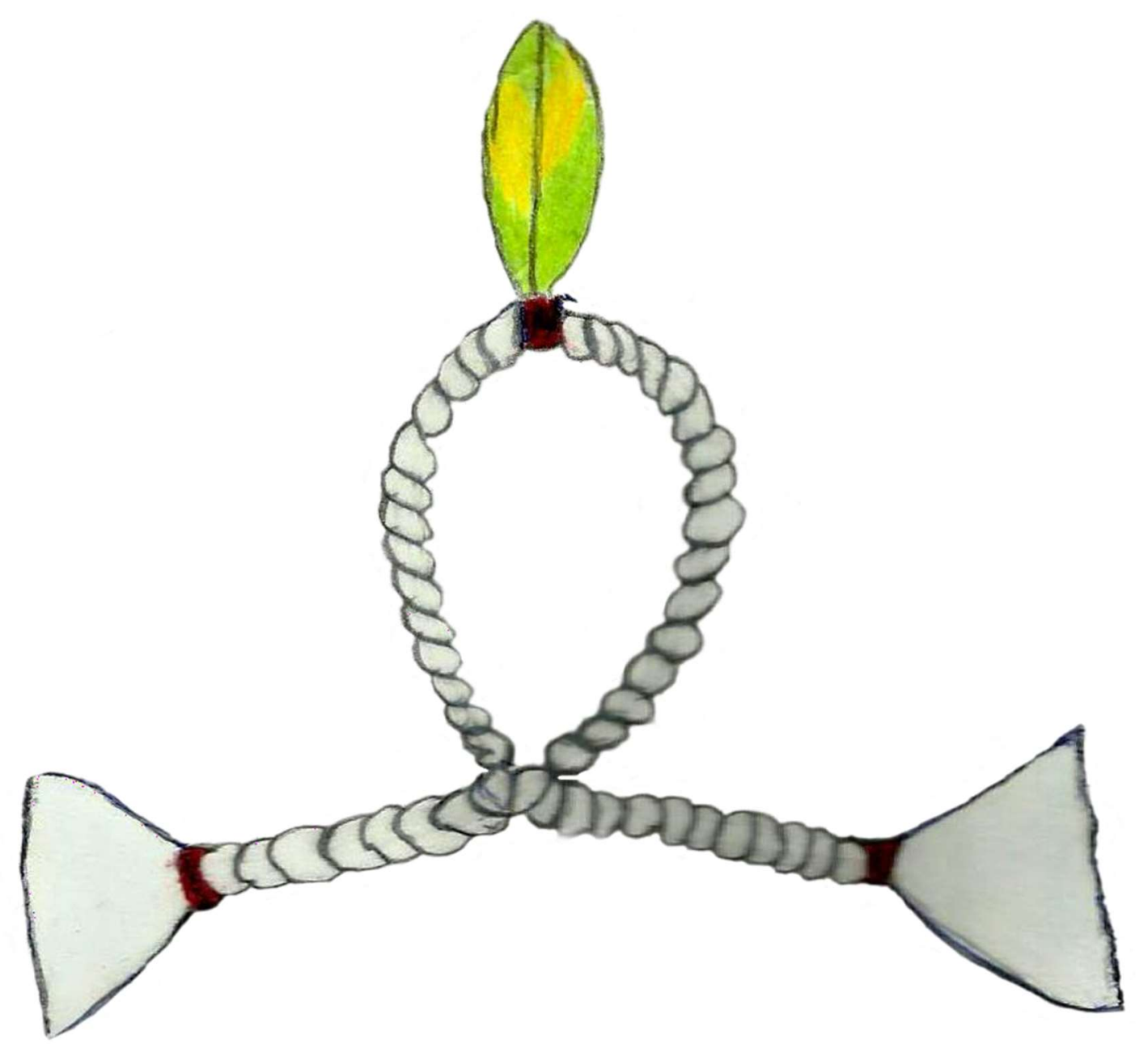

DOCUMENTO FINAL A'UWẼ UPTABI DE PROPOSIÇÕES PARA A POLITICA DE EDUCAÇÃO ESCOLAR INDÍGENA PARA O ESTADO DE MATO GROSSO 


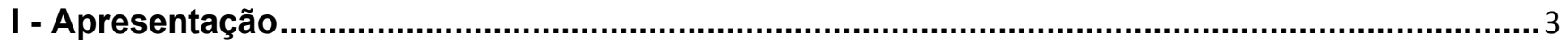

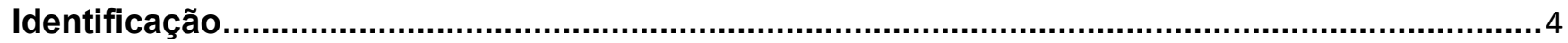

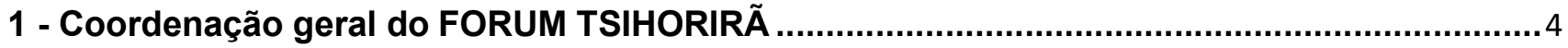

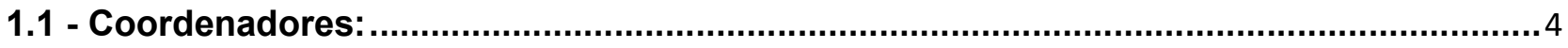

1.2 - Membros:

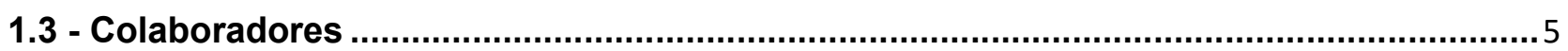

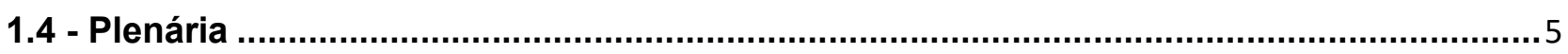

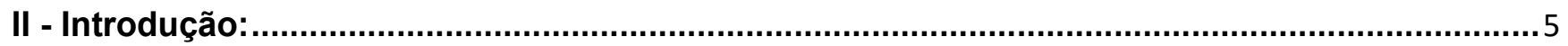

OBJETIVOS

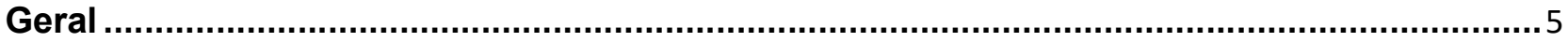

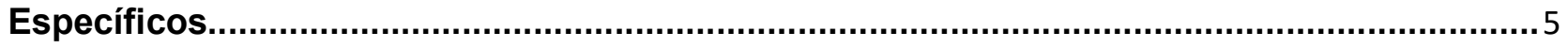

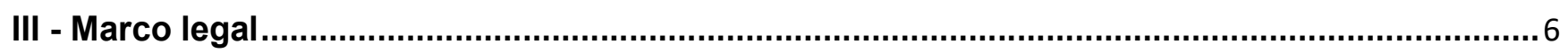

IV - Marco situacional e Marco filosófico ......................................................................................

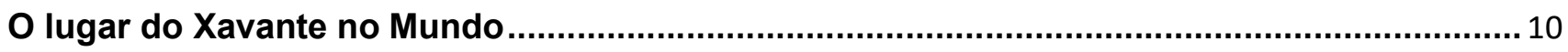

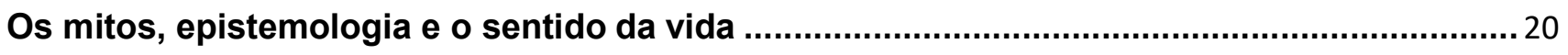

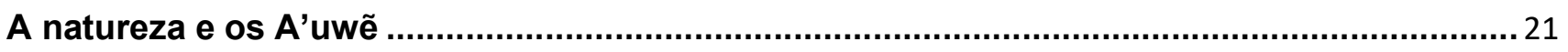

Luto e o pacificador: desencontro do tempo dos acontecimentos e do relógio ......................2 21

Tempo e Espaço e Dualidade .................................................................................................. 23

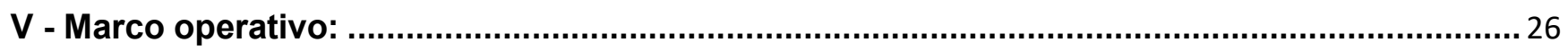

EIXO 1- Território Etnoeducacional A'uwẽ Uptabi, Unidades Desconcentradas de Educação Escolar Xavante e Regime de colaboração para a garantia da educação escolar indígena, Gestão

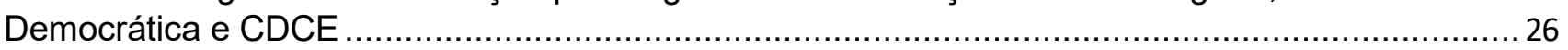

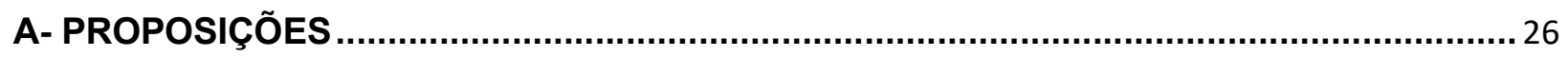

EIXO 2- Organização da Educação Escolar Indígena (PPP, Ciclo de formação humana/currículo).32

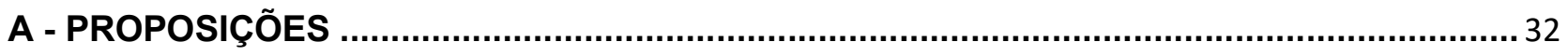

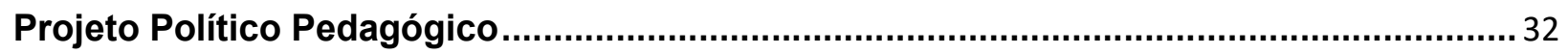

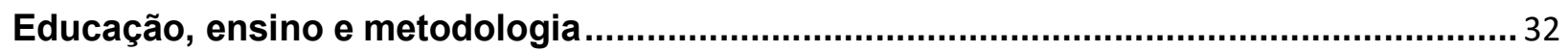

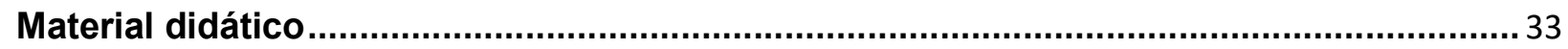

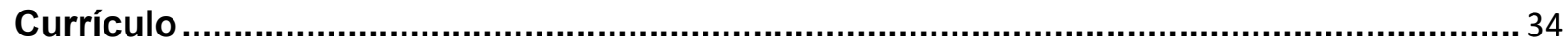

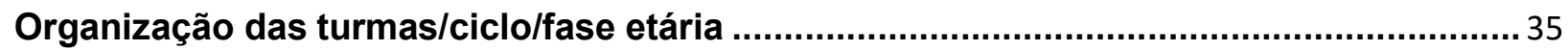


EIXO 3- FORMAÇÃO PROFISSIONAL

3.1 - Formação inicial e continuada: formação para o eixo profissional, licenciatura e magistério

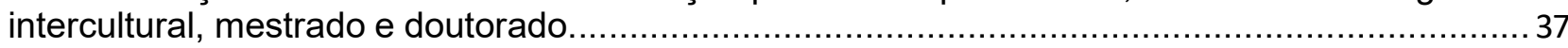

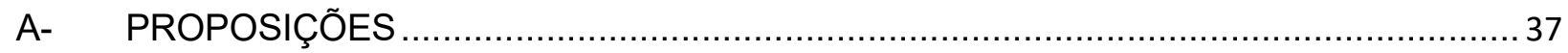

3.2 - Formação Continua e Desenvolvimento Profissional ................................................ 39

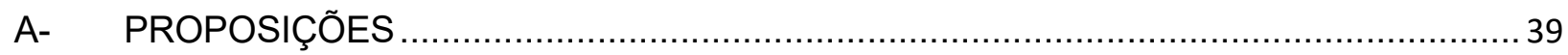

EIXO 4- Carreira dos profissionais da educação: concurso público específico, categoria:

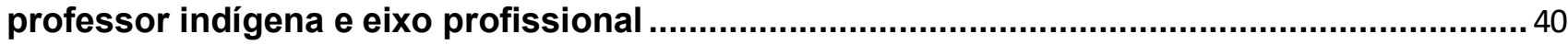

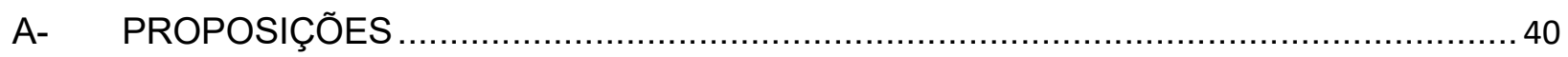

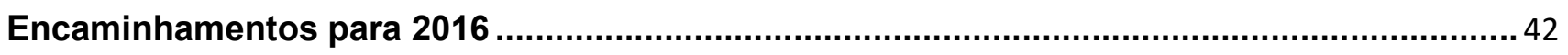

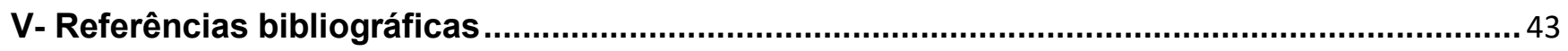

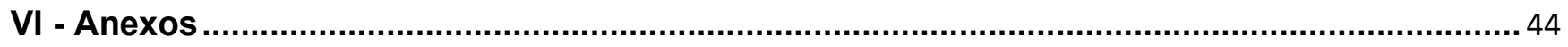

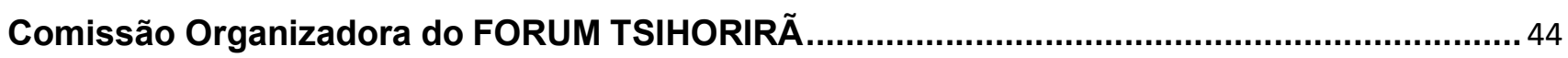




\section{I - Apresentação}

Esse documento representa a síntese das proposições, realizadas pelo fórum Tsihorirã A'uwẽ Uptabi, que surge em decorrência de uma reunião ordinária do Conselho Estadual de Educação Escolar Indígena - CEEI, em setembro de 2015, a partir da necessidade da elaboração da Política de Educação Escolar Indígena para Mato Grosso, de forma participativa e consultiva dos povos indígenas e dos profissionais de educação.

Desse modo, nasce o FORUM Tsihorirã no âmbito do Território Etnoeducacional A'uwẽ Uptabi (TEEAU), envolvendo as Terras Indígenas Xavante: Pimentel Barbosa, Areões, Marãiwatsédé, Marechal Rondon, São Marcos, Sangradouro, Parabubure e Ubawawe, com o apoio das instituições parceiras ( FUNAI, UFMT,UNEMAT, NPD, CEFAPRO/BGA/PVA, SUDE, SUFP, SAPE, UNEMAT, Assessorias Pedagógicas de Barra do Garças, General Carneiro, Campinápolis) 


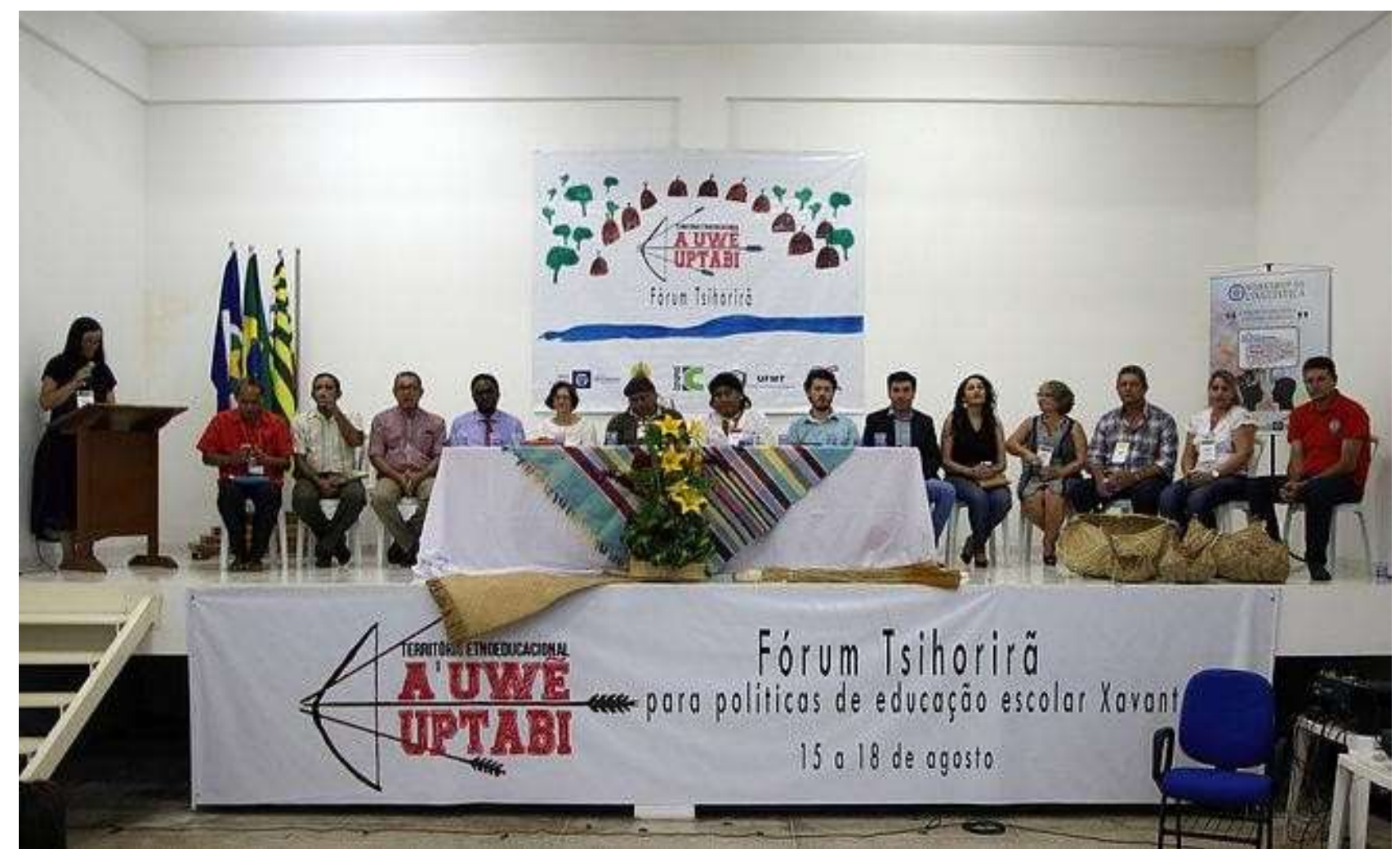

\section{Identificação}

\section{1 - Coordenação geral do FORUM TSIHORIRÃ:}

(É Composta por membros oriundos das instituições fundadoras e dos representantes das Terras Indígenas A'uwẽ Uptabi)

\section{1 - Coordenadores:}

Owawe: Xisto Tserenhi'ru Tserenhimi'rami

Poreza'ono: Jurandir Siridiwe Xavante

\section{2 - Membros:}

Areões: Anderson Siruiá e José Upté Xavante;

Parabubure: Elias Tsibodo'pré Nomotse e Saturnino Wapotowe Rudzane Edi;

Ubawawe: Sam Hamilton Seredi;

Pimentel Barbosa: Caimi Waiasse Xavante e Leandro Parinaia Xavante

Marãiwatsédé: Carolina Rewaptu e Cosme Rite

São Marcos: Leandro Aptsire e Nilson Tserewetsa Tsaeomowa

Sangradouro: Bartolomeu Patira Pronhopa e Januário Tseredzaro Ruri'õ 
Marechal Rondon: Natal Wa'awe e Orlando Tsipetsewe.

Coordenadoria da EEI: Felix Rondon Adugoenau e Sebastião Ferreira de Souza;

FUNAI CR Xavante - BGA: Gabriel Gomes Muria e Carlos Henrique Silva

CEFAPRO/BGA: Beloni Eliza Secretti Ceretta e Rita Natalia Batista da Silva;

CEFAPRO/ Primavera do Leste: Milton Alcover Neto e Karina Aparecida Geraldo;

UFMT/CUA: Marly Augusta Lopes de Magalhães e Magno Silvestri;

UCDB: Pe. Aquilino Tsere'ubu'õ Tsirui'a,

UNEMAT: Adailton Alves da Silva

UFG: Carlos A. Bianchi e Dayane Renata Silva Pereira;

Assessoria Pedagógica de General Carneiro: Vanessa Aline Busanello e Lucineyde

Francisco Moreno.

\section{3 - Colaboradores:}

Luciana Akeme Sawasaki Manzano Deluci, Flávia Cunha Lima, Luciene de Morais Rosa, Alissandra da Silva Santos Sousa, Rosaline Rocha Lunardi e Elza das Dores Ferreira.

\section{4 - Plenária:}

É composta pelos representantes do povo Xavante e convidados

\section{II - Introdução:}

\section{OBJETIVOS}

\section{Geral:}

- Apresentar diretrizes que subsidiem a construção e implantação da Política de Educação Escolar Indígena para o Estado de Mato Grosso

\section{Específicos:}

- articular a organização escolar com o ciclo de formação, tempos e espaços Xavante;

- propor a inserção do profissional da Educação Xavante na carreira do magistério;

- indicar demandas de Formação profissional em nível inicial, continuada, continua e desenvolvimento profissional;

- fortalecer o Território Etnoeducacional A'uwe Uptabi. 


\title{
III - Marco legal:
}

\begin{abstract}
"A educação escolar indígena é responsabilidade do Estado. A descentralização da execução dos projetos, através dos Estados e Municípios, com a supervisão e apoio do MEC, da FUNAl e das universidades, só será efetiva se as diretrizes deste documento forem assumidas por todos os agentes envolvidos. A formação de professores índios e a formação de quadros não-índios em nível local (nas Secretarias de Estado, nas administrações regionais da FUNAI e delegacias do MEC, nas Prefeituras, etc.) é tarefa urgente e indispensável." ( MEC, 1993, p.1)
\end{abstract}

São inquestionáveis os avanços conquistados, a partir da CF/88, em relação aos direitos dos povos indígenas, principalmente no que diz respeito ao acesso a uma educação escolar específica, intercultural, bilíngue (multilíngue) que contribua para a afirmação étnica e cultural dos povos. A educação escolar deixou de ser 'reprodutora' de uma única cultura - dominante - em detrimento da valorização de outras culturas. Dessa forma os saberes e práticas indígenas devem ancorar o acesso a outros conhecimentos, de modo a valorizar os modos próprios de conhecer, investigar e sistematizar de cada povo indígena, valorizando a oralidade e a história indígena (DELUCI, 2013, p.126-129).

Convém notar, segundo Grupioni, que a educação escolar indígena é pauta política relevante, assim deixou de ser uma temática secundária, ganhando importância à medida em que mobiliza diferentes atores, instituições e recursos. Assim, "hoje não mais se discute se os índios têm ou não que ter escola, mas sim que tipo de escola." (GRUPIONI, 2016)

Além da Lei de Diretrizes e Bases da Educação Nacional, de 1996, e da Resolução 3/99 do Conselho Nacional de Educação, a educação indígena está contemplada nos Planos Nacional e Estadual de Educação. A legislação específica da educação escolar indígena tem apresentado formulações que se abrem para a construção de uma escola indígena que, inserida no sistema educacional nacional, mantenha atributos particulares como o uso da língua indígena, a sistematização de conhecimentos e saberes tradicionais, o uso de materiais pedagógicos adequados e preparados pelos próprios professores indígenas bem como um calendário que se adapte ao ritmo de vida e das atividades cotidianas e rituais, a elaboração de currículos diferenciados, a participação efetiva da comunidade na definição dos objetivos e rumos da escola.

Compreendendo esse panorama, Grupioni diz que:

Avanços e consensos na área de educação escolar indígena se deram tanto no plano legal quanto no plano administrativo. Todavia, ainda não se estruturou um sistema que atenda às necessidades educacionais dos povos indígenas de acordo com seus 
interesses, respeitando seus modos e ritmos de vida, resguardando o papel da comunidade indígena na definição e no funcionamento do tipo de escola que desejam. A impressão que se tem é que a educação escolar indígena caminha a passos lentos: avança-se em direção a algumas conquistas, mas inúmeros obstáculos se apresentam a cada momento. (GRUPIONI, socioambiental.org, 2016)

As legislações também tem colocado os povos indígenas e suas comunidades como os principais sujeitos da escola indígena. Porém, essas legislações encontram-se ainda mais como princípios do que como práticas presentes no sistema de educação, sendo necessário avançarmos nessa construção em que se efetive os pilares da educação específica e diferenciada. No entanto, diversas são as amarras administrativas que dão morosidade ao processo, embora constatarmos que já avançamos muito enquanto estado nessa direção. Pois,

\begin{abstract}
O que a legislação nacional estabelece é um conjunto de princípios que, de modo geral, atende à extrema heterogeneidade de situações vividas hoje pelos mais de 210 povos indígenas contemporâneos no Brasil. Essa legislação permite a expressão do direito a uma educação diferenciada, a ser pautada localmente, em respeito às diferentes situações socioculturais e sociolinguísticas de cada povo indígena, bem como em relação aos seus diferentes projetos de futuro. Todavia, esses princípios precisam encontrar respaldo e acolhimento nas normatizações estaduais que vão disciplinar o funcionamento das escolas indígenas, como unidades integrantes dos sistemas estaduais de ensino, bem como regularizar a situação dos professores indígenas como profissionais contratados pelo estado ou pelo município. É aqui, portanto, no âmbito estadual, que os princípios federais precisam ganhar efetividade, gerando normas e procedimentos que Ihes possam dar vazão. É nesse âmbito que se consolida o direito a uma educação diferenciada, na medida em que se implementa e se realiza o direito a uma escola própria e diferenciada. (GRUPIONI, p. 135)
\end{abstract}

Essa legislação permite a expressão do direito a uma educação diferenciada, a ser pautada localmente, em respeito às diferentes situações socioculturais e sociolinguísticas de cada povo indígena, bem como em relação aos seus diferentes projetos de futuro. Todavia, esses princípios precisam encontrar respaldo e acolhimento nas normatizações estaduais que vão disciplinar o funcionamento das escolas indígenas, como unidades integrantes dos sistemas estaduais de ensino, bem como regularizar a situação dos professores indígenas como profissionais contratados pelo estado ou pelo município. É aqui, portanto, no âmbito estadual, que os princípios federais precisam ganhar efetividade, gerando normas e procedimentos que lhes possam dar vazão. É nesse âmbito que se consolida o direito a uma educação diferenciada, na medida em que se implementa e se realiza o direito a uma escola própria e diferenciada.

Nesse sentido, esse Fórum realizou a consulta previa e informada sobre a Educação Escolar junto ao povo Xavante e legitimar suas vozes no encaminhamento da Política Pública de Educação de MT e na efetivação da escola indígena específica e diferenciada. 


\section{IV - Marco situacional e Marco filosófico:}

O mundo está globalizado, mundo que tem tecnologia, o mundo está sempre em movimento. Tem guerra, está civilizado em duas partes, por que às vezes a gente procura saber da vida dos brancos e os brancos querem saber da nossa vida, estamos construindo uma nova forma de conhecimento. A comunicação e informações por meio da internet, telefone e meios de transporte continuam avançando sempre.

Tem muito desmatamento, poluição do ar, devastação, queimadas. A energia elétrica entrou em nossas vidas, já faz parte do cotidiano da aldeia. Foi bom e também ruim, traz conhecimento, mas ruim, pois pode acontecer um acidente. Todas as sociedades estão ameaçadas pela poluição, pelos desmatamento, pela PEC 215, que consequentemente levará a um processo de aquecimento global, que afeta o meio ambiente e principalmente com povo Xavante que tem uma relação vital com a natureza.

Convivemos numa sociedade cujo sistema econômico é o capitalismo, e no capitalismo quem manda é o dinheiro, existe diferença entre as pessoas que podem e não podem comprar e acessar os bens e o conhecimento. O capitalismo é tão intenso que até as pessoas estão vendendo os seus direitos.

Existe competição desigual entre as pessoas, que mesmo estudando não conseguem passar no vestibular e conseguir bons empregos. Existe preconceito contra muitos brasileiros: povos indígenas, assentados, ribeirinhos, quilombolas, deficientes.

Existe muita corrupção e muitos conflitos, manifestação para melhoria das condições de vida e das políticas públicas de educação e saúde. O mundo está desenvolvendo, a produção agrícola e pecuária e servem aos interesses e lucros dos empresários e traz impactos ao ambiente com o uso indiscriminado de agrotóxicos, que poluem o ar, rios e a chuva. $O$ mundo industrializado estimula o consumo. No mundo há drogas, álcool e muita violência.

Atualmente há uma mudança nas relações de tempo e concepção, através do mundo global, e portanto "a escola é um dos caminhos para preservar o que temos, para isso ela deve acompanhar o anseio e desejo da comunidade Xavante".

A sociedade tem se afastado de suas raízes, sua identidade. A proximidade de outras 
culturas tem influenciados a nossa forma de vida e nossas aparências. Nessa relação criamos a necessidades de usos de equipamentos de tecnologia de não indígenas, sofremos a pressão do capitalismo e do consumo cada vez mais forte. Foi nesse sentido enfraquece o controle o sócio cultural tradicional do povo Xavante.

Preconizada em lei a educação intercultural vem ganhando espaço, na escola que por muito tempo tinha um caráter colonizador, porém ainda carece de mecanismos efetivos de garantias de diferenciação entre os povos em especial se tratando da diversidade em que se encontram os povos de Mato grosso e em especifico em considerando o povo Xavante, que é um povo que apesar de um contato recente com a sociedade não indígena, porém com muita intensidade visto a forma de demarcação de nossas terras e dos projetos de expansão econômica e de ocupação do Brasil Central.

Assim, não temos uma política estadual que atenda a educação escolar indígena. Os encontros que estão acontecendo com vários povos indígenas são tentativas de conseguir gestão e financiamento especifico para a dinâmica territorial, cultural e linguística de cada povo. Não há legislação estadual que assegure a educação indígena pedagógica e política, que contemple a educação escolarizada indígena e a A'uwẽ Uptabi. Quando se trata do marco filosófico para a educação A'uwẽ Uptabi, é preciso discutir uma forma de estabelecer um diálogo entre as comunidades das diferentes terras Xavante. Pois, é necessário lidar com os dois mundos em que estamos vivendo.

No contexto de identificação de ser A'uwẽ Uptabi ao mesmo tempo existe a ansiedade determinada por fatores que fazem parte da caminhada da vida cotidiana do povo A'uwẽ Uptabi e as necessidades advindas do mundo externo. Somos povos originários, indígenas deste país. Tenho ouvido que a expressão A'uwẽ Uptabi, é muito antiga. Este é o momento de discutir sobre esse assunto, sobre nossa origem, que vem de tempos antigos, imemoriais, e é passado de geração em geração pela oralidade. Assim, aprendemos que não se faz troca entre o mesmo clã e também entre o mesmo grupo. Se faz troca entre clãs diferentes na família, com alguns critérios entre o grau de parentesco, por exemplo. A nossa educação vem do berço, é na família que se recebe os primeiros ensinamentos, desde a barriga da mãe.

Ser Xavante é casar com Xavante, é viver como Xavante, é defender o povo Xavante. Para construir o marco filosófico é preciso ser Xavante autêntico, saber sobre a medicina, 
aspectos da filosofia, da natureza, da espiritualidade. A filosofia inclui a educação, os ritos, as crenças e até a orientação sobre sexualidade.

Assim sendo, na elaboração do marco filosófico do povo Xavante, refletimos, antes de partir e avançar, sobre o equilíbrio entre o ter e o ser, quando muitas vezes na realidade não existe este equilíbrio e pende-se para o ter, e que não se encaixa muito bem para a cosmologia Xavante, porque quebra o termo reciprocidade que é vivenciada no cotidiano.

Queremos esse equilíbrio entre ser e o ter e não avançarmos para a ruptura. Pois o ter tem sentido de competição, de propriedade, de posse, da individualidade e para se manterno emprego assalariado é individual e não coletivo. Também há necessidade de entendermos mais sobre o avanço tecnológico para não perdemos a relação do Eu e o outro e a reciprocidade e manter a circularidade do território, não deixar que a individualidade sobreponha o coletivo.

A força espiritual do Xavante está nos mitos, assim como em outras culturas os mitos sustentam a sua filosofia, a exemplo da mitologia grega, o que se assemelha com os mitos Xavante, pois para constituir o SER cremos no sobrenatural, que não está desvinculado da filosofia para nós, Xavante. A constituição histórica do SER Xavante na perspectiva de reviver as mitologias produz o sentido da vida A'uwẽ Uptabi.

\section{O lugar do Xavante no Mundo}

O TER rompe com a constituição do ciclo de vida Xavante, pois o TER enquanto eu individual, não reconhece a alteridade, a diferença do outro, nos aspectos das relações sociais, pois a essência do ser Xavante se constitui no coletivo. Então, na medida em que estamos sendo seduzidos para o lado do possuir, se está caminhando para a ruptura do ser Xavante. Nesse intuito, a globalização está acabando com o mundo, mas é preciso saber lidar com ela para vivermos bem. É preciso fortalecer e vivenciar a filosofia Xavante, no sentido de rever a caminhada do povo Xavante, e entender para onde estamos indo.

O reconhecimento do eu no outro se reflete, na força espiritual, na higiene pessoal, na dieta alimentar durante as cerimônias e nas etapas da vida, assim evitar certos alimentos que não abastecem, mas desabastecem a força espiritual. Nessa perspectiva, o saber espiritual não pode ser passado para o papel, pois com isso perde sua força, ele é passado oralmente 
dentro do contexto da educação Xavante, constituindo-se em tempos e espaços da vida, do coletivo para o individual. Em consequência disso não é fácil para o professor ensinar valores espirituais no contexto escolar, ele deve vivenciar com os alunos esses valores a partir do movimento da comunidade. Os valores que sustentam a cosmovisão Xavante são o respeito e a reciprocidade. O professor em contexto de ensino deve levar em conta a arte e outros aspectos da cultura, que é por onde é possível vivenciar os valores espirituais e sociais.

Os grandes mestres Paulo Freire e Vigotsky, nos ensinaram que o aprendizado se dá nas relações com o outro, e que o sujeito se forma no contexto social e histórico. Quando lemos, seus escritos, percebemos que nossos ancestrais já nos ensinavam sobre isso, apenas não sistematizamos cientificamente estes conhecimentos que fazem parte da lógica Xavante. O ser Xavante aprende desde o ventre da mãe e esse conhecimento influencia por toda a vida.

A discussão sobre a filosofia Xavante perpassa pelo respeito aos clãs, o respeito aos mais velhos, a distinção dos papéis masculino e feminino, até para sexo somos orientados por ritos que são definidos pelo conhecimento ancestral expresso pela cultura A'uwẽ. Quando vemos com os olhos da cultura, a preservamos. Todos os Xavante foram ensinados pela tradição.

Porém, hoje, intensificada pela globalização, somos cada vez mais influenciados pelo sistema capitalista, pelo dinheiro, manobras de competição na política e que tem contaminado em todos os aspectos da vida do povo Xavante. Estamos em constante movimento dual de aproximação ora para o conservadorismo, ora para a ruptura, assim como a vida do Xavante em que a dualidade que está presente em nossa relações.

O mundo Xavante divide-se em dois: quando o sol nasce e quando se põe e vem a noite. São detalhes que aprendem diariamente nos rituais. São ensinados a não brigar à toa, quando é o momento certo para brincadeira. Para a criança, o espaço não tem limite e depois começam a surgir as fronteiras imaginárias. Aprender a respeitar fortalece a formação. A preparação física e espiritual é muito importante e é desenvolvida em diversos momentos, em rituais, como o öi'o, o uiwede, o danhono, darini entre outros, que representa a formação completa A'uwẽ Uptabi e para acontecer é fundamental nosso território, a natureza, o cerrado e a mata. O Rö (cerrado) é uma grande escola da cultura Xavante. Se acabar essa estrutura de viver Xavante, não tem casamento, não tem alimento, pode acabar com a cultura Xavante. 
É preocupante a fragmentação do povo Xavante, porém, o fato de estarmos separados em terras, não nos impede de nos juntarmos para discutir os assuntos importantes para povo Xavante, além disso temos a filosofia Xavante que nos une e que é fundamental para fortalecer entre outras coisas a espiritualidade e preparar psicologicamente para viver em grupo com os desafios dos dois mundos: A'uwẽ e waradzu.

A natureza também é uma fonte de conhecimento para o Xavante, ela nos ensina sobre a vida e a morte. O Xavante pertence à natureza, no cheiro do rio, nos peixes, nas flores. Aquele que tem conhecimento conversa com a natureza, a exemplo quando forma uma chuva, o curandeiro que percebe que a chuva pode ser perigosa com muito vento, faz gestos e pede que o temporal vá embora para que não atinja as pessoas que não a esperavam e a chuva muda de direção, o mesmo acontece com outros fenômenos naturais.

$\mathrm{Na}$ natureza temos tudo o que precisamos para viver e não é necessário destruí-la, entretanto temos visto que na sociedade não indígena, que o sistema econômico capitalista associado ao uso da tecnologia tem contribuído para que se avance indiscriminadamente na exploração dos recursos naturais e o desmatamento, em consequência disso há o desequilíbrio econômico e ambiental afetando nossas vidas. A tecnologia é muito boa se soubermos usá-la muito bem. Assim, a tecnologia é boa, mas também traz malefícios. Um exemplo, disso é que ela nos leva ao sedentarismo, o consumo de alimentos industrializados, e nos acometem as doenças advindas dessa forma de vida, entre outros fatores.

O impacto da modernidade sobre a cultura Xavante, a imposição das leis e a colonização da cultura predominante tem sido cada vez mais intensa, assim, torna-se um desafio construir o projeto de escola e romper paradigmas impostos, marcado pela finalidade na implantação das escolas nas terras Xavante. Além desse desafio, também há o de contemplar nesse projeto de escola, a forma de organização escolar de acordo com as diversidades entre os Xavante, advinda da demarcação das terras em "ilha" e as diferentes formas de contato com a sociedade não indígena.

Existe muita riqueza no sentido da diversidade cultural para ser valorizada também no espaço da escola, todavia o sistema não nos permite e impõe outros modos de organização. Ex: o sistema on line de diários que não condiz com a realidade do cotidiano na aldeia e com as condições materiais e de conhecimento. A que se pensar sobre um mecanismo para motivar 
o professor em sala de aula. Respeitar a iniciativa do professor em sala de aula, a autoridade e o prestígio dado a ele pela comunidade, por meio do warã ${ }^{1}$, é a valorização maior do que somente o salário dinheiro. A sociedade não indígena valoriza aquele que possui maior graduação, e não é raro ver jovens brancos que não respeitam e nem oferecem ajuda para os mais velhos que necessitam, enquanto que para o indígena o mais sábio (o mestre) é o mais velho, o que merece nosso maior respeito são eles, que detêm o saber mais importante para nossa vida de Xavante verdadeiro, são valores diferentes entre essas sociedades.

Nós Xavante valorizamos muito a oralidade e queremos preservar isso na nossa cultura e em todo os espaços educativos. Aprendemos durante nossa vida, com a família o que uma pessoa precisa saber, por meio das histórias e conselhos que recebemos de alguém mais experiente e sábio, seja pais, padrinhos/madrinhas, seja no warã, de acordo com a fase de vida. O povo Xavante valoriza muito o espaço, o loco, a vivência. O waradzu não valoriza o lugar em que vive: o cerrado.

Alguns aspectos da cultura Xavante têm mudado, como por exemplo, o tipo de moradia. Cada um sabia sobre a função de cada artefato cerimonial e de cada erva medicinal. Quando nascemos, já acontece o aprendizado. O povo Xavante trabalha muito com o respeito, família, são guerreiros preparados para morrer, tanto na política, como fisicamente.

${ }^{1}$ Warã, o lugar das decisões e relações políticas e culturais dos A'uwẽ 
Para cada fase de vida, há um aprendizado. Quando nasce uma criança, ela pertence a toda a aldeia. Quando nasce uma menina, a família começa a prepará-la para a função dela na aldeia, sua responsabilidade com a sua família, sua casa, seus filhos. Para o povo Xavante a vida é um ciclo. Nossa geração está diante do desafio de garantir a sobrevivência da cultura e do povo. Outro desafio, é o de preparar os jovens para se tornarem lideranças e manterem o equilíbrio entre a tradição e o novo que vem por meio das relações externas.

Somos vítimas de preconceito em vários locais, inclusive na escola. Relembramos sempre aos jovens que devem representar e defender a cultura Xavante onde estiverem. Entretanto, ainda é preciso que as outras culturas conheçam o povo Xavante para que possam romper com o preconceito, assim estabelecer conosco uma relação de respeito.

A filosofia Xavante deve referendar a organização da escola Xavante e a organização da escola em conformidade com Ciclo de formação humana, contemplando as fases de vida e aprendizados Xavante.

Qualquer conteúdo que queira ser desenvolvido deve ser a partir do jeito de ser xavante, assim todas as escolas Xavante vão trabalhar com base nessa referência filosófica, resguardando algumas especificidades locais. Nosso mundo mítico e filosófico deve ser transformado em realidade nas escolas nas semanas pedagógicas

Embora muitas escolas rejeitem o ciclo, porque ele mais ou menos está encaixado no ciclo A'uwẽ. Mas o ritmo da escola seriada prejudica o ciclo de vida cotidiana dos alunos, ele restringe a vida a liberdade, o despertar. A organização por ciclos permite que a criança crie e se divirta com a mesma faixa etária. O nosso desafio, é prever se todas escolas acompanham o ciclo de vida real Xavante e não imaginário, teremos com certeza, um impacto, em virtude de estar firme no sistema tradicional. Essa organização que existe hoje não é a única forma de organização, podemos avançar para a nossa forma de organização das fases de vida.

Para entendermos as variações entre as fases da vida A'uwẽ e a organização em ciclo de formação humana, apresentamos o seguinte quadro: 


\begin{tabular}{|c|c|c|c|}
\hline $\begin{array}{c}\text { Fase da vida } \\
\text { A'uwẽ }\end{array}$ & Idades & Ciclo & Idades \\
\hline \multirow{2}{*}{$\begin{array}{c}\text { Waté bremi e } \\
\text { Ba'ono }\end{array}$} & 4 a 8 anos & Educação infantil & 4 e 5 anos \\
\cline { 3 - 4 } & \multirow{2}{*}{$\begin{array}{c}\text { Ai'repudu e } \\
\text { Adzarudu }\end{array}$} & I ciclo & 6,7 e 8 anos \\
\hline Wapté & & II ciclo & 9,10 e 11 anos \\
\hline \multirow{2}{*}{ Adabá } & 12 a 18 anos & III ciclo & $12,13,14$ anos \\
\cline { 3 - 4 } & 12 a 18 anos & Ensino Médio & $15,16,17$ anos \\
\cline { 3 - 4 } & & III ciclo & $12,13,14$ anos \\
\hline
\end{tabular}

Na fase do wapté, o adolescente não deve ter contato com as mulheres, isso para nossa filosofia, enfraquece o corpo e o espírito do rapaz e atrapalha o desenvolvimento dele no objetivo de se tornar um Xavante verdadeiro. Parte de sua educação acontece no Hö, que é o espaço propício para ampliação, onde acontece a difusão de todos os valores tradicionais. É o lugar onde o adolescente recebe os ensinamentos dos padrinhos.

O padrinho promove pequena caçada, pescaria, é como uma ensaio para a vida, fazem artesanato. O que está no espaço maior se foram, e vem o jovem para ocupar o espaço maior (renovação por meio das gerações). É o espaço de diálogo dos padrinhos. O aprendizado do Hö não se fortifica, se o adolescente tiver contato com a mulher, por isso que não pode misturar.

Na educação A'uwẽ Uptabi, os elementos essenciais para que aconteçam aprendizagem acontecem em dois espaços: a casa e o Rô. O Rô é uma complementação da educação tradicional, em que os meninos (solteiros) aprendem com seus padrinhos certas habilidades

\footnotetext{
${ }^{2}$ Fase que caracteriza-se pelo afastamento da família e moradia no Hö, casa dos adolescentes, ficando sob responsabilidade do padrinho até a passagem para a fase 'rite'wa.

${ }^{3}$ Algumas nesta idade já podem ter filhos e sendo chamada a partir da maternidade de Ai'raté.
} 
intelectuais: histórias etc. A comunidade também acompanha o desempenho dos meninos, mas não pode ser qualquer pessoa que pode ser padrinho. Os padrinhos tem dia e hora marcados para fazer o acompanhamento dos alunos.

A Metodologia de ensino no Hö é: observar, analisar, participar. A Filosofia é proteger a aldeia. O grupo que acabou de sair do hö, eles farão mais expedição no cerrado, eles são os guardiões do cerrado. Cadê os guardiões? Chamam com alegria, os guardiões que fazem expedições para. Não pode rastro, observar o inimigo e trazer informações.

O tratamento de pessoas é aprendido no hö, assim também é ensinado o tratamento que a moça deve ter como os parentes e a constituição tradicional das relações entre gênero e clã. Os rapazes tem uma educação relacionada ao tratamento também ouvindo o conselho dos padrinhos, aihö'ubuni, Pahöri'wa e o respeito a hierarquia. Tem também a preparação do corpo: a resistência ao sol, ao frio, as mudanças climáticas, a fome, desenvolvendo a sua força. Aprender a ouvir e depois praticar é a preparação para a vida adulta a passagem no hö. Pra ser guerreiro e bom A'uwe. O tratamento ao wapte tem que ser diferente sem isso o xavante não vai aprender, porque a passagem no Hö é o momento de preparação e assim deve ficar separado e depois voltar a ser junto na fase do Ritei'wa. A educação do wapté não é aberta, só vai ser aberto quando estiverem na fase ritei'wa. O wapté não pode falar com as moças senão enfraquece o seu espírito. Portanto queremos que na fase do wapté os rapazes sejam separados das moças e para isso instituímos o nosso PPP com o nome de Hö, casa tradicional de educação do adolescente, é o centro educacional, toda a comunidade vê e acompanha, é discutido no warã, e cada wapté é avaliado o tempo todo pela comunidade. Tem sua avaliação própria e aprovação própria, se caso não seguir como deve será feita a furação antecipada e prejudica o próprio grupo, recebe o nome de Atsitõ, porém sempre vai ser do grupo, porém não vai participar da festa na sequencia da cultura, pois ele já pode casar e não tem mais a obrigação de seguir o processo, pois sua furação acontece antes.

Com relação a atuação dos profissionais da Seduc, da Semec, e outros técnicos, é necessário rever a forma de lidar com o Xavante. Muitas vezes a assessora pedagógica não está apropriada ao cotidiano escolar das comunidades. Os tempos e espaços do governo e seus representantes são diferentes da comunidade. Todos os representantes do governo 
inclusive os que tratam de assuntos escolares ao visitarem a aldeia, deveriam apresentar-se diretamente no Warã para tratar desses assuntos. Muitos secretários de educação não têm respeitado o direito de indicação da comunidade para os cargos de direção e acabam indicando alguém para a direção da escola sem os critérios da comunidades e se envolvem assim em politicagens e não nas questões políticas da cultura. Esses trâmites devem estar na linha filosófica da cultura.

Existe um movimento político e social horizontal, em que a comunidade tem autonomia e participação nas decisões. Já a verticalidade, as hierarquias é exercido por meio das relações com a cultura não xavante. Cria-se os cargos de diretor, coordenador, que está acima dos professores, isso não é da nossa cultura, não é assim que se constitui poder. Essa visão é eurocêntrica, que vem colonizar nosso povo.

Os filhos da comunidade que atuam na escola são escolhidos não só pelo cacique e sim pelos pais e comunidades, por meio da discussão promovida no warã, porque o warã decide de forma igualitária. E sua atuação também não é individual, mas em conformidade com as discussões e decisões do warã.

Na cultura os Riteiwa ainda não têm direito de assumir a função da direção, no espaço maior, mesmo que ele tenha a formação superior, ele tem que seguir. Nessa fase de Ritewa não se deve assumir papel de professor, por isso não pode assumir esses papéis, não estaria de acordo com a nossa filosofia. Isso tem relação com fortalecer o "ser" está o "ter".

O grupo que estão assumindo o papel do padrinho, ser padrinho na responsabilidade, fazer parte do espaço maior, já faz parte do conselho maior, já tem direito de voto e pronunciar na hora de decisão. As principais discussões acontecem no warã, é no centro que resolvemos tudo e se faz os encaminhamentos. As discussões pequenas podem acontecer na reunião do riteiwa fora, mas tem que passar pelo warã.

O warã no seu formato reflete a união, a reciprocidade, a cultura como um todo, a identidade, relação política e social dentro da comunidade. Não é qualquer pessoa que pode fazer uma palestra. Ela deve ter permissão para isso. É o espaço propício para se projetar, se promover outros anseios da qual a comunidade pode ser beneficiada. A Mulher também tem 
voz no warã por meio das mulheres anciãs e da família. Também são convidadas a participar do warã em algum momento específico.

É fundamental cobrar do Estado que eles possam ter uma relação política com a comunidade indígena e não apenas culturalmente. Promover apenas programas culturais confunde a proposta da comunidade do seu modo de vida. A relação do governo com o povo Xavante deve ser política e social. Se as relações com os povos indígenas são tratadas em nível federal, então, as demandas governamentais devem partir do governo federal, no entanto, para nós há leis estaduais, municipais. O regime de colaboração entre os governos não está bem organizado, está muito voltado para a administração local.

Tudo que entra de fora tem que passar pelo warã. E assim cada participante leva para sua casa as informações. Não somente assuntos da escola, mas também das associações, das relações com a saúde e educação, participação nos encontros fora da aldeia, tudo é repassado para a comunidade no centro. E dependendo do assunto se faz pequenos warã, para depois fazer documentos e as famílias cobram se teve decisão e não foi informado. Traz seu caráter coletivo no sentido da discussão aberta e exige participação de todos os membros, assim se grupo oposto que não estiver presente não leva a mensagem para casa. As decisões no warã acontecem na discussão entre os clãs, fazemos as discussões, intercalando cada clã na fala. Cada clã cuida de uma função e cada um discute o perfil de integrante dos clãs.

Desse modo, a relação dos professores e seus alunos é de preocupação e compromisso com a prática pedagógica com vivencia no cotidiano sentimento, pois ambos são membros da comunidade. E na comunidade estabelecem relações de clãs e parentesco, e a partir dessa referência, os professores devem ter uma postura ética com base na filosofia xavante e assim como ele deve estabelecer a relação professor aluno respeitando as regras sociais e familiares da cultura.

$E$ isso tem que ser respeitado. Toda atividade deve seguir o projeto do warã, tem dois desafios: diploma e responsabilidade diante da cultura. No warã as reuniões acontecem periodicamente, todos os dias, de manhã e à tarde, de manhã planeja e à tarde acontece a avaliação das ações. Todos os projetos escritos inclusive os da escola são discutidos. Neste espaço também exige uma linguagem específica. E acima da comunidade escolar, está o warã, 
sem dúvida alguma. E a escola pode agir conforme o warã na maneira de lidar e discutir com os vários assuntos consultando as famílias em um primeiro momento e mantendo a constância de diálogo com o warã nas decisões. As decisões da escola também devem ser discutidas pelo Warã para motivar cada segmento, faixa etária a participar dele.

O warã no seu formato reflete a união, a reciprocidade, a cultura como um todo, a identidade, relação política e social dentro da comunidade. Não é qualquer pessoa que pode fazer uma palestra. Ela deve ter permissão para isso. É o espaço propício para se projetar, se promover outros anseios da qual a comunidade pode ser beneficiada. Por isso é fundamental cobrar do Estado (governo) que eles possam ter uma relação política com a comunidade indígena e não apenas culturalmente. Promover apenas programas culturais confunde a proposta da comunidade do seu modo de vida. A relação do governo com o povo Xavante deve ser política e social. Os povos indígenas têm suas questões tratadas em nível federal, então, as demandas governamentais devem partir do governo federal, no entanto, para nós há leis estaduais, municipais. O regime de colaboração entre os governos não está bem organizado, está muito voltado para a administração local.

Há situação política nas tomadas de decisões hoje e que envolve a participação coletiva na escola. É preciso quebrar essa barreira no Warã. É preciso fortalecer as tomadas de decisões do Warã. As decisões tomadas pelo Warã são respeitadas e acatadas e é preciso que esse modelo de decisão coletiva seja também respeitada na escola.

Dentro do funcionamento jurídico da escola, passa pelo crivo do Warã. Existe uma fiscalização (acompanhamento) constante dos integrantes do Warã quanto às práticas pedagógicas dos professores.

Existe uma na Educação dificuldade com o município em dialogar ter representatividade dentro das assessorias pedagógicas aproveitar profissionais xavantes dentro das assessorias para cuidar das escolas indígenas para autonomia dar o desafio para a SEDUC ter a coordenadoria dentro da diversidade desconsiderando essa a educação escolar como modalidade e estar dentro da educação básica como está na Resolução 03/99 que institui uma categoria da educação básica, como modalidade da educação básica e não diversidade. 
É preciso primeiramente não duvidar da capacidade do ser humano xavante, ser sujeito de estudo e não objeto de estudo no reconhecimento em relação a diversidade de grupos e começar a utilizar os espaços de formação e estudos específicos para os povos indígenas com apoio dos não indígenas para entendimento das estruturas o que não resolve deixa-lo nesses espaços sem apoio.

\section{Os mitos, epistemologia e o sentido da vida}

Não há "cultura sem o horizonte mítico" e esses ajudam a compreender a complexidade do mundo contemporâneo, (Gadamer, p.136, 2011). É preciso aprofundar a relação entre mito e a vida. A descaracterização da cosmovisão de um povo altera a sua realidade. É preciso fazer uma consulta prévia do que se propõe a registrar, sobre os valores que fazem parte da filosofia de cada povo. O cocar, por exemplo, faz parte de uma das características do povo, porém só ele não representa a identidade do povo. Em vários outros momentos discutimos que o que dá significado para nossa vida é a crença, mas que não é possível ser materializada em imagens.

Valorizamos muito o canto, a tradição oral, somente depois vem a escrita. Temos utilizado muito a tecnologia audiovisual, que nos tem dado a oportunidade de divulgar nossa cultura para outros povos e outras comunidades. A internet tem sido mais usada nas questões administrativas, mas também para comunicação. Nas aldeias Xavante muitas famílias tem comprado celulares, para registrar suas músicas e fotografias. Temos compartilhado músicas, fotos e assuntos interessantes que estão fortalecendo os jovens entre as aldeias.

No Warã, os anciãos reclamaram sobre o uso de celular durante as reuniões. Temsido utilizados para gravar rituais. Alguns estabelecem regras para o equilíbrio do uso do celular nas casas, com limites. Os guardiões dos rituais estabelecem limites ou a proibição do uso do celular durante eles. A tecnologia não tem fronteiras, portanto, é preciso ter cuidado como se apresentar nela. Ela pode ser perigosa ou positiva (coisas não vistas). Acreditamos muitoque não estamos sozinhos no mundo. Como interpretar o cheiro, os sons, se estamos com fone no ouvido? 


\section{A natureza e os A'uwẽ}

A natureza estabelece a importância central na cultura A'uwẽ. A utilização do consumo de plantas, dos animais, da dieta alimentar são muito importantes e foram ensinadas pelos ancestrais para os que estão presentes hoje. Os sinais que são dados pela natureza devem ser observados e respeitados. As coisas que utilizamos como ornamento têm importância e seus significados. Ornamentos usados no pescoço identificam, por exemplo, aqueles que exercem funções de responsabilidade em um ritual ou evento, em que os outros devem se espelhar. A natureza, o cerrado, para nós é importante, porque dela, fazemos os adornos que usamos.

A gravata é um adorno que identifica o Xavante de outros povos. A gravata é utilizada em determinados rituais, mas também estabelece a relação de pertencimento. Mas seu uso não é em todas as terras Xavante. Tem os tipos de gravata, tem uma que é feita com pena de ema, que tem um significado. Os furadores de orelha usam um tipo de gravata. As gravatas são usadas por pessoas específicas e correspondem a uma função que ele exerce. A gravata pode ser presenteada a outro clã. O mesmo acontece com arco e flecha. Essa é a vida invisível do Warã.

\section{Luto e o pacificador: desencontro do tempo dos acontecimentos e do relógio}

Entre as várias questões de desencontros entre o tempo dos acontecimentos da culturae o tempo do relógio está o luto. Quando falece um membro da aldeia, toda a aldeia fica sentida, e isso pelo fato de que o falecido é dos membros da comunidade. É uma dor muito forte.

Tradicionalmente, os familiares e toda a aldeia ficam em silêncio e suspendem todas as atividades que são realizadas com mais frequência: rituais, roçado, etc. Quando há um falecimento, a gestão educacional salesiana mandava suspender as atividades somente no momento do funeral. Aí retornam as aulas imediatamente. Mas quando falecia um salesiano (waradzu ) havia interrupção total naquele dia das ações escolares. Certos rituais que duravam vários dias eram orientados pela escola que acontecessem durante o intervalo das atividades. Sempre houve intervenção da missão salesiana. Hoje sem a intervenção salesiana, a escola está mais próxima da comunidade. 
A dificuldade dos representantes atuais da comunidade está em como defender os rituais do luto. Precisamos definir com os responsáveis pelos rituais de luto (pacificadores) façam a mediação com a escola nesse sentido. O grupo de pacificadores fazem arranjos para amenizar o sofrimento da família do morto. Para cada idade são determinados a quantidade de dias em que se guarda o luto. Delimitar na diretriz curricular o tempo de luto do indivíduo Xavante que e deve ser decidido coletivamente.

A morte é importante pelos ritos do povo Xavante. Todos os pertences do falecido são queimados e estão representados na lembrança do canto e da chuva. E em todas as premonições, sonhos muitos importantes que traz a mensagem boa ou ruim.

A escola interferiu muito na doutrina da aldeia o luto do povo xavante e representado pelo corte do cabelo (todos da família, e amigos em sentido de solidarização com a família) cortam o cabelo preto e põe no rio e queima todos os pertences do falecido a ótica de ver o aparecimento do falecido colocar na matriz curricular do povo xavante a questão do reconhecimento do luto.

Escola indígena acontecerá quando o governo puder enxergar o povo indígena na sua diversidade. No intervalo de luto não exatamente a paralisação total das atividades que são feitas pelo pacificador de outro clã no momento da solidarização para com a família. Quando se fala na educação em luto total e seu conhecimento vem dessa realidade do intervalo de luto que deve ser ensinada na escola também. A morte não só atinge a família, mas a aldeia toda sente a perda.

Quando uma pessoa morre ela é preparada para seguir outra dimensão (alguns colocam agua se e uma criança alguns colocam leite. Reconhecimento de detalhes do momento em que muitas vezes a pessoa mostra estar lá não só pelo vulto mas também de outras formas.

Durante o acontecimento se trabalha bastante o significado da morte (explicação, relato de sua existência) a escola deve ter o papel de trabalhar profundamente o luto xavante o choro cerimonial precisa ser fortalecido principalmente pela escola, também precisa ser fortalecido pela escola a simbologia de raspar a cabeça sem sentir vergonha pois e um detalhe doluto.

A morte e sagrada aproxima a família as aldeias e precisa ser respeitada e não definida o tempo e ser fortalecida pela escola e o símbolo da terra onde foi enterrado estiver lizinho e 
que o se já esta vivendo em outra dimensão. O ciclo de formação de vida e o significado do habitat da aldeia também atinge a formação do grupo familiar xavante assim como a teia de aranha e circular vem o compartilhamento a colaboração e a união no rituais por ser a vida um círculo e quando completa o círculo continua circulando.

\section{Tempo e Espaço e Dualidade}

Temos dificuldade para contar o tempo. Pensamos o tempo como cotidiano. Temos marcadores de tempo como o canto dos pássaros, o ciclo de permanência do sol durante o dia e das estrelas as constelações, e da época de chuva (țsiruru). Tempo na nossa interpretação é o dia-a-dia da aldeia, que está no espaço e esse tempo é calculado pelo ciclo lunar, tempos de sequencias prolongadas em meses. O dia-a-dia é calculado pelo movimento do nascer e do pôr do sol, e o que se consegue realizar dentro desse período. As pausas do dia são determinadas pela localização do sol e pelo calor. O dia é dividido em matutino e vespertino.

As atividades são apropriadas para cada período do dia. Por exemplo: aquelas que exigem maior desgaste físico, acontece pela manhã. As mulheres no período da manhã se

dedicam às atividades de mais exigência física: buscar lenha etc, no período da tarde se dedicam mais aos cuidados dos filhos e dos netos. As atividades escolares são mais frequentes de manhã. O tempo limitado da escola influencia no comportamento, no jeito dos jovens. Nosso cotidiano está dentro do horário definido da escola. O tempo definido para o I ciclo está adequado para as crianças pequenas, mas para os demais não. Precisamos discutir com os mais velhos e com a comunidade toda, sobre a melhor proposta para atender a todos.

Seria bom que a escola indígena tivesse a mesma estrutura da escola dos brancos. De manhã, é desgastante para as crianças chegarem bem cedo na escola. O funcionamento da escola deve respeitar a faixa etária dos alunos. Há um diálogo com os professores para que aproveitem bem o tempo com os estudantes. Com a atual organização da escola, alguns dos mais jovens que estão envolvidos com plantio da roça se sentem cansados para estudar no período da tarde. Alguns anciãos preferem que os meninos sejam separados das meninas na escola. Como fazer isso? E como diferenciar a educação de meninos das meninas. Isso seria 
um retorno às origens de educação Xavante. Esse ensino envolveria os padrinhos, por exemplo, que são responsáveis de ensinarem a confeccionar as cordinhas e ensinar os mitos.

Conforme diagnóstico apresentado pela Funai sobre o tempo e espaço, a escola não está voltada para o movimento do corpo, mas o contrário. A criança por exemplo, o movimento dela não sendo considerado pela escola, muitas vezes ocasionando indisciplina delas (gritaria). Nem o tempo e nem o espaço da escola estão adequados para a aldeia. Mas vários aspectos do cotidiano deve ser mudado por conta do calendário e da matriz curricular. Deve-se rever essa configuração que foi implementada pelo sistema educacional e que passou a impor o tempo da aldeia, mas que não concordam entre si. A escola está vindo para a comunidade e antes a comunidade é que ia para a escola. Até os projetos feitos pelos engenheiros e arquitetos são impostos sem considerar as sugestões da comunidade.

A escola é apenas um prédio onde se difunde os saberes, que são extensões dos saberes que aprendem em casa. A escola também deve ter um formato circular. A escola deveriaficar em um local que não receba interferências sonoras externas, mas que não fiquem tão distante da comunidade para que ela também tenha acesso para participar das atividades. A escola já foi introduzida na aldeia de forma radical e já está na hora de definir limites para ela.

No nosso Projeto Político Pedagógico já se discute a questão de tempo e espaço escolar e de como garantir uma educação diferenciada. O tempo de horas aula (quatro horas) não tem se mostrado eficiente para nós. É uma estrutura muito estranha porque vem de fora. Fomos questionados pelos anciãos pelo tempo/horas aula que nós queremos. O tempo de horas aula que foi imposto tem influenciado o comportamento dos jovens de várias formas, entre outras coisas como o uso do uniforme, por exemplo. $O$ jeito de educar o corpo também tem-se modificado.

Convém notar, que a dieta alimentar modificou-se completamente. Muitos estão hipertensos em decorrência do sedentarismo. Muitos estão deixando hábitos alimentares em troca de consumir alimentos que não sabem como foram preparados. É comum as crianças faltarem aulas na época das frutas de murici, buriti e caju e é bom senso não punir os alunos por causa disso porque estão aprendendo também. Nessa atividade e a caça não são medidas por horas correspondentes às quatro horas de aula, muitas vezes as atividades extrapolam as 
quatro horas; elas são consideradas aprendizados do modo de vida A'uwẽ. Trabalhamos muito a importância da manutenção do ambiente em que vivemos sempre limpo. O que é mais importante, a qualidade do ensino ou formato de salas quadradas dela? Estamos discutindo com a SEDUC sobre um modelo arquitetônico sugerido de escola. A escola faz parte do Warã. A escola não pode ficar desarticulada da organização espacial da aldeia.

O maior desafio da educação escolar indígena é conseguir um ensino de qualidade diferenciada, no sentido de atender as comunidades indígenas. Cabe ao estado se preparar para essa nova dinâmica, pois se tratam de 44 povos indígenas em Mato grosso, com suas filosóficas correspondentes.

Ensinamos nossos alunos conhecimentos dos não índios desde cedo na escola, e não temos materiais didáticos específicos voltados para a realidade da comunidade Xavante. Não temos uma didática de ensino específica para as escolas Xavantes. O governo incluiu saberes de inclusão sobre técnicas agroecológicas, tecnologias indígenas, e confecção de artesanatos. As aulas devem ser ministradas na língua materna. Muitos alunos relatam que não conseguem assimilar o conhecimento em duas línguas. A escola organizada em ciclos traz desvantagens para nós porque muitos alunos passam de ano sem adquirir o conhecimento necessário para seu crescimento individual. A escola organizada por ciclo tem dificultado bastante o nosso trabalho. Antigamente o seriado era melhor, porque estudávamos muito com medo de reprovar. Influencia até mesmo osalunos chegam atrasados. Trabalhamos com conteúdos de concepção eurocêntrica. Temos que trabalhar conteúdos de acordo com a realidade Xavante.

Em síntese, queremos uma escola que valorize e fortaleça a cultura, língua e crença do povo A'uwe Uptabi. Para isso é necessário profissionais que sejam formados em mestrado, doutorado e também o sejam sua própria cultura, assim, promover o acesso ao conhecimento intercultural. Todos que queiram devem ter acesso à educação. As leis precisam ser cumpridas, garantindo os direitos e deveres constitucionais e o resguardo às formas de ensino e aprendizagem tradicional, do sistema de formação humana A'uwe Uptabi e ao mesmo tempo garantir aos estudantes e profissionais da educação o acesso aos conhecimentos e bens tecnológicos do mundo atual. 
Queremos ajudar a formar um aluno que respeite e vivencie as crenças e a identidade A'uwẽ Uptabi Xavante, participe da organização da comunidade, que busque os conhecimentos A'uwẽ, que produza histórias escritas na língua A'uwẽ Uptabi. E que também precisa ter conhecimento das línguas não indígenas e as relações interculturais: língua estrangeira, comércio, financeiro, artes, história geral, todas as ciências e tecnologia. $E$ demais conhecimentos da cultura global.

Valores: amizade, companheirismo, respeito, amor ao próximo. (empenho e dedicação aos valores da cultura)

A partir desses valores cultivados na sociedade A'uwẽ acreditamos que a organização e o sistema de educação tradicional deve ser considerado na organização escolar. A divisão dos grupos, os clãs, as funções nas cerimônias e a estrutura social e cultural.

\section{V - Marco operativo:}

EIXO 1- Território Etnoeducacional A'uwẽ Uptabi, Unidades Desconcentradas de Educação Escolar Xavante e Regime de colaboração para a garantia da educação escolar indígena, Gestão Democrática e CDCE

\section{A- PROPOSIÇÕES}

1- Estruturar um programa de educação escolar A'uwẽ Uptabi, com a participação dos representantes das comunidades indígenas, das suas organizações e dos demais atores institucionais relacionados à ações educacionais, como universidades, organizações não-governamentais, órgãos e setores da administração pública, de forma que se concretizem em programas, projetos, metas e ações com os preceitos existentes na legislação em relação ao direito dos indígenas a uma educação especifica diferenciada pública, gratuita e de qualidade.

2- Criar e implantar do Centro de Educação Escolar A'uwẽ Uptabi de acompanhamento, assessoramento, monitoramento e orientação para as escolas Xavante com a função administrativa, pedagógica e de formação. Considerando o âmbito de gestão do território etnoeducacional A'uwẽ Uptabi e a ampliação do diálogo do regime de colaboração entre os sistemas de ensino.

3- Regulamentar a educação escolar indígena avançando na garantia de que as conquistas legais em âmbito nacional sejam estendidas para os ordenamentos jurídicos, municipais e estadual. 
4- Assegurar que a gestão das escolas indígenas A'uwẽ Uptabi ocorra em regime de colaboração entre estado, municípios e comunidades indígenas, constituído em sistema de educação próprio que disponha de condições técnicas e financeiras adequadas

5- Fortalecer e fazer cumprir a política de regime de colaboração entre os entes federativos, promovendo orientação técnica aos gestores públicos da Educação Escolar Indígena no Estado e nos municípios.

6- Prover as escolas A'uwẽ Uptabi de recursos financeiros, humanos e materiais visando o pleno atendimento da educação básica para as suas comunidades.

7- Garantir ao WARÃ (Assembleia Xavante) através da participação da comunidade a tomada de decisões de gestão financeira antes das decisões da escola através do CDCE.

8- Contribuir para o projeto societário e para o bem viver de cada comunidade indígena A'uwẽ Uptabi, contemplando ações voltadas à manutenção e preservação de seus territórios e dos recursos neles existentes.

9- Desenvolver processos e ações de investigação cultural e formação específica que possibilitem a preparação de materiais didáticos em português e na língua A'uwẽ Uptabi, respeitando diversidade regional, de acordo com cada ciclo e nível de ensino.

10- Garantir produção, publicação e distribuição de materiais didáticos específicos da cultura A'uwẽ Uptabi.

11- Desenvolver capacidades bilíngues nas modalidades, oral e escrita, em português e nas línguas indígenas faladas e conhecidas em sua comunidade.

12- Desenvolver programas de interesse da comunidade que integrem ensino e pesquisa, com a participação, acompanhamento e avaliação do povo A'uwẽ Uptabi.

13- Garantir a implantação de magistério intercultural e cursos técnicos específicos e diferenciados, integrados ao Ensino Médio, conforme demanda da comunidade.

14- Garantir recursos técnicos e financeiros aos programas de educação intercultural das comunidades A'uwẽ Uptabi.

15- Cumprir a legislação relativa à organização, criação e implementação da política pública de "Educação Escolar Indígena" no estado e municípios que visem à melhoria das condições de trabalho dos profissionais da educação nas Terras Indígenas (infraestrutura e transporte)

16- Garantir a execução do Regimento Interno do TEE em conformidade com a CF de 1988, o Decreto 5.051/2004 que promulga a OIT 169 e demais dispositivos legais 
vigentes com ênfase na realização de reuniões da comissão permanente previstas no TEE, conforme Decreto $n^{\circ} 6.861 / 09$, artigos $5^{\circ}$ e $6^{\circ}$.

17- Manter, fortalecer e estruturar a coordenadoria de Educação Escolar Indígena/SEDUC/CEEI, Assessorias Pedagógicas e CEFAPROS com estruturas internas especificas e condições físicas e humanas para o atendimento das demandas da EEI.

18- Criar e implementar em conexão com o Warã colegiado de instituições que lidam com a questão indígena (SEDUC, SEMEC, CEFAPRO, FUNAI, DSEI-XAVANTE (CONDISIX), COORD. ED. IND. e ASSESSORIA PEDAGÓGICA) para o atendimento e acompanhamento (do estudante) na escola da cidade.

19- Garantir o acompanhamento de técnicos da SEDUC e SEMEC com o seguinte perfil: formação especializada na política indigenista brasileira, experiência acumulada na questão Educação Escolar Indígena, noção e experiência sobre a educação inclusiva e de alteridade.

20- Garantir capacitação específica aos profissionais da SEDUC E SEMEC, que atuam diretamente com educação escolar indígena.

21- Organizar as turmas na Escola do Povo Xavante por ciclo de formação humana, pois, coincide com a estrutura social do povo Xavante.

22- Organizar o calendário escolar do Povo Xavante em conformidade com o ciclo de vida da comunidade, entendendo que a escola está para o aluno e não aluno para a escola.

23- Garantir e respeitar no currículo e no calendário escolar do Povo A'uwẽ Uptabi atividades de caráter social: caçada longa, expedição, iniciação dos adolescentes, perfuração de lóbulos de orelhas de guerreiros, ritual de Wai'arini, denominação de nome da mulher e demais rituais da cultura A'uwẽ Uptabi, e ainda, a pescaria, o roçado e a coleta de frutas silvestres.

24- Assegurar que as secretarias de educação promovam para a comunidade escolar, cursos de capacitação em ações administrativas, contábeis, educacionais e demais políticas públicas de educação.

25- Garantir que o Estado e os Municípios participem e executem efetivamente programas e projetos desenvolvidos nas escolas indígenas.

26- Promover, em parceria com instituições governamentais e não governamentais, cursos, seminários e fóruns que garantam a afirmação da identidade cultural.

27- Garantir o acompanhamento das escolas indígenas pelo MEC, SEDUC, SEMEC, FUNAI, SESAI, Universidades, Organizações não governamentais e Organizações tradicionais de cada comunidade.

28- Garantir formação pedagógica e magistério intercultural aos A'uwẽ Uptabi para que atuem como técnicos na SEDUC e nas SEMECs, contribuindo para a 
melhoria da qualidade da Educação Escolar.

29- Garantir a formação de profissionais A'uwẽ Uptabi na área de saúde, para que atuem como técnicos no DSEI-XAVANTE e contribuam para a melhoria no atendimento à saúde, respeitando os conhecimentos da medicina tradicional A'uwẽ Uptabi, assim como atuem em ações de promoção à saúde nas escolas. Para tanto é imprescindível garantir a regulamentação da carreira dos profissionais da saúde: AIS e AISAN.

30- Garantir que o sistema da EEI siga a orientação da EEI Diferenciada e tenha educação própria

31- Garantir que a escola seja inserida no sistema de educação tradicional, com a participação dos anciãos, dos padrinhos e pais, pois são eles que norteiam a educação cultural das aldeias.

32- Assegurar a participação e controle social da comunidade junto à escola.

33- Garantir e respeitar que a escolha dos diretores, coordenadores, professorese demais profissionais da educação seja a critério do Warã (Assembleia Xavante).

34- Assegurar autonomia da comunidade no que se refere às decisões sobre a estrutura física das escolas.

35- Garantir que a estrutura fisica da escola da aldeia contemple todos os espaços, por exemplo: quadra de esportes, laboratórios, cozinha, salas de direção e coordenação e equipamentos, etc.

36- Viabilizar a utilização do sistema on line, para tanto, disponibilizar computadores e acesso a internet de qualidade, além de capacitar os profissionais da escola A'uwẽ Uptabi.

37- Assegurar a implementação do documento final da primeira Conferencia Nacional de Educação Escolar Indígena Diferenciada.

38- Garantir a implementação do Plano Nacional de Educação Escolar Indígena.

39-Promover a articulação do diálogo entre a SEDUC/COORDENARIA DE EDUCAÇÃO ESCOLAR INDÍGENA, SEMEC e as escolas A'uwẽ Uptabi.

40-Garantir a capacitação dos profissionais da SEDUC e assegurar o seu compromisso com a EEI diferenciada, com o projeto educacional para os povos indígenas, através de consulta em reuniões nas escolas.

41- Assegurar que o cardápio da merenda escolar seja elaborado a partir de diagnóstico da dieta na comunidade, fortalecendo o consumo de produtos da alimentação tradicional e a redução de consumo de industrializados.

42- Garantir que a SEDUC E SEMEC disponibilizem o transporte da merenda escolar para as escolas. 
43- Fornecer combustível e materiais de pesca e caça para viabilizar o consumo de alimentos tradicionais na merenda escolar.

44- Viabilizar a prestação de contas da aquisição de alimentos tradicionais das comunidades por meio da emissão de nota e recibo com a apresentação de documentação da pessoa física.

45- Garantir a responsabilidade da direção da escola na aquisição de alimentos quando em Supermercado.

46- Reduzir a burocracia na educação escolar indígena, pois o excesso burocrático prejudica e desorganiza a dinâmica da cultura e da tradição.

47- Manter e praticar a participação dos anciões, pais, mães e da comunidade nas atividades pedagógicas EEl.

48- Assegurar que os professores apresentem os resultados das atividades pedagógicas ao final de cada bimestre ou semestre, de acordo com o PPP da escola.

49- Garantir que a Educação Escolar A'uwẽ Uptabi em andamento seja respeitada e reconhecida em nível nacional.

50- Promover o diálogo nas comunidades A'uwẽ Uptabi a respeito dos motivos que levam a saída de alunos para as escolas da cidade buscando a compreensão e resolução do problema em cada comunidade.

51- Garantir que a educação escolar A'uwẽ Uptabi possua um sistema próprio.

52- Garantir que o TEE invista em material pedagógico específico A'uwẽ Uptabi e na formação inicial e continuada para os profissionais da educação e comunidade.

53- Assegurar a manutenção de todas as instituições que atendem as escolas A'uwẽ Uptabi, evitando a criação de outras e promover melhores condições para as que já estão em funcionamento, garantindo a continuidade nos trabalhos.

54- Promover condições para que os alunos indígenas estudem o ensino médio em uma escola nucleada ou salas anexas dentro da sua terra, para isso, os alunos que moram distantes devem contar com transporte.

55-Garantir as condições necessárias (profissionais capacitados) para a implantação do ensino médio nas aldeias.

56- Garantir o acompanhamento quinzenal da formação continuada e orientação pedagógica semanal nas escolas A'uwẽ Uptabi.

57- Garantir a implantação da unidade gestora do TEE para execução de recursos na produção de material didático pedagógico, para a construção de prédio escolar, para formação contínua e implantação de unidades desconcentradas. 
58-Em cumprimento a CF, a LDB, a OIT/169, a Declaração da ONU sobre o direito dos povos indígenas, garantir que não haja privatização da educação escolar A'uwẽ Uptabi.

59- Assegurar que seja criada a Secretaria Executiva de Educação Escolar indígena ligada diretamente com Ministério da Educação-MEC, com garantia de recursos próprios, para descentralização e execução, fortalecendo a autonomia da educação escolar indígena.

60-Garantir a participação do ancião e padrinho por meio de convite e/ou contrato (se possível) para fortalecer o ensino nas escolas xavantes. Com o amparo no artigo 78 da Lei de Diretrizes e Base (n. 9394/96), resolução CEB/CNE n.5/2012 artigo $8^{\circ} \S 3^{\circ}$ inciso I, que citam a valorização e recuperação das nossas histórias. Por isso, os anciãos ou também padrinhos deveriam estar presentes nas escolas A'uwẽ Uptabi.

61- Assegurar a Educação Escolar Indígena somente para indígenas com ensino especifico e próprio do A'uwẽ Uptabi, já que é diferente da Educação do Waradzu .

62- Assegurar como função da escola A'uwẽ Uptabi a manutenção da língua materna no processo de aprendizagem e a valorização da cultura.

63- Garantir a diferenciação da escola indígena, em relação ao bilinguismo e interculturalidade conforme estabelicido na LDB.

64- Assegurar os modos próprios de transmissão dos saberes A'uwẽ Uptabi respeitando os aspectos da cultura como princípio educacional básico.

65-Garantir, conforme legislação, que a comunidade tenha autonomia para optar sobre o vínculo a um sistema, municipal ou estadual de ensino.

66- Garantir que a regulamentação da educação escolar A'uwẽ Uptabi possibilite novos referenciais e paradigmas de flexibilidade da gestão pedagógica e da diversidade curricular, tanto das escolas quanto dos cursos de formação de professores A'uwẽ Uptabi. 
$67-$

EIXO 2- Organização da Educação Escolar Indígena (PPP, Ciclo de formação humana/currículo).

\section{A - PROPOSIÇÕES}

\section{Projeto Político Pedagógico}

1- Garantir no PPP no que se refere a autonomia pedagógica das Escolas Indigenas Xavante: organização do tempo e espaço, conforme o ciclo de vida e sociolinguistica da comunidade; estrutura social, as práticas culturais (como o luto, cujo o ritmo funeral fica por conta do pacificador, danhöno, darini, nominaçäo das mulheres, entre outras) e sustentabilidade, a religião, a filosofia, a cosmologia e economia; o sistema próprio de aprendizagem, os saberes milenares e produção e publicaçäo de material didático de interesse aa comunidade.

2- Cada comunidade escolar deve construir o seu PPP seja ela da rede estadual ou municipal, mas a matriz curricular é a mesma.

3- O PPP deve ser construído com a participação da comunidade, junto com os técnicos indígenas que tem conhecimento sobre a educação do indígena e do warazu.

4- O PPP será construído no warã, onde a comunidade discute e avalia normalmente e onde toda comunidade participa, também foi colocado, que a indicação para direção da escola seja decidido no Warä no consenso da comunidade da aldeia.

5- Retomar o PPP das duas escolas de forma a garantir a gestão democrática, atendimento as demandas e indicaçöes propostas pela comunidade. Focando em "Que aluno queremos ajudar a formar, e para isso que escola precisamos ter"

Educação, ensino e metodologia

6- Organizar o ensino da Língua Materna por: meio de diferentes textos, infantil, literários, quadrinhos, textos religiosos e cânticos da tradição 
A'uwẽ ; de cartilhas impressas na língua maternal e de método construtivismo ou Paulo Freire.

7- Organizar a Educação de Jovens e Adultos Indígenas por: meio da área de conhecimento, de acordo com as fases, visando maior participação e envolvimento dos alunos; a partir do tema textual e coleção de conteúdos de interesse dos alunos e voltada para a autonomia e autoestima dos educandos.

8- Procuramos novos conhecimentos e transmitir para nova geração e jovens. Dialogar mais para entrar em um acordo.

9- Procuramos entender o mundo e buscando outro conhecimento cientifico que procura assegurar o fortalecimento da nossa culturae tradições vividas hoje, respeitando a especificidade de cada território Xavante.

10- Levar a escola para o meio da comunidade e sua gestão. Fortalecer a cultura, a língua e religião.

11- Todo e qualquer documento referente a escola e ou educação indígena, Devem ser elaborado e construído de acordo com a realidade e participação da comunidade.

12- Valorizar o papel da família, padrinhos e do conselho de ancião na educação integral do estudante;

\section{Material didático}

13- $\quad$ Produzir material para Escola Indígena em conformidade com o sociocultural da comunidade (origens, cosmovisão, cosmologia, política) que contenha conteúdo próximo a realidade do aluno; deve ser impresso e encadernado ou produzido.

14- Elaborar e publicar materiais didáticos ilustrativos bilíngue e no contexto da realidade Xavante.

15- Melhorar o material didático para melhorar o ânimo das crianças

16- Elaborar material didático por meio de oficinas pedagógicas 
17- Criar livro didático Xavante normal e livro didático A'ãma, e/ou fazer levantamento daquele que tem material já produzido, edepois traduzir em xavante e português.

18- Criar livro didático Xavante normal e livro didático A'ãma, e/ou fazer levantamento daquele que tem material já produzido, edepois traduzir em xavante e português.

19- Reproduzir livro didático próprio com a participação das comunidades, respeitando as produções já produzidas na aldeia de cada região.

\section{Curriculo}

20- Selecionar os conteúdos na Escola do Povo Xavante a partir do interesse e curiosidade dos alunos, seja na língua materna e língua portuguesa; deve ser encadernado e impresso para melhor controle do material.

21- Organizar o currículo na Escola do Povo Xavante de acordo com a filosofia e cosmologia do A'uwẽ; deve ser flexível e consciente, frente as mudanças tecnológicas do século XXI.

22- O Currículo deve priorizar o ensino das áreas Ciências da Natureza; Matemática; Ciências Humanas e Sociais; Linguagens e Saberes Indígenas do povo Xavante com o uso das Tecnologias de Informação e Comunicação.

23- Nomear e/ou renomear as Escolas, conforme desejo e identidade do povo Xavante.

24- Elaborar currículo para as diferentes formas e articulação da educação escolar indígena com diversos níveis de educacionais, priorizando o trabalho como princípio educativo no conhecimento cientifico da educação indígena, considerando-se a realidade do mundo do trabalho e ciências. 


\section{Currículo A’uwẽ Uptabi}

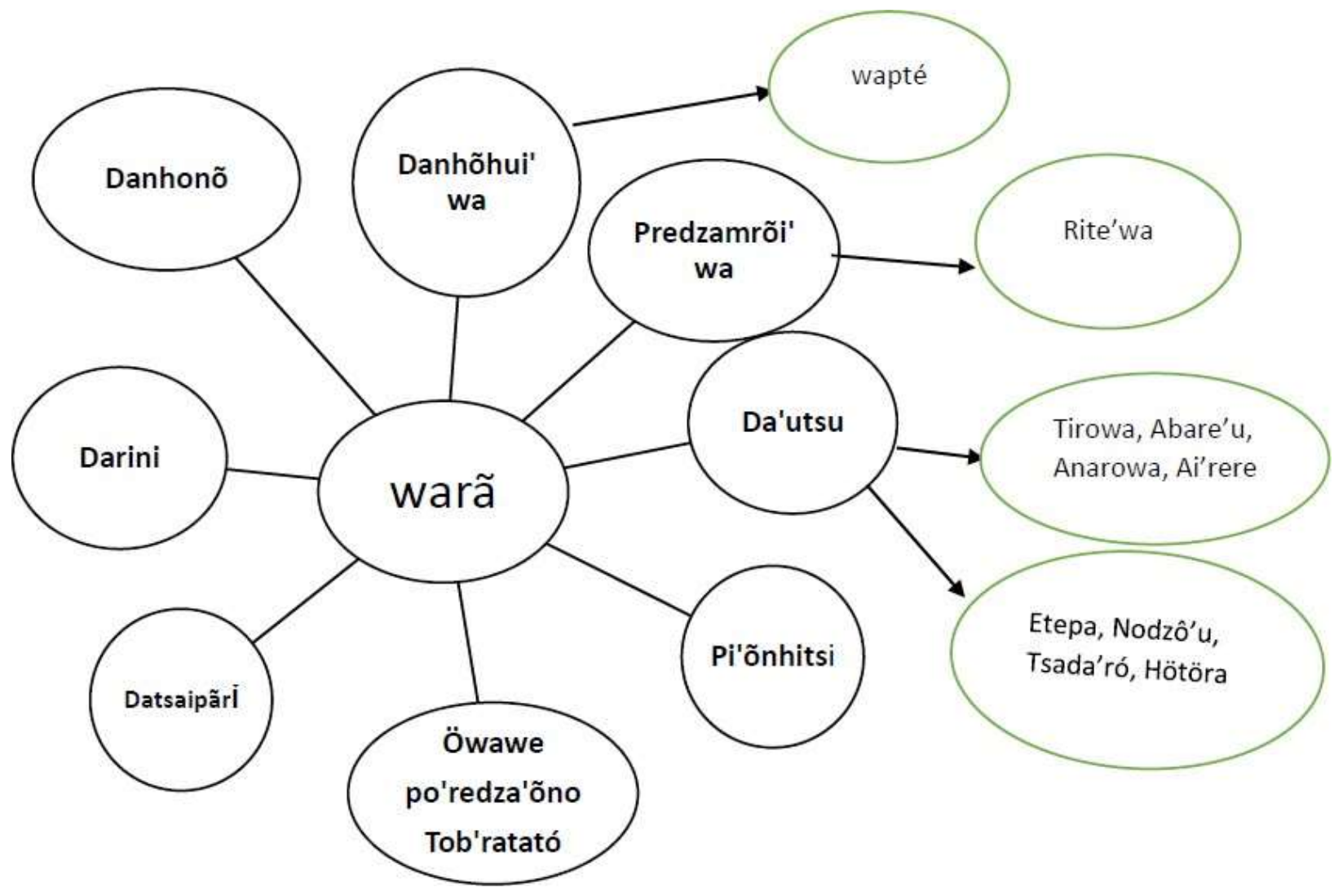

\section{Organização das turmas/ciclo/fase etária}

25- $\quad$ As turmas dos alunos do povo Xavante devem ser por geração de acordo com faixa etária e crianças conforme a sua idade.

26- Na fase do Wapté os alunos serão divididos dos demais. Para que o procedimento pedagógico e filosófico Xavante seja executado

\section{Calendário}

27- $\quad$ As turmas dos alunos do povo Xavante devem ser por geração de acordo com faixa etária e crianças conforme a sua idade.

28- O tempo do calendário deve ser organizado respeitando o tempo e espaço de cada aldeia nas terras indígenas.

29- Considerar como dias letivos as atividades de danhono, waia, caçada e pescaria cerimonial, darini, Wai, Uiwede e danhore. 
30- O calendário específico será flexivel de acordo com as cerimönias das aldeias atetadas. Calendário será dividido em quatro etapas: as férias serão no mës de agosto e setembro. Serão considerados sábado e domingo como dias letivos, mas também da realização de cerimönia qualquer dia da semana. Considerar 200 dias letıvos, consıderar datas comemoratıvas Xavante.

Calendário A'uwẽ - Ciclo do ano

3) CALENDÁRIO ( Wah'uwatsu'udzé - Ciclo do ano)

Tsa'u'u $\longrightarrow$ Maio, Junho

A'eta $\longrightarrow$ Novembro, Dezembro, Janeiro, Fevereiro, Março e Abril

Rob'ró'o $\longrightarrow$ Julho, Agosto, setembro, Outubro 


\section{Calendário A'uwẽ - Ciclo dos principais rituais: Danhono e Darini}

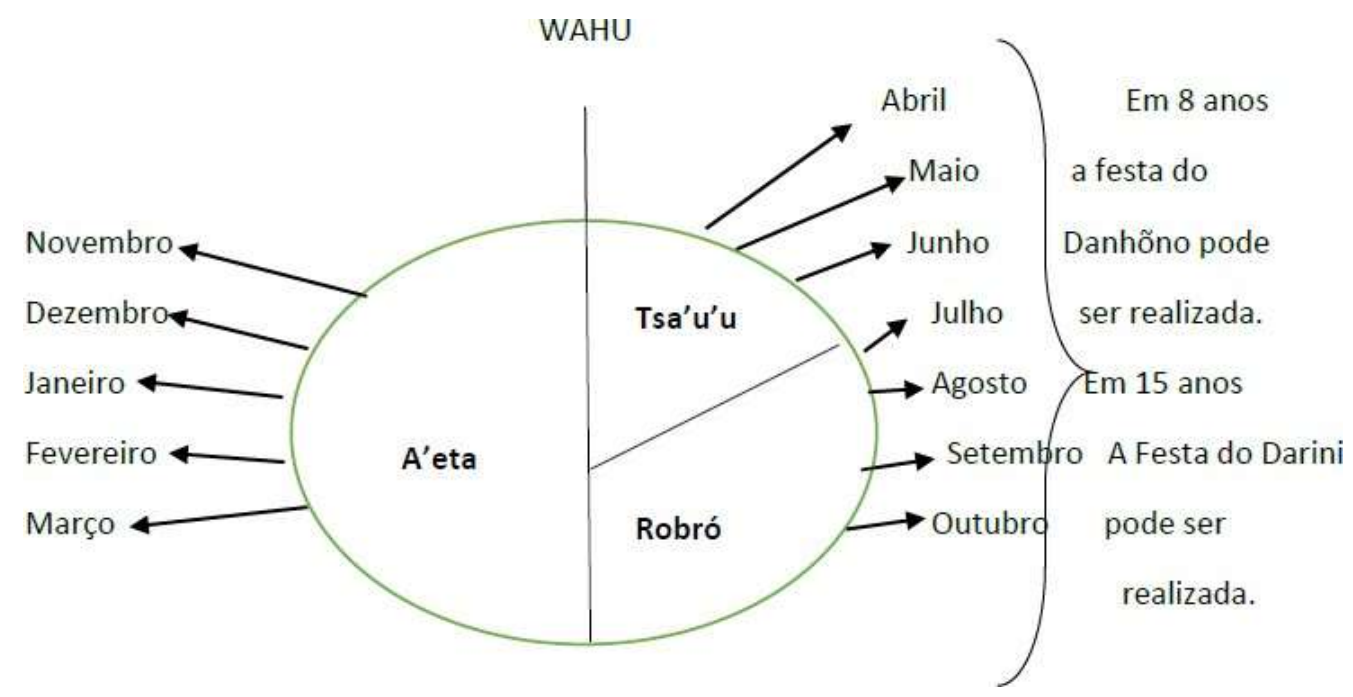

\section{EIXO 3- FORMAÇÃO PROFISSIONAL}

3.1 - Formação inicial e continuada: formação para o eixo profissional, licenciatura e magistério intercultural, mestrado e doutorado

\section{A- PROPOSIÇÕES}

1- Proporcionar cursos de licenciatura e bacharelado em diferentes áreas do conhecimento pelas instituições de ensino superior pública e privada mais próximo e que atenda à demanda da comunidade Xavante.

2- Criar núcleos de extensão nas Universidades (UNEMAT e UFMT) com participação dos acadêmicos indígenas e não indígenas, de diferentes áreas do conhecimento para aproximação e sensibilização dos processos culturais Xavante, política indigenista, entre outros.

3- Que as Universidades possam oferecer ações de acolhimento contínua com equipe psicossocial (bilíngue) aos acadêmicos Xavante, proporcionando ações nas instituições como oficinas, seminários, entre outros, para minimizar o preconceito e racismo institucional. 
4- Que as Universidades possam ter ações de fomento aos egressos Xavante da graduação e Pós-graduação possibilitando a formação contínua desse profissional indígena.

5- Os processos seletivos das universidades com ações afirmativas para a pós-graduação devem exigir critérios, como ata de consulta à comunidade (warã) e carta de apoio das lideranças, referente a intenção do candidato, conforme legislação vigente.

6- Que as Universidades vinculem a bolsa permanência aos acadêmicos Xavante independentemente de programas e gestão federal e estadual.

7- A formação nos cursos de magistério oferecido pela SEDUC e graduação pelas Universidades UFMT e UNEMAT devem estar em consonância com a realidade do povo Xavante, fortalecendo as práticas dos saberes tradicionais e notório saber. Deve ainda ocorrer em serviço e concomitantemente à sua própria escolarização em busca de sua titulação.

8- Que o MEC e/ou SEDUC/MT possam garantir recursos para processos de formação política, acadêmica e profissional ao povo Xavante.

9- Que na UNEMAT seja criado a Faculdade intercultural indígena com garantia de recursos próprios para manutenção e execução dos cursos.

10-Inserir componente curricular História e Cultura A'uwẽ Uptabi, onde existem campus de Universidades públicas no âmbito do TEEAU,;

11-Criar as faculdades intercultural para o território Xavante;

12-Criar curso de extensão de língua Xavante nas Universidades Públicas (UFMT; Unemat) e Privadas no território A'uwẽ Uptabi;

13-Incluir componente curricular da História e Cultura A'uwẽ Uptabi nos cursos de graduação da UFMT e Unemat no território A'uwẽ Uptabi, preferencialmente onde já existe campus destas instituições (Nova Xavantina e Barra do Garças);

14-Criar a Faculdade Intercultural Indígena no território A'uwẽ Uptabi, preferencialmente onde existe Campus da UFMT ou Unemat (Nova Xavantina e Barra do Garças);

15-Criar cursos de pós-graduação (especialização, mestrado e doutorado) específico A'uwẽ Uptabi;

16-Formalizar a orientação indígena A'uwẽ e a presença de indígenas A'uwẽ nas bancas de defesa de trabalhos em cursos de graduação e pós-graduação;

17-Mestrado profissional para os Xavante, pela UFMT, UNEMAT, UFG.

18-Criar na universidade estadual curso de linguística Xavante a fim de fortalecer a língua escrita A'uwẽ, considerando o número de falantes em Mato Grosso.

19-Diversificar os trabalhos de conclusão de cursos da faculdade intercultural, valorizando também a cultura oral dos povos indígenas, podendo ser cantos, musicas, filmes, documentários, relatos, assim em outras linguagens, que não somente a escrita. 
20-Produzir trabalhos acadêmicos: TCC, dissertações, teses, artigos na língua Xavante.e em Língua Portuguesa.

\section{2- Formação Continua e Desenvolvimento Profissional}

\section{A- PROPOSIÇÕES}

1- A formação contínua deve ter uma articulação entre município, estado e união, com relação aos convênios, ouvindo as comunidades indígenas A'uwẽ uptabi, em observância a realidade de cada comunidade Xavante.

2- As instituições que desenvolvem a formação continua devem ter conhecimento da realidade e da cultura do povo xavante, respeitando as atividades culturais dos profissionais da educação enquanto membro dessa sociedade.

3- Criar condições financeiras e de transporte para que a formação continua possa acontecer quinzenalmente, entre os profissionais da educação da escola xavante, da sede e das salas anexas.

4- A metodologia da formação continua e da proposta de desenvolvimento profissional deve considerar a epistemologia Xavante e os conhecimentos waradzu relevantes para o ensino e aprendizagem do profissional da educação Xavante.

5- O atendimento para a formação contínua dos profissionais da educação deve ser uma decisão coletiva dos responsáveis da instituição e da comunidade.

6- O desenvolvimento profissional dos profissionais da escola deve acontecer a partir dos desafios propostos em sua prática, considerando as diferentes funções.

7- A formação continua e o desenvolvimento profissional deve considerar o diagnóstico das necessidades de aprendizagem dos estudantes.

8- Os CEFAPROs são membros do Territorio Etnoeducacional A'uwẽ Uptabi e do fórum, junto com as instituições formadoras: UFMT, UNEMAT, IFMT, Escolas técnicas. E o trabalho dos CEFAPROs será a formação contínua e o desenvolvimento profissional.

9- A SEDUC deve ofertar formação contínua, relacionando teoria e prática com objetivo de melhorar a qualidade do ensino e aprendizagem nas escolas indígenas.

10-Os Cefapros e a Coordenação Pedagógica da escola devem acompanhar e orientar os profissionais indígenas de perto nas suas atividades formativas.

11-A SEDUC deve promover intercâmbio dos profissionais das escolas indígenas entre si e entre os profissionais das escolas indígenas e não indígenas. 
12-Os CEFAPROs devem ofertar oficinas sobre PPP para os profissionais das escolas indígenas, para que revisem seus planos de trabalho.

13-Os CEFAPROs deve ofertar oficinas de plano de ensino e de Plano de aula para equipe gestora e professores das escolas indígenas.

14-A SEDUC por meio dos Cefapros deve ofertar formação em alfabetiação para os professores alfabetizadores das escolas indígenas.

15-Ofertar oficinas de produção de material didático especifico para as escolas Xavante.

16- Realizar em parcerias com os cineastas indígenas oficinas de produções audiovisuais, para uso didático, nas escolas Xavante.

17-Realizar formação em alimentação escolar, por meio do PROFTAAE e Profuncionário, com ênfase em alimentação saudável e de qualidade nas escolas Xavante.

18-A SEDUC deve realizar seminário estadual para discutir as práticas pedagógicas e as políticas de Educação Escolar Indígena.

19- Realizar oficina "Usos das Tecnologias digitais da informação e da comunicação na educação nas práticas pedagógicas dos profissionais nas escolas indígenas A'uwẽ".

20- Implantar os saberes indígenas nas escolas indígenas estaduais e municipais em parceria MEC, UFMT, UNEMAT, UFG, FUNAI, CEFAPRO, IFMT.

\section{EIXO 4- Carreira dos profissionais da educação: concurso público específico, categoria: professor indígena e eixo profissional.}

\section{A- PROPOSIÇÕES}

1- A formação para a entrada dos profissionais da Educação Escolar Indígena na carreira:

$>$ De professores indígenas deve ser com magistério warazulintercultural ou graduação, mestrado, doutorado.

> Técnico Administrativo Educacional e Apoio Administrativo Educacional com formação em Ensino Médio completo.

2- Deve ser por processo seletivo de forma diferenciada com duas etapas:

$>1^{\text {a }}$ Etapa- Deve ser de acordo com a escolha da comunidade em reunião no Warã, considerando o nível de escolaridade do profissional e sua formação específica.

$>2^{\mathrm{a}}$ Etapa- Com a contagem de pontos/processo seletivo warã/(assembleia Xavante)SEMEC/SEDUC. 
3- Realizar concurso público específico e diferenciado para Educação Escolar Indígena da rede estadual e municipal juntamente com o edital previsto para dezembro/2016.

4- Criar a categoria de profissional da Educação Escolar Indígena com recurso, normas e plano de carreira diferenciado, baseada em estudos junto a comunidade indígena.

5- Criar a categoria de professor da educação escolar indígena com os níveis:

> Nível 1- Professor da Base Comum Curricular com formação específica de entrada na carreira

$>$ Nível 2- Professor Saberes Indígenas

6- Garantir remuneração de acordo com o Piso Nacional.

7- Garantir a participação do Warã na escolha e continuidade dos profissionais da educação na carreira

8- A carga horária dos profissionais da Educação Escolar Indígena ficará a critério de cada rede considerando a realidade das comunidades. Podendo variar de vinte a quarenta horas semanais.

9- Considerar as linhas de pesquisa em nível de pós-graduação que abrangem os saberes indígenas/interculturais para elevação de classe. 


\section{Encaminhamentos para 2016:}

- entrega do documento final do fórum ao secretário de estado de educação Sr. Marco Marrafon, local: SEDUC, final de outubro de 2016.

- reunião com as universidades sobre os cursos de formação inicial intercultural para formação de professores Xavante, local: Terra São Marcos, primeira semana de dezembro de 2016.

- entrega ao Governador e Secretário de Estado de Educação, de documento solicitando a criação e implantação do Centro de Educação Escolar A'uwẽ Uptabi de acompanhamento, assessoramento, monitoramento e orientação para as escolas Xavante com a função administrativa, pedagógica e de formação. Considerando o âmbito de gestão do território etnoeducacional A'uwẽ Uptabi e a ampliação do diálogo do regime de colaboração entre os sistemas de ensino. 


\section{V- Referências bibliográficas:}

BRASIL. Congresso Nacional. Lei n. 9.394. Lei de Diretrizes e Bases da Educação, 1996.10 . Ministério da Educação. Referencial Curricular Nacional para as Escolas Indígenas.

Brasília: MEC/SEF, 1998.

. Conselho Nacional de Educação. Parecer CNE/CEB n. 14. Diretrizes Curriculares Nacionais da Educação Escolar Indígena. Brasília: MEC, 1999.

. Conselho Nacional de Educação. Resolução CNE/CEB n. 03. Diretrizes Nacionais para o funcionamento das escolas indígenas. Brasília: MEC, 1999

- Decreto $\mathrm{n}^{\circ}$ 6.861, de 27 de maio de 2009. Disponível em: http://www.planalto.gov.br/ccivil_03/_ato2007-2010/2009/decreto/d6861.htm. Acesso em 14/06/2016.

. Parecer CNE/CEB No 13/2012

Resolução $N^{\circ} 5$, Ministério da Educação

MEC/SEF Luís Donizete Grupioni, Do Nacional ao local, do federal ao estadual: as

leis e a Educação Escolar Indígena

MEC, SEF, DIRETRIZES para a Política Nacional de Educação Escolar Indígena. Brasília: 1993. 22p. (Cadernos educação básica. Série institucional, 2).

INSTITUTO SOCIOAMBIENTAL.Dos direitos a Diferença. Disponível em:www.http://pib.socioambiental.org/pt/c/direitos/constituicoes/introducao. Acesso em 14/06/2016.

MATO GROSSO. Plano Estadual de Educação e Plano Nacional de Educação. Secretaria de Educação de Estado de Mato Grosso. Cuiabá: 2014 


\section{VI - Anexos}

\section{Comissão Organizadora do FORUM TSIHORIRÃ}

\begin{tabular}{|c|c|c|}
\hline & & Equipe \\
\hline 1 & Coordenação Geral & $\begin{array}{l}\text { Xisto Tserenhi'ru Tserenhimi'rami } \\
\text { Jurandir Siridiwe Xavante } \\
\text { Beloni Eliza Secretti Ceretta - CEFAPRO } \\
\text { Gabriel Muria - FUNAI } \\
\text { Carlos Henrique Silva } \\
\text { Felix Rondon Adugoenau - Coordenadoria de } \\
\text { EEI/SUDE } \\
\text { Luciana Akeme Sawasaki Manzano Deluci- } \\
\text { CEFAPRO } \\
\text { Marly Augusta Lopes de Magalhães- UFMT } \\
\text { Rosaline Rocha Lunardi - UFMT } \\
\end{array}$ \\
\hline 2 & Secretaria executiva & $\begin{array}{l}\text { Rita Natalia Batista da Silva } \\
\text { Suelma Soares dos Santos } \\
\text { Simone Silva }\end{array}$ \\
\hline 2 & $\begin{array}{l}\text { Equipe de orientação e } \\
\text { divulgação local }\end{array}$ & $\begin{array}{l}\text { Carolina Rewaptu } \\
\text { Fortunato Tsereneiwa Pratse ( IN MEMORIAN) } \\
\text { Francisco Carlos Machado } \\
\text { Lucas Ruri'o } \\
\text { Karina Aparecida Geraldo } \\
\text { Luciana Akeme Sawazaki Manzano Deluci } \\
\text { Luciene de Morais Rosa } \\
\text { Odila Maria Zampirollo } \\
\text { Rita Natália Batista da Silva } \\
\text { Vanessa Aline Bussanello } \\
\text { Vítor Ten Caten } \\
\text { Xisto Tserenhi'ru Tserenhimi'rami } \\
\text { Nivaldo Rai'rate } \\
\text { Severiá Maria Idioriê Xavante }\end{array}$ \\
\hline 3 & $\begin{array}{l}\text { Logística, equipamentos, } \\
\text { credenciamento e } \\
\text { certificação }\end{array}$ & $\begin{array}{l}\text { Marly Augusta Lopes de Magalhães } \\
\text { Gabriel Gomes Muria } \\
\text { Beloni Eliza Secretti Ceretti } \\
\text { Lucineyde F. Moreno } \\
\text { Elza das Dores Ferreira } \\
\text { Euslene Ferreira Leal Noleto } \\
\text { Rita Natalia Batista da Silva } \\
\text { Suelma Soares dos Santos } \\
\text { Neuzamar Marques }\end{array}$ \\
\hline
\end{tabular}




\begin{tabular}{|c|c|c|}
\hline & & $\begin{array}{l}\text { Maria Gorete Barrichello } \\
\text { Marli Prolo }\end{array}$ \\
\hline 4 & Cerimonial de Abertura & $\begin{array}{l}\text { Ernandes Araujo Nascimento } \\
\text { Alissandra da Silva Santos Sousa } \\
\text { Beloni Eliza Secretti Ceretta } \\
\text { Adriana Aparecida de Assis Silva } \\
\text { Simone Silva }\end{array}$ \\
\hline 5 & $\begin{array}{l}\text { Mesa de abertura e mesa } \\
\text { temática }\end{array}$ & $\begin{array}{l}\text { Lilian Ferreira Silva Ferraz } \\
\text { Adriana Aparecida de Assis Silva } \\
\text { Ernandes Araujo Nascimento }\end{array}$ \\
\hline 6 & GTs & $\begin{array}{l}\text { Ednalva Antonia Ribeiro Coelho } \\
\text { Raimundo Nonato Silva de Oliveira } \\
\text { Edmara da Costa Castro Dallabrida } \\
\text { Luciana Akeme Sawazaki Manzano Deluci } \\
\text { Luciene de Morais Rosa } \\
\text { Rita Natália Batista da Silva } \\
\text { Severiá Maria Idiorie Xavante } \\
\text { Ismael Donizete Cardoso de Moraes } \\
\text { Sebastião Ferreira de Souza } \\
\text { Antonina da Silva } \\
\text { Warley Carlos de Souza } \\
\text { Magno Silvestri } \\
\text { Paulo Cipassé Xavante } \\
\text { Marly Augusta Lopes de Magalhães } \\
\text { Maxwell Miranda } \\
\text { Vanessa Aline Bussanello } \\
\text { Águeda Aparecida da Cruz Borges } \\
\text { Rosaline Rocha Lunardi } \\
\text { Gilves Furtado de Queiroz } \\
\text { Josélia de S. Soares Ferreira } \\
\text { Marizete Alves Neves Ten Caten } \\
\text { Mônica Maria dos Santos } \\
\text { Egislaine de Nez } \\
\text { Simone Aparecida Silva } \\
\text { Alissandra da S. Santos } \\
\text { Francisco Carlos Nogueira } \\
\text { Ednalva Antonia Coelho } \\
\text { Manoel Pereira Maia }\end{array}$ \\
\hline 7 & $\begin{array}{l}\text { Plenária e instituição do } \\
\text { Fórum permanente }\end{array}$ & $\begin{array}{l}\text { Xisto Tserenhi'ru Tserenhimi'rami } \\
\text { Gabriel Muria } \\
\text { Alissandra da Silva Santos Sousa } \\
\text { Rosaline Rocha Lunardi }\end{array}$ \\
\hline
\end{tabular}




\begin{tabular}{|c|c|c|}
\hline 8 & Sistematização & $\begin{array}{l}\text { Luciene de Morais Rosa } \\
\text { Luciana Akeme Sawazaki Manzano Deluci } \\
\text { Rita Natália Batista da Silva } \\
\text { Xisto Tserenhi'ru Tserenhimi'rami } \\
\text { Rosaline Rocha Lunardi } \\
\text { Ednalva Antonia Ribeiro Coelho }\end{array}$ \\
\hline 9 & $\begin{array}{l}\text { Divulgação, registro, TI, } \\
\text { imprensa e convites }\end{array}$ & $\begin{array}{l}\text { Luciana Akeme Sawasaki Manzano Deluci } \\
\text { Luciene de Morais Rosa } \\
\text { Gilson Moraes Costta } \\
\text { Kariny Ellen Oliveira Rocha } \\
\text { Andressa Dias de Oliveira } \\
\text { Angela Maria Vivan } \\
\text { Caimi Waisse Xavante } \\
\text { Euslene Ferreira Leal Noleto } \\
\text { Suelma Soares dos Santos } \\
\text { Jociene Carla Bianchini Ferreira Pedrini } \\
\text { Marly Augusta Lopes de Magalhães } \\
\text { Beatriz Mariana Talhari Bitineli }\end{array}$ \\
\hline 10 & Noite cultural & $\begin{array}{l}\text { Ernandes Araujo Nascimento } \\
\text { Eduardo de Lima Cunha } \\
\text { Beloni Eliza Secretti Ceretta } \\
\text { Águeda Aparecida Borges }\end{array}$ \\
\hline 11 & Cinema & $\begin{array}{l}\text { Kariny Ellen Oliveira rocha } \\
\text { Jociene Carla Bianchini Ferreira Pedrini } \\
\text { Gilson Moraes Costta } \\
\text { Beatriz Mariana Talhari Bitineli }\end{array}$ \\
\hline
\end{tabular}

